\title{
ARE 'GREEN' LANDSCAPES ASSOCIATED WITH 'GREEN' BEHAVIOURS? A STUDY INTO THE RELATIONSHIP BETWEEN URBAN GREEN SPACE VISITATION AND PRO- ENVIRONMENTAL BEHAVIOUR IN WELLINGTON, NEW ZEALAND.
}

Ivana Giacon

A thesis submitted to Victoria University of Wellington in partial fulfilment of requirements for the degree of Master of Environmental Studies

School of Geography, Environment and Earth Sciences

Victoria University of Wellington 


\begin{abstract}
With global environmental change looming there is a call for urban societies to change behaviours and lead more sustainable lifestyles. However, behaviour change policies have mostly been ineffective with urban society's weak emotional connection to nature cited as a major barrier. Wilson's (1986) biophilia hypothesis posits humans have an innate desire to preserve and protect the natural environment programmed into our biological evolution and that exposure to nature fosters this desire. With fifty percent of the world's population now living in urban environments there is the concern that a reduced contact with nature will further reduce emotional connections to nature and acceptance of pro-environmental behaviour change. Governments worldwide have neglected to incorporate nature exposure into pro-environmental behaviour change policies highlighting the need for empirical evidence to demonstrate a positive relationship between nature exposure and pro-environmental behaviour. This study fills this literature gap. With urban green space acting as the main form of nature contact for many urban residents, urban green space visitation was used as a proxy for nature exposure. Data collected by the Wellington City Council was examined for a relationship between urban green space visitation and pro-environmental behaviour using a series of regression techniques. Regressions restricted to different types of urban green space and pro-environmental behaviours were analysed for significant correlations. Gender, age, income, pride, and quality of life were also examined for moderating effects. A statistically significant relationship was reported between urban green space visitation and pro-environmental behaviour with sports field visitation the weakest predictor. There was no evidence of significant moderation by gender, age, income, pride, or quality of life. My results provide evidence for further research into urban green space expansion and promotion as a behaviour change tool.
\end{abstract}

Keywords: Urban green space; pro-environmental behaviour; biophilia; connections to nature; behaviour change policy 


\section{ACKNOWLEDGEMENTS}

A huge thanks needs to go out to my awesome supervisor, Dr. Bethany Haalboom! I honestly could not have done this without all your support and encouragement. There were points where I had lost confidence in myself and my project and it was during these times you reassured me I was doing well - I honestly can't explain how lucky I was to have you as my supervisor.

To my stats supervisor, Dr. Phil Morrison. Thank you for your advice and encouragement. As I had little statistics knowledge, quantitative analysis was going to be extremely challenging for me. While the final results may not be quite as robust as a statistician would prefer, I did try my best and I thank you for being patient with me.

I cannot forget to thank Taputu, Mike, and Sara, who were hugely supportive of me through the early stages of my research and write up. Going through Uni together with you Taps has been so good! Having someone going through similar issues and having similar concerns helped me feel like I wasn't alone and that things would be OK. Thanks for everything and I am so proud of what we have achieved.

To my amazing family! Mum, Dad, Gabs, Cardo, and Mac, you guys have been so supportive! Knowing that you are proud of me means the world. Thank you for listening to me complain when things were going badly, and being proud of me when things were going good. I love you guys so much. Gabba, I dedicate this to thesis to you! Thanks for being my best friend throughout this entire process. I wish you all the luck in the world on your own academic journey ahead. 


\section{CONTENTS}

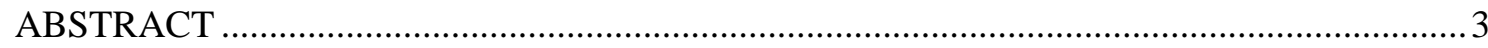

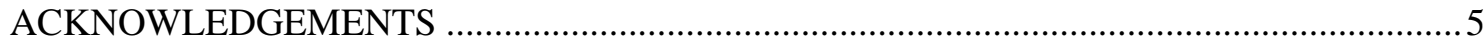

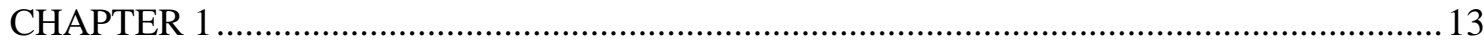

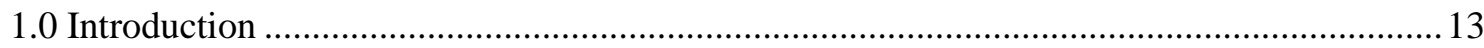

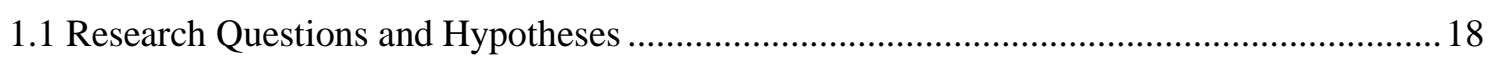

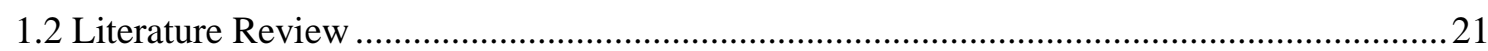

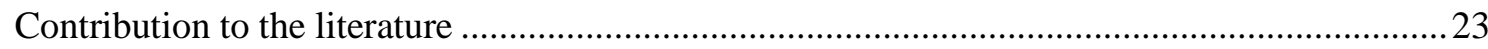

1.2.1 Nature Exposure and Emotional Connections and Attitudes to Nature...............................2 24

1.2.2 Emotional Connections to Nature, Pro-environmental Attitudes and Pro-Environmental

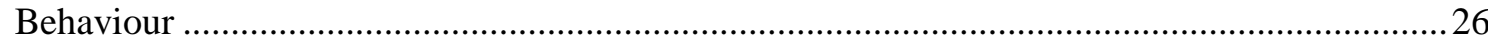

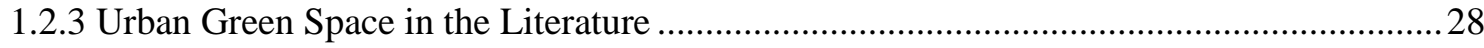

1.2.4 Emotional Connections to Nature, Pro-environmental Attitudes, Urban Green Space

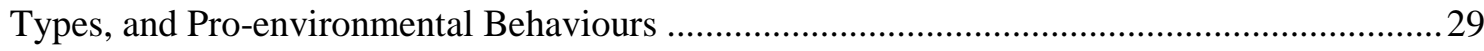

1.2.5 Socio-demographics, Urban Green Space and Pro-environmental Behaviour..................... 30

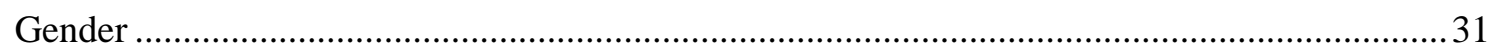

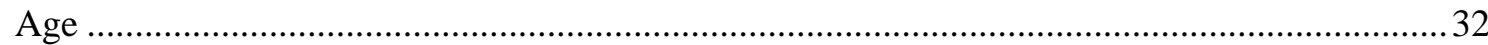

Income

1.2.6 Pride, Connections to Nature, and Pro-environmental Behaviour........................................ 36

1.2.7 Quality of life, Connections to Nature, and Pro-environmental Behaviour. .........................36

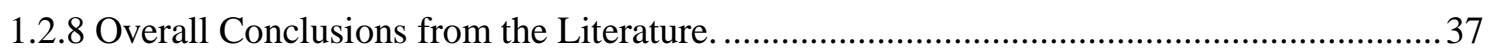

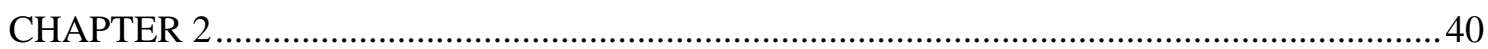

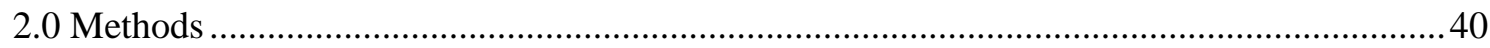

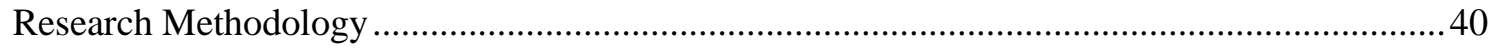

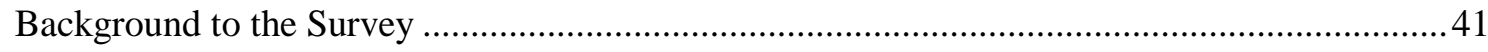

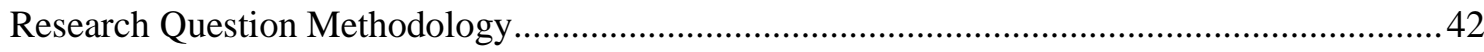

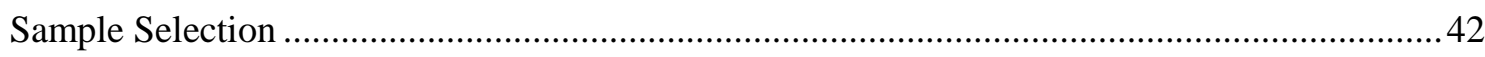

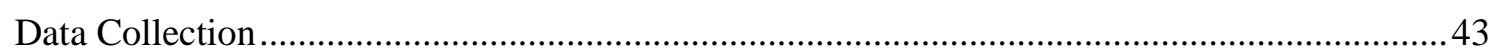

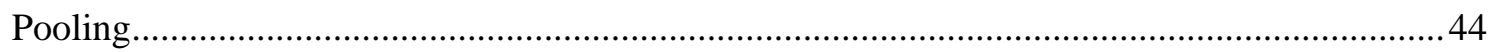

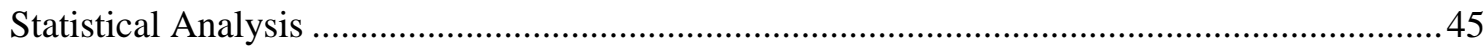

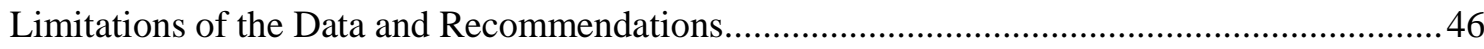

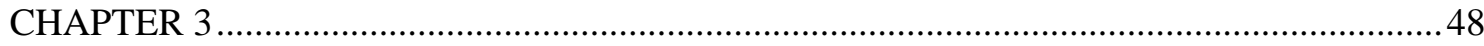

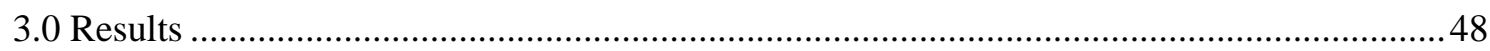

3.1 Urban Green Space Visitation and Pro-environmental Behaviour ........................................4 49

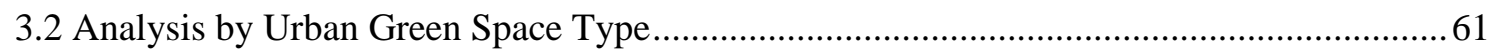

3.3 Analysis by Urban Green Space Type and Pro-Environmental Behaviour Type................... 78

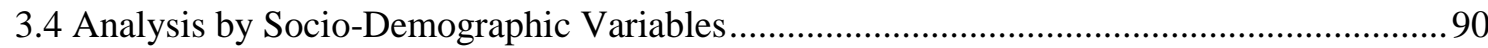

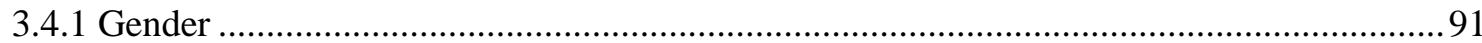

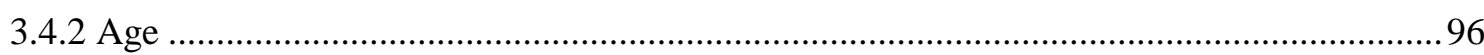




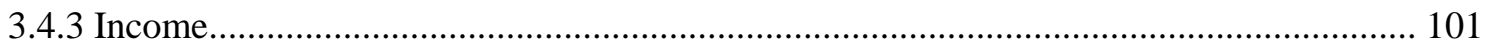

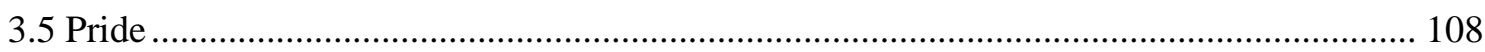

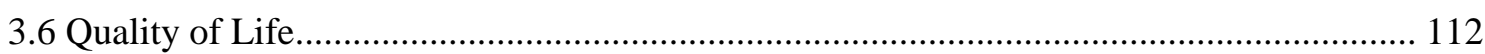

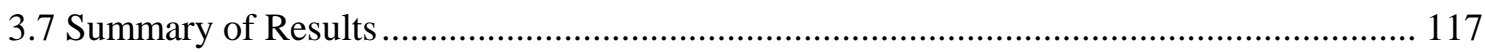

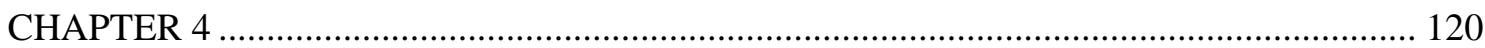

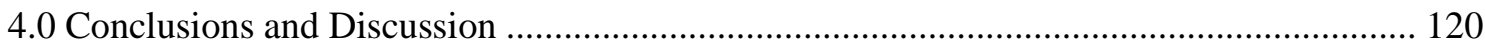

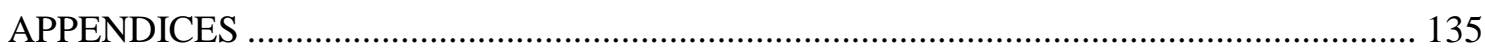

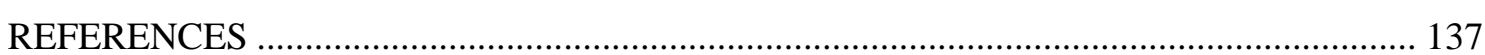

\section{List of Tables}

Table 1: Survey responses per year for each of the three Wellington City Council Residents Satisfaction Surveys, 2010 - 2012.

Table 2: Descriptive statistics for Total PEB and Total UGS using the concatenated sample. . 50

Table 3: Frequency table for Total PEB using the concatenated sample................................... 51

Table 4: Frequency table for Total UGS using the concatenated sample. Values .00 through 20.00 only shown (values 21.00 through 41.00 continued in table 5) . ........................................ 52

Table 5: Frequency table for Total UGS using the concatenated sample. Values 21.00 through 41.00 only shown. (See table 4 for values 0.00 through 20.00).

Table 6: Descriptive statistics detailing the minimum, maximum and mean values for total time's urban green space was visited over a twelve month period. 55

Table 7: Frequency table showing distribution of responses for Total UGS binary using the concatenated sample. 58

Table 8: Frequency table showing distribution of responses for Total PEB binary using the concatenated sample.

Table 9: Frequency table showing distribution of responses for Total UGS Yes or No using the concatenated sample.

Table 10: Cross tabulation of Total UGS Yes or No and Total PEB binary showing conditional probabilities of performing more than seven pro-environmental behaviours. Total UGS Yes or No represented by .00 indicating no visitation and 1.00 indicating visitation at least once in 12 months. Total PEB binary represented by .00 indicating seven or less of the 14 proenvironmental behaviours were performed and 1.00 indicating more than seven proenvironmental behaviours were performed.

Table 11: Cross tabulation of Total UGS binary and Total PEB binary showing conditional probabilities of performing more than seven pro-environmental behaviours. Total UGS binary represented by .00 indicating visitation less than once a month and 1.00 indicating visitation once a month or more. Total PEB binary represented by .00 indicating seven or less of the 14 pro-environmental behaviours were performed and 1.00 indicating more than seven proenvironmental behaviours were performed.

Table 12: Frequency table showing distribution of responses for each urban green space type using the concatenated sample.

Table 13: Frequency table showing distribution of responses for visitation to Wellington city's coastal areas, harbours, and beaches using the concatenated sample. $(0.00=$ most days, $1.00=$ once a week, $2.00=$ once every $2-3$ weeks, $3.00=$ once a month, $4.00=$ once every $2-3$ months, $5.00=$ once every $4-5$ months, $6.00=$ once every 6 months or less, $7.00=$ never in the past 12 months).

Table 14: Frequency table showing distribution of responses for visitation to botanic gardens using the concatenated sample. $(0.00=$ most days, $1.00=$ once a week, $2.00=$ once every $2-3$ 
weeks, $3.00=$ once a month, $4.00=$ once every $2-3$ months, $5.00=$ once every $4-5$ months, 6.00 $=$ once every 6 months or less, $7.00=$ never in the past 12 months).

Table 15: Frequency table showing distribution of responses for visitation to parks. Categories span from .00 indicating no visitation to 7.00 indicating visitation most days. $(0.00=$ most days, $1.00=$ once a week, $2.00=$ once every $2-3$ weeks, $3.00=$ once a month, $4.00=$ once every $2-3$ months, $5.00=$ once every $4-5$ months, $6.00=$ once every 6 months or less, $7.00=$ never in the past 12 months).

Table 16: Frequency table for visitation to the town belt or outer green belt using the concatenated sample. $(0.00=$ most days, $1.00=$ once a week, $2.00=$ once every $2-3$ weeks, 3.00 $=$ once a month, $4.00=$ once every $2-3$ months, $5.00=$ once every $4-5$ months, $6.00=$ once every 6 months or less, $7.00=$ never in the past 12 months).

Table 17: Frequency table for visitation to city walking tracks using the concatenated sample. $(0.00=$ most days, $1.00=$ once a week, $2.00=$ once every $2-3$ weeks, $3.00=$ once a month, 4.00 $=$ once every $2-3$ months, $5.00=$ once every $4-5$ months, $6.00=$ once every 6 months or less, $7.00=$ never in the past 12 months).

Table 18: Frequency table for visitation to Wellington city council outdoor grass sports fields using the concatenated sample. $(0.00=$ most days, $1.00=$ once a week, $2.00=$ once every $2-3$ weeks, $3.00=$ once a month, $4.00=$ once every $2-3$ months, $5.00=$ once every $4-5$ months, 6.00 $=$ once every 6 months or less, $7.00=$ never in the past 12 months).

Table 19: Results of regression analysis of Total PEB as a function of Total UGS across each urban green space type, separately. 95\% confidence intervals for $\mathrm{R}^{2}$ values included for comparison.

Table 20: Correlation matrix showing Pearson correlation coefficients and associated $p$ values for all list wise comparisons of visitation to urban green space. Visitation was measured retaining the eight categories of visitation frequency, from never to most days.

Table 21: Table of total variance explained after principle components analysis on six urban green space types. Component values greater than one account for more variance than did the original variable.

Table 22: Component matrix of urban green space visitation variables using principle component analysis. Two components are shown.

Table 23: Frequency table showing distribution of responses for visitation to Vegetated urban green space using the concatenated sample. With there being four types of vegetated urban green space (botanics, parks, town belt, and tracks) each value represents how many of the vegetated urban green spaces were visited once a month or more. The value, .00 indicates visitation to none of the vegetated spaces once a month or more, 1.00 indicates visitation to one, 2.00 indicates visitation to two, 3.00 indicates visitation to three, and 4.00 indicates all four vegetates spaces were visited once a month or more.

Table 24: Cross tabulation table displaying conditional probabilities of performing more than seven pro-environmental behaviours (1.00) or seven or less pro-environmental behaviours (.00) and visiting Vegetated urban green spaces once a month or more (1.00) or less than once a month (.00).

Table 25: Cross tabulation table displaying conditional probabilities of performing more than seven pro-environmental behaviours (1.00) or seven or less pro-environmental behaviours (.00) and visiting Coastal urban green spaces once a month or more (1.00) or less than once a month (.00).

Table 26: Cross tabulation table displaying conditional probabilities of performing more than seven pro-environmental behaviours (1.00) or seven or less pro-environmental behaviours (.00) and visiting sports field urban green spaces once a month or more (1.00) or less than once a month (.00).

Table 27: Table of coefficients from binary logistic regression of vegetated UGS visitation and Total PEB binary using the concatenated sample. No visitation to coasts set as base.

Vegetated $(1)=$ visitation once every six months or less, Vegetated $(2)=$ visitation once every 45 months, Vegetated(3) = visitation once every $2-3$ months, Vegetated $(4)=$ visitation once a 
month, Vegetated $(5)=$ visitation once every $2-3$ weeks, Vegetated $(6)=$ visitation once or twice a week, Vegetated $(7)=$ visitation most days.

Table 28: Table of coefficients from binary logistic regression of coast visitation and Total PEB binary using the concatenated sample. No-visitation to coasts set as base. Coasts $(1)=$ visitation once every six months or less, Coasts $(2)=$ visitation once every 4-5 months, Coasts $(3)=$ visitation once every 2-3 months, Coasts $(4)=$ visitation once a month, Coasts $(5)=$ visitation once every 2-3 weeks, Coasts $(6)=$ visitation once or twice a week, Coasts $(7)=$ visitation most days.

Table 29: Table of coefficients from binary logistic regression of sports field visitation and Total PEB binary using the concatenated sample. No visitation to coasts set as base. Sports Fields $(1)=$ visitation once every six months or less, Sports Fields $(2)=$ visitation once every $4-5$ months, Sports Fields (3) = visitation once every 2-3 months, Sports Fields $(4)=$ visitation once a month, Sports Fields $(5)=$ visitation once every $2-3$ weeks, Sports Fields $(6)=$ visitation once or twice a week, Sports Fields $(7)=$ visitation most days......

Table 30: Output table from forward selection linear regression with Total PEB as the dependent and the six urban green space variables as predictors. Four steps are shown before termination.

Table 31: Cross tabulation table displaying conditional probabilities of performing home composting (1.00) or not (.00) and visiting the town belt once a month or more (1.00) or less than once a month $(.00)$.

Table 32: Table of statistically significant odds ratios from independent binary logistic regression of pro-environmental behaviour and urban green space visitation. A binary variable for urban green space was used (.00 indicating visitation less than once a month, 1.00 indicating visitation once a month or more). Statistically significant odds ratios are denoted by $*$ and $* *$ in accordance with significance level. Odds ratios interpreted as the increase in odds of proenvironmental associated with urban green space visitation once a month or more. Blank cells indicate no statistical association.

Table 33: Significant Pearson chi squares from cross-tabulation analysis using urban green space visitation (with eight visitation categories retained) and pro-environmental behaviour. Each cross-tabulation compared one urban green space type with one pro-environmental behaviour. Statistically significant associations are indicated *.

Table 34: Correlation matrix showing Pearson correlation coefficients for all pairwise comparisons of urban green space visitation variables.

Table 35: Pearson Correlation Coefficients $(\mathrm{P})$ between fourteen pro-environmental behaviours using the concatenated sample. Significance denoted by $*$ for significance at $1 \%$ level and $* *$ for significance at $5 \%$ level.

Table 36: Frequency table showing distribution of male and female respondents using the concatenated sample.

Table 37: Cross tabulation table displaying conditional probabilities of performing more than seven pro-environmental behaviours (Total PEB binary $=1.00$ ) and visiting urban green space at least once a year (Total UGS Yes or No $=1.00$ ) for male and female respondents separately.

Table 38: Cross tabulation table displaying conditional probabilities of performing more than seven pro-environmental behaviours (Total PEB binary $=1.00$ ) and visiting urban green space once a month or more (Total UGS binary $=1.00$ ) for male and female respondents separately. 93 Table 39: Frequency table showing the distribution of responses using the concatenated sample across the five categories of age.

Table 40: Conditional probabilities of performing more than seven pro-environmental behaviours (Total PEB binary $=1.00$ ) if urban green space is visited once a month or more (Total UGS binary $=1.00$ ) and the individual is over 40 years of age using the concatenated sample.....

Table 41: Regression output displaying coefficients and significance of age, urban green space visitation, and Age-UGS interaction variables for the prediction of Total PEB using the 
concatenated sample. Age is categorised using dummy variables with 65 years or over acting as the base variable. The associated significance denotes whether the age category significantly alters the prediction of Total UGS relative to the base, 65 years or over.

Table 42: Regression output after testing for significance of main effects of Age and Total UGS visitation and the interaction term, Age*UGS using the concatenated sample.

Table 43: Frequency table showing distribution of responses for the six categories of income using the concatenated sample.

Table 44: Cross tabulation analysis showing conditional probabilities of performing more than seven pro-environmental behaviours (Total PEB binary $=1.00$ ) and visiting urban green space once a month or more Total UGS binary $=1.00)$ for four levels of income $(.00=\$ 20,000$ $\$ 30,000,1.00=\$ 30,001-\$ 70,000,2.00=\$ 70,000-\$ 100,000,3.00=$ more than $\$ 100,000)$ using the concatenated sample.

Table 45: Cross tabulation analysis showing conditional probabilities of performing more than seven pro-environmental behaviours (Total PEB binary $=1.00$ ) and visiting urban green space once a month or more (Total UGS binary $=1.00$ ) for two levels of income (less than the New Zealand median and more than New Zealand median).

Table 46: Regression coefficients from logistic regression of Total PEB binary with the main effects of Total UGS visitation and the income-UGS interaction term with the main effect of income included as dummy variables using the concatenated sample.

Table 47: Table of coefficients and significance for the regression of Total PEB and Total UGS using the concatenated sample. Main effects of UGS visitation and income and the interaction term are shown.

Table 48: Frequency table showing the distribution of responses across the five categories of pride using the concatenated sample. Pride represented by five categories pertaining to how much a respondent agrees or disagrees with the statement, 'I feel a sense of pride in the way the city looks and feels' $(1.00=$ strongly disagree, $2.00=$ disagree, $3.00=$ neither agree nor disagree, $4.00=$ agree, $5.00=$ strongly agree $)$.

Table 49: Two way-ANOVA testing the presence of an interaction between Total UGS and pride on the prediction of Total PEB.

Table 50: Frequency table for distribution of responses across the five categories of quality of life using the concatenated sample. Quality of life depicted by $1.00=$ extremely poor, $2.00=$ poor, $3.00=$ neither poor nor good, $4.00=$ good, $5.00=$ extremely good.

\section{List of Figures}

Figure 1: Map of Wellington City (Google, 2014).

Figure 2: Causal diagram illustrating proposed direction of study .........................................23

Figure 3: The low-cost hypothesis of environmental behaviour (Diekmann and Preseindörfer, 2003).

Figure 4: Low-cost and high-cost situations and the role of environmental concern (Diekmann and Preseindörfer, 2003).

Figure 5: Theoretical progression illustrating the hypothesised relationship between urban green space (UGS) visitation, emotional connections to nature, and pro-environmental behaviour (PEB), using biophilia and the theory of planned behaviour (TPB) as supporting arguments.

Figure 6: Linear relationship between pro-environmental behaviour (measured as a score out of 14) as a function of urban green space visitation (measured as a combined score for visitation to six urban green space types).

Figure 7: Linear relationship between pro-environmental behaviour (measured as a score out of 14) as a function of urban green space visitation (measured as number of times over a 12 month period urban green space was visited for six urban green space types). 
Figure 8: Linear relationship between pro-environmental behaviour (measured as a score out of 14 ) as a function of urban green space visitation (measured as a combined score for visitation to six urban green space types). Linear trend lines fitted for the subgroups of gender.

Figure 9: Linear relationship between pro-environmental behaviour (measured as a score out of 14) as a function of urban green space visitation (measured as a combined score for visitation to six urban green space types). Linear trend lines fitted for the subgroups of age.

Figure 10: Linear relationship between pro-environmental behaviour (measured as a score out of 14) and urban green space visitation (measured as a combined score for visitation to six urban green space types). Linear trend lines are fitted for the six subgroups of household income

Figure 11: Linear relationship between pro-environmental behaviour (measured as a score out of 14) as a function of urban green space visitation (measured as a combined score for visitation to six urban green space types). Linear trend lines fitted for the subgroups of gender. Pride categories denoted by five values pertaining to how strongly they agree or disagree with the statement, 'I feel a sense of pride in the way the city looks and feels' $(1.00=$ strongly disagree, $2.00=$ dis agree, $3.00=$ neither agree nor disagree, $4.00=$ agree, $5.00=$ strongly agree $).$

Figure 12: Linear relationship between Total PEB (number of pro-environmental behaviours performed) as a function of Total UGS visitation (combined score from all six urban green space types) for each of the five subgroups of Quality of Life. Quality of life depicted by five categories $(1.00=$ extremely poor, $2.00=$ poor, $3.00=$ neither poor nor good, $4.00=\operatorname{good}, 5.00$

$=$ extremely good).

Figure 13 Linear relationship between Total PEB (number of pro-environmental behaviours performed) and Total UGS visitation (combined score from all six urban green space types). Trend lines fitted for four subgroups of Quality of Life. Quality of life depicted by four categories, $.00=$ neither good nor poor quality of life, $1.00=$ extremely poor or poor, $2.00=$ good, $3.00=$ extremely good. 


\section{CHAPTER 1}

\subsection{Introduction}

There is no doubt that human's contribution to global environmental change is significant (Poortinga et al., 2011). Current changes and those predicted for the future are largely driven by human behaviour, justifying the importance of behaviour change policy (Gifford et al., 2011). However, despite numerous attempts to implement such intervening policies, a widespread lack of participation in pro-environmental behaviour (PEB) remains a problematic issue (Lorenzoni et al., 2007). Lorenzoni et al. (2007) acknowledge the term 'engagement' and cite this area as a significant barrier to the efficacy of current behaviour change policy. Engagement is taken to mean a personal state of connection with an issue (Lorenzoni et al., 2007). For the purposes of my study I am referring to connections with nature. Before any behaviour change policy measures can be implemented effectively, a connection to the issue in question must exist (Gifford et al., 2011, Lorenzoni et al., 2007). It is not enough to simply 'know' about environmental issues; people must be emotionally connected to nature in order to be motivated to change behaviour (Lorenzoni et al., 2007).

Environmental psychologists have been working since the 1970s to identify factors that predict environmentally friendly actions (Gifford et al., 2011). The knowledge deficit model references the causal progression from environmental concern to proenvironmental behaviour (Gifford et al., 2011). Elucidating concern for nature can only be achieved if an individual feels suitably connected to it, justifying the importance of emotional connections to nature for pro-environmental behaviour change efficacy. Nisbet et al. (2009) posit that the necessary level of engagement with the environment is missing and is hindering positive change. There are examples beyond the environment arena where poor engagement has hindered policy implementation. Under the Obama administration, previous efforts to pass health care or immigration reforms have depended strongly on public support, when engagement was absent, the policies suffered major defeats (Nisbet, 2009).

It is clear that in order to build a sustainable future, the environmental attitudes and behaviours of society must change. Attempts to develop and implement policies designed to stimulate environmentally responsible behaviours have mostly been based on fiscal incentives, enforced environmental regulations, and provision of 
environmental information (Kollmuss and Agyeman, 2002, Lucas et al., 2008). While such factors do influence the environmental behaviour of society, Clowney (2013) believes these instruments to be superficial and ineffective and that 'deeper motivation could occur through cultivating innate attraction to nature' (Clowney, 2013:1). Attitudes towards pro-environmental behaviour are said to be relatively easy to modify with the introduction of new contextual surroundings and new circumstances (Gatersleben et al., 2012) and fostering attitudinal variables is posited as the most effective methodology for widespread pro-environmental behaviour uptake (Pooley and O’Connor, 2000). Exploring nature exposure as a means to foster emotional connections to nature and the necessary pro-environmental attitudes for pro-environmental behaviour change is thus of vital importance for policy makers and forms the purpose of this study.

Despite literature citing a lack of emotional connection to the natural landscape as a major reason behind low levels of pro-environmental behaviour, the role urban green space (UGS) plays in fostering such connections receives little attention from policy makers. Urban green space can be defined as outdoor places with significant amounts of vegetation, mainly existing as natural or semi-natural areas in urban centres (Yin and Kong, 2005). In Wellington, New Zealand, this definition extends to include areas of open space, for example, sports fields and parks (Greater Wellington Regional Council, 2009b). City walking tracks, botanic gardens, and town green belts are additional examples of how green landscapes can be incorporated into urban settings. Urban based water bodies, such as coasts, beaches, and harbours, termed the urban blue by Völker and Kistemann (2013), are also important 'green' spaces allowing built landscapes to retain naturalistic features. With $50 \%$ of the world's population now living within urban environments, urban expansion is encroaching further into these green areas (Mahmoudi et al., 2013). Consequently, it is now becoming common place for societies to experience nature via vicarious means rather than through direct contact, and it is this reduced contact which has been termed the 'extinction of experience' (Hinds and Sparks, 2008, Pyle, 2003). As exposure to natural landscapes becomes ever more limited, will the emotional connections to the landscape dwindle with it, thereby limiting pro-environmental behaviour? There is a need for research into the associations between urban green space experiences and pro-environmental behaviour to ascertain whether promoting urban green space development (and visitation) could lead to increased pro-environmental behaviours. 
The idea that nature exposure could increase pro-environmental behaviour stems from Edward O. Wilson's (1984), biophilia hypothesis. The biophilia hypothesis puts forward that humans have an innate want to preserve and protect the natural environment, a want that is programmed into our biological evolution (Kellert, 1993b, Wilson, 1984). Direct exposure to natural surroundings is said to enhance this feeling. Those that spend more time in an urban green space have been shown to hold strong emotional ties to the area and are more likely to speak up about changes or developments affecting or relating to present or proposed urban green space (Arnberger and Eder, 2012). Additionally, green space presence has been statistically shown to decrease the amount of nights residents spend away from that area (Abkar et al., 2010), possibly indicating a sub-conscious emotional connection with their city. There is no doubt that urban green space visitation promotes positive, emotional responses within those that experience them (Aspinall et al., 2013, Kabisch and Haase, 2013, Schäffler and Swilling, 2013, Schipperijn et al., 2013, Swanwick, 2009, Watts et al., 2013, Zhou and Kim, 2013). With help from the biophilia hypothesis, it can be posited that if a person is exposed to nature (via urban green space visitation) on a frequent basis, this exposure may foster positive affections to nature and the necessary pro-environmental attitudes to be motivated to preserve it.

If a relationship can be established between urban green space visitation and proenvironmental behaviour, therein lies further evidence for the justification of urban green space expansion and protection. If local government is to justify the money spent on the creation and maintenance of such spaces, urban green space must continue to be understood and portrayed as a socially valuable landscape. While causality is unable to be proven by my research due to time restrictions preventing a longitudinal or intervention study, the theory of biophilia links emotional connection with the natural landscape to an increased tendency for pro-environmental action. On top of this, the theory of planned behaviour (TPB) states that one's emotions are central to the prediction of one's behavioural intentions and subsequent behaviour (Ajzen, 1991, Hinds and Sparks, 2008, Hinds and Sparks, 2011). Using biophilia and the theory of planned behaviour as explanatory guides, if a link is found between pro-environmental behaviour and urban green space visitation, it can be posited that exposure to the natural environment is helping to foster emotional environmental connections, manifested as pro-environmental behaviour. Additionally, if it is revealed that certain green spaces are more strongly linked to pro-environmental behaviour in general or certain types of proenvironmental behaviour, therein lies evidence to prioritise these landscapes for their potential to stimulate environmental connections. 
While there is great benefit to understanding whether there is an association between urban green space visitation and pro-environmental behaviour and how biophilia may act to facilitate this association, it is also beneficial to understand how sociodemographic factors may moderate the relationship. Environmental behaviours have been shown to vary significantly across gender, age, and nature experience, with female students partaking in higher levels of nature related activities performing more environmentally responsible behaviours (Erdogan et al., 2012). Such studies are important as they allow policies to be efficiently tailored toward certain sociodemographics. While there is evidence showing socio-demographic factors to be associated with pro-environmental behaviour, there is no research looking at nature exposure and pro-environmental behaviour together with socio-demographics; something my research will address.

Along with socio-demographics, pride is a positive emotion that has been shown to help predict intentions for performing pro-environmental behaviour (Harth et al., 2013b). If policy makers are to understand how to maximise biophilia for the purposes of proenvironmental behaviour uptake, it is important that pride be investigated for how it interacts with urban green space visitation. It is likely that those with greater pride in their city are more susceptible to the positive emotional connections biophilia fosters, thus increasing the likelihood that nature exposure will manifest itself in proenvironmental behaviour.

Quality of life is another attitudinal variable that should also be examined for its moderating effect on the association between nature exposure and pro-environmental behaviour. Quality of life can be defined as referring to one's well-being or life satisfaction (Grinde and Patil, 2009). Quality of life, being positively correlated with life satisfaction, reflects well-being and the subsequent ability to focus on issues beyond one's self, following the affluence hypothesis of Givens and Jorgenson (2011) (Cervinka et al., 2012). It could be that the biophilia hypothesis is only true for those who have a high quality of life. My study will shed light on such theories.

Conducting such a study in New Zealand is pertinent considering the Ministry for the Environment's (MfE) statement of intent (SOI) 2010-2013 explicitly refers to 'behaviour change' (Ministry for the Environment, 2010). Additionally, the statement of intent alludes to pro-environmental behaviour when it states, "New Zealand's prosperity and quality of life will be enhanced if more New Zealanders adopt environmentally responsible practices" (Ministry for the Environment, 2010). Wellington city will thus 
act as the case study for this project. When comparing the amount of urban green space per person between cities and regions, Wellington performs very well. The Economist Intelligence Unit (2012) produced a Green City Index which rated cities and regions on their sustainability and environmental performance. Latin America was found to have the greatest amount of green space per person, with $255 \mathrm{~m}^{2}$ (Economist Intelligence Unit, 2012). Wellington city ranks better than this average, with $261 \mathrm{~m}^{2}$ of green space per person (Economist Intelligence Unit, 2013). With a vast array of urban green space (comprising 3,800 hectares) providing a range of opportunities for positive recreational experiences in nature, Wellington city provides the ideal setting for such a study (Greater Wellington Regional Council, 2009a).

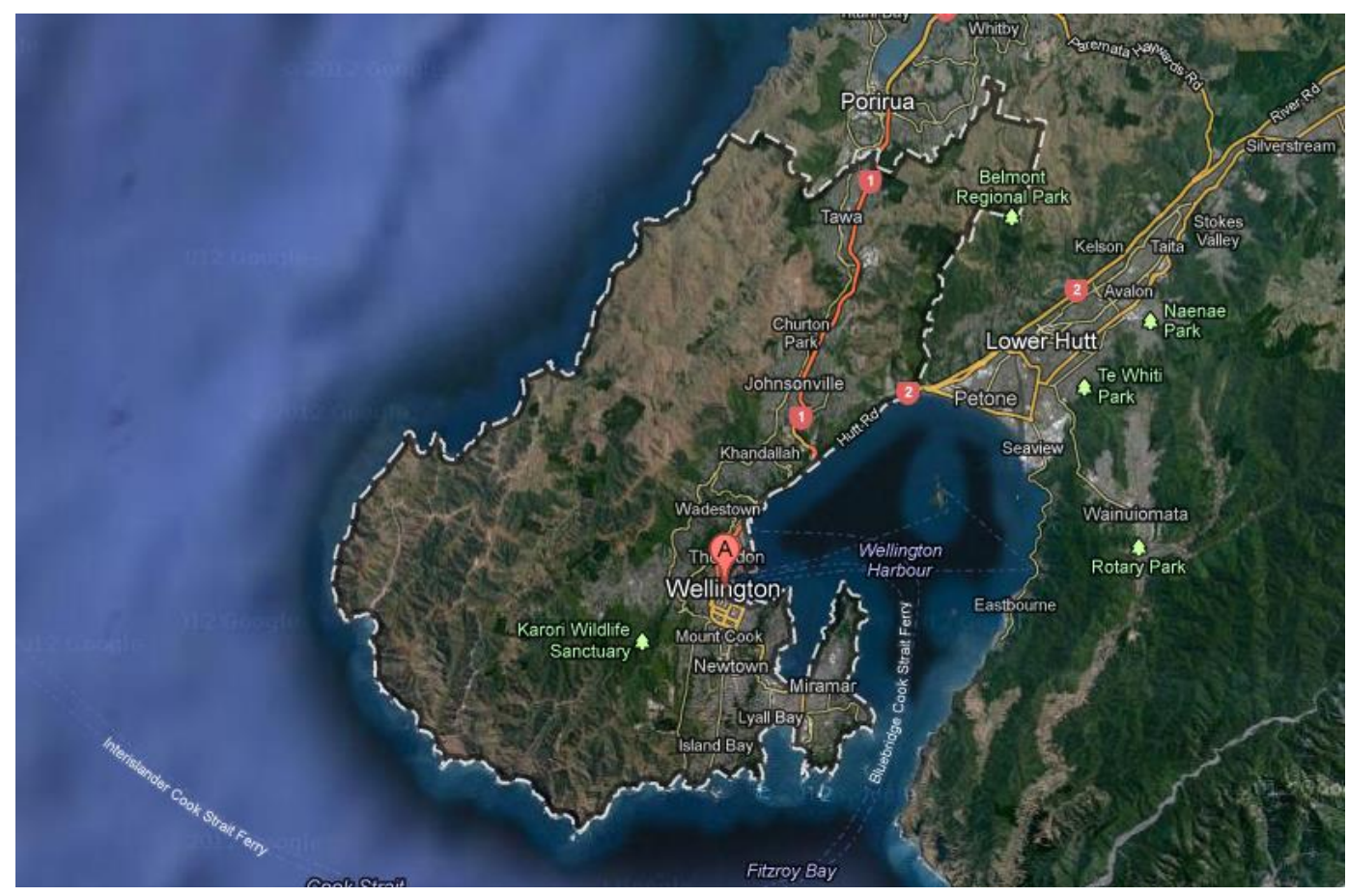

Figure 1: Map of Wellington City (Google, 2014).

The data set being analysed for this project was sourced from the 2010, 2011, and 2012 Wellington City Council Residents' Satisfaction Survey which was conducted on Wellington city residents (copies attached in appendices). The survey sought to assess whether the council was achieving the goals laid out in their annual plan and includes questions on urban green space visitation, pro-environmental behaviour, sociodemographics, as well as pride and quality of life. The council did not look for associations between these variables nor were interactions between urban green space visitation, socio-demographics, and attitudinal variables computed for moderating effects. My study employs correlation and regression analysis to examine the data for 
statistically significant relationships. I was looking for evidence to support the provision and maintenance of urban green space and pave the way for future research into biophilia as a behaviour change tool.

The following research aims to determine whether pro-environmental behaviours are linked to visitation of Wellington city's urban green space. The questions and hypotheses addressed in this research are as follows:

\subsection{Research Questions and Hypotheses}

1.0 What is the relationship between urban green space visitation and proenvironmental behaviour in Wellington city?

1.1 Do urban green space visitors and non-visitors exhibit a difference in their amount of pro-environmental behaviour?

1.2 Does the relationship between urban green space visitation and proenvironmental behaviour change depending on the type of urban green space visited and the particular pro-environmental behaviour measured?

1.3 How do socio-demographic factors moderate the relationship between urban green space visitation and pro-environmental behaviour?

1.4 How does pride moderate the relationship between urban green space visitation and pro-environmental behaviour?

1.5 How does quality of life moderate the relationship between urban green space visitation and pro-environmental behaviour?

Hypothesis for question 1.0:

- Those who visit urban green space will perform more pro-environmental behaviours than non- visitors. 
Hypothesis for question 1.1:

- Those who visit urban green space frequently will perform more proenvironmental behaviours than those who visit urban green space less frequently.

Hypotheses for question 1.2:

- Those who visit vegetated spaces will perform more pro-environmental behaviours than those visiting less vegetated urban green space.

- Those who visit coasts frequently will perform more pro-environmental behaviours that specifically relate to water.

Hypotheses for question 1.3:

- The relationship between urban green space visitation and pro-environmental behaviour will be stronger in females than males and will be positive.

- The relationship between urban green space visitation and pro-environmental behaviour will be stronger for those living in a higher income earning household and will be positive.

- The relationship between urban green space visitation and pro-environmental behaviour will be stronger in older individuals and will be positive.

Hypothesis for question 1.4:

- The relationship between urban green space visitation and pro-environmental behaviour will be stronger for those who have more pride in their city.

Hypothesis for question 1.5:

- The relationship between urban green space visitation and pro-environmental behaviour will be stronger for those with a higher quality of life. 
I begin my research with an in depth literature review of the relevant studies and theories that have shaped the development of my research questions and hypotheses. My method of analysis is then laid out followed by the results of my statistical tests. I conclude my thesis by discussing my results in relation to what was expected while providing recommendations for future research into biophilia as a behaviour change tool. 


\subsection{Literature Review}

My research seeks to fill a literature gap by statistically assessing the extent to which pro-environmental behaviour is associated with nature exposure within an urban centre (using urban green space visitation as a proxy for urban based nature exposure). More specifically, it is envisaged that my research will provide insight into the proenvironmental behaviour patterns of urban green space visitors, using the Wellington city population as a case study. Due to the importance of nature connections for proenvironmental behaviour uptake (Lorenzoni et al., 2007), it is hypothesised that those who are more exposed to nature will subsequently participate in more proenvironmental behaviours, as well as show preference for pro-environmental behaviours that are closely related to the type of urban green space they most frequently visit (for example, water pollution minimisation is expected to positively correlate with coast visitation).

Following the work of Lucas et al. (2008), Gifford et al. (2011), Lorenzoni et al. (2007), and Joye and Van den Berg (2011), at the crux of my proposed study is the assumption that when one is exposed to the natural environment, affective connections to nature are fostered, meaning people are more likely to develop pro-environmental attitudes and express these attitudes through pro-environmental behaviour. Of course, this assumes attitude-behaviour consistency. The relationship between one's emotions and attitudes and how one physically behaves is a well-researched area of study (Ajzen, 1991, Ajzen and Fishbein, 1977, Stern, 2000). Although a meta-analysis of the researched link between verbally expressed attitudes and physical behaviours concludes the relationship to be moderate at best, (Greenwald et al., 2009), Azjen and Fishbein (1977) point out the limitations of these studies by highlighting there to be two distinct types of attitudes; general attitudes (the subject of many attitude-behaviour studies) and specific attitudes toward performing particular behaviours. Using attitudes specifically relevant to religion and the church as an example, Azjen and Fishbein (1977) found religious specific attitudes to correlate strongly with broad patterns of religious behaviour. What can be concluded here is the evident link of attitudes in one domain being consistent with behaviours in a similar domain. Weigel and Newman (1976) produced similar results by showing attitudes towards protection of the environment were accurate predictors of pro-environmental behaviours. This concept is termed the principle of compatibility (Azjen, 1991). 
What should also be clarified here is the relationship between emotional connections to nature and pro-environmental attitudes, and how these factors are linked to behaviour. The theory of planned behaviour (TPB) (Azjen, 1991) can be used to explain this link. First, the reason nature exposure can be hypothesised as being associated with affective connections to nature comes from the work of Millar and Millar (1996) who state that with direct experiences, evaluations of that object tend to be affectively based, and these affective connections are enhanced with repeated exposure (Hinds and Sparks, 2008). Empirical evidence which shows emotional connections to be an important predictor of environmental attitudes is provided by Pooley and O'Conner (2000). Hinds and Sparks (2008) use the conclusions of Pooley and O'Conner (2000), as well as the work of Kals et al. (1999) (who show emotional affinity to nature to predict nature protective behaviour) when they describe the efficacy of the TPB in explaining environmentally responsible behaviour. The TPB tells us that attitudes are predictors of behaviour. Affective connections were proven by Hinds and Sparks (2008) to predict attitudes towards engaging with the natural environment.

What should be made clear is the direction of the proposed study and how it fits into the current literature. Figure two illustrates the relationship to be studied, as well as the paths that have already been addressed in the academic literature. Importantly, it depicts urban green space visitation as a form of nature exposure. While not depicted in the diagram, the relationship between urban green space and pro-environmental behaviour will be investigated further by breaking urban green space visitation down by type (e.g., coasts, botanic gardens, parks, town belt, tracks, and sports fields) and frequency of visitation, and assessing by type and amount of pro-environmental behaviour (e.g., recycling, putting rubbish in the bin, avoiding plastic). Additionally, sociodemographics may also play a role in the strength of the relationships examined. Gender, age, and income will therefore be incorporated into the statistical analysis in order to ascertain whether the associations are stronger for certain socio-demographics relative to others. Attitudinal factors (pride and quality of life) may also act as moderators and will therefore be examined for such an effect.

As illustrated in figure two, each section in the literature review is dedicated to a particular link in the flow chart. Section 1.2.2 covers emotional connections and attitudes to nature and how this relates to pro-environmental behaviour. Section 1.2.3 focuses on the way urban green space has been studied in the academic literature. An overview of how socio-demographic variables are currently understood to be associated 
with urban green space visitation and pro-environmental behaviour is covered in section 1.2.5. Section 1.2.6 and 1.2.7 look into how the attitudinal variables of pride and quality of life have been addressed in relation to their effect and influence on emotional connections to nature and pro-environmental behaviour. A final section (1.2.8) summarises the main conclusions of the literature, re-states the research hypotheses, and highlights study limitations.

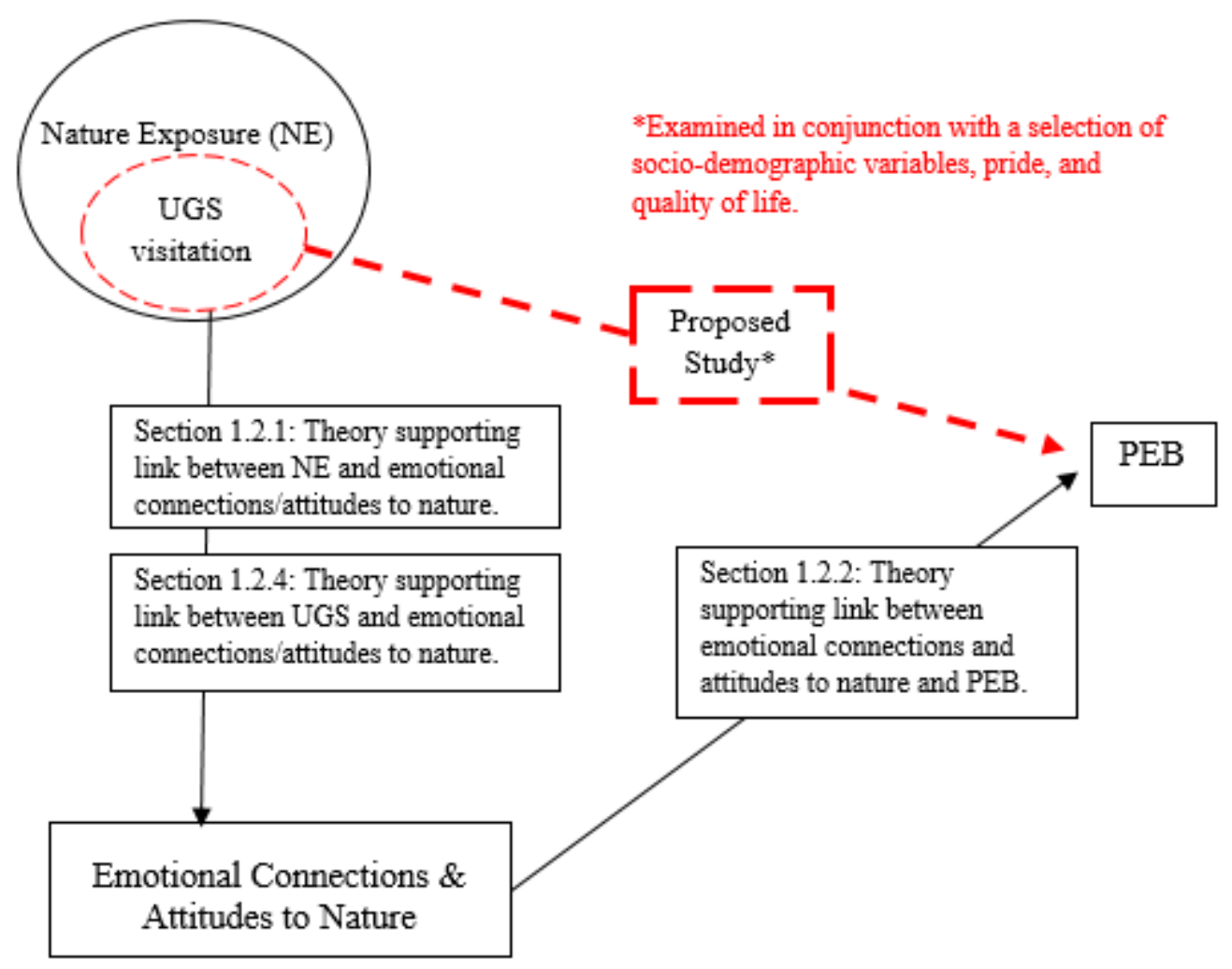

Figure 2: Causal diagram illustrating proposed direction of study.

\section{Contribution to the literature}

As there has not yet been an examination of the association between urban green space visitation and pro-environmental behaviour, the proposed study will fill a literature gap. By detailing the relationship across a range of pro-environmental behaviours, urban green space types, socio-demographic factors, as well as pride and quality of life variables, the results will provide policy makers with empirical evidence pertaining to how such factors moderate the relationship between urban green space visitation and pro-environmental behaviour. Within the literature, there is ample evidence to support the idea that those with greater exposure to nature hold stronger emotional connections 
to the environment and pro-environmental attitudes making them more inclined to perform pro-environmental behaviour (Finger, 1994, Hinds and Sparks, 2008, Kals et al., 1999, Nisbet et al., 2009). While there is adequate literature surrounding the link between nature exposure and environmental connections, as well as environmental connections and attitudes and their role in predicting environmentally responsible behaviours, there has been no such study which looks at urban green space visitation and pro-environmental behaviour and how such a relationship is moderated.

\subsubsection{Nature Exposure and Emotional Connections and Attitudes to Nature}

Research has reported individuals hold stronger self-reported connections to nature rather than built stimuli (Hinds and Sparks, 2008, Schultz and Tabanico, 2007), meaning there is reason to believe that increasing the presence of nature within urban surrounds could increase societies engagement with environmental issues. There are a number of scales which have been used to measure one's connectedness to nature including the Environmental Identity Scale; Schultz's (2000) Inclusion of Nature in Self scale; Mayer and Frantz's (2004) Connection to Nature scale, and the Nature Relatedness Scale of Nisbet et al. (2009), which all focus on the cognitive aspects of the people-nature dynamic (Schultz, 2000). All scales were developed using the assumption that humans have the ability to connect to nature and consequently hold emotions and attitudes pertaining to it. Nisbet et al. (2009) used the Nature Relatedness Scale to find that time spent in nature is positively correlated with a high score for connectedness to nature. If time spent in nature increases one's nature connectedness, it can then be assumed that urban green space visitation, being a form of nature visitation, will be positively correlated with nature connectedness.

An additional way of thinking about and describing nature connectedness has been expressed using emotional affinity towards nature (Mayer and Frantz, 2004). Kals and colleagues (1999) concept of an emotional affinity toward nature encompasses an inclination to care and protect for the natural environment after positive nature exposure. Emotional affinity toward nature has also been statistically shown to positively correlate with present (and past) frequency of time spent in nature (Kals et al., 1999). The role of nature exposure in the development of emotional connections and pro-environmental attitudes has been addressed in the literature with research centered on childhood experiences with nature and adult environmentalism (Kals et al., 1999, Lohr and Pearson-Mims, 2005, Louv, 2008, Wells and Lekies, 2006). All studies 
produced corroborating results supporting the hypothesis that nature exposure is linked to positive environmental attitudes and behaviours. Aberg and Tapsell (2013) have noted that it takes time for people to build up a caring and emotional connection to local green spaces, suggesting frequency of visits could increase emotional connection. Evidence confirming the ability of repeated exposure to enforce positive affective connections is presented by an additional array of authors (Finger, 1994, Hinds and Sparks, 2008, Nord et al., 1998, Teisl and O'Brien, 2003).

Importantly, it is acknowledged that nature based experiences must be positive to fuel emotional affinity (Kals et al., 1999). As it is the direct experience with an object or setting which tend to have the greatest impacts on affectively based evaluations (Hinds and Sparks, 2008, Millar and Millar, 1996), when these experiences are positive, affections and subsequent attitudes pertaining to that setting are likely to also be positive. Promoting positive experiences with the natural environment has been suggested as a possible means of mitigating the cycle of apathy and poor engagement with ecological issues (Hinds and Sparks, 2008:109). Biophilia is a theory which can help explain the findings linking nature exposure to positive environmental attitudes, as well as the emotional connections discussed earlier.

The biophilia hypothesis suggests humans have an evolutionary based affiliation with the natural environment which is enhanced through repeated exposure (Kahn Jr, 1997). The theory states that those with greater nature based experiences develop greater affective connections to nature. Theoretical underpinning for the proposed study is provided by the biophilia concept as it justifies the hypothesis that urban green space visitation is positively correlated with pro-environmental behaviour. Kellert (1993) posits that due to the relatively short period of time humans have begun living in urban environments, the value of nature for survival hardwired into human biology has not had time to be erased. Biophilia is thus a part of evolutionary development. The popularity of outdoor activities and natural scenery, as well as the positive emotional responses people gain from being in and around nature reported by psychologists worldwide is testament to Kellert's theory (Gatersleben, 2008, Hinds and Sparks, 2008, Kals et al., 1999, Millar and Millar, 1996, Nisbet et al., 2009). Ultimately, there is strong evidence supporting the statement that being exposed to nature predisposes an individual to feel positively towards it. Whether other literature agrees that holding positive affective connections and attitudes to nature then predisposes someone to perform pro-environmental behaviour is covered next. 


\subsubsection{Emotional Connections to Nature, Pro-environmental Attitudes and Pro- Environmental Behaviour}

Repeated exposure to nature fosters affective connections to nature (Hinds and Sparks, 2008, Hinds and Sparks, 2011), and a number of scholars have agreed that as empathy with a natural setting increases, so too does the likelihood emotional affinity will be reflected in behaviour (Kals et al., 1999, Kaplan and Kaplan, 1989, Schultz, 2000). Psychologists have held great interest in the connection between environmental attitudes and pro-environmental behaviour (Nisbet et al., 2009). Tarrant and Green (1999) posited that if one is emotionally attached to a physical landscape they are more likely to seek its preservation (requiring participation in pro-environmental behaviours). Empirical evidence to support Tarrant and Green's (1999) statement comes from the 2010 work of Gosling and Williams who showed that people who feel stronger connections to nature more often participate in pro-environmental behaviours.

Holding an emotional connection to nature is crucial in the fostering of proenvironmental behaviour and has been documented in the literature (Mayer and Frantz, 2004, Schultz, 2002). The concept even has its own measurement scale, the connection to nature scale (CNS) developed and applied by Schultz (2002) to show a significant correlation between connectedness to nature and self-reported pro-environmental behaviour. Nature relatedness, a similar measurement tool to Schultz' CNS, was developed in order to understand the role of connectedness to nature in predicting environmentally responsible behaviour (ERB) (Nisbet et al., 2009). It was ultimately concluded that spending more time in nature and partaking in $\mathrm{ERB}^{1}$ was positively correlated with 'nature relatedness'.

While attitudes towards nature protection are ultimately shaped by one's emotional connections to the natural environment (Hinds and Sparks, 2011), it is the concept of attitudes, as opposed to emotions, which has received greater attention in the environmental psychology literature, appearing in nearly two-thirds of publications (Kaiser et al., 1999). Attitudes have been tested for their predictive validity on proenvironmental behaviour with previous investigations into the relationship between environmental attitudes and ecological behaviour consistently achieving moderate support (Hines et al., 1987). Attitudes are complex constructs and can be conceptualised in various ways, with one description referring to attitudes as the inclination for an

\footnotetext{
${ }^{1}$ In this case, pro-environmental behaviour was measured by respondent's involvement in environmental organisations (Nisbet et al., 2009).
} 
individual to evaluate aspects in a particular manner (be it favourable or unfavourable) (Balram and Dragićević, 2005). As a number of authors have concluded, attitudes are powerful predictors of behaviour and distinct environmental influences (such as nature exposure) can potentially reveal distinct clusters of the population who share similar attitudes (such as those which are pro-environmental) (Ajzen, 1991, Balram and Dragićević, 2005, Kaiser et al., 1999). Using the principle of compatibility (which explains the phenomenon whereby specific attitudes are predictors of related behaviours); it is thus likely that those clusters of people exhibiting pro-environmental behaviour are doing so due to their pro-environmental attitudes. Whether these clusters of pro-environmental behaviour actors also share similar rates of 'green' experiences remains an important literature gap.

With biophilia providing supporting theory for the link between nature exposure and pro-environmental attitudes, the link between pro-environmental attitudes and proenvironmental behaviour is supported by the theory of planned behaviour (TPB). The TPB is the most common model appearing within the environmental attitudes and behaviour literature. Developed by Azjen (1991), the TPB posits that people behave in a way that reflects their intentions regarding a particular action, which is in turn governed by attitudes, habits, and perceived behavioural control (how much control they perceive themselves to have over the behaviour) (Hinds and Sparks, 2008, Kaiser et al., 1999). With pro-environmental behaviour being action taken with the intent to ameliorate or prevent environmental degradation (Blake, 2001), the TPB uses measures of environmental attitudes to ascertain the extent to which pro-environmental behaviour may be performed. Kaiser et al. (1999) unified measures of environmental values and knowledge to represent environmental attitudes (using Azjen's (1991) TPB) and subsequently showed environmental attitudes to explain $40 \%$ of the variance in proenvironmental behaviour intention (motivation and willingness to perform proenvironmental behaviour). Pro-environmental behaviour intention subsequently explained $75 \%$ of the variance in pro-environmental behaviour itself (Kaiser et al., 1999). Such evidence proves that pro-environmental behaviour is strongly influenced by one's environmental attitudes. If the link between attitude and behaviour was weak or non-existent, it would have been inappropriate to hypothesise that urban green space visitation is associated with pro-environmental behaviour. My study covers the missing link in the chain, the statistical association between urban green space visitation (nature exposure) and pro-environmental behaviour. 
The theories presented so far (biophilia, principle of compatibility, TPB) suggest emotive variables, including attitudes and emotional connections to nature, are stimulated by nature exposure and are important in the prediction of pro-environmental behaviour. However, there is still debate in the literature pertaining to the significance of such emotive variables in behaviour change. Thogerson and Olander (2006) and Pooley and O'Connor (2012) state such variables to be the dominant motivation behind pro-environmental behaviours, yet other authors believe structural factors and sociodemographics to be more important (Bamberg et al., 2003, Jackson, 2005, Kollmuss and Agyeman, 2002). There is, however, ample theory and empirical evidence overall to support the causal progression from pro-environmental attitudes to pro-environmental behaviour. Unfortunately, current policy does not recognise the potential of promoting nature exposure to foster pro-environmental attitudes to increase pro-environmental behaviour. With urban green space visitation being a form of nature exposure within an urban setting, examining the relationship between urban green space visitation and proenvironmental behaviour is a justified research direction.

\subsubsection{Urban Green Space in the Literature}

While town planners have always recognised the importance of allowing for urban green space, the motivations behind their inclusion have shifted over the past few decades (Carpenter, 2013). The original purpose of urban green space was to provide visual enjoyment, while their current importance is based upon the ecological functions they provide, as well as their contributions to physical health and fitness (Bingley, 2013, Cariñanos and Casares-Porcel, 2011, Lee and Maheswaran, 2011). The direct ecological benefits of urban green space, as habitat and ecosystem service providers, rainwaterrunoff reducers, and urban heat distributors, is addressed within the ecology based scientific literature (Bolund and Hunhammar, 1999, Choi and Lee, 2011). The ability of urban green space to act as carbon sinks and provide additional ecosystem services such as habitat corridors is also strongly supported (Holt et al., 2012, Schäffler and Swilling, 2013, Sushinsky et al., 2013).

Within the social science and public health literature there is little debate surrounding the role of urban green space for the improved health (weight loss, stress reduction, improved fitness) of those who visit such areas. Empirical evidence shows stress levels, fitness, and blood pressure of individuals exposed to forested areas around a townscape (e.g., a town belt) to be, on average, superior to that of urban workers (Beil and Hanes, 
2013, Bingley, 2013, Tsunetsugu et al., 2013). Additionally, the significant benefits of living close to urban green space for residents emotional and psychological well-being has been widely acknowledged (Aspinall et al., 2013, Swanwick, 2009, Tzoulas and James, 2010, Völker and Kistemann, 2013). A study measuring the emotional experience of walkers in three types of urban environments (including one urban green space) reported urban green space to be associated with the greatest level of moodenhancing stimuli (Aspinall et al., 2013). It is clear that urban green space has many positive impacts for urban centres, in terms of both ecological and public health. With urban green space able to take a variety of forms (from parks to sports fields) it would be beneficial to determine which forms show a stronger relationship between visitation and pro-environmental behaviour, possibly indicating a stronger effect of biophilia.

\subsubsection{Emotional Connections to Nature, Pro-environmental Attitudes, Urban Green Space Types, and Pro-environmental Behaviours}

An important aspect of my study is the opportunity to examine urban green space visitation and pro-environmental behaviour relationships broken down by urban green space and pro-environmental behaviour type. Different types of urban green space include the predominantly man-made sports fields, more 'natural' and more 'vegetated' walking tracks and town belt, and water based harbours and coastal zones. There is also the distinction between the typical urban green (i.e., terrestrial urban green space) and the urban blue (i.e., water based urban green space, for example, coasts and harbours). A tendency of society to value ${ }^{2}$ environments with greater vegetative cover (for example, city walking tracks or the town belt) was reported by Jim and Chen (2006). Volker and Kistemann (2013) and Walker and Ryan (2008) showed some landscape types are more inclined to promote emotional connections than others. Walker and Ryan (2008) produced a study which showed that water scenes induced the highest selfreported scores for place attachment ${ }^{3}$ (over vegetative, land based scenes). Place attachment is an important concept to mention here as it speaks to the emotional connections people develop with their surroundings (Vaske and Donnelly, 1999). People have been shown to prefer certain natural surroundings over others with an array of authors reporting a preference for waterscapes (Chiesura, 2004, Han, 2007, Kaplan

\footnotetext{
${ }^{2}$ Value here is to do with the perceived worth an individual places on a particular natural setting relative to another (Jim and Chen, 2006).

${ }^{3}$ Place attachment refers to the bonding that occurs between an individual and their environment (Scannell and Gifford, 2010) and was the proxy used by the authors to measure emotional connection to the landscape (Walker and Ryan, 2008).
} 
and Kaplan, 1989, Walker and Ryan, 2008) and others citing a preference for vegetated (Jim and Chen, 2006). Gordon Orian's 'Savannah hypothesis' states the opposite by positing that humans have a subconscious attachment to half-open, park-like spaces, such as savannahs, as this is the habitat humans evolved from (Wilson, 1984). The Savannah hypothesis contradicts the findings and theories of authors listed above, but is useful to be aware of in the process of discussing and interpreting results as it may be the case that one theory is found to be supported more so than another.

It is not just variance in urban green space type that could potentially reveal differences in relationship strength. Tarrant and Green (1999) have noted that individuals are more likely to partake in pro-environmental behaviours which directly benefit the green space they are most emotionally connected to and visit most. In other words, people are more likely to engage in pro-environmental behaviours which preserve or maintain the space where they gain the most positive, emotive responses. For example, pro-environmental behaviour related to responsible disposal of paints and chemicals (rather than disposing down household sinks) may be performed more by those who more frequently visit coasts. Using such evidence, I have hypothesised that those who visit coasts will perform more pro-environmental behaviours related to water pollution minimisation. The data set employed for the proposed study allows this hypothesis to be statistically tested, thus contributing new empirical evidence to the academic literature.

\subsubsection{Socio-demographics, Urban Green Space and Pro-environmental Behaviour}

With the overarching research aim of my study being to better understand the association between urban green space visitation and pro-environmental behaviour, research question 1.3 seeks to understand how socio-demographic factors moderate this particular relationship. Although biophilia and the theory of planned behaviour are employed to back up the role of emotions and attitudes to nature in pro-environmental behaviour participation, it would be ignorant to assume that these work independently of socio-demographics. The data employed for the proposed study allows the relationship between urban green space visitation and pro-environmental behaviour to be examined by gender, age, and income.

Literature which speaks to the socio-demographic characteristics of those exhibiting pro-environmental behaviour is strong (Barbosa et al., 2007, Barr, 2003, Barr, 2007, Barr et al., 2011, Cottrell, 2003, Cottrell and Graefe, 1997, Dahlstrand and Biel, 1997, Diamantopoulos et al., 2003, Diekmann and Preisendörfer, 2003, Dupont, 2004, 
Guagnano and Markee, 1995, Torgler and Garcia-Valiñas, 2007). As policy makers seek to promote more sustainable and energy efficient cities and citizens, research has turned to the socio-demographic makeup of those who perform pro-environmental behaviour in order to create a profile of the environmentally friendly citizen (Barr, 2003, Barr, 2007, Teisl and O'Brien, 2003). An in-depth review of the literature pertaining to the associations between socio-demographics, pro-environmental behaviour and environmental knowledge, behaviour, and attitudes was performed by Diamantopolous et al. (2003). The significance, strength and direction of associations between select socio-demographic variables and environmental consciousness was then examined. On the whole, associations between socio-demographic variables and environmental consciousness ${ }^{4}$ were not as consistent as would be expected (i.e., it was not confirmed that females participate in more pro-environmental behaviour than males, or that high earners participate in more pro-environmental behaviour than low earners) and this has been attributed to the effect of geographic region, more specifically, the difference in environmental legislation and infrastructure that exist in different political zones (Guagnano and Markee, 1995, Diamantopoulos et al., 2003). Such contextual differences may enable certain socio-demographic groups to be more or less influenced to engage in pro-environmental behaviour than others (Diamantopoulos et al., 2003). Despite the inconsistencies, patterns are also obvious, particularly relating to gender, income, and age. The following section outlines how such socio-demographics have been studied in conjunction with pro-environmental behaviour and urban green space, and puts forward a series of testable hypotheses.

\section{Gender}

Diamantopoulos et al. (2003) found females held stronger attitudes to environmental quality relative to men and were more likely to participate in recycling or green consumerist behaviour. Similarly, Steel (1996) produced results indicating that women were more likely than men to engage in pro-environmental behaviour. Dupont (2004) found support for their hypothesis that gender differences exist in the willingness to pay (WTP) for environmental improvements (a pro-environmental behaviour), with women showing a stronger willingness to pay. Dupont (2004) also predicted the genders to express different values regarding the environment. Different values were predicted to be expressed through a greater willingness to pay for action that will benefit one's

\footnotetext{
${ }^{4}$ Environmental knowledge, behaviour, and attitudes was collectively termed environmental consciousness in this study (Diamantopolous et al., 2003).
} 
children in women - cited by Blocker and Eckberg (1989) as the "mother effect" (Dupont, 2004). The "mother effect" posits that women with children express relatively more concern for local environmental problems than non-mothers, with the "father effect" manifesting itself as a greater concern for the material well-being of the family. Similarly, Bord and O'Connor (1997) used risk valuation gap analysis to explain why there might be a difference between men and women with children. Mothers were more likely to perceive vulnerability than non-mothers as they are said to be more sensitive to environmental quality (Bord and O'Connor, 1997). Stern et al. (1993) state that, compared to men, women (regardless of whether they are mothers or not) are more attentive to the links between the environment and the things that they value (recall valuation to be how much worth someone places on an object/setting relative to another object/setting). Huddart and Kennedy (2013) also reported a significant positive correlation between females and environmental concern. It may therefore be the case that females are more sensitive to environmental needs and may show a stronger relationship between urban green space visitation and pro-environmental behaviour. Torgler and Garcia-Valiñas (2007) also found reported differences in charitable giving between the genders and it is argued that traditional gender norms and stereotyping mould females to be more concerned for the lives of others and the environment. Gender is clearly an important variable to be aware of when examining the relationships in question and is potentially a significant interaction term in equation building.

\section{Age}

Age has been shown to be significantly correlated with environmental attitudes and willingness to pay for environmental improvements, with some evidence to support the hypothesis that the older generation partake in more pro-environmental behaviour (Dupont, 2004). Additionally, a recent study by Huddart and Kennedy (2013) showed age to be insignificantly associated with environmental concern. After examining the effect of age on environmental protection, Torgler and Garcia-Valiñas (2007) found two types of age effects to be present. The most relevant to my study being the aging effect which refers to the tendency for older individuals to experience natural settings differently to younger respondents due to an expectation of a lower return from investment in environmental preservation (Torgler and Garcia-Valiñas, 2007). It could therefore be possible that older individuals will show a weaker relationship between urban green space visitation and pro-environmental behaviour relative to those that are 
younger, as they are less motivated to invest in environmental protection. It may alternatively be that those who are older have had more time to visit and be exposed to natural spaces and thus be more likely to hold stronger emotional connections to such settings. Those who are younger, but visit just as frequently, may not have had the lengthy exposure required for biophilia to manifest as pro-environmental behaviour. If this is the case, my study will reveal a stronger association between urban green space visitation and pro-environmental behaviour in older individuals.

Age also has a strong influence on one's lifestyles, social norms and habits, and their ability to perform pro-environmental behaviour. It may be that older individuals, may visit urban green space more and perform more pro-environmental behaviours. However, older people may also be physically restricted from visiting the less accessible urban green spaces and performing pro-environmental behaviours requiring a greater level of mobility, such as taking recycling to the recycling station. Ultimately, the research from Torgler and Garcia-Valiñas (2007) leads me to hypothesise that there will be a stronger relationship between urban green space visitation and proenvironmental behaviour in the older demographic, who have potentially been visiting urban green space for many years, enhancing emotional connections to nature.

\section{Income}

When it comes to pro-environmental behaviour change, fiscal instruments have been the first point of call for many policymakers, particularly in Europe (Lorenzoni et al., 2007, Lucas et al., 2008). As outlined earlier, without an emotional connection to environmental issues, people are less willing to co-operate with market-based and/or economic incentives for pro-environmental behaviour change (Lorenzoni et al., 2007). There is a hypothesis related to environmental concern and pro-environmental behaviour which suggests that with increasing cost (meaning negative impacts of the activity, including time cost, monetary cost, and impact on convenience) of a proenvironmental behaviour, the association with environmental concern decreases (Diekmann and Preisendörfer, 2003). Diekmann and Preisendörfer's (2003) hypothesis suggests that the interaction term differs depending on the cost intensity of the behaviour. In other words, the amount of environmental concern and the strength of its effect on behaviour changes in accordance with behaviour cost. Applying such a hypothesis to my study allows me to posit there will be a stronger association between urban green space visitation and low cost forms of pro-environmental behaviour 
(putting rubbish in the bin). The socio-demographic of income is a useful variable to include in my examination as it could account for some of the variance in proenvironmental behaviour performance not explained by urban green space visitation. Using the hypothesis of Diekmann and Preseindörfer (2003), it is likely that those respondents in living in a higher earning household may find it less costly to make proenvironmental behaviour changes and may therefore show a stronger association between urban green space visitation and pro-environmental behaviour.

Figure three illustrates the hypothesis of Diekmann and Preseindörfer (2003). As the cost of pro-environmental behaviour increases, the effect of environmental concern decreases, making way for factors such as socio-demographic variables to play a greater role in the decision to pursue such pro-environmental behaviour. Diekmann and Preseindörfer (2003) developed the illustration in figure four to conceptualise the cost differences between two types of pro-environmental behaviour, recycling and public transportation to work. Figure four illustrates that the cost difference between recycling and not recycling is small for most people, while the difference is large for the proenvironmental behaviour of using public transportation. People will be more willing to take up behaviours that are less costly to them. For someone that is more financially stable, the risks and costs involved in changing to more costly behaviours is less, supporting the hypothesis that those who earn more will perform more proenvironmental behaviour (as they will be more likely to perform those proenvironmental behaviours that are more costly).

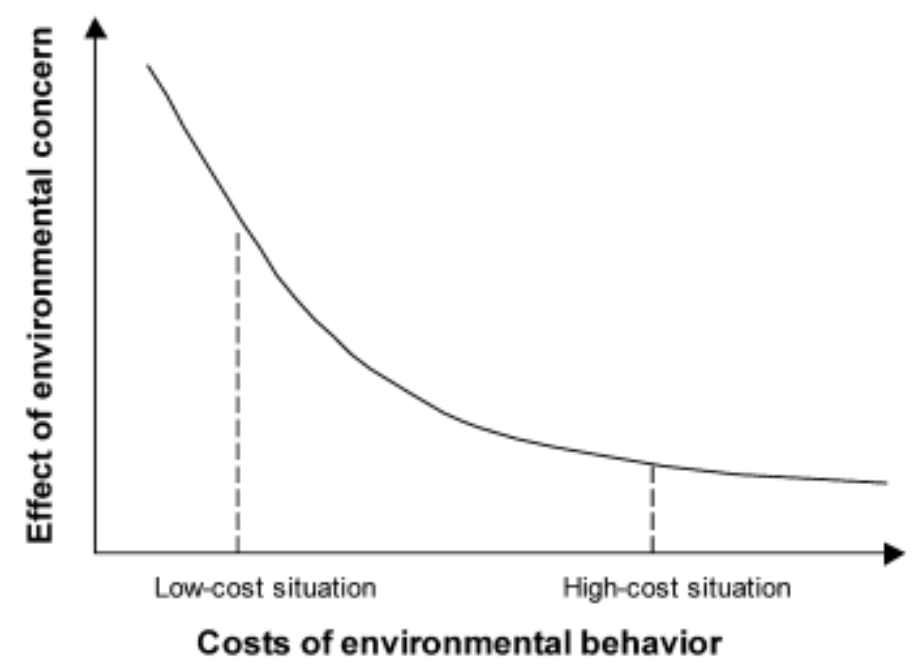

Figure 3: The low-cost hypothesis of environmental behaviour (Diekmann and Preseindörfer, 2003). 
(a) Low-cost situation (e.g. $R=$ recycling)

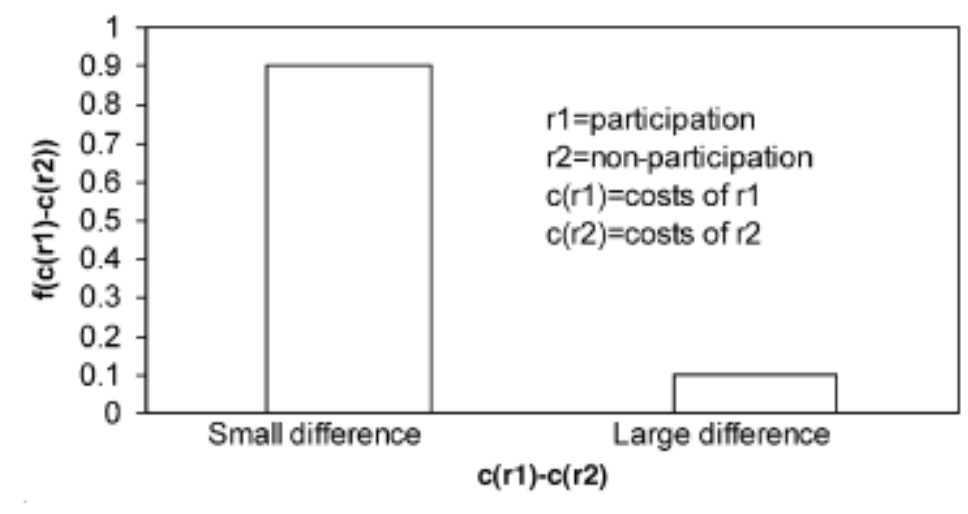

(b) High-cost situation (e.g. T = travel mode choice for work)

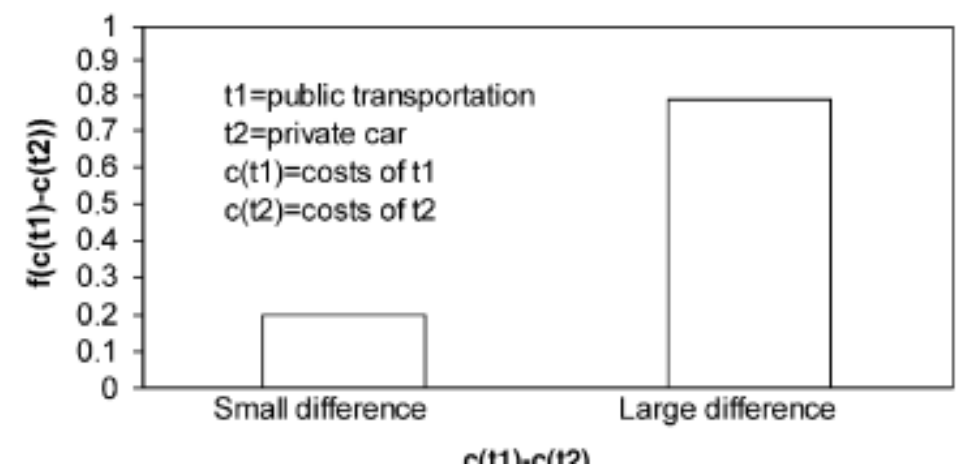

Figure 4: Low-cost and high-cost situations and the role of environmental concern (Diekmann and Preseindörfer, 2003).

Income has always been acknowledged as having some bearing on environmental protection and willingness to pay for environmental protection programs (Torgler and Garcia-Valiñas, 2007). With fewer economic concerns, individuals are more willing to think about issues beyond their personal situation and are more capable of making lifestyle changes for the benefit of the environment (Torgler and Garcia-Valiñas, 2007). This phenomenon has been termed the affluence hypothesis (Givens and Jorgenson, 2011). Diekmann and Preisendörfer's (2003) study showed that low-cost proenvironmental behaviours, including recycling, switching off lights, and buying refills, were significantly correlated with environmental concern, whereas the higher cost proenvironmental behaviour changes such as shopping without a car, weekend trips without a car, and no car in the household, were not significantly correlated. My study will determine whether income moderates how urban green space visitation explains pro-environmental behaviour. 


\subsubsection{Pride, Connections to Nature, and Pro-environmental Behaviour}

Along with socio-demographic variables it is possible that attitudinal variables such as pride may moderate the relationship between urban green space visitation and proenvironmental behaviour. Emotions and their influence on three intentions for proenvironmental behaviour were explored by Harth et al. (2013b). It was concluded that pride helped predict intentions for favouring environmental protection (Harth et al., 2013a). Intentions here do not represent one's pro-environmental behaviour, but do indicate one's desire to engage in a more sustainable lifestyle. Ultimately, Harth et al. (2013b), along with Ferguson and Branscombe (2010) found that positive emotions such as pride can motivate pro-environmental behaviour. Ferguson and Branscombe (2010) mirror the work of Tracy and Robins (2007), when they state that positive emotions (e.g., pride) may motivate pro-environmental behaviour. Importantly, it has not been assessed whether someone's level of pride moderates the association. With empirical evidence suggesting a link between place attachment and pride (Brown et al., 2003, Scannell and Gifford, 2010), and with place attachment linked to urban green space visitation (Budruk et al., 2009) it is expected that those who have higher levels of pride will be more responsive to the effects of biophilia as they are more likely to want to preserve the source of their pride - the urban green space.

\subsubsection{Quality of life, Connections to Nature, and Pro-environmental Behaviour.}

Research question 1.5 seeks to ascertain how quality of life moderates the relationship between urban green space visitation and pro-environmental behaviour. From the literature, it is clear that such a question has not yet been addressed. There is plenty of evidence linking nature exposure to enhanced quality of life (which can also be referred to as well being or life satisfaction) (Cervinka et al., 2012, Grinde and Patil, 2009, Özgüner et al., 2012). Cervinka et al. (2012) reported nature connectedness to not only predict pro-environmental behaviour but also predict well-being. Well-being has been used as a proxy for quality of life and it has been suggested these two concepts to be synonymous and interchangeable with each other (Cervinka et al., 2012).

In the past, pro-environmental behaviour has been seen as a threat to one's quality of life due to the associated costs and indirect benefits associated with such behaviour (Venhoeven et al., 2013). Recently, it has been shown that pro-environmental behaviour is positively correlated with life satisfaction (Venhoeven et al., 2013). I therefore 
expected those with a high quality of life would show a stronger association between urban green space visitation and pro-environmental behaviour.

\subsubsection{Overall Conclusions from the Literature.}

An illustrated theoretical progression from nature exposure (urban green space visitation) to pro-environmental behaviour, incorporating biophilia and the theory of planned behaviour (TPB) is depicted in figure five, below.

\begin{tabular}{|l|l|l|l|}
\hline \multirow{2}{*}{ UGS visitation } & Biophilia & $\begin{array}{l}\text { Affective connections to } \\
\text { nature and pro- } \\
\text { environmental attitudes }\end{array}$ & TPB \\
\cline { 3 - 3 } & Biophilia & PEB \\
\cline { 3 - 4 } & &
\end{tabular}

Figure 5: Theoretical progression illustrating the hypothesised relationship between urban green space (UGS) visitation, emotional connections to nature, and pro-environmental behaviour (PEB), using biophilia and the theory of planned behaviour (TPB) as supporting arguments.

After canvassing the literature for supporting theory and evidence to back up assumptions underpinning my proposed direction of study, the following conclusions can be made.

- Humans hold stronger associations to natural as opposed to built stimuli.

- Nature exposure has the ability to foster emotional affinity towards the natural environment and repeated exposure to nature based experiences increases the likelihood a person will hold emotional connections to nature.

- The theory of planned behaviour posits the importance of attitudes in predicting behaviour.

- The principle of compatibility puts forward that those holding proenvironmental attitudes are likely to perform pro-environmental behaviours.

- Urban green space visitation has not been examined for a relationship with proenvironmental behaviour despite being a form of nature exposure. 
- Different types of urban green space entail different levels of emotional response. Water based scenes and vegetative scenes are reported to have stronger positive impacts and are the landscape types humans prefer.

- When people gain positive emotions (enjoyment) from a particular landscape they are more likely to seek its preservation.

- The biophilia hypothesis is a theoretical explanation for the above patterns and conclusions which puts human's affiliation for the natural environment as an evolutionary trait written into our biological makeup. It is argued that whilst being an innate phenomenon, affiliation to nature must be nurtured for it to be manifested in pro-environmental behaviour. It is exposure to nature which provides the necessary stimuli for biophilia to be developed.

- Socio-demographic factors (gender, age, and income), as well as attitudinal factors (pride and quality of life) could moderate the relationship between urban green space visitation and pro-environmental behaviour. Studies have shown positive correlations to exist between pro-environmental behaviour, quality of life, pride, emotional connections to nature and certain socio-demographic characteristics. As yet, there has not been a study explicitly investigating how such factors influence biophilia.

One of the major limitations of my study is the inability to prove causality. Without a longitudinal or intervention study, I am unable to conclusively state that the proenvironmental behaviour individuals are reporting is due to their urban green space visitation. However, with the application of the biophilia hypothesis, these limitations are reduced.

Thus far, the majority of environmental psychology research has looked into the cognitive aspects of human-nature interactions with limited analysis of how behaviours in one domain (urban green space visitation) are reflected in other physical expressions of internal values and attitudes (e.g., pro-environmental behaviour). While researchers have delved into the area of attitude-behaviour consistency, as well as green landscape perceptions, a common theme in these studies is an obvious irregularity in the proxies used. Values, attitudes, concern and place attachment indices have all been used to assess the role of green landscapes on the cognitive makeup of individuals with no one variable exclusively prioritised over another. Herein lies the issue within the current literature. Without an in-depth source of research which consistently applies one method 
of measurement, it is difficult to accurately ascertain the extent to which these studies support each other. It is clear that emotional connections are crucial in the performance of pro-environmental behaviour, but due to difficulties in their measurement it would be ideal to find a more tangibly measurable option for predicting pro-environmental behaviour. Whether urban green space visitation has the potential to serve this role remains to be seen. 


\section{CHAPTER 2}

\subsection{Methods}

The purpose of my study was to examine the relationship between urban green space visitation and pro-environmental behaviour to ascertain whether there was a statistically significant correlation. I also wanted to test whether there were any differences in the presence or strength of correlation in accordance with different urban green space types and different types of pro-environmental behaviour. Socio-demographic characteristics were also examined with the aim of finding those socio-demographics which were statistically significant moderators. I used regression techniques to produce statistical equations illustrating how urban green space visitation is associated with proenvironmental behaviour and whether the association was stronger for certain sociodemographic groups. Cross-tabulations and odds ratios also aided in the examination of the relationship.

The purpose of this methods chapter is to (1) describe the research methodology, (2) explain the sample selection, (3) describe the procedure used in designing the instrument and collecting the data, (4) provide an explanation of the statistical procedures used to analyse the data, and (5) outline limitations of the data and methods as well as recommendations for future surveys.

\section{Research Methodology}

A positivist quantitative research methodology was chosen for this study based on the research questions, which are as follows:

1.0 What is the relationship between urban green space visitation and proenvironmental behaviour in Wellington city?

1.1 Do urban green space visitors and non-visitors exhibit a difference in their amount of pro-environmental behaviour?

1.2 Does the relationship between urban green space visitation and proenvironmental behaviour change depending on the type of urban green space visited and the particular pro-environmental behaviour measured? 
1.3 How do socio-demographic factors moderate the relationship between urban green space visitation and pro-environmental behaviour?

1.4 How does pride moderate the relationship between urban green space visitation and pro-environmental behaviour?

1.5 How does quality of life moderate the relationship between urban green space visitation and pro-environmental behaviour?

As the research questions sought to determine whether a statistically significant relationship between urban green space visitation and pro-environmental behaviour existed, a large sample size was required. While a survey to gather my own data was initially proposed, due to time constraints for the study, developing and piloting a survey dedicated to answering the research questions would have been time consuming, expensive, and run the risk of returning an insufficient number of responses for robust statistical analysis. However, it became apparent that there was an option for using three pre-administered surveys where data had already been collected and was ready to be analysed.

\section{Background to the Survey}

The Wellington City Council (WCC) runs an annual Residents' Satisfaction Survey (RSS) to gather information pertaining to residents' satisfaction with council services (see appendices). In February and May each year, Wellington City Council contracts Nielson New Zealand (an independent market research company) to conduct the surveys which are designed to assess whether the council is achieving the goals laid out in their annual plan. Results are presented in the Annual Report with highlights found in the Topline Report of the respective year's survey. Wellington City Council compare the answers to survey questions across the years (i.e., 2010, 2011, and 2012) to determine whether there have been changes in satisfaction or service use from one year to the next. Due to the length of the interview (taking, on average, 23 minutes) the surveys were designed to be administered in two parts. At the halfway mark, respondents were given the option of continuing on with the remaining questions (which may be part one or part two, determined by the interviewer), to be called back at another time, or to end the interview at that point. Only those who answered both parts of the questionnaire were useful for my study as questions relating to urban green space 
visitation were found in part one, whereas the questions relating to pro-environmental behaviour were located in part two. Socio-demographic questions were asked in both sections.

\section{Research Question Methodology}

The research questions were developed from hypotheses which were guided by a review of relevant literature. A hypo-deductive method was employed which meant I took a hypothesis and tested it using statistical means. Using biophilia and the theory of planned behaviour, my primary hypothesis was that nature exposure builds stronger nature connections, resulting in a greater likelihood one holds the attitudes necessary for pro-environmental behaviour. The survey design did not allow for emotional connections to nature to be measured or tested and, therefore, significant theoretical assumptions were applied here. As pro-environmental attitudes were not measured in the survey, pro-environmental behaviour was taken to be a physical expression of one's pro-environmental attitudes and emotional connections to nature. Urban green space visitation and pro-environmental behaviour were thus used as proxies for nature exposure and environmental attitudes, respectively.

Research question 1.3 sought to determine the role of socio-demographics in the relationship between urban green space visitation and pro-environmental behaviour. The variables used included gender, age, and income. It was hypothesised that different socio-demographic groups would be influenced differently by nature exposure and their subsequent likelihood to perform pro-environmental behaviour would vary. The influence of each socio-demographic variable on the relationship between urban green space visitation and pro-environmental behaviour was examined using statistical techniques. A large sample size was imperative, especially as analysis was broken down by each socio-demographic variable, further decreasing the amount of responses.

\section{Sample Selection}

The Resident's Satisfaction Survey from the years 2010 through 2012 provided the data required to answer the research questions set out in my study. The sample was restricted to Wellington city residents who were over the age of 15 . As the survey was developed and commissioned by the Wellington City Council to measure resident's satisfaction with council performance and services, the sample included only those who physically resided in Wellington city. As mentioned earlier, only those respondents who elected to 
complete both parts of the survey were of use for my study. Survey responses across the years are detailed in table one.

Table 1: Survey responses per year for each of the three Wellington City Council Residents Satisfaction Surveys, 2010 - 2012.

\begin{tabular}{|c|c|c|c|c|}
\hline Year & Total & Part One only & Part Two only & Both Parts \\
\hline 2010 & 881 & 280 & 275 & 326 \\
\hline 2011 & 871 & 266 & 268 & 337 \\
\hline 2012 & 894 & 294 & 294 & 306 \\
\hline Total & & & & 969 \\
\hline
\end{tabular}

The cocatenated sample size of 969 was a sufficient number for reliable statistical tests. While one survey alone presented over 300 responses (deemed a substantial sample size in many instances), upon disaggregation by socio-demographic and visitation frequency, some of the cross tabulation tables reported insufficient values to render chisquare tests valid (i.e., the statistical assumption of a chi-square test that each cell must have a value greater than or equal to five was violated in some instances). Pooling the survey responses together prevented such an issue.

Along with gaining a suitable sample size, gaining a representative sample was an equally important aspect of the study design. Nielson New Zealand ensured their sample accurately represented the makeup of Wellington city residents. Soft quotas (approximately 5\% above the known makeup of the population) were thus employed in accordance with ward of residence, age, and gender.

\section{Data Collection}

The process of collecting the data was performed by fully trained staff at Neilson New Zealand who used telephones from the Oceanic Customer Interaction Services Ltd (OCIS) Computer Assisted Telephone Interviewing (CATI) facility in Auckland. Only fully trained field staff were used to carry out the interviews using a questionnaire programmed into the computer to allow control over the order of questions and ensure 
consistency, as well as allowing for monitoring of interviewing standards (see appendices).

Data was collected between 5:00pm and 9:00pm weekdays, 11:00am - 3:00pm and 3:30pm - 7:30pm Saturday, as well as 11:30am $-3: 30 \mathrm{pm}$ and 4:00pm $-8: 00 \mathrm{pm}$ Sunday. Such times were chosen to ensure a representative sample of both working and non-working individuals. Each survey was conducted over the month of March in their respective years with 10 pilot surveys administered in the week preceding. When collecting the data, a random digit dialling (RDD) process was used to select household phone numbers from the council databank and interviewers asked to speak to the person in that household who most recently had a birthday. In the 2012 survey, up to five call backs were made until that house was abandoned, while three call backs was the limit in 2010 and 2011. Only those over the age of 15 were eligible for the survey. Response rates varied from $42 \%$ in 2010, 36\% in 2011 and 32\% 2012. A recent marketing study in the United States reported telephone survey response rates have decreased from $25 \%$ in 2000 to $9 \%$ in 2012 meaning the response rates for the Resident's Satisfaction Survey were greater than the United States average (Marketing Charts, 2012). In regards to confidentiality of answers, Neilson New Zealand made clear to the respondent that their answers would remain confidential. Access to the raw data necessary for the proposed study required the consent of the Wellington City Council. Raw data was sent through in SPSS format via email and required pooling together into one SPSS file for analysis of a grouped sample.

\section{Pooling}

The Resident's Satisfaction Survey is an annual survey that changes little across the years. Having continuity in the questions allowed the responses to be pooled together, creating a larger sample size - important for quantitative robustness. However, as the designers of the survey did not foresee the need to pool the data together, there were several inconsistencies in variable labelling, with some new questions added in the 2012 version which required relabeling. The data was transformed into an excel file in order for changes to be made to ensure there were no discrepancies in variable labelling, ensuring a seamless merge. Years 2010, 2011, and 2012 were the surveys chosen to be pooled; these were the most recent and temporally relevant surveys which differed least in their order and form of questions. 


\section{Statistical Analysis}

The statistical package used for analysing the data was SPSS (Statistical Package for Social Sciences). Using SPSS, the following statistical procedures were conducted in order to help answer the research questions.

1. A series of cross tabulations were examined to determine whether urban green space visitation was statistically associated with pro-environmental behaviour.

2. Scatterplots of Total UGS visitation versus Total PEB were created to produce trend lines illustrating the direction and slope of the relationship, fitted to subgroups of gender, age, income, pride, and quality of life.

3. Linear regression of Total UGS versus Total PEB was conducted to determine slope and strength of statistical association.

4. A logarithmic model was tested for its ability to predict Total PEB from Total UGS (recoded for linearity), relative to the linear model.

5. Binary logistic regression was used where the variables for urban green space visitation and pro-environmental behaviour were in a binary form. Resulting odds ratios were used to describe the associations.

6. Linear regression (broken down by urban green space type) was performed with $95 \%$ confidence intervals for respective $R^{2}$ values included. $R^{2}$ values and $\beta$ coefficients were compared to determine which were statistically different and conclude whether there was one type of urban green space better suited to predicting Total PEB than the others.

7. I conducted a correlation matrix for visitation to the six different urban green space types to determine whether people who visit one type of urban green space also visit another just as frequently.

8. Principle component analysis was performed to find those urban green spaces where significant statistical correlation allowed for merging and dimension reduction.

9. To see if vegetated or water based urban green spaces were better predictors of Total PEB than sports fields, three linear regressions were conducted, each incorporating one of the three explanatory variables. $R^{2}$ values and $\beta$ coefficients were then compared.

10. With one of my research questions seeking to determine whether certain types of urban green space visitation are better at explaining certain types of proenvironmental behaviour, linear regression was performed using each urban 
green space type separately and regressing with pro-environmental behaviours, grouped in accordance with their similarities. Dimensionality reduction was performed to find those pro-environmental behaviours that loaded highly onto each other and were able to be used as one 'form' of pro-environmental behaviour.

11. Binary logistic regression and odds ratios were used to describe the relationship between urban green space visitation (at two levels) and each of the 14 proenvironmental behaviours.

12. Linear and/or binary logistic regressions were performed to determine whether gender, age, income, pride, and quality of life moderated the relationship between urban green space visitation and pro-environmental behaviour.

Note: In order for 'Total PEB' to be assessed, a new variable had to be created. Using the 'recode into different variables' tool in SPSS, question 51 and 54 were grouped together and labelled 'Total PEB', which represented the total amount of pro-environmental behaviour performed. Similarly, urban green space visitation was recoded to create a variable (Total UGS) which gave a score representing total urban green space visitation (irrespective of urban green space type).

\section{Limitations of the Data and Recommendations}

Perhaps the greatest limitation of the data was the inability to determine causation. While the research questions sought to identify the strength and direction (positive or negative) of the relationship, regression and correlation analysis could not determine whether it was urban green space visitation causing the result in pro-environmental behaviour, or vice versa, or whether it was another covariate entirely. As mentioned earlier, such a conclusion requires an intervention or longitudinal study.

Additionally, due to the nature of the survey's original purpose, pro-environmental behaviour performance was limited to the areas of resources and waste and storm water pollution. There were no questions asking about green consumerism, membership to conservation groups, alliance with green politics, or green advocacy. Without a detailed range of pro-environmental behaviours to choose from the results neglect behaviours that may require a greater level of environmental commitment, for example, green advocacy. 
The questions pertaining to respondent's pro-environmental behaviour also failed to account for frequency of participation. While the questions on urban green space visitation used an 8 item Likert scale to assess the extent of one's visitation (from most days to never in the last 12 months), pro-environmental behaviour was recorded as either 'yes' or 'no'. While there are statistical methods that can work with bivariate data (chi-square), to determine how the amount of urban green space visitation correlated with a particular pro-environmental behaviour would have yielded further beneficial results. For example, it would have been useful to detect whether someone that visits urban green space more frequently is more consistent in their pro-environmental behaviour. 'Yes-no' answers do not indicate whether that individual recycles more frequently than someone else who may also indicate 'yes'. Using a Likert scale to measure pro-environmental behaviour participation is thus a recommendation for future editions of the survey.

What must be taken into account is the way the Likert scale was laid out. The unequal distance between Likert items used to record urban green space visitation (most days, once a week, once every 2-3 weeks, once a month, once every 2-3 months, once every 4-5 months, once every 6 months or less, never in the past 12 months) meant a linear relationship may not fit as well as an exponential curve. It may be that the linear regression used in my study is not an accurate measure of the relationship.

There is also the caveat that it is a specific group of people that are willing to cooperate with telephone surveys, only those that have a home phone for example, and those who are not particularly busy and are willing to give up 30 minutes of their time to complete the entire survey. Also, the fact that it is a survey measuring the performance of the Wellington City Council may motivate those who feel strongly for or against the council's performance to participate. All such factors must be taken into account when analysing the results and drawing conclusions. 


\section{CHAPTER 3}

\subsection{Results}

I used quantitative methods to analyse the data set and address the research questions listed. It should be noted that there are at least four possible sources of 'error' (variance unaccounted for) associated with such analysis:

I. Measurement error (as I am unable to measure pro-environmental behaviour or urban green space visitation exactly).

- In order to try account for this discrepancy, I tried different measures of urban green space visitation and pro-environmental behaviour. I assessed non-visitors versus visitors, and those who visit once a month or more versus those who visit less than once a month. Urban green space visitation was also measured by type, as well as in 'total' form. Proenvironmental behaviour was aggregated to form the variable, Total PEB.

II. Aggregation of the various 'types' of both urban green space and proenvironmental behaviour.

- Different types of aggregations were used. To help answer the research questions most effectively, urban green space types that shared similar characteristics were aggregated to form a new, combined variable. For example, town belt, walking tracks, parks, and botanic gardens were aggregated to create the variable, Vegetated UGS. Additionally, responses for Total PEB and Total UGS were aggregated to form binary variables for analysis via binary logistic regression.

III. Missing variables as arguments

- The missing variables refer to those who answered as 'don't know' or 'refused to answer', or that provided an answer different to the options laid out in the survey (in the case of questions 51 and 54, where respondents were allowed to cite 'other' and give examples of the type of pro-environmental behaviour they performed). With these responses set as system missing I removed these individual responses from the random sample.

IV. Non-linearity in the linear model. 
- While linear regression was the primary statistical test to analyse the relationship between urban green space visitation and pro-environmental behaviour, it is possible that the relationship is non-linear with each successive increase in urban green space visitation having less of an influence on pro-environmental behaviour (i.e., it may be a log linear relationship). Fitting a semi-log plot (with the log of the 'Total UGS recoded for linearity' variable taken) was conducted to test whether such a model proved to be a better predictor of 'Total PEB'.

\subsection{Urban Green Space Visitation and Pro-environmental Behaviour}

"Do urban green space visitors and non-visitors exhibit a difference in their amount of pro-environmental behaviour?"

Research question 1.1 asked whether those who visit urban green space perform more or less pro-environmental behaviour relative to those who do not. The question also sought to determine whether frequent urban green space visitation correlates with a greater likelihood to perform more types of pro-environmental behaviour. Using biophilia, my analysis assumed urban green space visitation to be the explanatory variable and proenvironmental behaviour to be the dependent variable.

Note: The Resident's Satisfaction Survey measured urban green space visitation on an 8 item Likert scale, ranging from 'most days' to 'never in the past 12 months'. For ease of reading of resulting equations and graphs, the variable for urban green space visitation was recoded so a score of 0 was the equivalent of 'never in the past 12 months', while a score of 7 represented a visitation frequency of 'most days'. Pro-environmental behaviour, however, was measured in a binary fashion with respondents given the option of answering 'yes' or 'no' to whether they performed a selection of 14 proenvironmental behaviours. A 'high' score for Total PEB meant the respondent answered, 'yes' to seven or more of the 14 pro-environmental behaviours. A high score for urban green space visitation was hypothesised to positively correlate with a high score for pro-environmental behaviour.

In order to use linear regression to determine whether a linear pattern existed between urban green space visitation and pro-environmental behaviour the data was recoded to create two new variables, 'Total UGS' and 'Total PEB'. Responses from each individual for the six types of urban green space were added together to create an 
overall value of urban green space visitation, irrespective of type. For example, an individual who visited all six urban green space types once every 2-3 months (with a corresponding score of 3 ) received a total score of 18 . Another individual who visited the town belt and city walking tracks most days (corresponding score of 7), but visited the four other types less than once every six months (corresponding score of 1) would also end up with a Total UGS score of 18. If someone indicated they visited all forms of urban green space most days their Total UGS score would be 42 .

Computing the variable, 'Total PEB' required a similar process whereby the respondents answers for whether they performed the pro-environmental behaviours listed in question 51 were added to the pro-environmental behaviours in question 54. A value of 1 was attributed to a 'yes' response with 0 equating to 'no'.

Table 2: Descriptive statistics for Total PEB and Total UGS using the concatenated sample.

\begin{tabular}{|c|c|c|}
\hline & Total PEB & Total UGS \\
\hline Valid & 969 & 969 \\
\hline Missing & 0 & 0 \\
\hline Mean & 9.3168 & 17.6275 \\
\hline Mode & $9.00^{\mathrm{a}}$ & 6.00 \\
\hline Std. Deviation & 2.34691 & 7.44543 \\
\hline Minimum & .00 & 6.00 \\
\hline Maximum & 14.00 & 41.00 \\
\hline
\end{tabular}

a. Multiple modes exist. The smallest value is shown. 
Table 3: Frequency table for Total PEB using the concatenated sample.

\begin{tabular}{|r|r|r|r|r|}
\hline & Frequency & Percent & \multicolumn{1}{|c|}{$\begin{array}{c}\text { Valid } \\
\text { Percent }\end{array}$} & $\begin{array}{c}\text { Cumulative } \\
\text { Percent }\end{array}$ \\
\hline .00 & 1 & .1 & .1 & .1 \\
1.00 & 3 & .3 & .3 & .4 \\
2.00 & 5 & .5 & .5 & .9 \\
3.00 & 8 & .8 & .8 & 1.8 \\
4.00 & 12 & 1.2 & 1.2 & 3.0 \\
5.00 & 29 & 3.0 & 3.0 & 6.0 \\
6.00 & 59 & 6.1 & 6.1 & 12.1 \\
7.00 & 76 & 7.8 & 7.8 & 19.9 \\
8.00 & 123 & 12.7 & 12.7 & 32.6 \\
9.00 & 170 & 17.5 & 17.5 & 50.2 \\
10.00 & 170 & 17.5 & 17.5 & 67.7 \\
11.00 & 144 & 14.9 & 14.9 & 82.6 \\
12.00 & 99 & 10.2 & 10.2 & 92.8 \\
13.00 & 54 & 5.6 & 5.6 & 98.3 \\
14.00 & 16 & 1.7 & 1.7 & 100.0 \\
Total & 969 & 100.0 & 100.0 & \\
\hline
\end{tabular}


Table 4: Frequency table for Total UGS using the concatenated sample. Values .00 through 20.00 only shown (values 21.00 through 41.00 continued in table 5).

\begin{tabular}{|c|c|c|c|c|c|}
\hline & & Frequency & Percent & Valid Percent & $\begin{array}{c}\text { Cumulative } \\
\text { Percent }\end{array}$ \\
\hline & .00 & 21 & 2.2 & 2.3 & 2.3 \\
\hline & 1.00 & 26 & 2.7 & 2.8 & 5.1 \\
\hline & 2.00 & 12 & 1.2 & 1.3 & 6.4 \\
\hline & 3.00 & 18 & 1.9 & 2.0 & 8.4 \\
\hline & 4.00 & 24 & 2.5 & 2.6 & 11.0 \\
\hline & 5.00 & 22 & 2.3 & 2.4 & 13.4 \\
\hline & 6.00 & 23 & 2.4 & 2.5 & 15.9 \\
\hline & 7.00 & 33 & 3.4 & 3.6 & 19.5 \\
\hline & 8.00 & 27 & 2.8 & 2.9 & 22.4 \\
\hline & 9.00 & 40 & 4.1 & 4.4 & 26.8 \\
\hline Valid & 10.00 & 34 & 3.5 & 3.7 & 30.5 \\
\hline & 11.00 & 35 & 3.6 & 3.8 & 34.3 \\
\hline & 12.00 & 30 & 3.1 & 3.3 & 37.6 \\
\hline & 13.00 & 38 & 3.9 & 4.1 & 41.7 \\
\hline & 14.00 & 42 & 4.3 & 4.6 & 46.3 \\
\hline & 15.00 & 47 & 4.9 & 5.1 & 51.4 \\
\hline & 16.00 & 53 & 5.5 & 5.8 & 57.2 \\
\hline & 17.00 & 25 & 2.6 & 2.7 & 59.9 \\
\hline & 18.00 & 31 & 3.2 & 3.4 & 63.3 \\
\hline & 19.00 & 23 & 2.4 & 2.5 & 65.8 \\
\hline & 20.00 & 40 & 4.1 & 4.4 & 70.2 \\
\hline & Total & 918 & 94.7 & 100.0 & \\
\hline Missing & ystem & 51 & 5.3 & & \\
\hline & Total & 969 & 100 & & \\
\hline
\end{tabular}


Table 5: Frequency table for Total UGS using the concatenated sample. Values 21.00 through 41.00 only shown. (See table 4 for values 0.00 through 20.00).

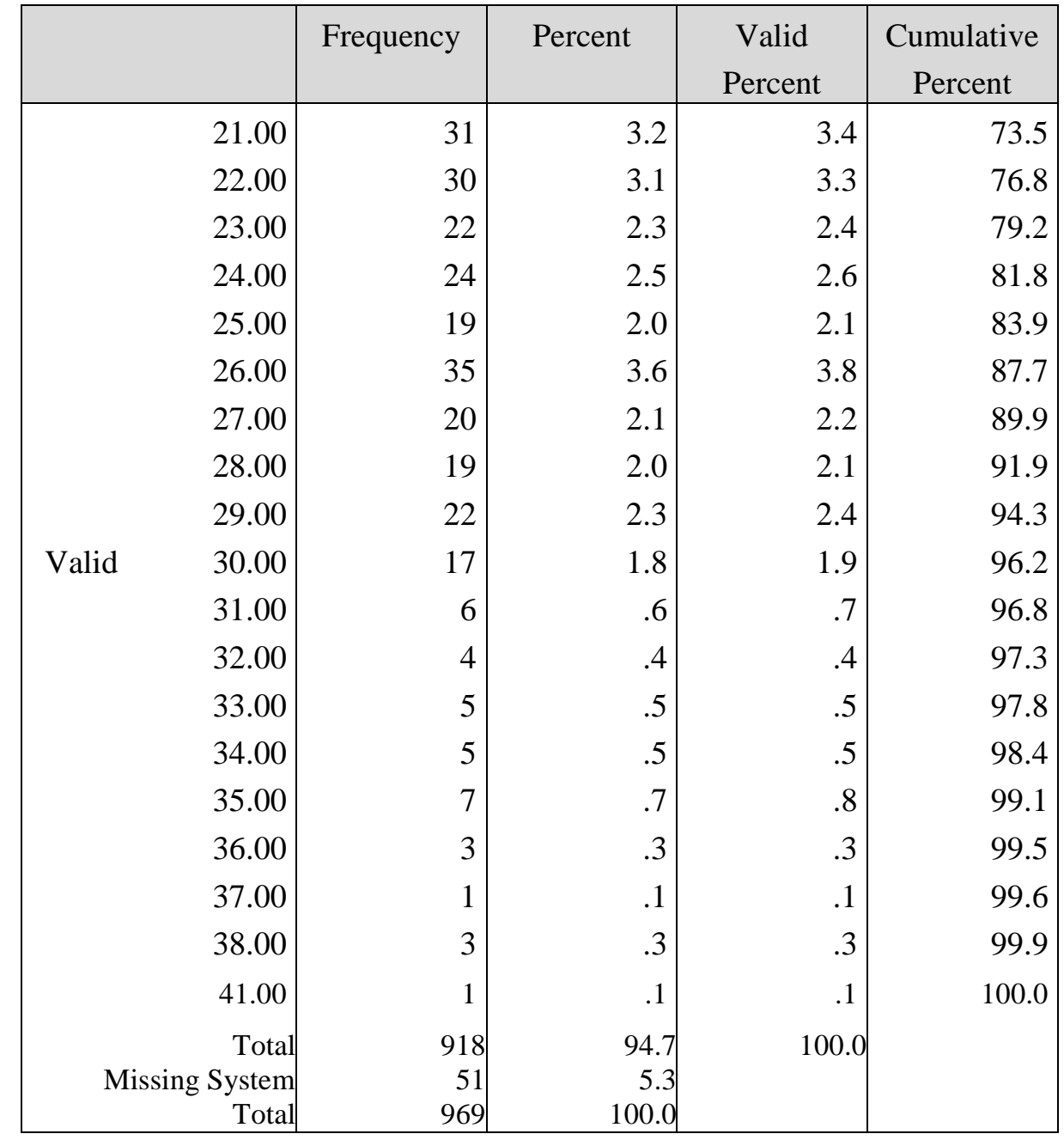

Linear regression was performed using 'Total PEB' as the dependent variable and 'Total UGS' as the independent (Equation 1).

Equation 1

$$
\text { Total } \mathrm{PEB}_{i}=8.116+0.079 \text { Total } \mathrm{UGS}_{i} \quad \mathrm{R}=0.289 ; \mathrm{R}^{2}=0.084 ; \mathrm{N}=918 .
$$

(52.562) (9.152)

An $\mathrm{R}^{2}$ value of 0.084 was returned meaning only $8.4 \%$ of the variance in Total PEB was explained by the predictor, Total UGS visitation. Such a low value was to be expected with micro data, such as that being used in my study, indicating there are various other factors contributing to the relationship. A p value of 0.000 was encouraging as it allowed me to reject the null hypothesis that Total UGS visitation and Total PEB are independent of one another (at the 1\% significance level). A coefficient of 0.079 means for every one unit increase in urban green space visitation, the amount of pro- 
environmental behaviour for the ith person randomly selected from the concatenated sample, rises by 0.079 .

To illustrate the association between urban green space visitation and pro-environmental behaviour, an X-Y scatterplot was produced (see figure six). A fitted trend line illustrates the model in equation one. What can be gathered from the graph and accompanying equation is an estimate of pro-environmental behaviour for a certain amount of urban green space visitation. Someone who returns a score of 40 for Total UGS is predicted to perform 11.276 pro-environmental behaviours. Of course there are issues here pertaining to the ordinal nature of Total PEB, however, the graph and equation is useful in that it depicts a statistically significant, positive association - a result I had expected.

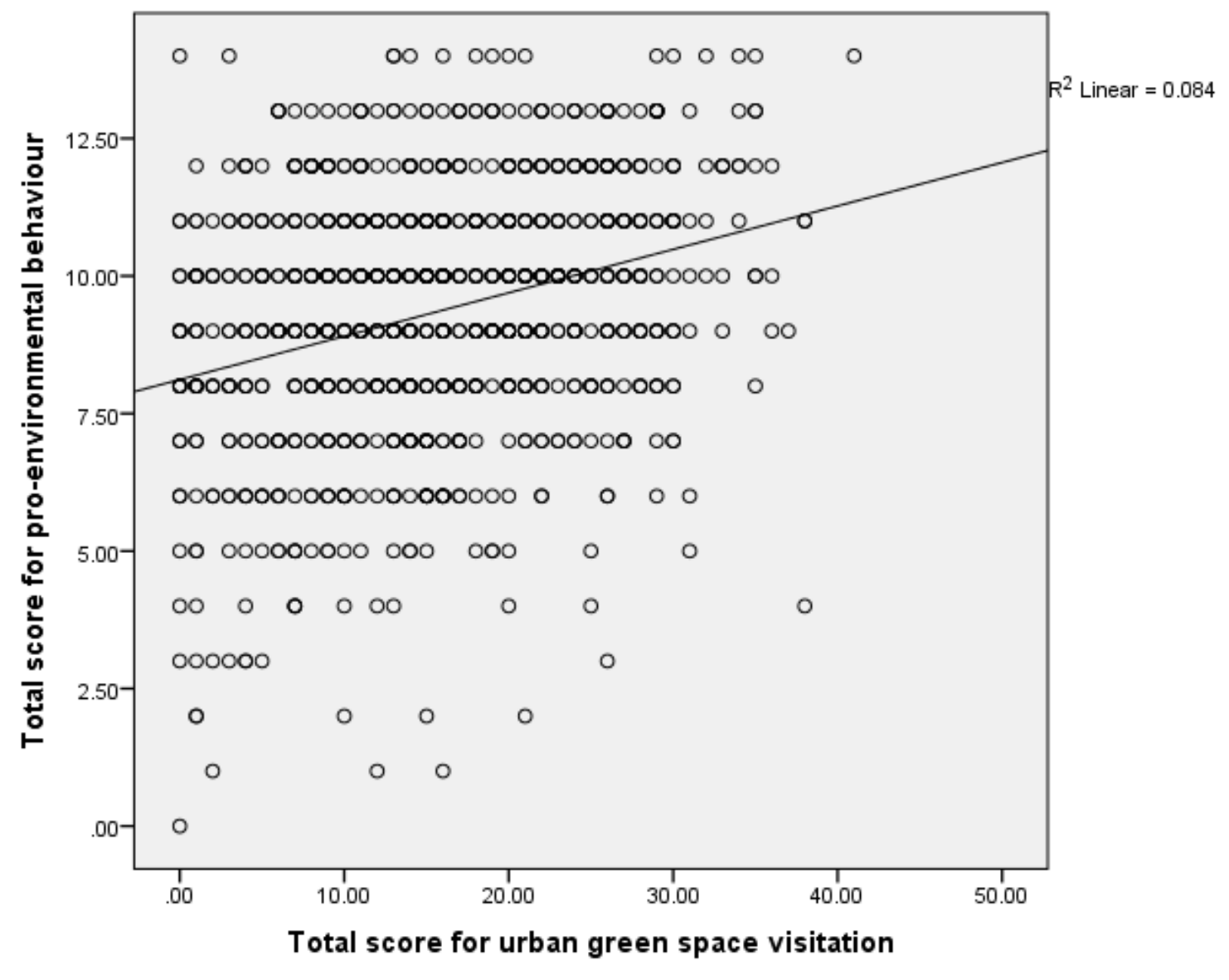

Figure 6: Linear relationship between pro-environmental behaviour (measured as a score out of 14) as a function of urban green space visitation (measured as a combined score for visitation to six urban green space types). 
An issue with equation one and the scatterplot (figure six) should be noted. The $\mathrm{x}$-axis of the scatterplot in figure six suggests visitation is measured in a linear fashion. This is not the case. Question 39 (urban green space visitation) recorded visitation in a categorical manner. The distance between visitation 'most days' and 'once or twice a week' is not equal to the distance between visitation 'once every 6 months or less' and 'never in the last 12 months', despite the corresponding values ( 0 through 7$)$ suggesting otherwise. When recoded so urban green space visitation scores were represented as daily visitations ${ }^{5}$, a different $\mathrm{X}$-axis scale was produced (see figure seven). Descriptive statistics are listed in table six.

Table 6: Descriptive statistics detailing the minimum, maximum and mean values for total time's urban green space was visited over a twelve month period.

\begin{tabular}{|l|r|r|r|r|l|}
\hline & N & Minimum & Maximum & Mean & \multicolumn{1}{c|}{$\begin{array}{c}\text { Std. } \\
\text { Deviation }\end{array}$} \\
\hline $\begin{array}{l}\text { Total urban green space } \\
\text { visitation (recoded for linearity) }\end{array}$ & 918 & .00 & 1378.00 & 147.1460 & 184.93811 \\
Valid N (list wise) & 918 & & & & \\
\hline
\end{tabular}

The minimum amount of times urban green space was reportedly visited in a year was zero. The maximum amount of times urban green space was visited in a year was 1378 , with the average being 147 . The reason the maximum value is so high is due to the way the daily visitation scores for each urban green space were added together For example, an individual who reportedly visited coasts, walking tracks, town belt, botanic gardens, and parks most days, and sports fields once or twice a week would receive a score of $1378(260+260+260+260+260+78)$. Obviously, it cannot be said that that individual visits urban green space 1378 days per year, instead, the value refers to the amount of times urban green space was visited over a 12 month period. The scatterplot in figure seven used this recoded variable to allow the $\mathrm{x}$-axis to represent number of times urban green space was visited. The recoding more accurately reflects the relative distances between each category in question 39 .

\footnotetext{
${ }^{5}$ Note: Question 39 was recoded so the corresponding value reflected the amount of times per year that answer suggested the person visited urban green space. With 'most days' taken to mean 5 out of the 7 days per week, 260 was the value attributed to an answer of 'most days'. Once or twice a week was taken as 1.5 days a week, therefore a corresponding value of 78 was given. Once every $2-3$ weeks was represented by $21(52$ weeks/2.5 =20.8). $12=$ once a month. 5 was used to represent visitation once every $2-3$ months $(12$ months / $2.5=4.8)$. 3 represented once every $4-5$ months $(12$ months $/ 4.5=2.67)$. Values of 2 and 0 were used to logically represent the final two categories of once every 6 months or less often and never in the last 12 months, respectively. The values for each UGS were collated together to create a Total UGS variable (recoded for linearity).
} 


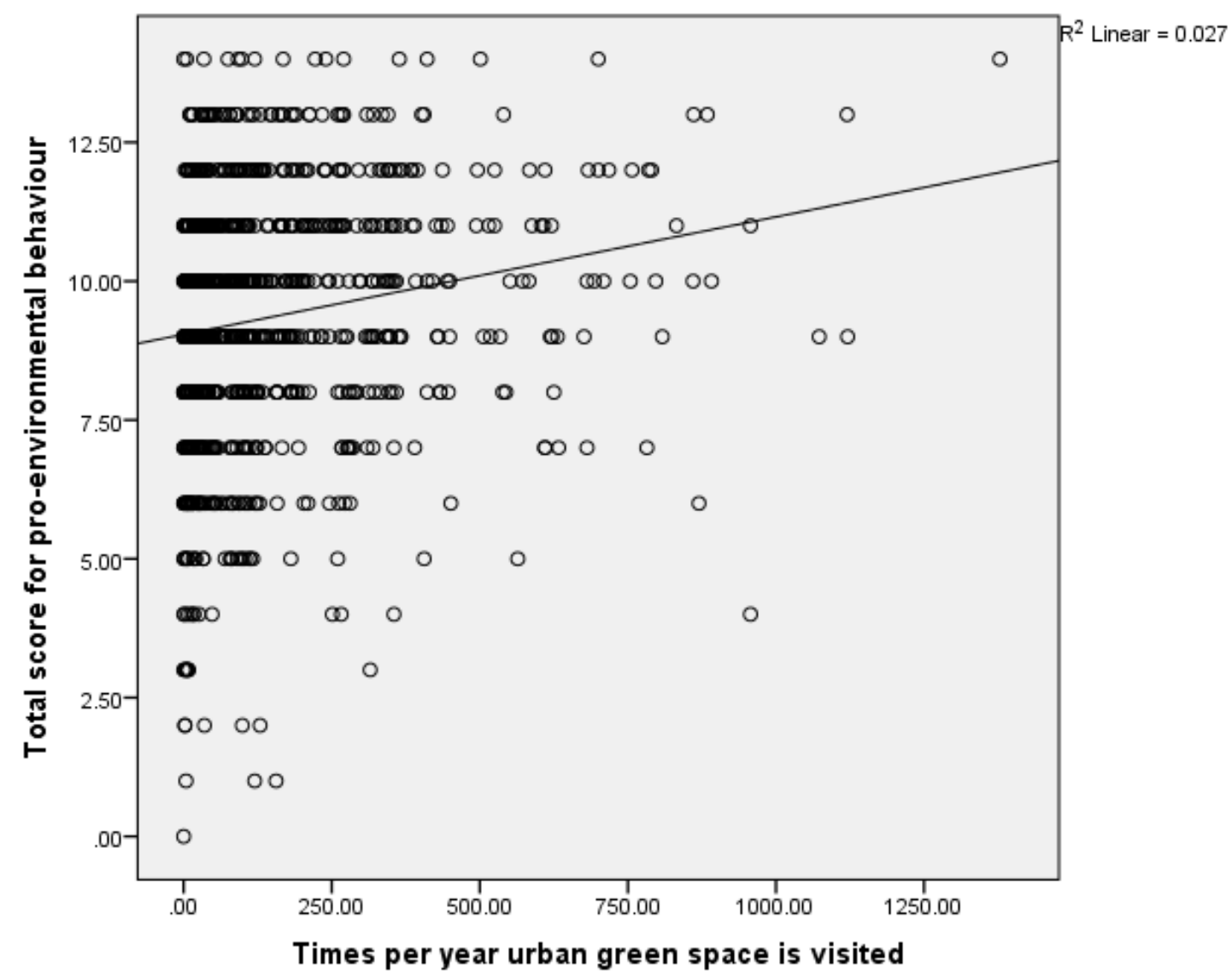

Figure 7: Linear relationship between pro-environmental behaviour (measured as a score out of 14) as a function of urban green space visitation (measured as number of times over a 12 month period urban green space was visited for six urban green space types).

I applied both a linear (equation two) and log-linear (equation three) model to the data with the semi-log plot (equation three) reporting a stronger co-efficient $(9.303>5.086)$.

Equation 2

$$
\begin{aligned}
\text { Total } \mathrm{PEB}_{i} & =9.041+0.002 \text { Total } \mathrm{UGS}_{i} \quad \mathrm{R}=0.166 ; \mathrm{R}^{2}=0.027 ; \mathrm{N}=917 . \\
& (91.945)(5.086)
\end{aligned}
$$

Equation 3

$$
\text { Total } \mathrm{PEB}_{i}=4.835+1.515 \ln \text { Total } \mathrm{UGS}_{i} \quad \mathrm{R}=0.294 ; \mathrm{R}^{2}=0.086 ; \mathrm{N}=917 .
$$$$
\text { (9.839) (9.303) }
$$

Equation two shows that for each additional visit to urban green space per year, the amount of pro-environmental behaviour one performs rises by 0.002 . The $p$ value (0.000) tells me that there is a statistically significant association here, meaning there is evidence to reject the null hypothesis that pro-environmental behaviour is independent of urban green space visitation. 
Importantly, the t statistic for the co-efficient for Total UGS is more significant in the logarithmic model compared with the linear $(9.303>5.086)$. The stronger significance of the co-efficient for In Total UGS tells me that the log-linear relationship is a better fit for the data (when the data is recoded for linearity). While both models are statistically significant, it appears that the log-linear model is a more accurate portrayal of the relationship. My results suggest that changing someone's visitation habits from 'nothing' to 'something' is potentially more beneficial than increasing urban green space visitation for those who already visit urban green spaces many times per year. When the model is plotted on the graph I can see that there is a greater influence of increases in urban green space visitation on pro-environmental behaviour at the lower end of the $\mathrm{x}$-axis. Such a conclusion is crucial for policy makers as it suggests that proenvironmental behaviour could improve if urban green space visitation is increased from once or twice a year to once a week. Equation three suggests that someone who increases their urban green space visitation from twice a year (2.00) to once a week (52.00) would show an increase in pro-environmental behaviour of 4.92. For someone who increases their urban green space visitation from once a month (12) to once a day (365), the associated increase in pro-environmental behaviour, as predicted by the loglinear model in equation three, is 2.95 . There may be greater benefit in fostering urban green space visitations amongst those who do not currently visit green spaces at all for the purposes of achieving pro-environmental behaviour change.

Question 1.1 sought to determine whether there was a difference in the amount of proenvironmental behaviour performed by frequent urban green space visitors versus less frequent visitors. A statistically significant positive relationship allows me to conclude that higher urban green space visitation is associated with a higher score for proenvironmental behaviour.

Linear regression analysis allowed me to illustrate the statistically significant positive association between Total UGS and Total PEB. There are alternative methods of answering question 1.1 such as binary logistic regression and the use of cross tabulation analysis. Such methods allow for easier interpretation of the relationship between the two variables (pro-environmental behaviour and urban green space visitation) and more appropriately illustrate whether there is a difference in pro-environmental behaviour performance between those who never visit urban green space and those who do. Three new variables were created; Total UGS binary, Total PEB binary, and Total UGS Yes or No. Total UGS binary collated Total UGS visitation into two categories, visitation 
once a month or more (1.00) or less than once a month (.00). Total PEB binary collated Total PEB visitation into two categories, more than seven pro-environmental behaviours (1.00) or seven or less pro-environmental behaviours (.00).

Table 7: Frequency table showing distribution of responses for Total UGS binary using the concatenated sample.

\begin{tabular}{|rl|r|r|r|r|}
\hline $\begin{array}{l}\text { Total UGS } \\
\text { binary }\end{array}$ & Frequency & Percent & Valid Percent & $\begin{array}{l}\text { Cumulative } \\
\text { Percent }\end{array}$ \\
\hline \multirow{3}{*}{ Valid } & .00 & 727 & 75.0 & 75.0 & 75.0 \\
& 1.00 & 242 & 25.0 & 25.0 & 100.0 \\
& Total & 969 & 100.0 & 100.0 & \\
\hline
\end{tabular}

Table 8: Frequency table showing distribution of responses for Total PEB binary using the concatenated sample.

\begin{tabular}{|rl|r|r|r|r|}
\hline $\begin{array}{l}\text { Total PEB } \\
\text { binary }\end{array}$ & Frequency & Percent & Valid Percent & $\begin{array}{c}\text { Cumulative } \\
\text { Percent }\end{array}$ \\
\hline \multirow{4}{*}{ Valid } & .00 & 193 & 19.9 & 19.9 & 19.9 \\
& 1.00 & 776 & 80.1 & 80.1 & 100.0 \\
& Total & 969 & 100.0 & 100.0 & \\
\hline
\end{tabular}

Table 9: Frequency table showing distribution of responses for Total UGS Yes or No using the concatenated sample.

\begin{tabular}{|r|r|r|r|r|}
\hline $\begin{array}{c}\text { Total UGS Yes } \\
\text { or No visitation }\end{array}$ & Frequency & Percent & Valid Percent & $\begin{array}{c}\text { Cumulative } \\
\text { Percent }\end{array}$ \\
\hline \multirow{2}{*}{ Valid $\quad 00$} & 21 & 2.2 & 2.2 & 2.2 \\
1.00 & 948 & 97.8 & 97.8 & 100.0 \\
Total & 969 & 100.0 & 100.0 & \\
\hline
\end{tabular}

Cross tabulation analysis (see table ten) revealed those who visited urban green space at least once a year were $18.6 \%$ more likely to perform more than seven proenvironmental behaviours relative to someone who had never visited urban green space in the past 12 months. Pearson chi square statistic (4.447) was significant at the 5\% level (0.035) and the odds of someone performing more than seven types of proenvironmental behaviour increased 2.538 times if they visited urban green space (relative to if they did not visit at all) (Wald $=4.158 ; \mathrm{p}=0.041$ ). 
Table 10: Cross tabulation of Total UGS Yes or No and Total PEB binary showing conditional probabilities of performing more than seven pro-environmental behaviours. Total UGS Yes or No represented by .00 indicating no visitation and 1.00 indicating visitation at least once in 12 months. Total PEB binary represented by .00 indicating seven or less of the 14 proenvironmental behaviours were performed and 1.00 indicating more than seven proenvironmental behaviours were performed.

\begin{tabular}{|c|c|c|c|c|c|}
\hline & & & \multicolumn{2}{|c|}{ Total UGS Yes or No } & \multirow[t]{2}{*}{ Total } \\
\hline & & & .00 & 1.00 & \\
\hline \multirow{2}{*}{ Total PEB binary } & .00 & $\begin{array}{l}\text { Count } \\
\% \text { within } \\
\text { Total UGS Yes or No }\end{array}$ & $\begin{array}{r}8 \\
38.1 \%\end{array}$ & $\begin{array}{r}185 \\
19.5 \%\end{array}$ & $\begin{array}{r}193 \\
19.9 \%\end{array}$ \\
\hline & 1.00 & $\begin{array}{l}\text { Count } \\
\% \text { within } \\
\text { Total UGS Yes or No }\end{array}$ & $\begin{array}{r}13 \\
61.9 \%\end{array}$ & $80.5 \%$ & $\begin{array}{r}776 \\
80.1 \%\end{array}$ \\
\hline
\end{tabular}

Further cross tabulation analysis (see table 11) showed the conditional probability that an individual who visits urban green space (on average) more than once a month performs more than seven pro-environmental behaviours to be 0.872 , compared to 0.777 if the individual visits less than once a month (on average). There was thus a 9.5\% greater likelihood that an individual performs more than seven pro-environmental behaviours if they visited urban green space once a month or more. The result was significant at the $1 \%$ level (Pearson chi square $=10.216 ; \mathrm{p}=0.001)$. Both cross tabulations suggest that there is a greater probability of performing more proenvironmental behaviour if someone also visits urban green space. The difference in probability is greater across non-visitors and visitors, supporting the notion that increasing visitation from 'nothing' to 'something' could lead to the greatest changes in pro-environmental behaviour uptake. Again, such results support my original hypothesis and give support to the theory of biophilia. Nature exposure does appear to be positively associated with pro-environmental behaviour. 
Table 11: Cross tabulation of Total UGS binary and Total PEB binary showing conditional probabilities of performing more than seven pro-environmental behaviours. Total UGS binary represented by .00 indicating visitation less than once a month and 1.00 indicating visitation once a month or more. Total PEB binary represented by .00 indicating seven or less of the 14 pro-environmental behaviours were performed and 1.00 indicating more than seven proenvironmental behaviours were performed.

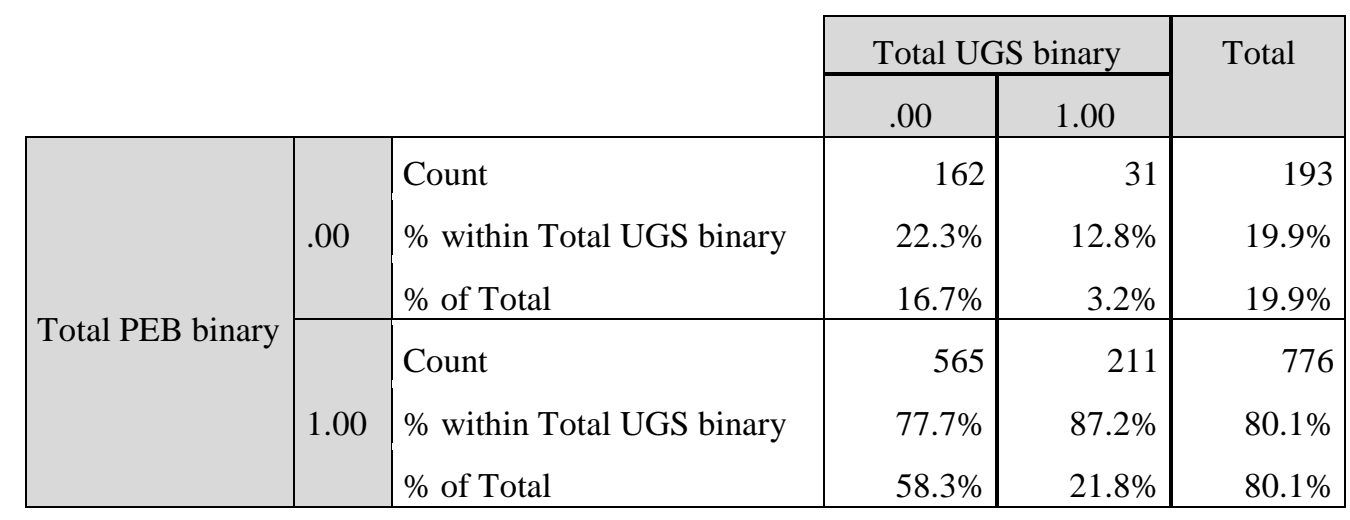

Through the creation of two new binary variables for Total UGS and Total PEB I was able to perform binary logistic regression, a form of regression on limited dependent variables as in the binary case (see equation 4).

\section{Equation 4}

Total PEB binary $_{i}=1.249+0.669$ Total UGS binary $i \quad \mathrm{R}^{2}=0.011 ; \mathrm{N}=969$. $(196.478)(9.948)$

Such analysis produced an odds ratio for pro-environmental behaviour performance. The odds ratio is a useful way of representing the association between urban green space visitation and pro-environmental behaviour. If the odds ratio is equal to 1 , urban green space visitation does not affect the odds of performing pro-environmental behaviour. If the odds ratio is greater than 1, urban green space visitation once a month or more is associated with higher odds of performing more than seven proenvironmental behaviours. Odds ratios are different to probabilities so the interpretation is different to that used for analysing the results in cross tabulations. For example, $P$ is the probability of something happening (performing a pro-environmental behaviour) and the odds can be considered as the number of 'successes' ('yes' to proenvironmental behaviour) for every 'failure' ('no' to pro-environmental behaviour) on average. High odds correspond to high probabilities. The ratio of two odds is termed the odds ratio and is useful for explaining how much more likely one event is relative to another. My results here show the odds of an individual performing more than seven types of pro-environmental behaviour almost doubles (odds ratio $=1.95$ ) if they visit urban green space more than once a month. The result was significant at the $1 \%$ level 
(Wald $=9.948 ; p=0.002)$. In order to determine the difference in odds of performing more than seven pro-environmental behaviours between visitors and non-visitors, logistic regression using Total UGS Yes or No (as opposed to Total UGS binary) was used. The result was significant $(\mathrm{p}=0.041)$ with the odds of performing more than seven pro-environmental behaviours increasing 2.538 times if a person visits urban green space (compared to no visitation at all). People who visit urban green space more often perform more pro-environmental behaviour and the difference is greatest between those who don't visit at all and those who do.

The preceding analysis focused solely on Total UGS and Total PEB meaning particular types of pro-environmental behaviour and urban green space were not separately accounted for in the conclusions reached. Therefore, while it was concluded that there was a statistically significant, positive association, these results may hide some important patterns and trends with respect to specific pro-environmental behaviour and urban green space types.

\subsection{Analysis by Urban Green Space Type}

"Does the relationship between urban green space visitation and pro-environmental behaviour change depending on the type of urban green space visited?"

Table 12: Frequency table showing distribution of responses for each urban green space type using the concatenated sample.

\begin{tabular}{|l|l|l|l|l|l|l|}
\hline & \multicolumn{1}{|c|}{ Coasts } & $\begin{array}{r}\text { Botanic } \\
\text { Gardens }\end{array}$ & \multicolumn{1}{|c|}{ Parks } & Town Belt & \multicolumn{1}{c|}{ Tracks } & Sports Fields \\
\hline N Valid & 969 & 969 & 961 & 935 & 960 & 962 \\
Missing & 0 & 0 & 8 & 34 & 9 & 7 \\
\hline
\end{tabular}

Question 1.2 specifically asked whether the relationship between urban green space visitation and pro-environmental behaviour differs depending on the type of urban green space visited. In order to determine whether the statistically significant relationship between Total UGS and Total PEB is also present when Total UGS is broken down by urban green space type, two methods were used. First, the sample was partitioned into the particular urban green space types and linear regressions were conducted in order to compare the significance of the coefficients. Tables 13 through 18 show frequency distributions for responses. Table 19 displays the regression output. 
Table 13: Frequency table showing distribution of responses for visitation to Wellington city's coastal areas, harbours, and beaches using the concatenated sample. $(0.00=$ most days, $1.00=$ once a week, $2.00=$ once every $2-3$ weeks, $3.00=$ once a month, $4.00=$ once every $2-3$ months, $5.00=$ once every $4-5$ months, $6.00=$ once every 6 months or less, $7.00=$ never in the past 12 months).

\begin{tabular}{|c|c|c|c|c|c|}
\hline & & Frequency & Percent & Valid Percent & $\begin{array}{c}\text { Cumulative } \\
\text { Percent }\end{array}$ \\
\hline \multirow{9}{*}{ Valid } & .00 & 83 & 8.6 & 8.6 & 8.6 \\
\hline & 1.00 & 102 & 10.5 & 10.5 & 19.1 \\
\hline & 2.00 & 50 & 5.2 & 5.2 & 24.3 \\
\hline & 3.00 & 140 & 14.4 & 14.4 & 38.7 \\
\hline & 4.00 & 154 & 15.9 & 15.9 & 54.6 \\
\hline & 5.00 & 203 & 20.9 & 20.9 & 75.5 \\
\hline & 6.00 & 182 & 18.8 & 18.8 & 94.3 \\
\hline & 7.00 & 55 & 5.7 & 5.7 & 100.0 \\
\hline & Total & 969 & 100.0 & 100.0 & \\
\hline
\end{tabular}

Table 14: Frequency table showing distribution of responses for visitation to botanic gardens using the concatenated sample. $(0.00=$ most days, $1.00=$ once a week, $2.00=$ once every $2-3$ weeks, $3.00=$ once a month, $4.00=$ once every $2-3$ months, $5.00=$ once every $4-5$ months, 6.00 $=$ once every 6 months or less, $7.00=$ never in the past 12 months).

\begin{tabular}{|c|c|c|c|c|c|}
\hline & & Frequency & Percent & Valid Percent & $\begin{array}{c}\text { Cumulative } \\
\text { Percent }\end{array}$ \\
\hline \multirow{9}{*}{ Valid } & .00 & 227 & 23.4 & 23.4 & 23.4 \\
\hline & 1.00 & 233 & 24.0 & 24.0 & 47.5 \\
\hline & 2.00 & 77 & 7.9 & 7.9 & 55.4 \\
\hline & 3.00 & 195 & 20.1 & 20.1 & 75.5 \\
\hline & 4.00 & 113 & 11.7 & 11.7 & 87.2 \\
\hline & 5.00 & 64 & 6.6 & 6.6 & 93.8 \\
\hline & 6.00 & 40 & 4.1 & 4.1 & 97.9 \\
\hline & 7.00 & 20 & 2.1 & 2.1 & 100.0 \\
\hline & Total & 969 & 100.0 & 100.0 & \\
\hline
\end{tabular}


Table 15: Frequency table showing distribution of responses for visitation to parks. Categories span from .00 indicating no visitation to 7.00 indicating visitation most days. $(0.00=$ most days, $1.00=$ once a week, $2.00=$ once every $2-3$ weeks, $3.00=$ once a month, $4.00=$ once every $2-3$ months, $5.00=$ once every $4-5$ months, $6.00=$ once every 6 months or less, $7.00=$ never in the past 12 months).

\begin{tabular}{|c|c|c|c|c|c|}
\hline \multicolumn{2}{|c|}{ Parks } & \multirow{2}{*}{$\begin{array}{c}\text { Frequency } \\
151\end{array}$} & \multirow{2}{*}{$\begin{array}{c}\text { Percent } \\
15.6\end{array}$} & \multirow{2}{*}{$\begin{array}{c}\text { Valid Percent } \\
15.7\end{array}$} & \multirow{2}{*}{$\begin{array}{c}\begin{array}{c}\text { Cumulative } \\
\text { Percent }\end{array} \\
15.7\end{array}$} \\
\hline \multirow{8}{*}{ Valid } & .00 & & & & \\
\hline & 1.00 & 102 & 10.5 & 10.6 & 26.3 \\
\hline & 2.00 & 56 & 5.8 & 5.8 & 32.2 \\
\hline & 3.00 & 122 & 12.6 & 12.7 & 44.8 \\
\hline & 4.00 & 124 & 12.8 & 12.9 & 57.8 \\
\hline & 5.00 & 158 & 16.3 & 16.4 & 74.2 \\
\hline & 6.00 & 192 & 19.8 & 20.0 & 94.2 \\
\hline & 7.00 & 56 & 5.8 & 5.8 & 100.0 \\
\hline \multirow{3}{*}{$\begin{array}{r}\text { Missing } \\
\mathrm{To} \\
\end{array}$} & Total & 961 & 99.2 & 100.0 & \\
\hline & System & 8 & .8 & & \\
\hline & & 969 & 100.0 & & \\
\hline
\end{tabular}

Table 16: Frequency table for visitation to the town belt or outer green belt using the concatenated sample. $(0.00=$ most days, $1.00=$ once a week, $2.00=$ once every $2-3$ weeks, 3.00 $=$ once a month, $4.00=$ once every $2-3$ months, $5.00=$ once every $4-5$ months, $6.00=$ once every 6 months or less, $7.00=$ never in the past 12 months).

\begin{tabular}{|cc|c|c|c|c|}
\hline & Frequency & Percent & Valid Percent & $\begin{array}{c}\text { Cumulative } \\
\text { Percent }\end{array}$ \\
\hline & .00 & 384 & 39.6 & 41.1 & 41.1 \\
1.00 & 125 & 12.9 & 13.4 & 54.4 \\
2.00 & 52 & 5.4 & 5.6 & 60.0 \\
& 3.00 & 89 & 9.2 & 9.5 & 69.5 \\
Valid & 4.00 & 93 & 9.6 & 9.9 & 79.5 \\
& 5.00 & 66 & 6.8 & 7.1 & 86.5 \\
& 6.00 & 90 & 9.3 & 9.6 & 96.1 \\
& 7.00 & 36 & 3.7 & 3.9 & 100.0 \\
Total & 935 & 96.5 & 100.0 & \\
Missing System & 34 & 3.5 & & \\
Total & 969 & 100.0 & & \\
\hline
\end{tabular}


Table 17: Frequency table for visitation to city walking tracks using the concatenated sample. $(0.00=$ most days, $1.00=$ once a week, $2.00=$ once every $2-3$ weeks, $3.00=$ once a month, 4.00 $=$ once every $2-3$ months, $5.00=$ once every $4-5$ months, $6.00=$ once every 6 months or less, $7.00=$ never in the past 12 months).

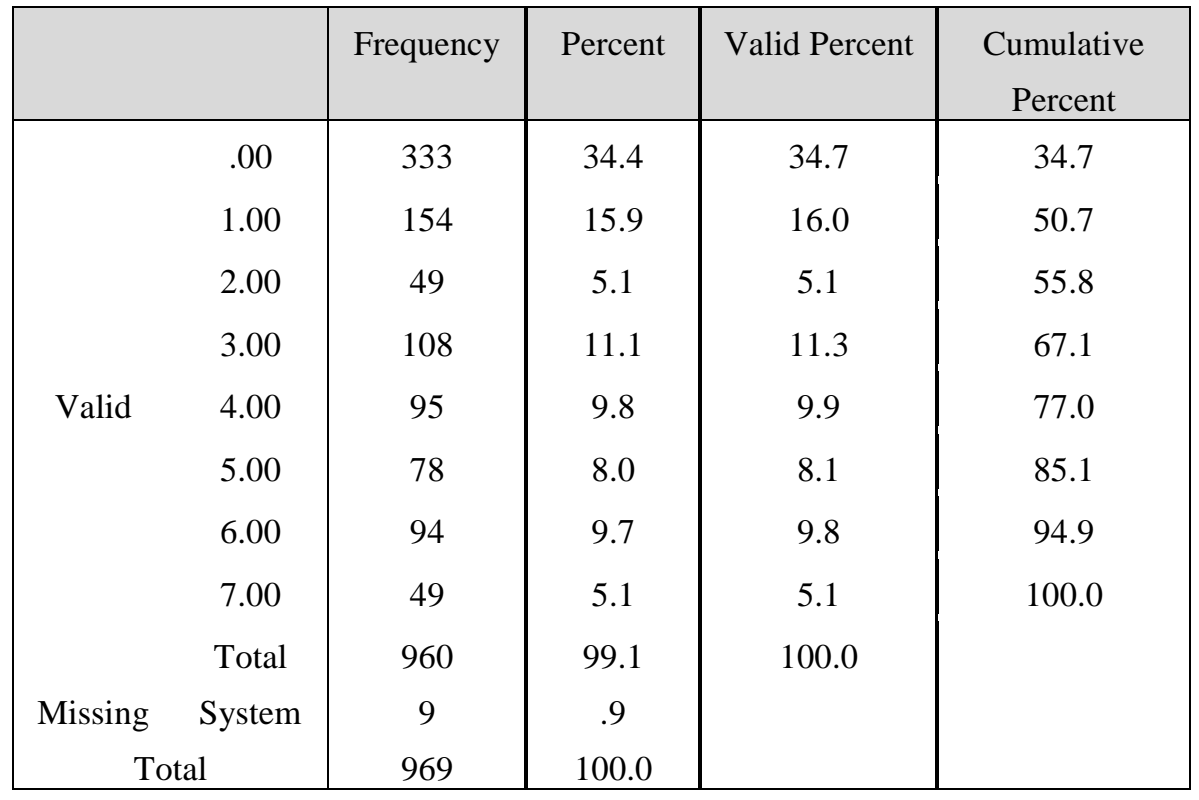

Table 18: Frequency table for visitation to Wellington city council outdoor grass sports fields using the concatenated sample. $(0.00=$ most days, $1.00=$ once a week, $2.00=$ once every $2-3$ weeks, $3.00=$ once a month, $4.00=$ once every $2-3$ months, $5.00=$ once every $4-5$ months, 6.00 $=$ once every 6 months or less, $7.00=$ never in the past 12 months).

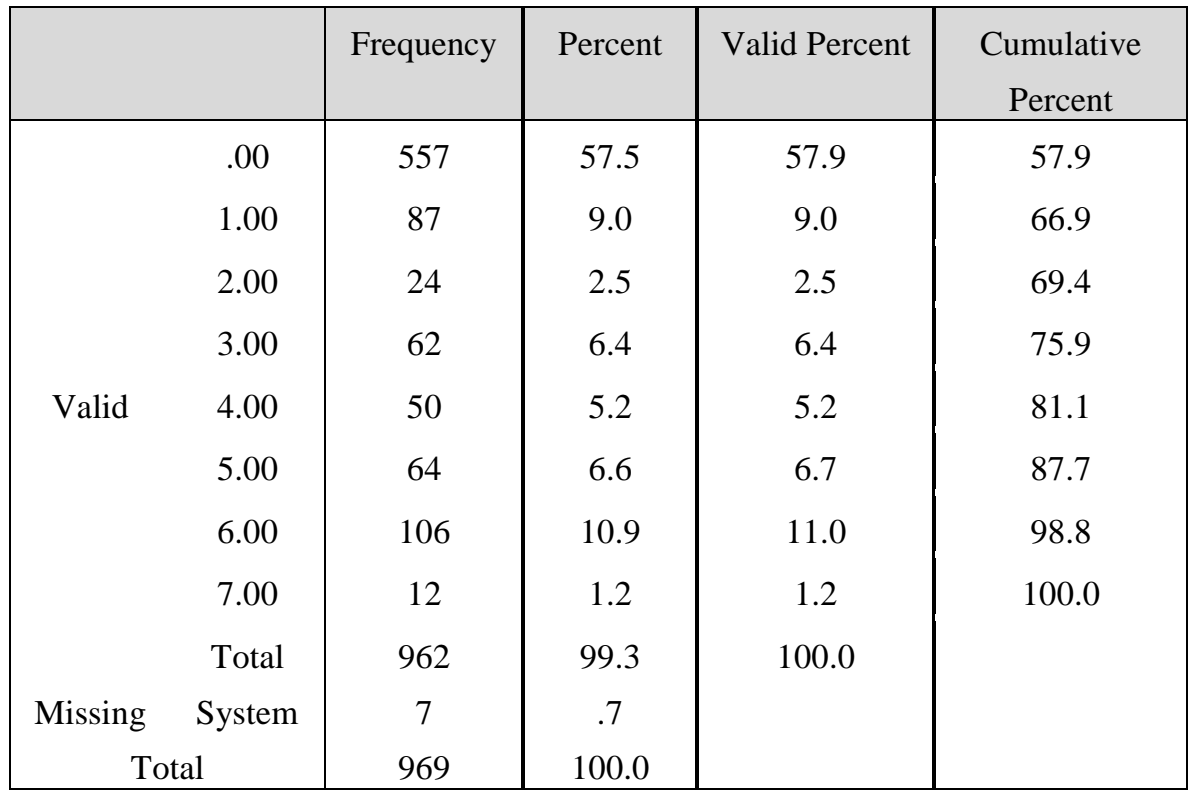


Table 19: Results of regression analysis of Total PEB as a function of Total UGS across each urban green space type, separately. $95 \%$ confidence intervals for $\mathrm{R}^{2}$ values included for comparison.

\begin{tabular}{|c|c|c|c|c|c|}
\hline UGS & $\mathrm{N}$ & $\mathrm{R}^{2}$ & $\begin{array}{l}\mathrm{R}^{2} 95 \% \\
\text { C.I }\end{array}$ & $\begin{array}{c}\mathrm{P} \\
\text { value }\end{array}$ & Equation \\
\hline Coasts & 969 & 0.043 & $\begin{array}{c}0.01807 \\
\leq \mathrm{R} 2 \leq \\
0.06793\end{array}$ & .000 & $\begin{aligned} \text { Total } \mathrm{PEB}_{i} & =8.389+0.241 \text { Coasts } \\
& (53.029)(6.626)\end{aligned}$ \\
\hline Botanic & 969 & .044 & $\begin{array}{c}0.01881 \\
\leq \mathrm{R} 2 \leq \\
0.06919\end{array}$ & .000 & $\begin{aligned} \text { Total } \text { PEB }_{i} & =8.745+0.261 \text { Botanic } \\
& (77.482)(6.695)\end{aligned}$ \\
\hline Parks & 961 & 0.043 & $\begin{array}{c}0.01870 \\
\leq \mathrm{R} 2 \leq \\
0.06930\end{array}$ & .000 & $\begin{aligned} \text { Total } \mathrm{PEB}_{i}= & 8.552+0.216 \text { Parks } \\
& (62.007)(6.588)\end{aligned}$ \\
\hline Town Belt & 935 & 0.029 & $\begin{array}{c}0.00785 \\
\leq \mathrm{R} 2 \leq \\
0.05015\end{array}$ & .000 & $\begin{aligned} \text { Total }^{\mathrm{PEB}_{i}}= & 8.980+0.172 \text { Town Belt } \\
& (87.141)(5.260)\end{aligned}$ \\
\hline Tracks & 960 & 0.048 & $\begin{array}{c}0.02168 \\
\leq \mathrm{R} 2 \leq \\
0.07432\end{array}$ & .000 & $\begin{aligned} \text { Total } \mathrm{PEB}_{i}= & 8.816+0.218 \text { Tracks } \\
& (84.203)(6.915)\end{aligned}$ \\
\hline $\begin{array}{l}\text { Sports } \\
\text { Fields }\end{array}$ & 962 & 0.016 & $\begin{array}{c}0.00031 \\
\leq \mathrm{R} 2 \leq \\
0.03169\end{array}$ & .000 & $\begin{aligned} \text { Total } \mathrm{PEB}_{i}= & 9.117+0.129 \text { Sports Fields } \\
& (98.868)(3.909)\end{aligned}$ \\
\hline
\end{tabular}

There was a significant association between urban green space visitation and Total PEB for all urban green space types $(p<0.01)$. None of the urban green spaces alone were strong predictors of Total PEB. The lowest $\mathrm{R}^{2}$ values derived from sports field and town belt visitors ( 0.016 and 0.029 , respectively), suggesting these areas in particular are less effective at predicting pro-environmental behaviour relative to the other urban green space types. When looking at the $95 \%$ confidence interval for $\mathrm{R}^{2}$, there is overlap for all regressions. Tracks and sports fields showed the greatest difference, with only a slight overlap between 0.02168 (tracks minimum $\mathrm{R}^{2}$ ) and 0.03169 (sports fields maximum $\mathrm{R}^{2}$ ).

I hypothesised that sports fields would have less predictive power than urban green spaces such as walking tracks following literature which states vegetation to be a strong indicator of how connected to nature one will become through increased exposure (Jim and Chen, 2006). Sports fields, in this instance, consist of open grass land with little vegetative cover. My results showed those who visited such spaces were still performing more pro-environmental behaviours than those who did not. Gordan Orian's Savannah hypothesis can possibly explain such a result. The Savannah hypothesis posits 
that humans have a subconscious attachment to half-open, park-like spaces, such as savannahs, as this is the habitat humans evolved from (Wilson, 1984). All spaces appear to be significantly associated (positively) with pro-environmental behaviour. There could be issues with multicollinearity here. Perhaps, those who are visiting one type of urban green space are also visiting another just as frequently.

A correlation matrix (table 20) displays which of the urban green space types are highly correlated. All urban green space types were significantly correlated at the $1 \%$ level, with the exception of botanic gardens and sports fields, which were correlated at the $5 \%$ level (correlation of 0.081$)$. The strongest correlation (0.639) occurred between tracks and the town belt, likely due to the surrounding belt being home to many of the city's walking tracks. All correlations were positive meaning that individuals who visited one type of urban green space frequently were likely to frequently visit another type of urban green space. What such a pattern suggests is that those who visit urban green space hold characteristics and/or personality traits consistent with an interest in the outdoors. Azjen's (1991) principle of compatibility supports such an assumption as it states that behaviours that are similar are often positively correlated because they derive from similar attitudes. 
Table 20: Correlation matrix showing Pearson correlation coefficients and associated $\mathrm{p}$ values for all list wise comparisons of visitation to urban green space. Visitation was measured retaining the eight categories of visitation frequency, from never to most days.

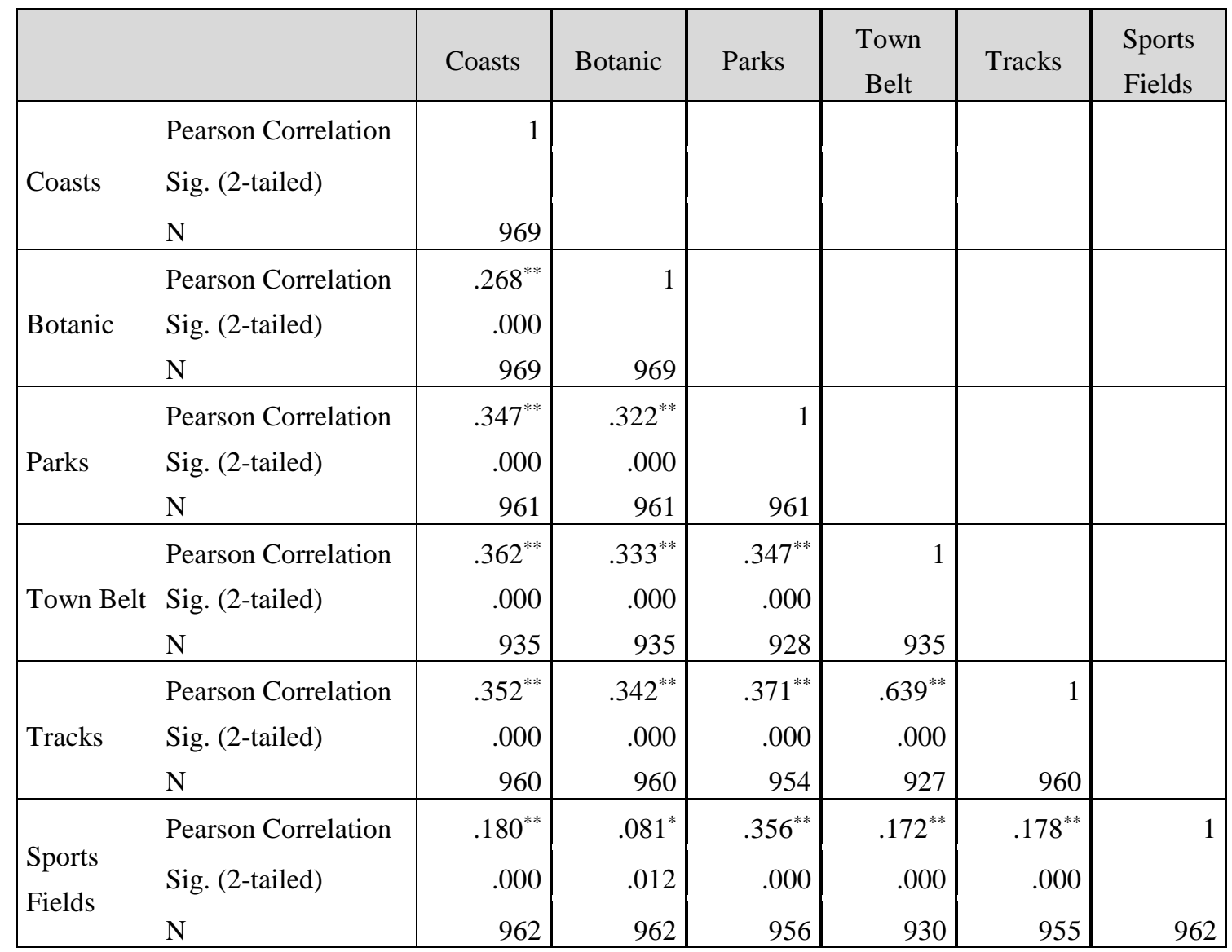

**. Correlation is significant at the 0.01 level (2-tailed).

*. Correlation is significant at the 0.05 level (2-tailed).

\section{Principle components analysis}

Principal component analysis is a technique which allows the dimensionality of data to be reduced. Due to the presence of statistically significant correlations (see table 20), it is possible that the number of urban green space variables could be reduced to a few principle components. First, Bartlett's test was performed which tests the null hypothesis that, in the correlation matrix, the diagonal elements are 1 and the off diagonal elements are 0 . Bartlett's test was significant, meaning there was evidence to accept the alternative hypothesis that there is some correlation between visitation rates to the different urban green space types. The Kaiser-Meyer-Olkin measure of sampling adequacy tests the data for its suitability to be subjected to factor analysis. Values closer to 1 are better with 0.6 being a minimum value. The value returned was 0.761 meaning analysis was $\mathrm{OK}$ to continue. 
Table 21 displays the total variance explained from principle components analysis. Eigenvalues are the variances of the principal components. As principal component analysis was conducted on the correlation matrix, the variables are standardized, which means each variable has a variance of one, and the total variance is equal to the number of variables used in the analysis, in this case, six. There are only two rows reproduced in the 'extraction sums of squared loadings' columns representing the principal components where the eigenvalues are greater than or equal to one. Those components with an eigenvalue of less than one account for less variance than did the original variable.

Table 21: Table of total variance explained after principle components analysis on six urban green space types. Component values greater than one account for more variance than did the original variable.

\begin{tabular}{|l|r|r|r|r|r|r|}
\hline \multirow{2}{*}{ Component } & \multicolumn{3}{|c|}{ Initial Eigenvalues } & \multicolumn{2}{|c|}{ Extraction Sums of Squared Loadings } \\
\cline { 2 - 7 } & Total & \multicolumn{1}{c|}{$\begin{array}{c}\text { \% of } \\
\text { Variance }\end{array}$} & $\begin{array}{c}\text { Cumulative } \\
\%\end{array}$ & Total & $\begin{array}{c}\text { \% of } \\
\text { Variance }\end{array}$ & Cumulative \% \\
\hline 1 & 2.637 & 43.955 & 43.955 & 2.637 & 43.955 & 43.955 \\
2 & 1.006 & 16.775 & 60.730 & 1.006 & 16.775 & 60.730 \\
3 & .747 & 12.457 & 73.187 & & & \\
4 & .702 & 11.705 & 84.892 & & & \\
5 & .545 & 9.078 & 93.970 & & & \\
6 & .362 & 6.030 & 100.000 & & & \\
\hline
\end{tabular}

Extraction Method: Principal Component Analysis.

Table 22 shows there were two components extracted. There was strong correlation amongst the urban green space types in component one (all types) and similarly amongst those listed under component two, parks and sports fields. Sports field visitation was most strongly associated with the second component. Principal component analysis allowed me to identify two components from the six variables pertaining to urban green space visitation. One component, consisting of only the variable for sports field visitation and the other component consisting of the remaining five variables (there is stronger support for 'parks' to be part of component one $(0.696>$ 0.359). Such results are consistent with the principle of compatibility which suggests that behaviours of a similar domain will be highly correlated (positively). Visitation to sports fields (being the least natural of the urban green space types) is better suited to being a variable of its own, whilst the remaining five suitably act as one variable. Such 
an outcome is not entirely surprising given the obvious differences in form and function existing between spaces such as the botanic gardens and sports fields.

Table 22: Component matrix of urban green space visitation variables using principle component analysis. Two components are shown.

\begin{tabular}{|l|r|c|}
\hline \multirow{2}{*}{} & \multicolumn{2}{|c|}{ Component } \\
\cline { 2 - 3 } & 1 & 2 \\
\hline Coasts & .641 & \\
Botanic & .600 & \\
Parks & .696 & .359 \\
Town Belt & .768 & \\
Tracks & .777 & \\
Sports Fields & .435 & .805 \\
\hline
\end{tabular}

Extraction Method: Principal

Component Analysis.

2 components extracted.

I next tested whether the association between pro-environmental behaviour and urban green space visitation was stronger when only the variable for coasts visitation was included in the model relative to if vegetated urban green spaces or sports fields were only included. By comparing the resulting t statistics for the $\beta$ coefficient across the three equations (see equation five through seven) I was able to posit which equation better explained pro-environmental behaviour. ${ }^{6}$

When compared to the $\beta$ coefficients in the regressions with coasts and sports fields alone, the $\beta$ coefficient for the regression with the vegetated variable was smaller suggesting there is a smaller influence of urban green space on predicted proenvironmental behaviour, i.e., for every one unit increase in Vegetated UGS, the associated rise in Total PEB is less than what is predicted for visits to coasts or sports fields. With the most significant coefficient associated with Vegetated UGS, it suggests vegetated spaces better explain pro-environmental behaviour $(8.522>6.262>3.909)$. The coefficient for coast visitation was more significant than that for sports fields, suggesting that sport field visitation is the least likely to accurately predict proenvironmental behaviour. Such a result is supported by the literature. I found

\footnotetext{
${ }^{6}$ While visitation to coasts correlated strongly with the variables in component one of the principle components analysis (see table 21), characteristic differences between terrestrial urban green and urban blue spaces (e.g., the latter space is water based the former is heavily vegetated) accompanied with literature stating water based scenes to illicit greater positive emotional responses, I chose to regress 'coasts' with Total PEB separately.
} 
considerable evidence indicating that vegetation induces stronger connections to nature, as well as evidence supporting waterscapes as the landscape evoking the most positive, emotional responses in visitors (which biophilia suggests leads to a greater want to preserve the environment). Such a result highlights that it is perhaps vegetated urban green spaces and coasts that should be prioritised for their potential to foster proenvironmental behaviour.

\section{Equation 5}

Total $\mathrm{PEB}_{i}=8.364+0.097$ Vegetated $\mathrm{UGS}_{i} \quad \mathrm{R}=0.271 ; \mathrm{R}^{2}=0.073 ; \mathrm{N}=921$. (60.532) (8.522)

\section{Equation 6}

Total $\mathrm{PEB}_{i}=9.117+0.129$ Sports Fields $\mathrm{UGS}_{i} \quad \mathrm{R}=0.126 ; \mathrm{R}^{2}=0.016 ; \mathrm{N}=962$. (98.868) (3.909)

Equation 7

Total $\mathrm{PEB}_{i}=8.389+0.241$ Coastal $\mathrm{UGS}_{i} \quad \mathrm{R}=0.207 ; \mathrm{R}^{2}=0.043 ; \mathrm{N}=969$. (53.029) (6.626)

I thought it would be interesting to ascertain whether the amount of vegetated urban green spaces visited once a month or more changes the conditional probability of performing more than seven pro-environmental behaviours. Table 23 outlines the percentage of respondents who visited one, two, three, or all four types of vegetated urban green space once a month or more (8.9\%) versus those who visited only one type (25.7\%). Sixty eight percent of Wellington city residents are visiting one or more types of vegetated urban green spaces at least once a month - possibly indicating why the variable for Total UGS visitation is still a better predictor of pro-environmental behaviour relative to when coast or vegetated urban green space is used alone. 
Table 23: Frequency table showing distribution of responses for visitation to Vegetated urban green space using the concatenated sample. With there being four types of vegetated urban green space (botanics, parks, town belt, and tracks) each value represents how many of the vegetated urban green spaces were visited once a month or more. The value, .00 indicates visitation to none of the vegetated spaces once a month or more, 1.00 indicates visitation to one, 2.00 indicates visitation to two, 3.00 indicates visitation to three, and 4.00 indicates all four vegetates spaces were visited once a month or more.

\begin{tabular}{|ll|r|r|r|r|}
\hline & & Frequency & Percent & Valid Percent & \multicolumn{2}{c|}{$\begin{array}{c}\text { Cumulative } \\
\text { Percent }\end{array}$} \\
\hline & .00 & 295 & 30.4 & 32.0 & 32.0 \\
& 1.00 & 249 & 25.7 & 27.0 & 59.1 \\
Valid & 2.00 & 158 & 16.3 & 17.2 & 76.2 \\
& 3.00 & 133 & 13.7 & 14.4 & 90.7 \\
& 4.00 & 86 & 8.9 & 9.3 & 100.0 \\
& Total & 921 & 95.0 & 100.0 & \\
Missing & System & 48 & 5.0 & & \\
Total & & 969 & 100.0 & & \\
\hline
\end{tabular}

In order to perform cross tabulation analysis and binary logistic regression, a new variable, 'vegetated visitation once a month or more' was computed and labelled Vegetated binary. All those individuals who indicated they visited at least one of the four types of vegetated urban green space at least once a month or more were coded, one. Cross tabulation of this new variable with the binary form of Total PEB (performing more than seven pro-environmental behaviours (1.00) or performing less than seven (0.00)) was conducted in order to assess the extent visiting more types of vegetated urban green space increases the likelihood of performing more than seven pro-environmental behaviours (see table 24). Similar cross tabs were performed for coast visitation and sports field visitation (table 25 and table 26, respectively) in order to compare likelihoods.

An individual who visited vegetated urban green space once a month or more was $8.5 \%$ more likely to perform more than seven pro-environmental behaviours relative to someone who visited less. There was an $83.1 \%$ chance a 'once a month or more' visitor performed more than seven pro-environmental behaviours, dropping to $74.6 \%$ if they visited less than once a month. When the cross tab was restricted to coast visitation, there was a $10 \%$ difference in probability. The likelihood of performing more than seven pro-environmental behaviours was $84.3 \%$ if the individual visited coasts once a month or more, compared to $73.3 \%$ if they visited less. For sports field visitation, performing more than seven pro-environmental behaviours was $9.6 \%$ more likely for 
those who visited sports fields once a month or more $(87.5$ - 77.9). All cross tabs reported a statistically significant Pearson chi-square at the $1 \%$ significance level $(\mathrm{p}=$ $0.002,0.000,0.001$, for tables 24,25 , and 26 , respectively).

Table 24: Cross tabulation table displaying conditional probabilities of performing more than seven pro-environmental behaviours (1.00) or seven or less pro-environmental behaviours (.00) and visiting Vegetated urban green spaces once a month or more (1.00) or less than once a month (.00).

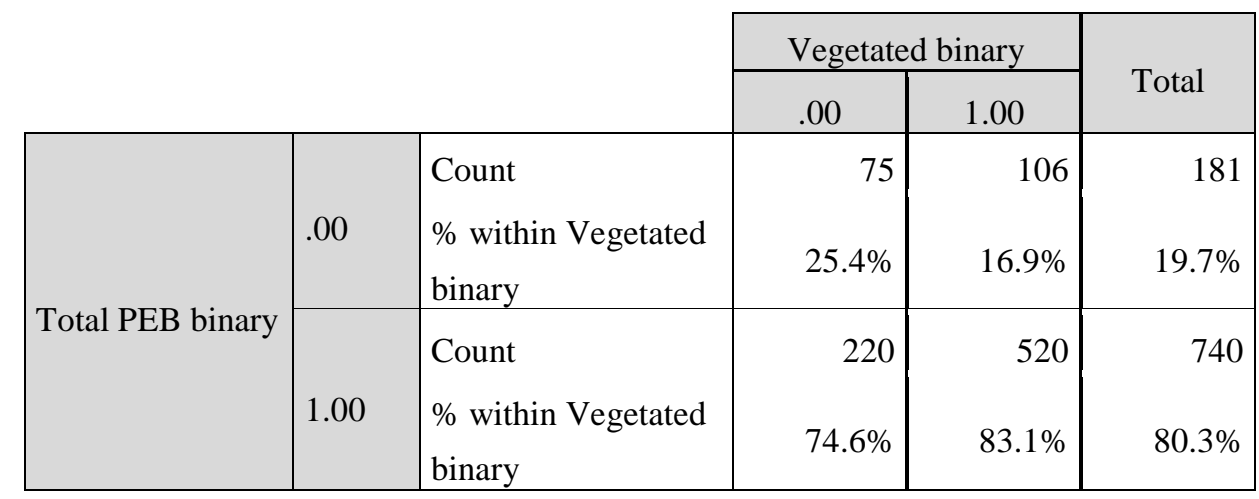

Table 25: Cross tabulation table displaying conditional probabilities of performing more than seven pro-environmental behaviours (1.00) or seven or less pro-environmental behaviours (.00) and visiting Coastal urban green spaces once a month or more (1.00) or less than once a month (.00).

\begin{tabular}{|l|l|l|r|r|r|}
\cline { 3 - 4 } \multicolumn{2}{c|}{} & \multicolumn{2}{c|}{ Coasts binary } & \multirow{2}{*}{ Total } \\
\cline { 3 - 5 } Total PEB binary & .00 & $\begin{array}{l}\text { Count } \\
\% \text { within Coasts } \\
\text { binary }\end{array}$ & 100 & 1.00 & 193 \\
\cline { 2 - 5 } & 1.00 & $\begin{array}{l}\text { Count } \\
\text { \% within Coasts } \\
\text { binary }\end{array}$ & $26.7 \%$ & $15.7 \%$ & $19.9 \%$ \\
\hline
\end{tabular}

Table 26: Cross tabulation table displaying conditional probabilities of performing more than seven pro-environmental behaviours (1.00) or seven or less pro-environmental behaviours (.00) and visiting sports field urban green spaces once a month or more (1.00) or less than once a month (.00).

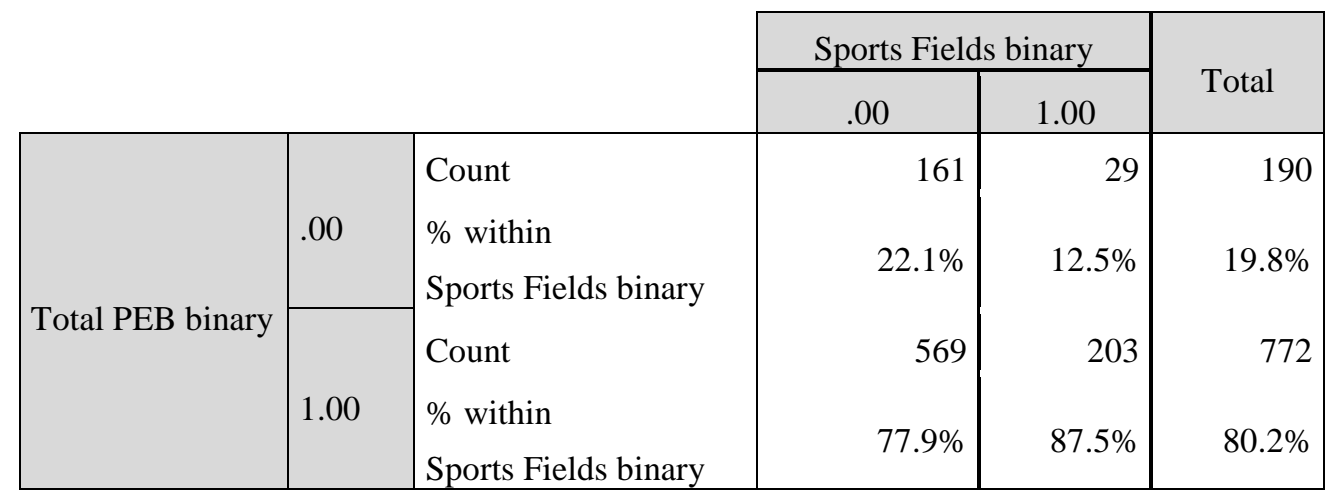




\section{Dummy variable analysis}

Next I used dummy variables to determine what levels of urban green space visitation (between coastal, vegetated, and sports fields) were statistically different from novisitation when it came to predicting the odds of someone performing more than seven pro-environmental behaviours. Table 27 shows the odds of performing more than seven pro-environmental behaviours increases 2.553 times if vegetated spaces are visited once every 2-3 months (relative to no visitation). It appears the greatest increase in odds (also accompanying the strongest statistical significance) occurs between no visitation to vegetated urban green spaces and visitation once every 2-3 weeks (odds ratio 5.020). The odds of performing more than seven pro-environmental behaviours increases five times if vegetative urban green spaces are visited once every 2-3 weeks relative to no visitation. Again, this result supports earlier conclusions that the likelihood of performing more pro-environmental behaviours increases if vegetated urban green space visitation is increased. Interestingly, the increase in odds is not significant between vegetated urban green space visitation 'most days' and 'never'. As concluded earlier, there is evidence here to suggest that there is greater benefit in achieving increases from 'nothing' to 'something', in terms of pro-environmental behaviour change.

Table 27: Table of coefficients from binary logistic regression of vegetated UGS visitation and Total PEB binary using the concatenated sample. No visitation to coasts set as base. Vegetated $(1)=$ visitation once every six months or less, Vegetated $(2)=$ visitation once every 45 months, Vegetated(3) = visitation once every 2-3 months, Vegetated(4) = visitation once a month, Vegetated $(5)=$ visitation once every $2-3$ weeks, Vegetated $(6)=$ visitation once or twice a week, Vegetated $(7)=$ visitation most days.

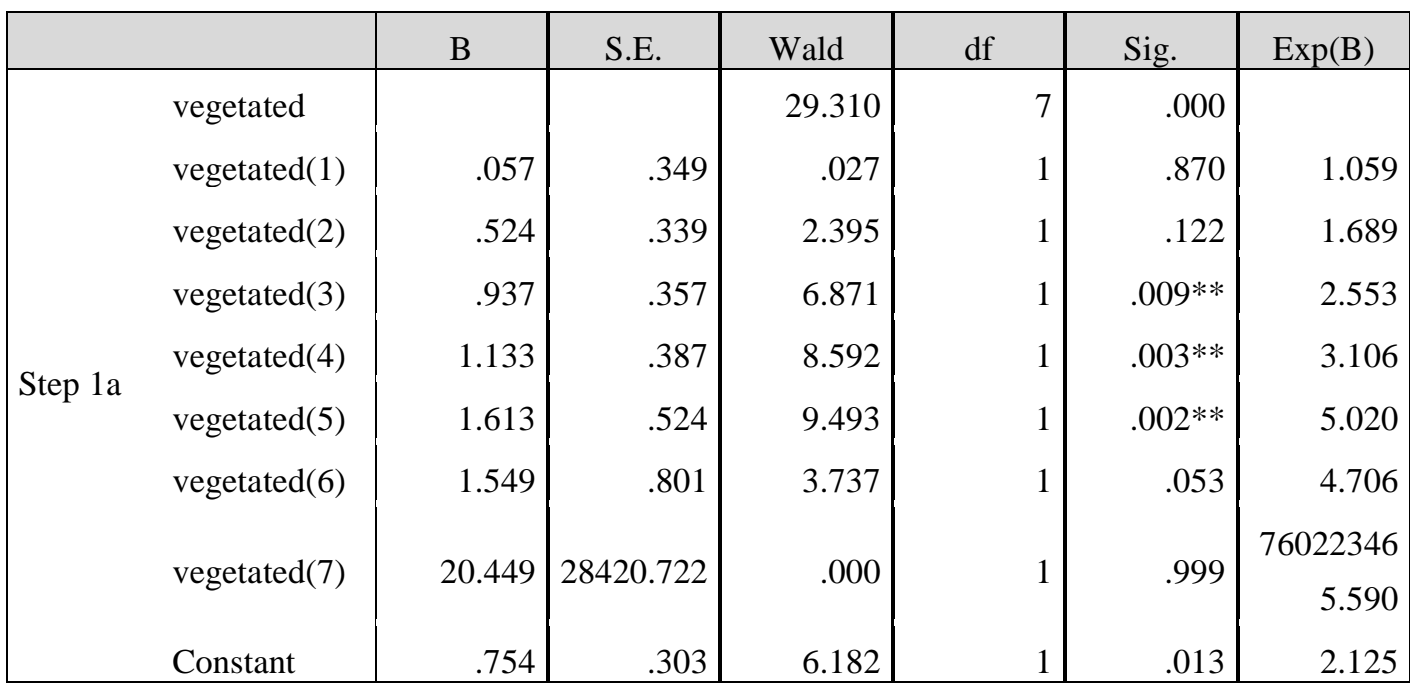

Variable(s) entered on step 1: vegetated.

* Significance at $5 \%$ level; ** Significance at $1 \%$ level. 
Unlike visitation to vegetated spaces, the coefficient for no coastal visitation is statistically different for all categories (except visitation once every 4-5 months). Table 28 shows the odds of performing more than seven pro-environmental behaviours for an individual who visits coasts most days to be 2.640 times the odds of a non-visitor, a statistically significant difference. Coast visitation as little as once every six months was statistically different from no-visitation in terms of the odds of performing more than seven pro-environmental behaviours. When sports field visitation was broken down by visitation level, only visiting once every 2-3 weeks or once or twice a week was statistically different to no-visitation (table 29). It seems that sports field visitation must be increased substantially more in order to achieve statistically different changes in proenvironmental behaviour performance.

Table 28: Table of coefficients from binary logistic regression of coast visitation and Total PEB binary using the concatenated sample. No-visitation to coasts set as base. Coasts $(1)=$ visitation once every six months or less, Coasts $(2)=$ visitation once every 4-5 months, Coasts(3) = visitation once every $2-3$ months, Coasts $(4)=$ visitation once a month, Coasts $(5)=$ visitation once every 2-3 weeks, Coasts(6) = visitation once or twice a week, Coasts $(7)=$ visitation most days.

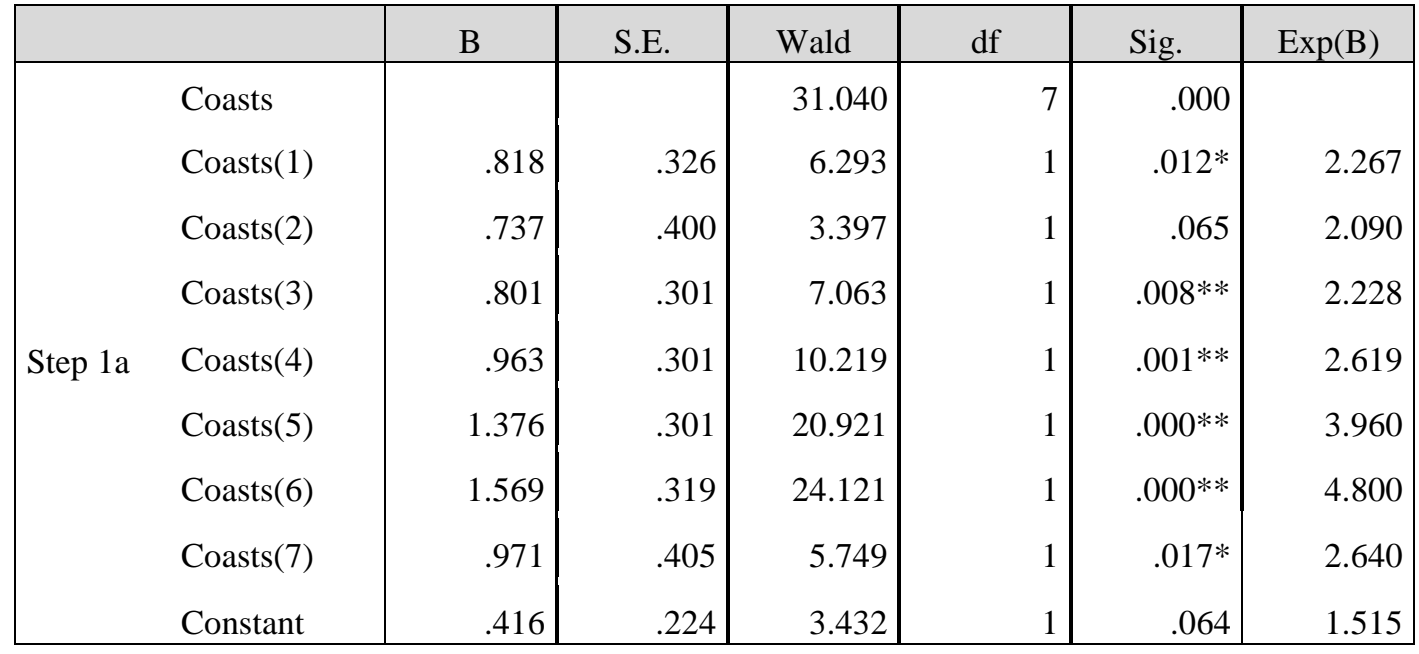

Variable(s) entered on step 1: Coasts.

* Significance at $5 \%$ level; ** Significance at $1 \%$ level. 
Table 29: Table of coefficients from binary logistic regression of sports field visitation and Total PEB binary using the concatenated sample. No visitation to coasts set as base. Sports Fields $(1)=$ visitation once every six months or less, Sports Fields $(2)=$ visitation once every 4-5 months, Sports Fields (3) = visitation once every 2-3 months, Sports Fields (4) = visitation once a month, Sports Fields (5) = visitation once every 2-3 weeks, Sports Fields (6) = visitation once or twice a week, Sports Fields (7) = visitation most days.

\begin{tabular}{|c|c|c|c|c|c|c|c|}
\hline & & B & S.E. & Wald & df & Sig. & $\operatorname{Exp}(B)$ \\
\hline \multirow{16}{*}{ Step 1a } & Sports Fields & \multirow{3}{*}{196} & \multirow{3}{*}{.289} & 15.015 & 7 & .036 & \multirow{3}{*}{1.216} \\
\hline & Sports & & & \multirow{2}{*}{.460} & \multirow{2}{*}{1} & \multirow{2}{*}{.498} & \\
\hline & Fields(1) & & & & & & \\
\hline & Sports & \multirow{2}{*}{1.916} & \multirow{2}{*}{1.026} & \multirow{2}{*}{3.484} & \multirow{2}{*}{1} & \multirow{2}{*}{.062 } & \multirow{2}{*}{6.793} \\
\hline & Fields(2) & & & & & & \\
\hline & Sports & \multirow{2}{*}{-.164} & \multirow{2}{*}{.307 } & \multirow{2}{*}{.283} & \multirow{2}{*}{1} & \multirow{2}{*}{.595} & \multirow{2}{*}{.849} \\
\hline & Fields(3) & & & & & & \\
\hline & Sports & \multirow{2}{*}{.773} & \multirow{2}{*}{447} & \multirow{2}{*}{2.992} & \multirow{2}{*}{1} & \multirow{2}{*}{.084} & \multirow{2}{*}{2.166} \\
\hline & Fields(4) & & & & & & \\
\hline & Sports & \multirow{2}{*}{.878} & \multirow{2}{*}{.413} & \multirow{2}{*}{4.514} & \multirow{2}{*}{1} & \multirow{2}{*}{$.034 *$} & \multirow{2}{*}{2.405} \\
\hline & Fields(5) & & & & & & \\
\hline & Sports & \multirow{2}{*}{.663} & \multirow{2}{*}{.304} & \multirow{2}{*}{4.754} & \multirow{2}{*}{1} & \multirow{2}{*}{$.029 *$} & \multirow{2}{*}{1.941} \\
\hline & Fields(6) & & & & & & \\
\hline & Sports & 300 & 781 & 240 & 1 & 618 & 1477 \\
\hline & Fields(7) & .590 & .101 & .249 & 1 & 年. & $1.4 / 1$ \\
\hline & Constant & 1.220 & .101 & 145.831 & 1 & .000 & 3.386 \\
\hline
\end{tabular}

Variable(s) entered on step 1: Sports Fields.

* Significance at $5 \%$ level; ** Significance at $1 \%$ level.

\section{Stepwise linear regression - forward selection}

With dummy variable analysis indicating that vegetated and coastal visitation is better than sports field visitation when it comes to increasing pro-environmental behaviour, I next wanted to find out if visitation to vegetated urban green space contributed more to the prediction of pro-environmental behaviour than coast visitation. To answer this, a stepwise linear regression was performed with forward selection used to find the model that best predicted Total PEB. In forward selection, at each step, the variable not yet in the equation with the smallest $\mathrm{p}$ value is entered. The method terminates when no more variables are eligible for inclusion, i.e., the inclusion of the next variable results in the $p$ value for another increasing above the threshold. In this case, that threshold was set at 0.05. For predicting Total PEB, forward selection terminated after the inclusion of variables, Vegetated, Coasts and Town Belt. The best model for predicting Total PEB (when vegetated was included) was thus as follows: 


\section{Equation 8}

Total $\mathrm{PEB}_{i}=7.980+0.112$ Vegetated +0.123 Coasts -0.115 Town Belt

$$
\text { (45.538) (5.692) (2.970) (-2.147) }
$$

$\mathrm{R}=0.294 ; \mathrm{R}^{2}=0.086 ;$ Adj. $\mathrm{R}^{2}=0.083 ; \mathrm{P}<0.01 ; \mathrm{N}=918$

Equation eight is potentially problematic as the three variables included are highly correlated meaning the standard error could be unstable. To check if addition of a new variable affected the estimate of the variable that remained in the equation, a model was run with Vegetated added first, then Coasts, then the rest. When Coasts was added to the model, the estimate for Vegetated decreased from $0.097(\mathrm{t}=8.499)$ to $0.080(\mathrm{t}=$ 6.255). When Town Belt was then added, the Vegetated coefficient estimate rose to $0.112(\mathrm{t}=5.692)$. Coasts exhibited a minor increase of 0.002 when Town Belt was included and a minor decrease of 0.004 when remaining variables were included.

When the aggregated variable for Vegetated was broken back down into its component parts, town belt visitation became insignificant in the model. The urban green spaces that were significant in the prediction of Total PEB are shown in equation nine.

\section{Equation 9}

Total $\mathrm{PEB}_{i}=7.977+0.106$ Tracks + 0.111 Parks +0.123 Coasts +0.120 Botanic

$$
\text { (44.643) (2.195) (2.951) (3.001) (2.753) }
$$

$\mathrm{R}^{2}=0.086 ;$ Adj. $\mathrm{R}^{2}=0.082 ; \mathrm{P}<0.01 ; \mathrm{N}=918$.

Sports fields and town belt visitation did not significantly contribute to the prediction of Total PEB. Stepwise regression produced the most efficient model for prediction using the least number of parameters. It is likely that due to the high correlation between town belt visitation and visitation to city walking tracks, only one of these variables was included. Sports field visitation, as predicted by the literature, was the weakest contributor and thus excluded from the model. Table 30 summarises the models tested, with four steps of inclusion occurring before termination. 
Table 30: Output table from forward selection linear regression with Total PEB as the dependent and the six urban green space variables as predictors. Four steps are shown before termination.

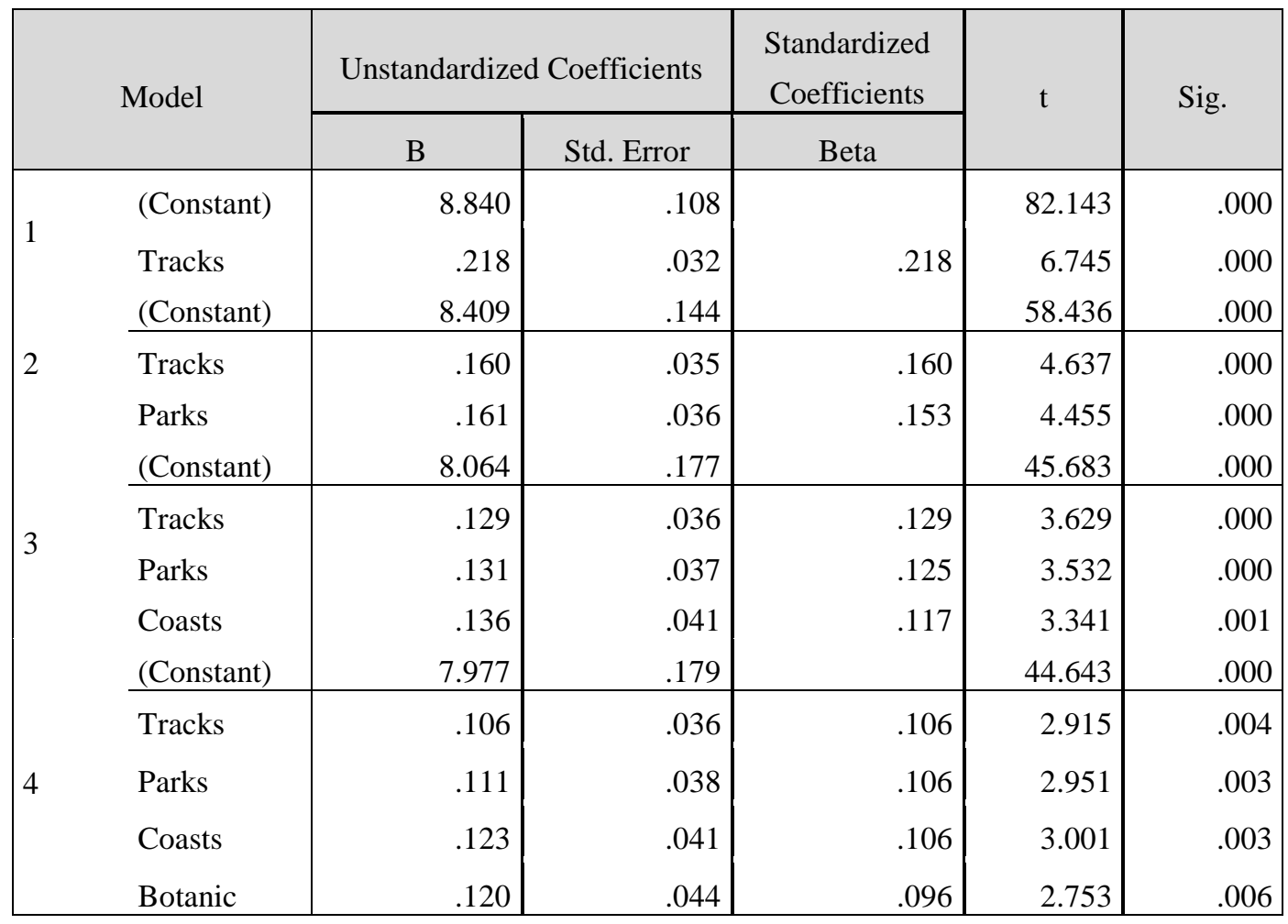

a. Dependent Variable: Total PEB

In summary, I can conclude there is a relationship between urban green space visitation and pro-environmental behaviour. After breaking down the variable, Total UGS, into its six separate types and combining those urban green spaces with similar physical characteristics, vegetated spaces (botanic gardens, city walking tracks, town belt, parks) showed the strongest $t$ statistic for the $\beta$ coefficient and the greatest $\mathrm{R}^{2}$, suggesting these urban green spaces to be the most effective predictors of pro-environmental behaviour relative to coasts and harbours, and sports fields. The best combination of urban green space variables for pro-environmental behaviour prediction omits visitation to sports fields and the town belt. 


\subsection{Analysis by Urban Green Space Type and Pro-Environmental Behaviour Type}

"Does the relationship between urban green space visitation and pro-environmental behaviour change depending on the type of urban green space and the type of pro-environmental behaviour measured?"

Section 3.2 sought to determine whether visitation to certain urban green spaces was more strongly correlated with certain forms of pro-environmental behaviour relative to others. The literature lead me to hypothesise that frequent visits to the coasts would be more strongly correlated with pro-environmental behaviours related to water pollution (e.g., washing paint/chemicals down household sinks), compared to pro-environmental behaviours with a more terrestrial impact (e.g., putting litter in the bin, recycling). Cross tabulation analysis was first performed (table 31$)$. The Total UGS binary variable $(1=$ visitation once a month or less, $0=$ visitation less than once a month) was used to determine the conditional probabilities of performing each pro-environmental behaviour.

Table 31: Cross tabulation table displaying conditional probabilities of performing home composting (1.00) or not (.00) and visiting the town belt once a month or more (1.00) or less than once a month (.00).

\begin{tabular}{|c|c|c|c|c|c|}
\hline & & & \multirow{2}{*}{\multicolumn{2}{|c|}{ Town Belt Visitation }} & \multirow{3}{*}{ Total } \\
\hline & & & & & \\
\hline & & & .00 & 1.00 & \\
\hline \multirow{6}{*}{$\begin{array}{l}\text { Home } \\
\text { Composting }\end{array}$} & \multirow{3}{*}{.00} & Count & 345 & 118 & 463 \\
\hline & & $\%$ within Town Belt & $53.1 \%$ & $41.4 \%$ & $49.5 \%$ \\
\hline & & $\%$ of Total & $36.9 \%$ & $12.6 \%$ & $49.5 \%$ \\
\hline & \multirow{3}{*}{1.00} & Count & 305 & 167 & 472 \\
\hline & & $\begin{array}{l}\% \text { within Town Belt } \\
\text { visitation }\end{array}$ & $46.9 \%$ & $58.6 \%$ & $50.5 \%$ \\
\hline & & $\%$ of Total & $32.6 \%$ & $17.9 \%$ & $50.5 \%$ \\
\hline
\end{tabular}

The conditional probability that an individual performed home composting and visited the town belt once a month or more was $11.7 \%$ higher than the conditional probability of performing home composting and visiting the town belt less than once a month (58.6 - 46.9). The association was statistically significant. People are more likely to perform home composting if they visit the town belt at least once a month. From all cross tabulations, those returning a $\mathrm{p}$ value of $<0.05$ were subjected to binary logistic regression with the odds ratios presented in table 32. 
Table 32: Table of statistically significant odds ratios from independent binary logistic regression of pro-environmental behaviour and urban green space visitation. A binary variable for urban green space was used (.00 indicating visitation less than once a month, 1.00 indicating visitation once a month or more). Statistically significant odds ratios are denoted by $*$ and $* *$ in accordance with significance level. Odds ratios interpreted as the increase in odds of proenvironmental associated with urban green space visitation once a month or more. Blank cells indicate no statistical association.

\begin{tabular}{|c|c|c|c|c|c|c|}
\hline & $\begin{array}{l}0 \\
\tilde{\pi} \\
0 \\
0\end{array}$ & 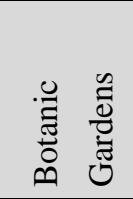 & $\frac{\tilde{y}}{\tilde{a}}$ & $\begin{array}{l}\text { 러 } \\
\infty \\
\text { E } \\
0\end{array}$ & 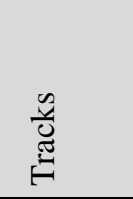 & $\begin{array}{l}\frac{y}{0} \\
0 \\
0 \\
0 \\
0 \\
0 \\
0\end{array}$ \\
\hline Home composting & & $1.429 *$ & $1.419 * *$ & $1.601 * *$ & $1.415^{*}$ & \\
\hline $\begin{array}{l}\text { Using Council's kerbside } \\
\text { recycling service }\end{array}$ & & 1.742 & $1.700 *$ & & $1.980 * *$ & \\
\hline $\begin{array}{l}\text { Taking things to the } \\
\text { recycling stations }\end{array}$ & $1.618 * *$ & $1.627 * *$ & $1.661 * *$ & $1.467 * *$ & $1.862 * *$ & $1.854 * *$ \\
\hline $\begin{array}{l}\text { Donating things to } 2 \text { nd hand } \\
\text { shops or charities }\end{array}$ & $1.555^{*}$ & $1.816^{*}$ & $1.554 *$ & & & $1.916^{*}$ \\
\hline Buying refills & $1.425^{*}$ & & $1.440 *$ & $1.481 *$ & & \\
\hline $\begin{array}{l}\text { Avoiding using plastic } \\
\text { bottles or bags }\end{array}$ & & & $1.375^{*}$ & $1.543 * *$ & & \\
\hline Reusing plastic containers & $1.720 * *$ & & & & & \\
\hline $\begin{array}{l}\text { Responsible disposal of oil, } \\
\text { paint or chemicals }\end{array}$ & $1.401 *$ & $1.434 *$ & & & $1.455^{*}$ & \\
\hline Washing paint brushes inside & & $1.388 *$ & $1.403 * *$ & & $1.421 *$ & $1.486^{*}$ \\
\hline $\begin{array}{l}\text { Pouring household waste } \\
\text { down inside sinks etc. }\end{array}$ & $1.609 * *$ & & $1.558 * *$ & & & \\
\hline Put litter in bin & No statis & ally signi & ant associ & & & \\
\hline Pick up dog droppings & & & $1.340^{*}$ & $1.515^{* *}$ & $1.675^{* *}$ & $1.073^{*}$ \\
\hline $\begin{array}{l}\text { Put sweepings out with } \\
\text { rubbish or compost }\end{array}$ & & & & & $1.394 *$ & \\
\hline $\begin{array}{l}\text { Wash car on lawn or at } \\
\text { carwash }\end{array}$ & & $1.413^{*}$ & & & & \\
\hline
\end{tabular}

** Significance at 0.01 level

* Significance at 0.05 level 
When cross tabulations were performed without recoding of urban green space visitation to represent two categories (i.e., the original eight categories were retained), the significant Pearson chi squares returned are denoted in table 33, below. The issue with such a disaggregation is that some of the cells have insufficient values $(<5)$ meaning an assumption of the chi-square test is violated. For the associations listed in table 33 regarding home composting, home composting is statistically significant for its association with visitation to botanic gardens, town belt, and tracks $(\mathrm{p}=0.01,0.003$, 0.000, respectively). The likelihood that someone performs home composting differs depending on the level at which that individual visits botanic gardens, town belt, and tracks.

The calculations in table 33 described whether a particular urban green space was statistically associated with a particular type of pro-environmental behaviour. I predicted that for the water pollution minimisation behaviours (right hand column) there would be a statistically significant association with visitation to coasts. I also predicted the resource and waste consumption based behaviours (left hand column) would be more associated with vegetated urban green space visitation (botanics, parks, town belt, tracks). While there was statistical association between coast visitation and water pollution minimisation behaviours, the association was not exclusive meaning there was also statistical association present between water based pro-environmental behaviours and vegetated urban green space visitation (e.g., washing a car at a carwash or on the lawn and visitation to parks). 
Table 33: Significant Pearson chi squares from cross-tabulation analysis using urban green space visitation (with eight visitation categories retained) and pro-environmental behaviour. Each cross-tabulation compared one urban green space type with one pro-environmental behaviour. Statistically significant associations are indicated $*$.

\begin{tabular}{|c|c|c|c|c|}
\hline Home Composting & $P$ value & $\mathbf{N}$ & $P$ value & Resp. chem. disposal \\
\hline $\begin{array}{l}\text { Coasts } \\
\text { Botanic } \\
\text { Parks } \\
\text { Town Belt } \\
\text { Tracks } \\
\text { Sports Fields }\end{array}$ & $\begin{array}{l}0.09 \\
0.01 * * \\
0.157 \\
0.003^{* *} \\
0.000^{* *} \\
0.261\end{array}$ & $\begin{array}{l}969 \\
969 \\
961 \\
935 \\
960 \\
962\end{array}$ & $\begin{array}{l}0.019^{*} \\
0.000^{* *} \\
0.030^{*} \\
0.329 \\
0.035^{*} \\
0.209\end{array}$ & $\begin{array}{l}\text { Coasts } \\
\text { Botanic } \\
\text { Parks } \\
\text { Town Belt } \\
\text { Tracks } \\
\text { Sports Fields }\end{array}$ \\
\hline Kerbside Recycling & $P$ value & $\mathbf{N}$ & $P$ value & Wash paint in inside sink \\
\hline $\begin{array}{l}\text { Coasts } \\
\text { Botanic } \\
\text { Parks } \\
\text { Town Belt } \\
\text { Tracks } \\
\text { Sports Fields }\end{array}$ & $\begin{array}{l}0.141 \\
0.002 * * \\
0.374 \\
0.067 \\
0.002 * * \\
0.906\end{array}$ & $\begin{array}{l}969 \\
969 \\
961 \\
935 \\
960 \\
962\end{array}$ & $\begin{array}{l}0.024^{*} \\
0.329 \\
0.002^{*} \\
0.622 \\
0.009^{* *} \\
0.040^{*}\end{array}$ & $\begin{array}{l}\text { Coasts } \\
\text { Botanic } \\
\text { Parks } \\
\text { Town Belt } \\
\text { Tracks } \\
\text { Sports Fields }\end{array}$ \\
\hline Using recycling stations & $P$ value & $\mathbf{N}$ & $P$ value & Liquid waste inside sink \\
\hline $\begin{array}{l}\text { Coasts } \\
\text { Botanic } \\
\text { Parks } \\
\text { Town Belt } \\
\text { Tracks } \\
\text { Sports Fields }\end{array}$ & $\begin{array}{l}0.002^{* *} \\
0.015^{* *} \\
0.000^{* *} \\
0.004^{* *} \\
0.000^{* *} \\
0.000^{* *}\end{array}$ & $\begin{array}{l}969 \\
969 \\
961 \\
935 \\
960 \\
962\end{array}$ & $\begin{array}{l}0.006^{* *} \\
0.764 \\
0.008^{* *} \\
0.157 \\
0.062 \\
0.514\end{array}$ & $\begin{array}{l}\text { Coasts } \\
\text { Botanic } \\
\text { Parks } \\
\text { Town Belt } \\
\text { Tracks } \\
\text { Sports Fields }\end{array}$ \\
\hline Donating & $P$ value & $\mathbf{N}$ & $P$ value & Litter in bin \\
\hline $\begin{array}{l}\text { Coasts } \\
\text { Botanic } \\
\text { Parks } \\
\text { Town Belt } \\
\text { Tracks } \\
\text { Sports Fields }\end{array}$ & $\begin{array}{l}0.146 \\
0.085 \\
0.106 \\
0.047 * \\
0.675 \\
0.343\end{array}$ & $\begin{array}{l}969 \\
969 \\
961 \\
935 \\
960 \\
962\end{array}$ & $\begin{array}{l}0.826 \\
0.125 \\
0.622 \\
0.989 \\
0.831 \\
0.491\end{array}$ & $\begin{array}{l}\text { Coasts } \\
\text { Botanic } \\
\text { Parks } \\
\text { Town Belt } \\
\text { Tracks } \\
\text { Sports Fields }\end{array}$ \\
\hline Buying Refills & $P$ value & $\mathbf{N}$ & P value & Pick up dog droppings \\
\hline $\begin{array}{l}\text { Coasts } \\
\text { Botanic } \\
\text { Parks } \\
\text { Town Belt } \\
\text { Tracks } \\
\text { Sports Fields }\end{array}$ & $\begin{array}{l}0.050 \\
0.001^{* *} \\
0.014 \\
0.125 \\
0.006^{* *} \\
0.905\end{array}$ & $\begin{array}{l}969 \\
969 \\
961 \\
935 \\
960 \\
962\end{array}$ & $\begin{array}{l}0.831 \\
0.725 \\
0.090 \\
0.022^{*} \\
0.025^{*} \\
0.322\end{array}$ & $\begin{array}{l}\text { Coasts } \\
\text { Botanic } \\
\text { Parks } \\
\text { Town Belt } \\
\text { Tracks } \\
\text { Sports Fields }\end{array}$ \\
\hline Avoiding plastic & $P$ value & $\mathbf{N}$ & $P$ value & Collect sweepings \\
\hline $\begin{array}{l}\text { Coasts } \\
\text { Botanic } \\
\text { Parks } \\
\text { Town Belt } \\
\text { Tracks } \\
\text { Sports Fields }\end{array}$ & $\begin{array}{l}0.062 \\
0.025 \\
0.108 \\
0.083 \\
0.062 \\
0.556\end{array}$ & $\begin{array}{l}969 \\
969 \\
961 \\
935 \\
960 \\
962\end{array}$ & $\begin{array}{l}0.059 \\
0.323 \\
0.274 \\
0.677 \\
0.335 \\
0.613\end{array}$ & $\begin{array}{l}\text { Coasts } \\
\text { Botanic } \\
\text { Parks } \\
\text { Town Belt } \\
\text { Tracks } \\
\text { Sports Fields }\end{array}$ \\
\hline Reusing plastic & $P$ value & $\mathbf{N}$ & $P$ value & Wash car on lawn \\
\hline $\begin{array}{l}\text { Coasts } \\
\text { Botanic } \\
\text { Parks } \\
\text { Town Belt } \\
\text { Tracks } \\
\text { Sports Fields }\end{array}$ & $\begin{array}{l}0.001 * * \\
0.000^{* *} \\
0.202 \\
0.375 \\
0.204 \\
0.853\end{array}$ & $\begin{array}{l}969 \\
969 \\
961 \\
935 \\
960 \\
962\end{array}$ & $\begin{array}{l}0.040^{*} \\
0.267 \\
0.038^{*} \\
0.582 \\
0.480 \\
0.599\end{array}$ & $\begin{array}{l}\text { Coasts } \\
\text { Botanic } \\
\text { Parks } \\
\text { Town Belt } \\
\text { Tracks } \\
\text { Sports Fields }\end{array}$ \\
\hline
\end{tabular}

** Significance at the $1 \%$ level.

* Significance at the 5\% level. 


\section{Binary logistic regression}

Binary logistic regression, with the urban green space types included as categorical variables, was next performed. Visitation was measured in binary form, with .00 indicating visitation less than once a month, and 1.00 indicating visitation once a month or more. It was highly likely that there was multicollinearity here, i.e., the visits are correlated. A correlation matrix was thus produced, see table 34, to show such correlation for the right hand variables. Visitation was statistically correlated in all comparisons and all were positive correlations. Therefore, people who visited one type of urban green space once a month or more were also visiting other types once a month or more. Presence of correlation should be kept in mind when interpreting the results of binary logistic regression, which is performed next.

Table 34: Correlation matrix showing Pearson correlation coefficients for all pairwise comparisons of urban green space visitation variables.

\begin{tabular}{|c|c|c|c|c|c|c|c|}
\hline \multicolumn{2}{|c|}{ Urban Green Space Type } & Coasts & Botanic & Parks & Town Belt & Tracks & Sports \\
\hline Coasts & $\begin{array}{l}\text { Pearson Correlation } \\
\text { Sig. (2-tailed) } \\
\text { N }\end{array}$ & $\begin{array}{r}1 \\
969 \\
\end{array}$ & & & & & \\
\hline Botanic & $\begin{array}{l}\text { Pearson Correlation } \\
\text { Sig. (2-tailed) } \\
\mathrm{N}\end{array}$ & $\begin{array}{r}.268 * * \\
.000 \\
969\end{array}$ & $\begin{array}{r}1 \\
969\end{array}$ & & & & \\
\hline Parks & $\begin{array}{l}\text { Pearson Correlation } \\
\text { Sig. (2-tailed) } \\
\mathrm{N}\end{array}$ & $\begin{array}{r}.347 * * \\
.000 \\
961 \\
\end{array}$ & $\begin{array}{r}.322 * * \\
.000 \\
961 \\
\end{array}$ & $\begin{array}{r}1 \\
961 \\
\end{array}$ & & & \\
\hline $\begin{array}{l}\text { Town } \\
\text { Belt }\end{array}$ & $\begin{array}{l}\text { Pearson Correlation } \\
\text { Sig. (2-tailed) } \\
\mathrm{N} \\
\end{array}$ & $\begin{array}{r}.362 * * \\
.000 \\
935 \\
\end{array}$ & $\begin{array}{r}.333 * * \\
.000 \\
935 \\
\end{array}$ & $\begin{array}{r}.347 * * \\
.000 \\
928 \\
\end{array}$ & $\begin{array}{r}1 \\
935 \\
\end{array}$ & & \\
\hline Tracks & $\begin{array}{l}\text { Pearson Correlation } \\
\text { Sig. (2-tailed) } \\
\mathrm{N}\end{array}$ & $\begin{array}{r}.352 * * \\
.000 \\
960 \\
\end{array}$ & $\begin{array}{r}.342 * * \\
.000 \\
960 \\
\end{array}$ & $\begin{array}{r}.371 * * \\
.000 \\
954 \\
\end{array}$ & $\begin{array}{r}.639 * * \\
.000 \\
927 \\
\end{array}$ & $\begin{array}{r}1 \\
960 \\
\end{array}$ & \\
\hline $\begin{array}{l}\text { Sports } \\
\text { Fields }\end{array}$ & $\begin{array}{l}\text { Pearson Correlation } \\
\text { Sig. (2-tailed) } \\
\mathrm{N}\end{array}$ & $\begin{array}{r}.180 * * \\
.000 \\
962 \\
\end{array}$ & $\begin{array}{r}.081 * \\
.012 \\
962 \\
\end{array}$ & $\begin{array}{r}.356^{* *} \\
.000 \\
956 \\
\end{array}$ & $\begin{array}{r}.172 * * \\
.000 \\
930 \\
\end{array}$ & $\begin{array}{r}.178 * * \\
.000 \\
955 \\
\end{array}$ & $\begin{array}{r}1 \\
962 \\
\end{array}$ \\
\hline
\end{tabular}

**. Correlation is significant at the 0.01 level (2-tailed).

*. Correlation is significant at the 0.05 level (2-tailed).

While cross tabulations have provided useful information regarding the conditional probabilities of performing a pro-environmental behaviour, logistic regression allows all the urban green space visitation variables to be included in a model and controlled for 
which minimises their effect on the result of the test. For example, controlling for the effects of visitation to coasts, parks, town belt, sports fields, and botanic gardens allows the influence of track visitation on a pro-environmental behaviour (e.g., home composting) to be more accurately represented by the odds ratio. Recall that the odds ratio represents the odds an individual will perform pro-environmental behaviour if they visit urban green space once a month or more, compared to the odds of performing proenvironmental behaviour if they do not visit once a month or more.

I next describe the relationship between visitation to urban green space (by type) and each of the fourteen pro-environmental behaviours measured.

- Taking things to the recycling station

Controlling for visitation to all other urban green space types, visitation to city walking tracks and sports fields once a month or more were the only statistically significant contributors to the model predicting the pro-environmental behaviour, taking things to the recycling station ( $p<0.05$ and $<0.01$, respectively). Visiting city walking tracks once a month or more increased the odds an individual takes things to the recycling station by $56.7 \%$. Visiting sports fields once a month or more increased the odds an individual takes things to recycling stations by $55.9 \%$. Biophilia theory lead me to predict there to be a positive association between urban green space visitation and pro-environmental behaviour, so it was not surprising visitation to tracks increased the odds someone takes things to recycling stations. However, it was surprising that visiting sports fields contributed more to the prediction of taking things to recycling stations than more vegetated spaces, such as the town belt or botanic gardens. The results tell me that visiting sports fields, despite their relative lack of vegetated characteristics, still increases the odds of an individual taking things to recycling stations.

Using the principle of compatibility, it was posited that visitation to sports fields was picking up on the all-round visitation habits of respondents as the principle allows me to assume those active in sport are also active in the outdoors, with sports field visitation picking up on such a correlation. However, the correlation matrix (see table 34) reported a weak correlation between sports field visitation and all urban green space types (there is the exception of park visitation, expected with sports fields potentially being interpreted as parks). Perhaps the nature of taking things to recycling stations, involving physical movement is biased towards those who are more mobile and active, and possibly younger; hence the association with sports field visitors. 
- Avoiding using plastic bottles or bags

Controlling for visitation to all other urban green spaces, only visitation to the town belt once a month or more was a statistically significant contributor to the model predicting the pro-environmental behaviour, avoiding using plastic bottles or bags. The odds that someone avoids using plastic bottles or bags increased by $45.7 \%$ if they visited the town belt once a month or more. Literature lead me to posit that with greater exposure to vegetation, connection to nature would increase, manifesting in more pro-environmental behaviour. Avoiding plastic bottles or bags is a behaviour requiring minimal effort and financial cost. Biophilia lead me to expect an increase in the odds of avoiding plastic bottles or bags if an individual visited vegetated spaces more frequently, with this expectation supported by my results.

- Pouring all household liquid wastes down an inside sink, toilet or gully trap

Controlling for visitation to all other urban green spaces, visitation to parks once a month or more was a statistically significant contributor to the model predicting pouring household liquid wastes down an inside sink, toilet, or gully trap. If someone visited parks once a month or more the odds that they performed this pro-environmental behaviour increased by $43.7 \%$. With literature stating people are most likely to want to preserve and protect spaces where they feel most strongly connected to, and the principle of compatibility citing behaviours to be strongly correlated within similar domains (i.e., visitation to coasts and water conservation), it was predicted that coastal visitation would be the most significant contributor in the model predicting the performance of this water based pro-environmental behaviour (Tarrant and Green 1999; Azjen 1991). However, it was visitation to parks that turned out to be the best explanatory factor. While the increase in odds of performing this pro-environmental behaviour (from low to high visitation) supports the overarching hypothesis of biophilia, the hypothesis that water based pro-environmental behaviours would be most associated with coastal visitation was not supported.

- $\quad$ Pick up droppings left by dogs:

Controlling for visitation to all other urban green spaces, visitation to city walking tracks once a month or more was the only statistically significant contributor in the model predicting the pro-environmental behaviour, picking up dog droppings. If someone visited city walking tracks once a month or more the odds that they picked up dog droppings increased by $51.8 \%$. Such a result is expected as the odds of 'success' 
(here meaning responding 'yes' to the question, 'do you pick up dog droppings?') are going to be much greater if an individual has more opportunity to do so. Visiting parks increases the likelihood that someone will be in the position to pick up dog droppings (as they would likely walk dogs here) thereby skewing the odds of success to be greater for those that visit parks more often. I have to be careful here to not make the conclusion that visitation to parks is associated with the behaviour of picking up dog droppings due to biophilia, but more so that picking up after dogs is a responsibility associated with being a dog walking, park user.

\section{Stepwise logistic regression - forward selection}

Stepwise logistic regression (forward selection) was performed separately for each of the 14 pro-environmental behaviours (14 dependent variables were tested). Similar to the way that forward selection produced the equation for those urban green spaces that best predicted Total PEB, forward selection was used here to find the urban green spaces that best predicted each of the 14 pro-environmental behaviours. While the preceding odds ratio analysis used the binary variables for urban green space visitation, the following analysis used Total UGS.

I hypothesised that coasts would be the best predictor of water based pro-environmental behaviours. For the more terrestrial based pro-environmental behaviours of recycling and avoiding plastic, I predicted vegetated urban green spaces would be better explanatory variables.

Equation 10

Logit $($ Home composting $i)=-0.363+0.092$ Town Belt +0.084 Botanic

(11.153) (8.962)

$$
\mathrm{R}^{2}=0.023 ; \mathrm{N}=918
$$

\section{Equation 11}

Logit(Using Council's kerbside recycling service $\left.{ }_{i}\right)=1.763+0.237$ Botanic

$$
\mathrm{R}^{2}=0.015 ; \mathrm{N}=918
$$

\section{Equation 12}

Logit $\left(\right.$ Taking things to the recycling station $\left.{ }_{i}\right)=-0.652+0.090$ Coasts +0.079 Botanic

+0.101 Tracks +0.103 Sports Fields

$(17.558)(4.609) \quad(4.067)$

(6.573) (10.984)

$\mathrm{R}^{2}=0.053 ; \mathrm{N}=918$. 


\section{Equation 13}

Logit(Donating things to 2 nd hand shops or charities $\left.{ }_{i}\right)=1.779+0.148$ Parks (93.407)(8.855)

$\mathrm{R}^{2}=0.010 ; \mathrm{N}=918$.

\section{Equation 14}

Logit $\left(\right.$ Buying refills $\left.s_{i}\right)=0.921+0.112$ Botanic

$$
\text { (64.502) (6.943) }
$$

$\mathrm{R}^{2}=0.008 ; \mathrm{N}=918$.

Equation 15

Logit(Avoiding using plastic bottles or bags $\left._{i}\right)=0.075+0.093$ Town Belt

(0.707) (9.959)

$\mathrm{R}^{2}=0.011 ; \mathrm{N}=918$

Equation 16

Logit(Reusing plastic containers such as food containers $\left.{ }_{i}\right)=1.504+0.154$ Coasts

(58.297) (9.540)

$\mathrm{R}^{2}=0.010 ; \mathrm{N}=918$

\section{Equation 17}

Logit(Disposing of oil, paint or chemicals by putting them out with your household rubbish or taking them for recycling $i)=0.426+0.110$ Botanic +0.089 Coasts

$$
\text { (7.210) (6.591) (5.643) }
$$

$\mathrm{R}^{2}=0.019 ; \mathrm{N}=918$.

\section{Equation 18}

Logit $\left(\right.$ Washing paint brushes in an inside $\left.\operatorname{sink}_{i}\right)=-0.289+0.077$ Parks +0.062 Tracks

$\mathrm{R}^{2}=0.017 ; \mathrm{N}=918$.

\section{Equation 19}

Logit(Pouring all household liquid wastes down an inside sink, toilet or gully trap p $_{i}$ )

$=0.526+0.127$ Coasts

$(12.104)(12.208)$

$\mathrm{R}^{2}=0.013 ; \mathrm{N}=918$.

\section{Equation 20}

Logit(Pick up droppings left by $\left.\operatorname{dogs}_{i}\right)=-1.201+0.110$ Tracks

(121.939)(12.836)

$\mathrm{R}^{2}=0.014 ; \mathrm{N}=918$.

\section{Equation 21}

Logit(Collect sweepings from your driveway, paths, or yards for composting or for disposal with your household rubbish $\left._{i}\right)=0.382+0.074$ Coasts

$$
\text { (6.829) (4.718) }
$$

$\mathrm{R}^{2}=0.005 ; \mathrm{N}=918$ 


\section{Equation 22}

Logit $\left(\right.$ Wash the car at a carwash or on the $\left.\operatorname{lawn}_{i}\right)=-0.368+0.098$ Botanic (12.997) (7.769)

$$
\mathrm{R}^{2}=0.008 ; \mathrm{N}=918
$$

Coasts was either the best predictor or one of the included predictors for the proenvironmental behaviours, 'responsible disposal of household waste, oil, paint and chemicals down inside sinks, toilets or gully traps', and 'collecting sweepings from property for disposal with household rubbish' (behaviours that prevent pollution entering the storm water system). Furthermore, vegetated urban green spaces (botanics, town belt, and tracks) were retained in the models best predicting the more terrestrial based pro-environmental behaviours of buying refills, avoiding plastic, donating to $2^{\text {nd }}$ hand shops/charities, using council's kerbside recycling service, and home composting.

What I then looked for was a correlation amongst the pro-environmental behaviours themselves. Azjen's (1991) principle of compatibility, which speaks to the findings of Weigel and Newman (1976) where attitudes towards protection of the environment were found to be accurate predictors of pro-environmental behaviours, lead me to expect a positive correlation between those pro-environmental behaviours similar in characteristic. If an individual has an attitude supportive of protecting water quality it is likely they will perform pro-environmental behaviours related to water pollution minimisation (e.g., washing paintbrushes in an inside sink). Is it then true that those proenvironmental behaviours specific to water pollution show equal rates of participation and those to do with waste reduction and resource consumption are also internally correlated? A correlation matrix addresses this question and is displayed below (table $35)$. 
Table 35: Pearson Correlation Coefficients $(\mathrm{P})$ between fourteen pro-environmental behaviours using the concatenated sample. Significance denoted by $*$ for significance at $1 \%$ level and $* *$ for significance at $5 \%$ level.

\begin{tabular}{|c|c|c|c|c|c|c|c|c|c|c|c|c|c|c|c|}
\hline & & 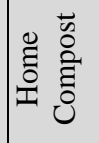 & 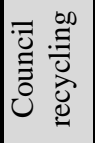 & 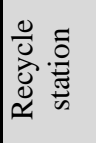 & 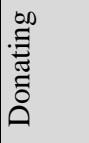 & 禹 & 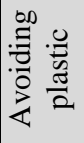 & 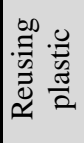 & 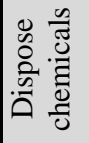 & 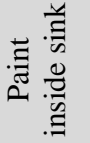 & 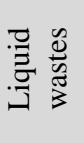 & 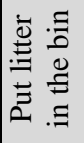 & 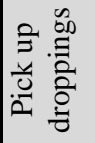 & 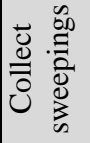 & 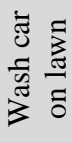 \\
\hline 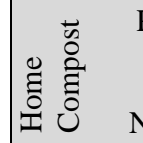 & $\begin{array}{l}\mathrm{P} \\
\mathrm{N}\end{array}$ & $\begin{array}{l}1 \\
969\end{array}$ & & & & & & & & & & & & & \\
\hline 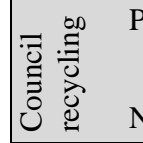 & P & $\begin{array}{l}.180^{* *} \\
.000 \\
969\end{array}$ & 969 & & & & & & & & & & & & \\
\hline 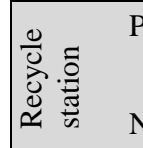 & $\begin{array}{l}\mathrm{P} \\
\mathrm{N}\end{array}$ & $\begin{array}{l}.106^{* *} \\
.001 \\
969\end{array}$ & $\begin{array}{l}.085^{* *} \\
.008 \\
969\end{array}$ & 969 & & & & & & & & & & & \\
\hline 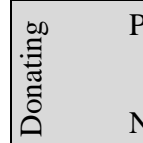 & $\mathrm{N}$ & $\begin{array}{l}.075^{*} \\
.020 \\
969\end{array}$ & $\begin{array}{l}.189^{* *} \\
.000 \\
969\end{array}$ & $\begin{array}{l}.159^{* *} \\
.000 \\
969\end{array}$ & 969 & & & & & & & & & & \\
\hline 些点咅 & $\mathrm{N}$ & $\begin{array}{l}.087^{* *} \\
.007 \\
969\end{array}$ & $\begin{array}{l}.152^{* *} \\
.000 \\
969\end{array}$ & $\begin{array}{l}.076^{*} \\
.019 \\
969\end{array}$ & $\begin{array}{l}.135^{* *} \\
.000 \\
969\end{array}$ & 969 & & & & & & & & & \\
\hline 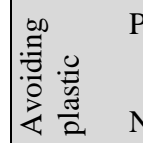 & $\mathrm{N}$ & $\begin{array}{l}.096^{* *} \\
.003 \\
969\end{array}$ & $\begin{array}{l}.091^{* *} \\
.005 \\
969\end{array}$ & $\begin{array}{l}.094^{* *} \\
.003 \\
969\end{array}$ & $\begin{array}{l}.143^{* *} \\
.000 \\
969\end{array}$ & $\begin{array}{l}.142^{* *} \\
.000 \\
969\end{array}$ & 969 & & & & & & & & \\
\hline 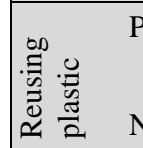 & $\begin{array}{l}\mathrm{P} \\
\mathrm{N}\end{array}$ & $\begin{array}{l}.122^{* *} \\
.000 \\
969\end{array}$ & $\begin{array}{l}.223^{* *} \\
.000 \\
969\end{array}$ & $\begin{array}{l}.119^{* *} \\
.000 \\
969\end{array}$ & $\begin{array}{l}.187^{* *} \\
.000 \\
969\end{array}$ & $\begin{array}{l}.210^{* *} \\
.000 \\
969\end{array}$ & $\begin{array}{l}.107^{* *} \\
.001 \\
969\end{array}$ & $\begin{array}{l}1 \\
969\end{array}$ & & & & & & & \\
\hline 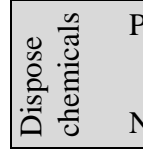 & $\mathrm{N}$ & $\begin{array}{l}.070^{*} \\
.029 \\
969\end{array}$ & $\begin{array}{l}.077^{*} \\
.017 \\
969\end{array}$ & $\begin{array}{l}.179^{* *} \\
.000 \\
969\end{array}$ & $\begin{array}{l}.107^{* *} \\
.001 \\
969\end{array}$ & $\begin{array}{l}.111^{* *} \\
.001 \\
969\end{array}$ & $\begin{array}{l}.047 \\
.141 \\
969\end{array}$ & $\begin{array}{l}.076^{*} \\
.019 \\
969\end{array}$ & 1 & & & & & & \\
\hline 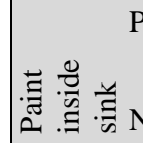 & $\begin{array}{l}\mathrm{P} \\
\mathrm{N}\end{array}$ & $\begin{array}{l}.075^{*} \\
.019 \\
969\end{array}$ & $\begin{array}{l}.079^{*} \\
.014 \\
969\end{array}$ & $\begin{array}{l}.111^{* *} \\
.001 \\
969\end{array}$ & $\begin{array}{l}.027 \\
.399 \\
969\end{array}$ & $\begin{array}{l}.055 \\
.086 \\
969\end{array}$ & $\begin{array}{l}.053 \\
.099 \\
969\end{array}$ & $\begin{array}{l}.008 \\
.792 \\
969\end{array}$ & $\begin{array}{l}.265^{* *} \\
.000 \\
969\end{array}$ & 969 & & & & & \\
\hline 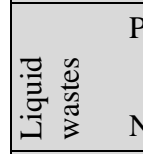 & $\mathrm{N}$ & $\begin{array}{l}.066^{*} \\
.040 \\
969\end{array}$ & $\begin{array}{l}.076^{*} \\
.018 \\
969\end{array}$ & $\begin{array}{l}.011 \\
.721 \\
969\end{array}$ & $\begin{array}{l}.091^{* *} \\
.005 \\
969\end{array}$ & $\begin{array}{l}.101^{* *} \\
.002 \\
969\end{array}$ & $\begin{array}{l}.027 \\
.407 \\
969\end{array}$ & $\begin{array}{l}.098^{* *} \\
.002 \\
969\end{array}$ & $\begin{array}{l}.160^{* *} \\
.000 \\
969\end{array}$ & $\begin{array}{l}.336^{* *} \\
.000 \\
969\end{array}$ & 969 & & & & \\
\hline 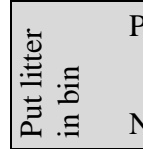 & $\mathrm{N}$ & $\begin{array}{l}.042 \\
.190 \\
969\end{array}$ & $\begin{array}{l}.041 \\
.201 \\
969\end{array}$ & $\begin{array}{l}.024 \\
.460 \\
969\end{array}$ & $\begin{array}{l}.079^{*} \\
.014 \\
969\end{array}$ & $\begin{array}{l}.055 \\
.086 \\
969\end{array}$ & $\begin{array}{l}.023 \\
.478 \\
969\end{array}$ & $\begin{array}{l}.088^{* *} \\
.006 \\
969\end{array}$ & $\begin{array}{l}.074^{*} \\
.020 \\
969\end{array}$ & $\begin{array}{l}.051 \\
.112 \\
969\end{array}$ & $\begin{array}{l}.066^{*} \\
.039 \\
969\end{array}$ & 969 & & & \\
\hline 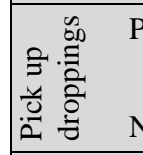 & $\mathrm{N}$ & $\begin{array}{l}.036 \\
.267 \\
969 \\
\end{array}$ & $\begin{array}{l}.074^{*} \\
.020 \\
969\end{array}$ & $\begin{array}{l}.028 \\
.392 \\
969\end{array}$ & $\begin{array}{l}.092^{* *} \\
.004 \\
969 \\
\end{array}$ & $\begin{array}{l}.028 \\
.384 \\
969 \\
\end{array}$ & $\begin{array}{l}-.049 \\
.126 \\
969 \\
\end{array}$ & $\begin{array}{l}.018 \\
.576 \\
969\end{array}$ & $\begin{array}{l}.086^{* *} \\
.007 \\
969\end{array}$ & $\begin{array}{l}.094^{* *} \\
.003 \\
969\end{array}$ & $\begin{array}{l}.091^{* *} \\
.005 \\
969\end{array}$ & $\begin{array}{l}.044 \\
.168 \\
969\end{array}$ & 969 & & \\
\hline 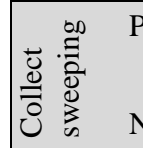 & $\mathrm{N}$ & $\begin{array}{l}.197^{* *} \\
.000 \\
969\end{array}$ & $\begin{array}{l}.107^{* *} \\
.001 \\
969\end{array}$ & $\begin{array}{l}.179^{* *} \\
.000 \\
969\end{array}$ & $\begin{array}{l}.145^{* *} \\
.000 \\
969\end{array}$ & $\begin{array}{l}.104^{* *} \\
.001 \\
969\end{array}$ & $\begin{array}{l}.072^{*} \\
.025 \\
969\end{array}$ & $\begin{array}{l}.057 \\
.076 \\
969\end{array}$ & $\begin{array}{l}.166^{* *} \\
.000 \\
969\end{array}$ & $\begin{array}{l}.013 \\
.684 \\
969\end{array}$ & $\begin{array}{l}.034 \\
.292 \\
969\end{array}$ & $\begin{array}{l}.018 \\
.579 \\
969\end{array}$ & $\begin{array}{l}.085^{* *} \\
.008 \\
969\end{array}$ & 969 & \\
\hline 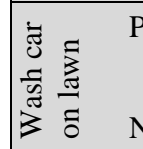 & $\mathrm{P}$ & $\begin{array}{l}.016 \\
.621\end{array}$ & $\begin{array}{l}.030 \\
.358\end{array}$ & $\begin{array}{l}.118^{* *} \\
.000 \\
969\end{array}$ & $\begin{array}{l}.069^{*} \\
.032\end{array}$ & $\begin{array}{l}.046 \\
.152\end{array}$ & $\begin{array}{l}.063 \\
.051\end{array}$ & $\begin{array}{l}.015 \\
.639\end{array}$ & $\begin{array}{l}.058 \\
.073\end{array}$ & $\begin{array}{l}.024 \\
.465\end{array}$ & $\begin{array}{l}.018 \\
.586\end{array}$ & $\begin{array}{l}.042 \\
.196\end{array}$ & $\begin{array}{l}.091^{* *} \\
.005 \\
969\end{array}$ & $\begin{array}{l}.125^{* *} \\
.000 \\
969\end{array}$ & 969 \\
\hline
\end{tabular}


Upon examination of the correlation matrix, the majority of comparisons were significant at either the $1 \%$ or $5 \%$ significance level. All significant correlations were positive, supporting the principle of compatibility. Such a result is encouraging for the biophilia theory as a tool for promoting environmental behaviour change as it suggests that as nature exposure stimulates engagement in one specific pro-environmental behaviour, spill-over could occur, resulting in further pro-environmental behaviour.

Additional support for the principle of compatibility is found in the results which show all pro-environmental behaviours relating to resources and waste (first seven listed) are correlated with each other. Similarly, all behaviours relating to water pollution minimisation (last seven listed) are correlated with each other. However, for the proenvironmental behaviours as a whole, there are a number of pairwise correlations that are not significant meaning that the performance rates of one have no correlation with the performance rates of another, i.e., they are independent. Most noticeably, 'avoiding using plastic bottles or bags' was not significantly correlated to water pollution minimisation behaviours (with the exception of "collecting sweepings and placing with compost or with household rubbish for disposal'). Reusing plastic containers was also not significantly correlated with the majority of the water pollution based behaviours, with the exception of 'pouring household liquid wastes down sink or gully trap', and 'putting litter in the bin rather than dropping it on the street or gutter'.

Pro-environmental behaviour is positively associated with urban green space visitation. While vegetated spaces and coasts are better than sports fields at predicting proenvironmental behaviour, there is not one type of urban green space that is obviously better at predicting pro-environmental behaviour on its own. While there was correlation found amongst pro-environmental behaviours of similar types, this correlation was not mirrored by a stronger association between water based proenvironmental behaviours and coast visitation.

The next step was to include socio-demographic variables in order to ascertain whether such factors moderate how urban green space visitation predicts pro-environmental behaviour and whether there exists any significant interactions. 


\subsection{Analysis by Socio-Demographic Variables}

"How do socio-demographic factors (gender, age, household income) moderate the relationship between urban green space visitation and pro-environmental behaviour?"

There is evidence in the literature highlighting the influence of socio-demographics on pro-environmental behaviour performance (Diamantopoulos et al., 2003, Torgler and Garcia-Valiñas, 2007). What is lacking, however, is research outlining how the sociodemographic characteristics of people could moderate biophilia. I hypothesised that females would show a stronger and steeper association between urban green space visitation and pro-environmental behaviour due to literature suggesting females to be more susceptible to the emotional responses being in nature evokes (Millar and Millar, 1996). I also posited that older individuals would show a stronger relationship between urban green space visitation and pro-environmental behaviour due to having less external commitments (such as children and a job) making them more able to acknowledge and act on the emotional responses being in nature instils. Additionally, I expected those on a higher income would show a stronger association between urban green space visitation and pro-environmental behaviour as they are less financially stressed and have a greater opportunity to act on any biophilic reactions gained from nature exposure - following the predictions of the affluence hypothesis (Givens and Jorgenson, 2011).

In addition to socio-demographic variables I also introduced an attitudinal variable, pride. It has been shown that pride helps predict intentions for favouring environmental protection (Harth et al., 2013b) and can motivate pro-environmental behaviour (Ferguson and Branscombe, 2010). It may be the case that the association between urban green space visitation and pro-environmental behaviour is stronger in those that hold more pride in the way the city looks and feels, as behaviour change to protect and preserve the environment works more effectively when attitudes in line with such behaviour are present. It was thus predicted that pride would act as a moderator. Additionally, similar to the role of income and following the affluence hypothesis, quality of life was predicted to act as a moderator, with those with a greater quality of life being more likely to respond to biophilia. 


\subsubsection{Gender}

Table 36: Frequency table showing distribution of male and female respondents using the concatenated sample.

\begin{tabular}{|rl|r|r|r|r|}
\hline & Frequency & Percent & Valid Percent & \multicolumn{2}{c|}{$\begin{array}{c}\text { Cumulative } \\
\text { Percent }\end{array}$} \\
\hline \multirow{4}{*}{ Valid } & Male & 431 & 44.5 & 44.5 & 44.5 \\
& Female & 538 & 55.5 & 55.5 & 100.0 \\
& Total & 969 & 100.0 & 100.0 & \\
\hline
\end{tabular}

When I restricted the sample to females, cross tabulation analysis (see table 37, below) showed a female who visited urban green space at least once a year was $23.9 \%$ more likely to perform more than seven pro-environmental behaviours relative to a female who did not visit urban green space at all. When the analysis was restricted to males only, the increase in likelihood of performing more than seven pro-environmental behaviours from non-visitors to visitors was only 9.5\%. There appears to be a significant difference in the influence of urban green space visitation on proenvironmental behaviour between male and females, corroborated by evidence in the literature pertaining to females being more emotionally influenced by nature exposure.

Table 37: Cross tabulation table displaying conditional probabilities of performing more than seven pro-environmental behaviours (Total PEB binary $=1.00$ ) and visiting urban green space at least once a year (Total UGS Yes or No $=1.00$ ) for male and female respondents separately.

\begin{tabular}{|c|c|c|c|c|c|c|}
\hline \multirow{2}{*}{\multicolumn{4}{|c|}{ Gender }} & \multicolumn{2}{|c|}{ Total UGS Yes or No } & \multirow{2}{*}{ Total } \\
\hline & & & & .00 & 1.00 & \\
\hline \multirow{4}{*}{ Male } & \multirow{4}{*}{$\begin{array}{l}\text { Total PEB } \\
\text { binary }\end{array}$} & & Count & 2 & 101 & 103 \\
\hline & & .00 & $\%$ within Total UGS Yes or & $33.3 \%$ & $23.8 \%$ & $23.9 \%$ \\
\hline & & & Count & 4 & 324 & 328 \\
\hline & & 1.00 & $\begin{array}{l}\% \text { within Total UGS Yes or } \\
\text { No }\end{array}$ & $66.7 \%$ & $76.2 \%$ & $76.1 \%$ \\
\hline \multirow{4}{*}{ Female } & \multirow{4}{*}{$\begin{array}{l}\text { Total PEB } \\
\text { binary }\end{array}$} & & Count & 6 & 84 & 90 \\
\hline & & & $\begin{array}{l}\% \text { within Total UGS Yes or } \\
\text { No }\end{array}$ & $40.0 \%$ & $16.1 \%$ & $16.7 \%$ \\
\hline & & & Count & 9 & 439 & 448 \\
\hline & & 1.00 & $\begin{array}{l}\% \text { within Total UGS Yes or } \\
\text { No }\end{array}$ & $60.0 \%$ & $83.9 \%$ & $83.3 \%$ \\
\hline
\end{tabular}


After performing binary logistic regression I found a female who visited urban green space at least once a year was 3.484 times more likely to perform more than seven proenvironmental behaviours than a female who did not visit urban green space at all (Wald $=5.336 ; \mathrm{p} 0.021 ; \mathrm{N}=538$ ). Visitation to urban green space at least once a year was a non-significant predictor for the male sample $(\mathrm{p}=0.589)$.

\section{Equation 23}

$$
\begin{aligned}
& \text { Logit }\left(\text { More than } 7 \mathrm{PEBs}_{\mathrm{i}} \text { female }\right)= \\
& \qquad \begin{array}{l}
(0.595)(1.248 \text { Total UGS Yes or No } \\
(0.021)
\end{array} \\
& \mathrm{R}^{2}=0.009 ; \text { Odds Ratio }=3.484 ; \mathrm{N}=538 .
\end{aligned}
$$

\section{Equation 24}

Logit $\left(\right.$ More than $\left.7 \mathrm{PEBS}_{\mathrm{i} \text { male }}\right)=0.693+0.472$ Total UGS Yes or No

$$
\text { (0.641) (0.293) }
$$

$$
\mathrm{R}^{2}=0.001 ; \text { Odds Ratio }=1.604 ; \mathrm{N}=431 \text {. }
$$

Importantly, when I used the binary variable, Total UGS Yes or No, there were few responses for no visitation (six males, 15 females). Using the binary variable for visitation (Total UGS binary) increased these numbers to avoid violation of assumptions of the chi square test (cells must have a minimum value of five). The resulting cross tabulation is shown in table 38 with equations $25-26$, displaying the results of logistic regression. Males who visited urban green space once a month or more were $8.9 \%$ more likely to perform more than seven pro-environmental behaviours. Females were $11.5 \%$ more likely. Binary logistic regression reported when urban green space visitation was held constant; being female was still a significant predictor of whether an individual performs more than seven pro-environmental behaviours. Females who visited urban green space more than once a month were 2.859 times more likely to perform more than seven pro-environmental behaviours than those who visited less (Wald $=8.133 ; \mathrm{P}$ 0.004; $\mathrm{N}=538$ ) (equation 25). The odds of a male who visits urban green space once a month or more performing more than seven pro-environmental behaviours was 1.685 times the odds of a male who visited less (equation 26). 
Table 38: Cross tabulation table displaying conditional probabilities of performing more than seven pro-environmental behaviours (Total PEB binary $=1.00$ ) and visiting urban green space once a month or more (Total UGS binary $=1.00$ ) for male and female respondents separately.

\begin{tabular}{|c|c|c|c|c|c|c|}
\hline \multirow{2}{*}{\multicolumn{4}{|c|}{ Gender }} & \multicolumn{2}{|c|}{ Total UGS binary } & \multirow{2}{*}{ Total } \\
\hline & & & & .00 & 1.00 & \\
\hline \multirow{4}{*}{ Male } & \multirow{4}{*}{$\begin{array}{l}\text { Total PEB } \\
\text { binary }\end{array}$} & 00 & \multirow{4}{*}{$\begin{array}{l}\text { Count } \\
\% \text { within Total UGS binary } \\
\text { Count } \\
\% \text { within Total UGS binary }\end{array}$} & \multirow{4}{*}{$\begin{array}{l}81 \\
26.5 \% \\
225 \\
73.5 \% \\
\end{array}$} & \multirow{4}{*}{$\begin{array}{l}22 \\
17.6 \% \\
103 \\
82.4 \% \\
\end{array}$} & 103 \\
\hline & & .00 & & & & $23.9 \%$ \\
\hline & & 100 & & & & 328 \\
\hline & & 1.00 & & & & $76.1 \%$ \\
\hline \multirow{4}{*}{ Female } & \multirow{4}{*}{$\begin{array}{l}\text { Total PEB } \\
\text { binary }\end{array}$} & & \multirow{4}{*}{$\begin{array}{l}\text { Count } \\
\% \text { within Total UGS binary } \\
\text { Count } \\
\% \text { within Total UGS binary }\end{array}$} & \multirow{4}{*}{$\begin{array}{l}81 \\
19.2 \% \\
340 \\
80.8 \%\end{array}$} & \multirow{4}{*}{$\begin{array}{l}9 \\
7.7 \% \\
108 \\
92.3 \%\end{array}$} & 90 \\
\hline & & .00 & & & & $16.7 \%$ \\
\hline & & & & & & 448 \\
\hline & & 1.00 & & & & $83.3 \%$ \\
\hline
\end{tabular}

\section{Equation 25}

Logit $($ More than seven PEBs ifemale $)=1.434+1.050$ Total UGS binary

$$
(134.611)(8.133)
$$

$\mathrm{R}^{2}=0.019 ; \mathrm{N}=538$

Odds Ratio $=2.859$ (the odds that a female who visits urban green space once a month or more performs more than seven pro-environmental behaviours is 2.859 times the odds of a female who visits UGS less than once a month).

\section{Equation 26}

Logit $\left(\right.$ More than seven PEBs $\left.i_{\text {male }}\right)=1.022+0.522$ Total UGS binary

$$
\text { (62.166) (3.787) }
$$

$\mathrm{R}^{2}=0.009 ; \mathrm{N}=431$

Odds Ratio $=1.685$ (the odds that a male who visits urban green space once a month or more performs more than seven pro-environmental behaviours is 1.685 times the odds of a male who visits less than once a month)

With evidence to suggest females are more likely to be influenced into proenvironmental behaviour through nature exposure, a scatterplot of Total PEB by Total UGS was produced to illustrate how the relationship differs between men and women (see figure 8). Linear regression equations were also conducted to report the relative coefficients in order to determine whether being female means urban green space visitation has a different influence on pro-environmental behaviour (equations 27 and 28). 


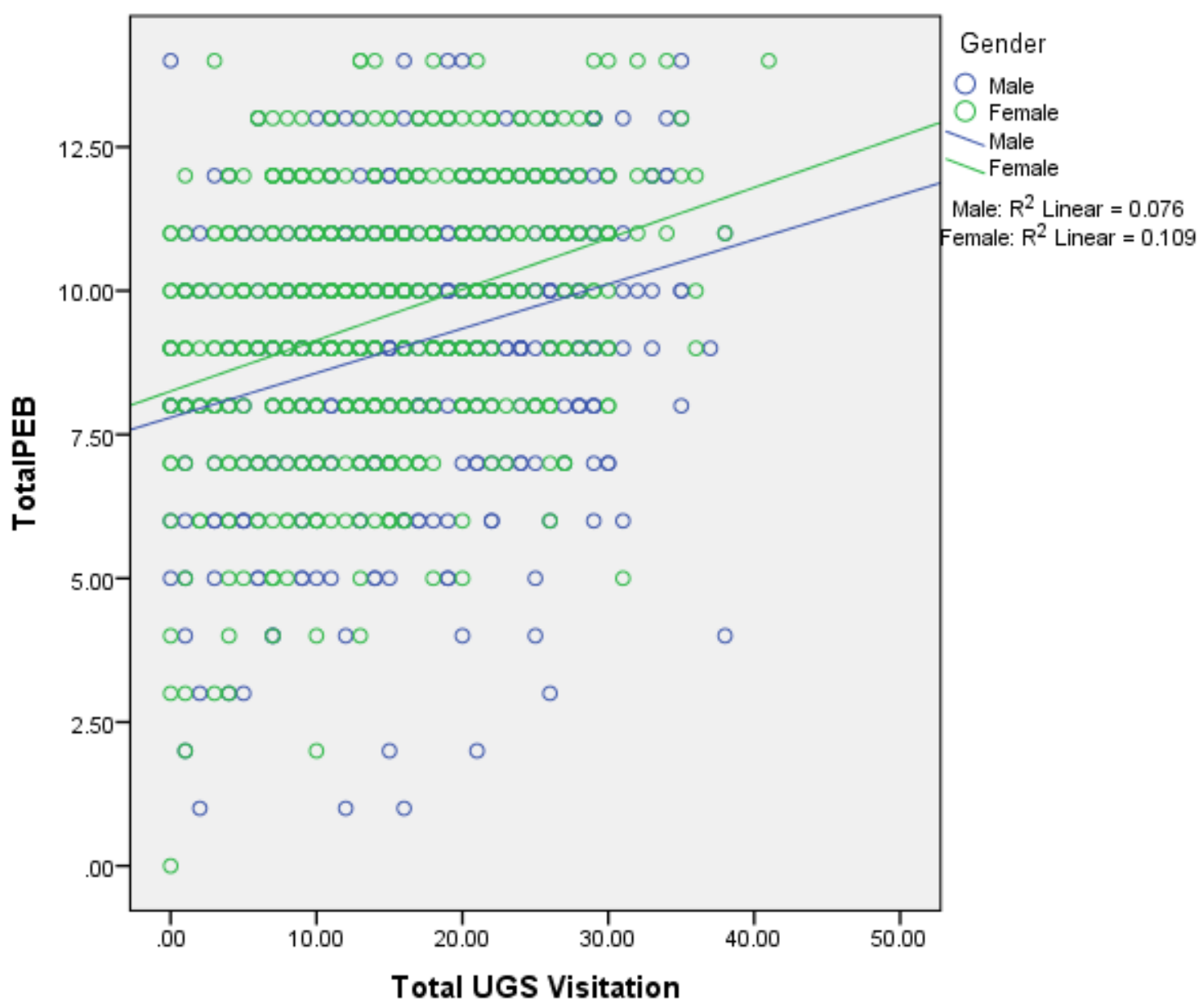

Figure 8: Linear relationship between pro-environmental behaviour (measured as a score out of 14) as a function of urban green space visitation (measured as a combined score for visitation to six urban green space types). Linear trend lines fitted for the subgroups of gender.

\section{Equation 27}

Total $\mathrm{PEB}_{i}($ Female $)=8.254+0.089$ Total UGS $\quad \mathrm{R}^{2}=0.109 ; \mathrm{N}=507$

$$
\text { (43.135) (7.868) }
$$

\section{Equation 28}

$$
\begin{aligned}
\text { Total } \mathrm{PEB}_{i}(\text { Male }) & =7.797+0.077 \text { Total UGS } & \mathrm{R}^{2}=0.076 ; \mathrm{N}=409 \\
& (30.902)(5.808) &
\end{aligned}
$$

The $t$ statistic for the $\beta$ coefficient associated with Total UGS was slightly larger in the female sample suggesting this linear model may more accurately account for variance in Total PEB relative to males. The slightly larger coefficient for urban green space visitation for the female sample suggests that for every one unit increase in urban green 
space visitation, females exhibit a stronger increase in pro-environmental behaviour (0.089 > 0.077). Urban green space visitation was a significant variable for both samples $(\mathrm{p}<0.01)$.

There is an alternative way of looking at the influence of gender. While my preceding analysis did produce useful results, the partitioning of the data reduced the sample size and resulted in a different sample size for the male and female tests. Dummy variables and interaction terms were used to overcome this issue and determine whether gender moderated the relationship.

\section{Dummy variable analysis}

When the gender variable was included in the model, the model was more accurate at predicting Total PEB. The equation below sets out the gender difference in probability of performing more than seven pro-environmental behaviours (if someone visited urban green space once a month or more).

\section{Equation 29}

$$
\begin{aligned}
& \text { More than seven PEBs } \mathrm{s}_{i}=\begin{array}{c}
0.107+0.071 \text { Total } \mathrm{UGS}+0.560 \text { Female } \\
(0.297)(42.362)
\end{array} \\
& \mathrm{R}^{2}=0.056 ; \mathrm{N}=918
\end{aligned}
$$

By incorporating gender as a dummy variable I was able to infer whether, after controlling for urban green space visitation, being a female influenced the likelihood of performing more than seven pro-environmental behaviours. The $\beta$ coefficient was 0.560 meaning that being female increased the likelihood of a 'success' (performing more than seven pro-environmental behaviours) by 0.56. Controlling for urban green space visitation, the odds of a female performing more than seven pro-environmental behaviours was 1.75 times the odds of a male. Both gender and urban green space visitation were significant in the model. Such a result was to be expected with the literature stating females to be more likely to perform pro-environmental behaviour.

However, such equations do not tell me whether being a female actually changes the influence of urban green space on pro-environmental behaviour. To test this, an interaction term (UGS*Female) was created. Logistic regression was again performed with the equation as follows. 


\section{Equation 30}

More than seven PEBs $s_{i}=0.198+0.064$ Total UGS +0.381 Female +0.014 Total

UGS*Gender

(0.667) (19.234) (1.352) (0.411)

$\mathrm{R}^{2}=0.056 ; \mathrm{N}=918$.

When main effects of Total UGS and gender were include, as well as the interaction term, both gender and the interaction term were shown to be insignificant in the model predicting more than seven pro-environmental behaviours $(\mathrm{p}=0.245$ and 0.522 , respectively). Therefore, there was no significant interaction between gender and urban green space visitation in predicting pro-environmental behaviour; therefore there is no statistically significant moderation.

\subsubsection{Age}

Table 39: Frequency table showing the distribution of responses using the concatenated sample across the five categories of age.

\begin{tabular}{|c|c|c|c|c|c|}
\hline & & Frequency & Percent & Valid Percent & $\begin{array}{l}\text { Cumulative } \\
\text { Percent }\end{array}$ \\
\hline \multirow{6}{*}{ Valid } & $15-24$ & 121 & 12.5 & 12.5 & 12.5 \\
\hline & $25-39$ & 250 & 25.8 & 25.8 & 38.3 \\
\hline & $40-59$ & 375 & 38.7 & 38.7 & 77.0 \\
\hline & $60-64$ & 77 & 7.9 & 7.9 & 84.9 \\
\hline & $65+$ & 146 & 15.1 & 15.1 & 100.0 \\
\hline & Total & 969 & 100.0 & 100.0 & \\
\hline
\end{tabular}

There is evidence in the literature suggesting older individuals perform more proenvironmental behaviour. Additionally, there is evidence illustrating how children who have had more nature exposure are more emotionally attached to the environment, with those growing up in rural areas more likely to perform pro-environmental behaviour as adults. Is it then true that older individuals show a stronger relationship between urban green space visitation and pro-environmental behaviour as they may have had more nature exposure over time to foster biophilia? To gain a better understanding of how urban green space visitation influences pro-environmental behaviour across the older and younger age groups, I first conducted cross tabulation analysis (see table 40) to outline the conditional probabilities of performing more than seven pro-environmental behaviours for under and over 40 year olds. ${ }^{7}$

\footnotetext{
${ }^{7}$ Such a division reflects a categorical split whereby two categories $(15-24,25-39)$ were aggregated to represent those under 40 years of age and the remaining three categories aggregated to represent those 40 years or over $(40-59,60-64,65$ year and over).
} 
The conditional probability that an individual under the age of 40 visited urban green space more than once a month and performed more than seven pro-environmental behaviours was $86.8 \%$ (11.7\% greater than if they visited less than once a month). The result was significant at the $5 \%$ level $(\mathrm{p}=0.013 ; \mathrm{N}=371)$. For those 40 or over, the conditional probability of performing more than seven pro-environmental behaviours if they visited more than once a month was $87.5 \%$ (8.3\% greater than if they visited urban green space less than once a month) $(\mathrm{p}=0.03 ; \mathrm{N}=598)$. However, such results did not tell me whether there was a difference between the age groups. With age being significantly associated with urban green space visitation and pro-environmental behaviour using the binary form of under and over 40 , the next step was to look at how each age range compared to the reference category (65 years or over) and whether the interaction term was significant in the model.

Table 40: Conditional probabilities of performing more than seven pro-environmental behaviours (Total PEB binary $=1.00$ ) if urban green space is visited once a month or more (Total UGS binary $=1.00$ ) and the individual is over 40 years of age using the concatenated sample.

\begin{tabular}{|c|c|c|c|c|c|c|}
\hline \multicolumn{4}{|l|}{ Age } & \multicolumn{2}{|c|}{ Total UGS binary } & \multirow{2}{*}{ Total } \\
\hline & & & & .00 & 1.00 & \\
\hline \multirow{4}{*}{ Under 40} & \multirow{4}{*}{$\begin{array}{l}\text { Total PEB } \\
\text { binary }\end{array}$} & 00 & Count & 66 & 14 & 80 \\
\hline & & & $\%$ within Total UGS binary & $24.9 \%$ & $13.2 \%$ & $21.6 \%$ \\
\hline & & 100 & Count & 199 & 92 & 291 \\
\hline & & 1.00 & $\%$ within Total UGS binary & $75.1 \%$ & $86.8 \%$ & $78.4 \%$ \\
\hline \multirow{4}{*}{$\begin{array}{l}40 \text { or } \\
\text { over }\end{array}$} & \multirow{4}{*}{$\begin{array}{l}\text { Total PEB } \\
\text { binary }\end{array}$} & \multirow{2}{*}{.00} & Count & 96 & 17 & 113 \\
\hline & & & $\%$ within Total UGS binary & $20.8 \%$ & $12.5 \%$ & $18.9 \%$ \\
\hline & & 100 & Count & 366 & 119 & 485 \\
\hline & & 1.00 & $\%$ within Total UGS binary & $\underline{79.2 \%}$ & $\underline{87.5 \%}$ & $81.1 \%$ \\
\hline
\end{tabular}


Table 41: Regression output displaying coefficients and significance of age, urban green space visitation, and Age-UGS interaction variables for the prediction of Total PEB using the concatenated sample. Age is categorised using dummy variables with 65 years or over acting as the base variable. The associated significance denotes whether the age category significantly alters the prediction of Total UGS relative to the base, 65 years or over.

\begin{tabular}{|ll|r|r|r|r|r|r|}
\hline & \multicolumn{1}{|c|}{ B } & \multicolumn{1}{c|}{ S.E. } & \multicolumn{1}{c|}{ Wald } & df & \multicolumn{1}{c|}{ Sig. } & $\operatorname{Exp}(\mathrm{B})$ \\
\hline Age & & & 9.001 & 4 & .061 & \\
& $15-24(1)$ & -.940 & .534 & 3.096 & 1 & .078 & .391 \\
& $25-39(2)$ & -.670 & .413 & 2.636 & 1 & .104 & .512 \\
Step 1a & -.069 & .314 & .049 & 1 & .825 & .933 \\
& $40-59(3)$ & .288 & .376 & .587 & 1 & .443 & 1.334 \\
& $60-64(4)$ & .126 & .030 & 18.219 & 1 & .000 & 1.134 \\
& Total UGS & -.020 & .009 & 5.105 & 1 & .024 & .980 \\
& Age UGS interaction & .709 & .297 & 5.712 & 1 & .017 & 2.032 \\
\hline
\end{tabular}

a. Variable(s) entered on step 1: Age, Total UGS, Age UGS interaction.

\section{Equation 31}

Logit $($ More than seven PEBs $\mathrm{i})=0.709-0.940\left(15\right.$ years -24 years $\left.\mathrm{i}_{\mathrm{i}}\right)-0.670(25$ years -

$$
\text { (5.712) (3.096) (2.636) }
$$

39 years $\left._{\mathrm{i}}\right)-0.069\left(40\right.$ years -59 years $\left._{\mathrm{i}}\right)+0.288\left(60\right.$ years -64 years $\left._{\mathrm{i}}\right)+0.126$ Total
$(0.049)$
$(0.587)$
(0.030)

$\mathrm{UGS}_{\mathrm{i}}-0.020$ Age*Total UGS

(5.105)

$\mathrm{R}^{2}=0.055 ; \mathrm{N}=918$

Looking at table 41, there was no statistically significant main effect of age on predicting performance of more than seven pro-environmental behaviours when controlling for urban green space visitation and the interaction term, Age*UGS. However, there was statistically significant interaction between age and Total UGS (p = 0.024). The interaction between age and Total UGS was negative meaning when age increased, the effect of urban green space visitation on pro-environmental behaviour decreased. The older an individual, urban green space visitation had a lower influence on pro-environmental behaviour (relative to the same amount of visitation at a younger age). When the relationship is plotted, the steeper slope for younger respondents (see figure nine) suggests that with greater urban green space visitation, there will be a greater increase in pro-environmental behaviour relative to older respondents who may visit urban green space just as often. 


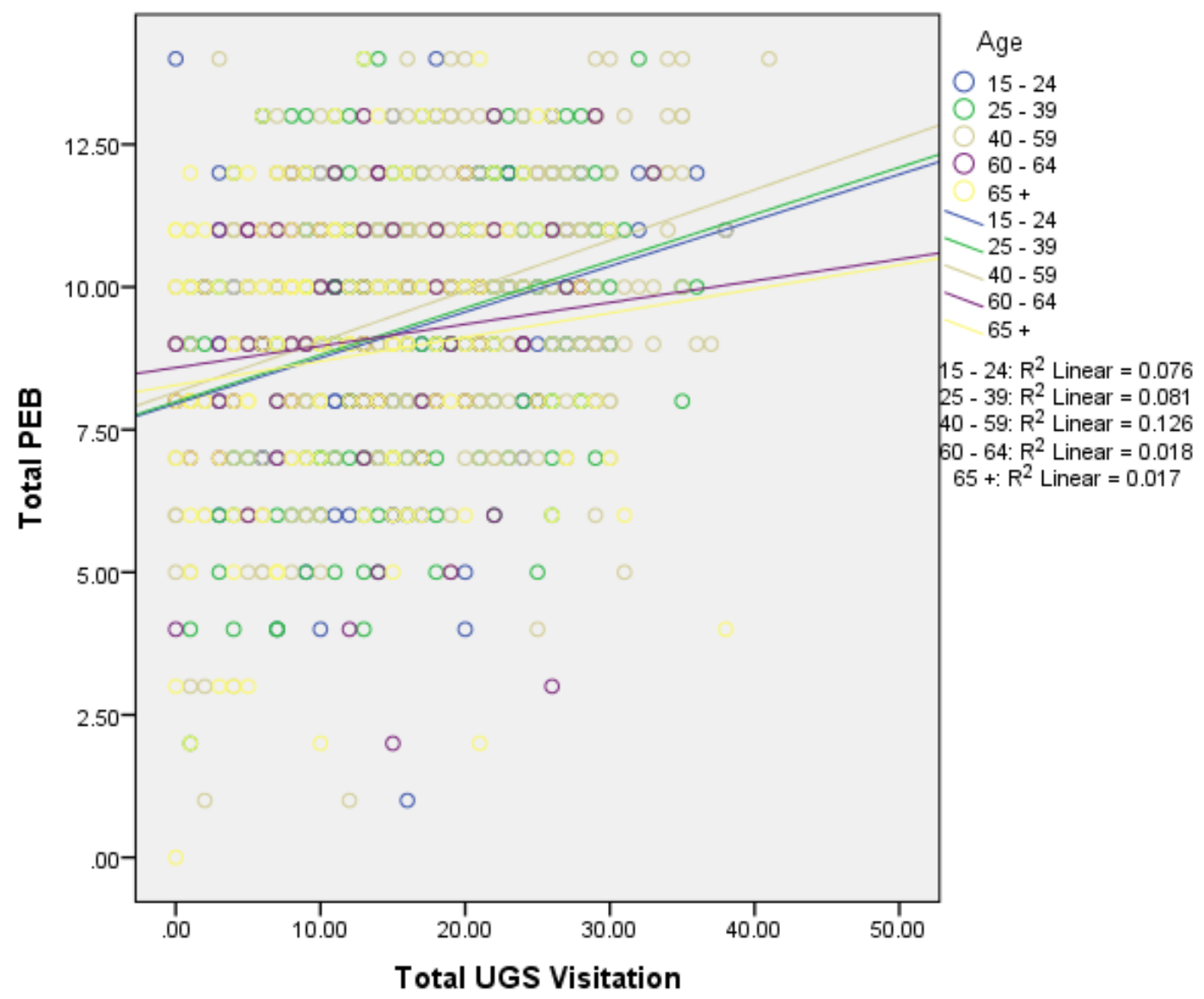

Figure 9: Linear relationship between pro-environmental behaviour (measured as a score out of 14) as a function of urban green space visitation (measured as a combined score for visitation to six urban green space types). Linear trend lines fitted for the subgroups of age.

There is some obvious lifestyle differences that exist across the categories of age used in my analysis. Dependents and students are likely to be part of the 15-24 age range, young, childless professionals likely comprise the 25 - 39 category, middle age (40 - 59) most likely holds those with children living at home, and the elderly and retired make up the 60-64 and 65 years and over category. When the data was aggregated to create those four age categories, linear regression (using Total PEB) revealed the following. After I compared the $\mathrm{R}^{2}$ values I found the middle aged category $(40-59)$ returned the linear model which explained the most variance in Total PEB. The model specific to the older age category (60 years and over) provided the poorest linear fit $(0.126>0.081>0.076$ $>0.019)$. 


\section{Equation 32}

Total $\mathrm{PEB}_{i 15-24 \text { year olds }}=7.955+0.080$ Total $\mathrm{UGS}_{\mathrm{i}}$

$$
\text { (15.445) (2.902) }
$$

$\mathrm{R}=0.276 ; \mathrm{R}^{2}=0.076 ; \mathrm{N}=103$.

\section{Equation 33}

Total $\mathrm{PEB}_{i 25}-39$ year olds $=7.990+0.082$ Total $\mathrm{UGS}_{i}$

$$
\text { (24.224) (4.557) }
$$

$\mathrm{R}=0.285 ; \mathrm{R}^{2}=0.081 ; \mathrm{N}=236$.

\section{Equation 34}

Total $\mathrm{PEB}_{i 40}-59$ year olds $=8.159+0.089$ Total $\mathrm{UGS}_{i}$

$$
\text { (34.970) (7.226) }
$$

$R=0.355 ; R^{2}=0.126 ; N=363$.

\section{Equation 35}

Total $\mathrm{PEB}_{i 60 \text { years and over }}=8.370+0.042$ Total $\mathrm{UGS}_{i}$

(26.563)(1.995)

$R=0.136 ; R^{2}=0.019 ; N=212$

All coefficients were significant at the 5\% level.

I then performed a linear regression with an interaction term to test whether there was a significant change in the effect of urban green space visitation on pro-environmental behaviour across the four age groups. Table 42, presents the results of the regression. The interaction term (Age*UGS visitation) was not significant in the model predicting Total PEB ( $p=0.310)$, a different result to when the binary form of pro-environmental behaviour and urban green space visitation was used.

\begin{tabular}{|c|c|c|c|c|c|c|}
\hline \multirow{2}{*}{\multicolumn{2}{|c|}{ Model }} & \multicolumn{2}{|c|}{$\begin{array}{c}\text { Unstandardized } \\
\text { Coefficients }\end{array}$} & \multirow{2}{*}{$\begin{array}{c}\text { Standardized } \\
\text { Coefficients } \\
\text { Beta }\end{array}$} & \multirow[t]{2}{*}{$\mathrm{t}$} & \multirow[t]{2}{*}{ Sig. } \\
\hline & & B & Std. Error & & & \\
\hline \multirow{3}{*}{1} & (Constant) & 8.116 & .154 & \multirow{3}{*}{.289} & 52.562 & .000 \\
\hline & Total UGS Visitation & .079 & .009 & & 9.152 & .000 \\
\hline & (Constant) & 8.212 & .261 & & 31.448 & .000 \\
\hline \multirow[t]{3}{*}{2} & Total UGS Visitation & .078 & .009 & \multirow{3}{*}{$\begin{array}{r}.287 \\
-.015\end{array}$} & 8.931 & .000 \\
\hline & Age & -.029 & .064 & & -.457 & .648 \\
\hline & (Constant) & 7.876 & .422 & & 18.674 & .000 \\
\hline \multirow{3}{*}{3} & Total UGS Visitation & .101 & .024 & .370 & 4.207 & .000 \\
\hline & Age & .079 & .125 & .040 & .635 & .526 \\
\hline & AgeUGSinteraction & -.008 & .008 & -.097 & -1.015 & .310 \\
\hline
\end{tabular}

Table 42: Regression output after testing for significance of main effects of Age and Total UGS visitation and the interaction term, Age*UGS using the concatenated sample. 
I concluded from my results that restricting the sample to middle age respondents improves the predictive ability of the linear model (relative to the total sample). The theory of biophilia appears to be better supported by middle aged respondents. Such a result is perhaps due to this generation possibly raising children and therefore has more to gain from preserving the environment. An internal want for a better future for family members, coupled with financial stability, may all be working together to help middle aged people respond to biophilia. Financial stability is an important factor to address. Whether there is any truth to the Givens and Jorgensen's (2011) affluence hypothesis which posits wealthier people will have fewer financial worries and an ability to focus on issues beyond their immediate self was next tested.

\subsubsection{Income}

Table 43: Frequency table showing distribution of responses for the six categories of income using the concatenated sample.

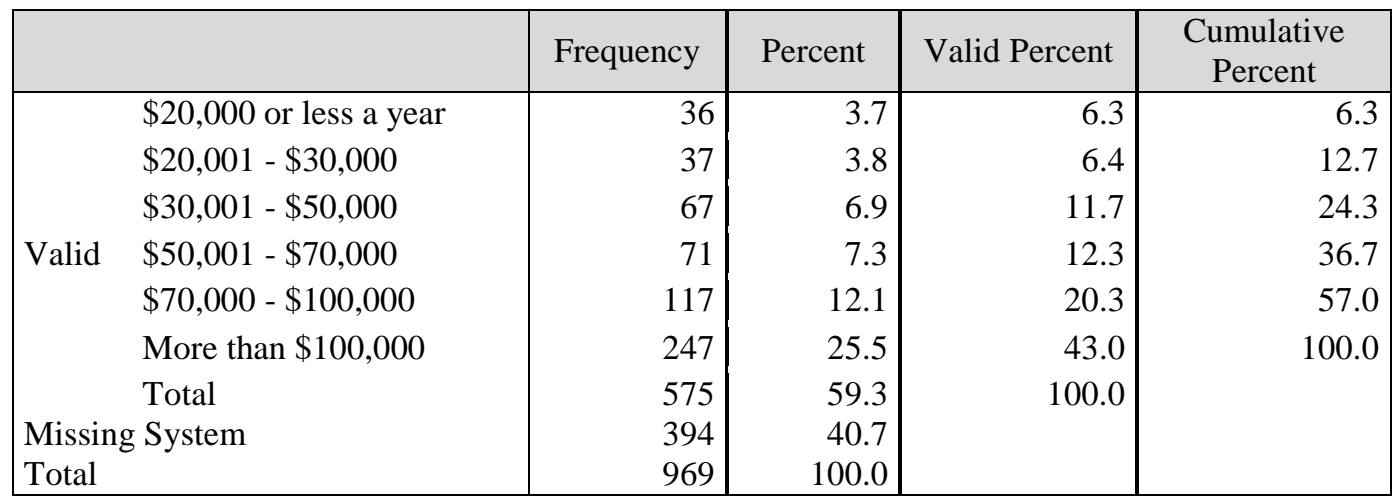

There is evidence in the literature suggesting that individuals with fewer financial worries are more likely to perform more pro-environmental behaviour (Givens and Jorgenson, 2011, Torgler and Garcia-Valiñas, 2007). Such a theory resonates with biophilia as it may be that those on a higher income have the financial comfort to focus on improvements outside of their immediate situation. Nature connectedness, as explained in the literature, requires more than 'nature exposure'. Individuals must be aware of their natural surrounds, in a position to appreciate such states and, most importantly, enjoy positive experiences within these natural areas. Financially stressed individuals may be unlikely to be focused on much more than making a living. Is it then true that those who live in wealthier households show a different relationship between 
urban green space visitation and pro-environmental behaviour relative to less wealthy households?

Cross tabulation analysis (see table 44) was first performed to illustrate the conditional probabilities of performing more than seven pro-environmental behaviours for three categories of income. What must be noted here is that the questionnaire specifically asked the respondent to indicate the total household income. Had income been restricted to the individual, a younger person living with an affluent family would have returned a low income score despite living in a financially stable environment. However, it must be kept in mind that the survey's measure of income runs the risk of a household with many low income earners being represented by a high income score.

There were six income categories listed in the questionnaire but in order to prevent the sample size from being excessively reduced, my cross tabulation analysis used four categories; $\$ 20,000$ - \$30,000, $\$ 30,001$ - $\$ 70,000, \$ 70,000-\$ 100,000$, and more than $\$ 100,000$. Such a division reflects the median income in New Zealand for June 2012 until June 2013 being \$44,000 (Statistics New Zealand 2013). Categories thus reflect low earning, median earning, above median earning, and high earning, respectively.

For those living in high earning households, the probability of performing more than seven pro-environmental behaviours for a person visiting urban green space once a month or more was $13 \%$ higher than if they visited less than once a month. There was a $10 \%$ and $10.6 \%$ difference in such a probability for above median and median earning households, respectively. Those living in low earning households showed a reversed trend, with a $50 \%$ chance of performing more than seven pro-environmental behaviours if they visited urban green space once a month or more and a $72.3 \%$ chance if they visited less. However, despite income in aggregate being statistically significant $(p=$ 0.007) only the results for high earners were statistically significant in the disaggregated case $(\mathrm{p}=0.014)$. 
Table 44: Cross tabulation analysis showing conditional probabilities of performing more than seven pro-environmental behaviours (Total PEB binary $=1.00$ ) and visiting urban green space once a month or more Total UGS binary $=1.00)$ for four levels of income $(.00=\$ 20,000$ $\$ 30,000,1.00=\$ 30,001-\$ 70,000,2.00=\$ 70,000-\$ 100,000,3.00=$ more than $\$ 100,000)$ using the concatenated sample.

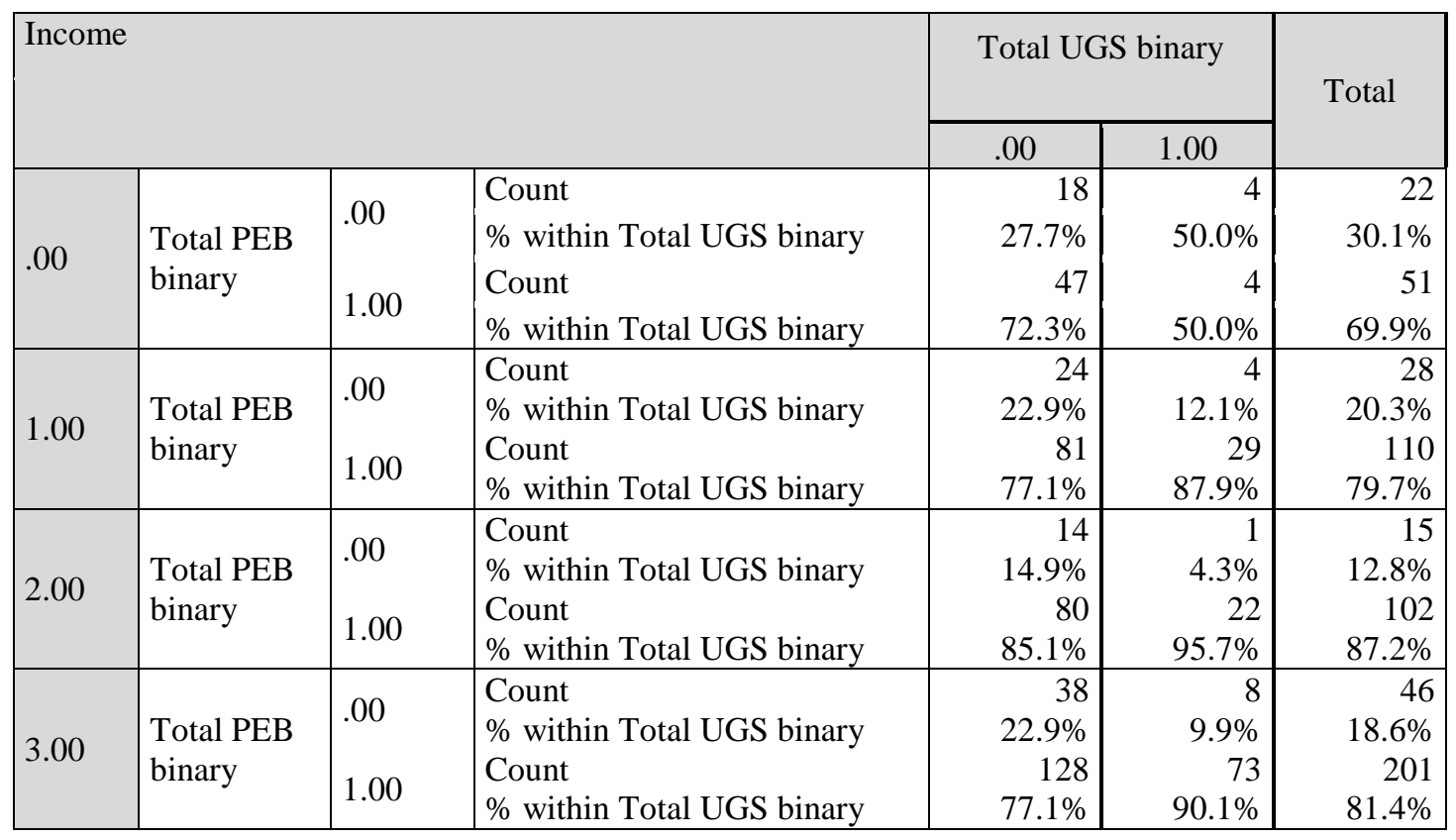

As some cells contained fewer than five counts, some assumptions of the chi-square test performed above were violated. To address this issue, income was recoded to represent two categories, income approximately equal to median or under $(\$ 50,000$ or less) and income greater than median $(\$ 50,001$ or over). Such a division collates the first three categories together and the last three categories together representing a more equal aggregation. The cross tabulation for such a division is illustrated in table 45, below.

Table 45: Cross tabulation analysis showing conditional probabilities of performing more than seven pro-environmental behaviours (Total PEB binary $=1.00$ ) and visiting urban green space once a month or more (Total UGS binary $=1.00$ ) for two levels of income (less than the New Zealand median and more than New Zealand median).

\begin{tabular}{|c|c|c|c|c|c|c|}
\hline \multicolumn{4}{|l|}{ Income } & \multicolumn{2}{|c|}{ Total UGS binary } & \multirow[t]{2}{*}{ Total } \\
\hline & & & & .00 & 1.00 & \\
\hline \multirow{4}{*}{$<$ median } & \multirow{4}{*}{$\begin{array}{l}\text { Total PEB } \\
\text { binary }\end{array}$} & \multirow{2}{*}{.00} & Count & 32 & 5 & 37 \\
\hline & & & $\%$ within Total UGS binary & $27.1 \%$ & $22.7 \%$ & $26.4 \%$ \\
\hline & & \multirow{2}{*}{1.00} & Count & 86 & 17 & 103 \\
\hline & & & $\%$ within Total UGS binary & $72.9 \%$ & $77.3 \%$ & $73.6 \%$ \\
\hline \multirow{4}{*}{$>$ median } & \multirow{4}{*}{$\begin{array}{l}\text { Total PEB } \\
\text { binary }\end{array}$} & \multirow{2}{*}{.00} & Count & 62 & 12 & 74 \\
\hline & & & $\%$ within Total UGS binary & $19.9 \%$ & $9.8 \%$ & $17.0 \%$ \\
\hline & & \multirow{2}{*}{1.00} & Count & 250 & 111 & 361 \\
\hline & & & $\%$ within Total UGS binary & $80.1 \%$ & $90.2 \%$ & $83.0 \%$ \\
\hline
\end{tabular}


Again, only the results for above median income earning households were significant ( $p$ $=0.011)$. There was thus only a statistical association between urban green space visitation and pro-environmental behaviour for individuals who resided in households earning above the median annual income of New Zealand. Such a result is consistent with the literature. An individual who visits urban green space once a month or more was $10.2 \%$ more likely to perform more than seven pro-environmental behaviours if they resided in a high earning household. The difference in probability was only $4.4 \%$ when restricted to lower income households and was not statistically significant.

Figure 10 displays an X-Y scatterplot illustrating the difference in trend lines for each category of income. There appears to be a distinct difference in the way urban green space explains pro-environmental behaviour across the six income categories. The two lower income categories return negative coefficients suggesting that with increasing urban green space visitation, pro-environmental behaviour decreases. In order to determine whether there was statistically significant difference and moderation, I conducted logistic regression including the main effects of each income bracket as dummy variables (with six figure earning households as the base), as well as an interaction term (equation 36 and table 46).

\section{Equation 36}

Logit $($ More than seven PEBs $i)=-0.048+0.579$ very low income +1.248 low income

$$
\text { (0.021) (0.832) (4.194) }
$$

+0.815 median income +0.667 high income +1.041 very high income -0.024 Total
(2.925)
(2.398)
(8.116)
$(0.445)$
$\mathrm{UGS}_{\mathrm{i}}+0.020$ income*UGS $^{*}$

(6.482)

$\mathrm{R}^{2}=0.067 ; \mathrm{N}=545$

Table 46: Regression coefficients from logistic regression of Total PEB binary with the main effects of Total UGS visitation and the income-UGS interaction term with the main effect of income included as dummy variables using the concatenated sample.

\begin{tabular}{|c|c|c|c|c|c|c|c|}
\hline & & B & S.E. & Wald & $\mathrm{df}$ & Sig. & $\operatorname{Exp}(B)$ \\
\hline \multirow{9}{*}{ Step $1^{\mathrm{a}}$} & Total UGS & -.024 & .036 & .445 & 1 & .505 & .976 \\
\hline & Income UGS interaction & .020 & .008 & 6.482 & 1 & .011 & 1.020 \\
\hline & Income & & & 10.629 & 5 & .059 & \\
\hline & Income(1) & .579 & .635 & .832 & 1 & .362 & 1.784 \\
\hline & Income(2) & 1.248 & .610 & 4.194 & 1 & .041 & 3.485 \\
\hline & Income(3) & .815 & .477 & 2.925 & 1 & .087 & 2.260 \\
\hline & Income $(4)$ & .667 & .431 & 2.398 & 1 & .121 & 1.949 \\
\hline & Income $(5)$ & 1.041 & .365 & 8.116 & 1 & .004 & 2.831 \\
\hline & Constant & -.048 & .333 & .021 & 1 & .884 & .953 \\
\hline
\end{tabular}

a. Variable(s) entered on step 1: TotalUGS, IncomeUGSinteraction, Income. 


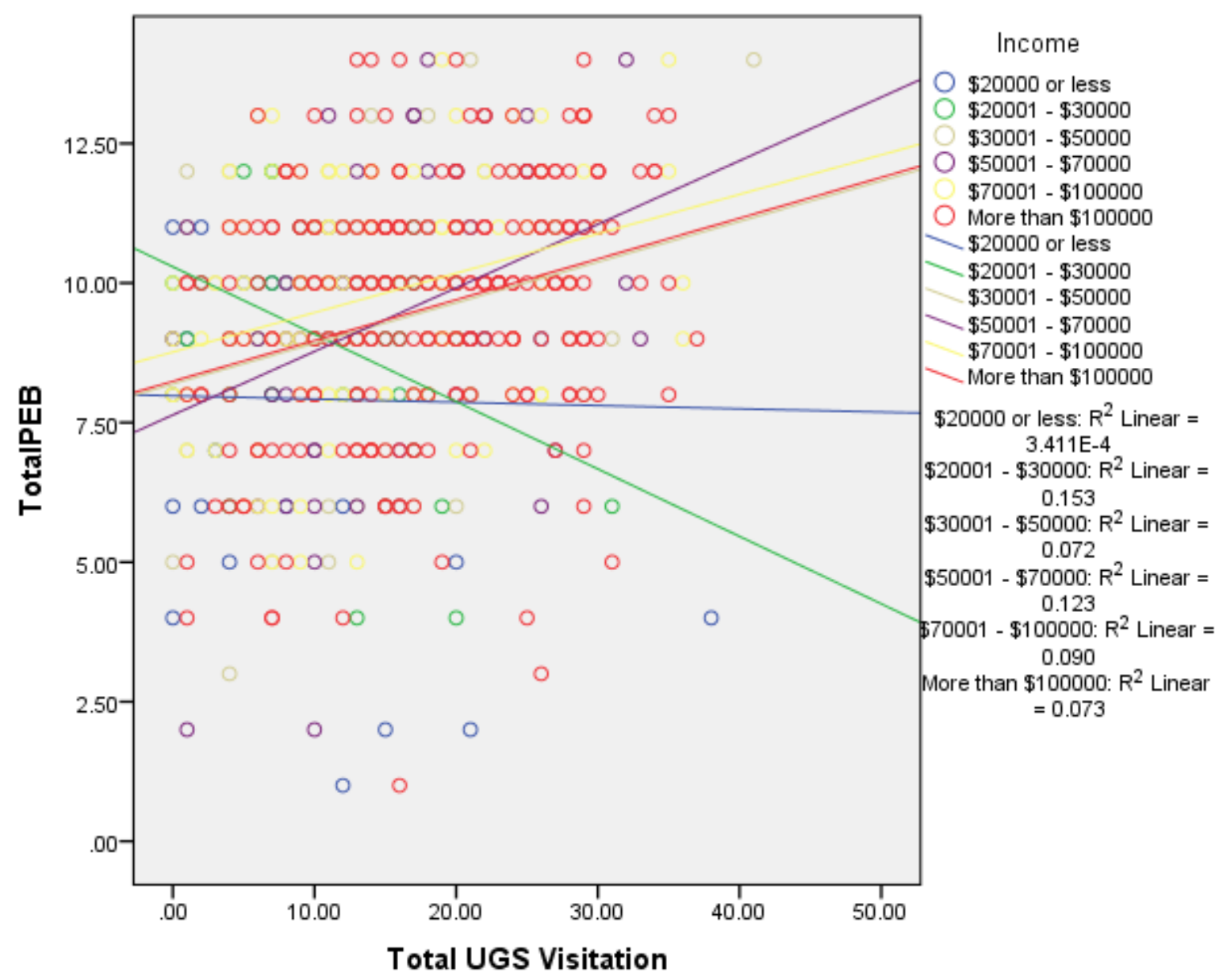

Figure 10: Linear relationship between pro-environmental behaviour (measured as a score out of 14) and urban green space visitation (measured as a combined score for visitation to six urban green space types). Linear trend lines are fitted for the six subgroups of household income.

From the logistic regression I found that, controlling for income, urban green space visitation was not statistically significant in predicting more than seven proenvironmental behaviours $(\mathrm{p}=0.505)$. The effect of low income earning households on pro-environmental behaviour was statistically different to six figure earning households. The interaction term was statistically significant at the 5\% level $(\mathrm{p}=0.011)$. The interaction term coefficient was positive suggesting that with increasing income, the influence of urban green space visitation on pro-environmental behaviour increases. The odds of performing more than seven pro-environmental behaviours for low income households was 3.485 times that for six figure households suggesting the relationship may be non-linear. 
When linear regression (for Total PEB) was conducted for each of the six income categories included in the questionnaire, equations 37 through 42 were returned. There was no statistically significant association between Total UGS and Total PEB in cases where the respondent's household income was less than $\$ 20,000$ a year (equation 37). Such a result was expected as it is likely that these individuals are unable to focus on issues beyond their immediate financial situation. Urban green space visitation was statistically significant in the model predicting Total PEB when restricted to household annual incomes between $\$ 20,001$ and $\$ 30,000$. However, the relationship was negative with one of the strongest $\mathrm{R}^{2}$ values of relationships tested (equation 38 ). In equation 39 , urban green space visitation was a significant predictor for pro-environmental behaviour. It is from this point that the relationship begins to change from non-existent or negative, to positive, suggesting that one's household income does have a role in determining how urban green space visitation is associated with pro-environmental behaviour. As financial situations become more 'comfortable', the relationship appears to strengthen and become positive. A strong $\mathrm{R}^{2}$ and $\mathrm{t}$ statistic for the Total UGS $\beta$ coefficient was returned for the above median income households with the equation significant at the $1 \%$ level.

Equation 37

$$
\begin{array}{rlrl}
\text { Total } \mathrm{PEB}_{\mathrm{i}} \$ 20,000 \text { or less } & = & 7.980-0.006 \text { Total } \mathrm{UGS}_{\mathrm{i}} & \mathrm{R}=0.00 ; \mathrm{R}^{2}=0.000 ; \mathrm{N}=33 \\
& (9.476)(-0.104) &
\end{array}
$$

Equation 38

$$
\begin{aligned}
\text { Total } \mathrm{PEB}_{\mathrm{i}} \$ 20,001-\$ 30,000 & =10.291-0.121 \text { Total } \mathrm{UGS}_{\mathrm{i}} \quad \mathrm{R}=0.391 ; \mathrm{R}^{2}=0.153 ; \mathrm{N}=34 \\
& (15.118)(-2.443)
\end{aligned}
$$

\section{Equation 39}

Total PEB $\$ \$ 30,001-\$ 50,000=8.190+0.073$ Total $\mathrm{UGS}_{\mathrm{i}} \quad \mathrm{R}=0.268 ; \mathrm{R}^{2}=0.072 ; \mathrm{N}=62$

$(14.528)(2.174)$

\section{Equation 40}

Total PEB $\mathrm{i}_{\$} \$ 50,001-\$ 70,000=7.637+0.114$ Total $\mathrm{UGS}_{\mathrm{i}} \quad \mathrm{R}=0.351 ; \mathrm{R}^{2}=0.123 ; \mathrm{N}=61$ $(11.254)(2.900)$ 


\section{Equation 41}

Total PEB $\mathrm{i}_{\$ 70,001-\$ 100,000}=8.764+0.071$ Total $\mathrm{UGS}_{\mathrm{i}} \quad \mathrm{R}=0.300 ; \mathrm{R}^{2}=0.090 ; \mathrm{N}=113$ (24.263) (3.323)

\section{Equation 42}

Total $\mathrm{PEB}_{\mathrm{i}} \$ 100,001$ or more $=8.240+0.073$ Total $\mathrm{UGS}_{i} \quad \mathrm{R}=0.270 ; \mathrm{R}^{2}=0.073 ; \mathrm{N}=236$ (24.389)(4.304)

The income category showing the greatest support for biophilia was households that earn between $\$ 20,001$ and $\$ 30,000$ a year $\left(R^{2}=0.159\right)$ with those living in households earning over $\$ 100,000$ returning a weak $\mathrm{R}^{2}$ despite literature suggesting high earners would be more able to respond to biophilia. Although, households earning around the median New Zealand salary also returned a relatively high $\mathrm{R}^{2}(0.123)$. There was no documented relationship between urban green space visitation and pro-environmental behaviours for households falling in the lowest income bracket.

However, linear regression testing whether income moderates the relationship between urban green space visitation and pro-environmental behaviour returned a statistically insignificant result. There was no evidence of moderation. While the scatter plot suggests there is a difference, this is not enough to be statistically significant (see table 47).

Table 47: Table of coefficients and significance for the regression of Total PEB and Total UGS using the concatenated sample. Main effects of UGS visitation and income and the interaction term are shown.

\begin{tabular}{|c|c|c|c|c|c|c|}
\hline \multirow[t]{2}{*}{ Mo } & & \multicolumn{2}{|c|}{$\begin{array}{l}\text { Unstandardized } \\
\text { Coefficients }\end{array}$} & $\begin{array}{l}\text { Standardized } \\
\text { Coefficients }\end{array}$ & \multirow[t]{2}{*}{$\mathrm{t}$} & \multirow[t]{2}{*}{ Sig. } \\
\hline & & B & Std. Error & Beta & & \\
\hline \multirow{3}{*}{1} & (Constant) & 8.347 & .204 & \multirow{3}{*}{246} & 40.941 & .000 \\
\hline & Total UGS Visitation & .067 & .011 & & 5.904 & .000 \\
\hline & (Constant) & 7.691 & .324 & & 23.756 & .000 \\
\hline \multirow[t]{3}{*}{2} & Total UGS Visitation & .060 & .012 & .221 & 5.190 & .000 \\
\hline & Income & .164 & .063 & .111 & 2.601 & .010 \\
\hline & (Constant) & 8.389 & .552 & & 15.184 & .000 \\
\hline \multirow{3}{*}{3} & Total UGS Visitation & .009 & .035 & .032 & 246 & .806 \\
\hline & Income & .008 & .119 & .005 & .067 & .947 \\
\hline & Income UGS interaction & .011 & .007 & .245 & 1.559 & .120 \\
\hline
\end{tabular}




\subsection{Pride}

Literature suggests pride to be positively associated with environmentally friendly attitudes and behaviours as well as being positively linked to the amount of nature present in one's place of residence. Pride refers to the positive connections one feels about a particular object, location, person, or themselves. Brown et al. (2003) used pride as a measure of place attachment, describing the latter as a positive bond between an individual and the physical and social setting. There has been a great deal of work into the role of nature in place attachment and pride has similarly been investigated for links with one's attachment to place. It would seem that there may be a moderating effect of one's level of pride on their ability to respond to the effects of biophilia. With biophilia revolving around nature exposure, as well as positive emotional responses to nature, I hypothesised someone who holds more pride in their city will be experiencing more positive responses from nature exposure and expressing biophilia induced behaviours, e.g., pro-environmental behaviour. With evidence to support the link between pride and connections to natural settings, as well to pro-environmental behaviour, how then does one's level of pride moderate the extent to which visitations to nature correlate with proenvironmental behaviour?

Pride was measured in question 16 of the Wellington City Council's Residents Satisfaction Survey which asked, "How strongly do you agree or disagree with the statement, 'I feel a sense of pride in the way Wellington looks and feels'?". A five item Likert scale was used to record answers $(1=$ strongly disagree, $2=$ disagree, $3=$ neither agree nor disagree, 4 = agree, 5 = strongly agree). Those that answered 'don't know' were recoded as system missing. Over half of respondents agreed that they held pride in the city (see table 48). 
Table 48: Frequency table showing the distribution of responses across the five categories of pride using the concatenated sample. Pride represented by five categories pertaining to how much a respondent agrees or disagrees with the statement, 'I feel a sense of pride in the way the city looks and feels' $(1.00=$ strongly disagree, $2.00=$ disagree, $3.00=$ neither agree nor disagree, $4.00=$ agree, $5.00=$ strongly agree) .

\begin{tabular}{|ll|r|r|r|r|}
\hline Pride & & Frequency & Percent & Valid Percent & \multicolumn{2}{|c|}{$\begin{array}{c}\text { Cumulative } \\
\text { Percent }\end{array}$} \\
\hline & 1.00 & 4 & .4 & .4 & .4 \\
& 2.00 & 19 & 2.0 & 2.0 & 2.4 \\
Valid & 3.00 & 75 & 7.7 & 7.8 & 10.1 \\
& 4.00 & 444 & 45.8 & 45.9 & 56.0 \\
& 5.00 & 425 & 43.9 & 44.0 & 100.0 \\
& Total & 967 & 99.8 & 100.0 & \\
Missing & System & 2 & .2 & & \\
Total & & 969 & 100.0 & & \\
\hline
\end{tabular}

As I wanted to assess whether one's level of pride moderated the association between urban green space visitation and pro-environmental behaviour, a new variable, PrideUGSvisitation, was computed by multiplying pride by urban green space visitation to create an interaction term. Linear regression was then conducted with equations listed below (equation 43 and 44).

\section{Equation 43}

Model 2:

$$
\begin{aligned}
& \text { Total } \mathrm{PEB}_{\mathrm{i}}=6.752+0.074 \text { Total UGS }+0.337 \text { Pride } \\
& (14.718)(8.513) \\
& \mathrm{R}^{2}=0.091 ; \mathrm{N}=916
\end{aligned}
$$

\section{Equation 44}

Model 3:

$$
\begin{aligned}
& \text { Total } \mathrm{PEB}_{i}=6.192+0.115 \text { Total UGS }+\underset{(7.567)(2.268)}{0.468 \text { Pride }-0.010 \text { Pride*UGS visitation }} \\
& \mathrm{R}^{2}=0.092 ; \mathrm{N}=916
\end{aligned}
$$

When Pride was included with Total UGS visitation as a main effect, both were statistically significant in the model predicting Total PEB, with an $\mathrm{R}^{2}$ of 0.091 (a statistically significant improvement on model one which only included Total UGS as the explanatory variable $(\mathrm{F}$ change $=10.517$; Sig F change $=0.001)$. However, when the interaction term was included, there was no significant improvement in the $\mathrm{F}$ ( $\mathrm{p}=$ 
0.409). Also, model three returned an insignificant coefficient for the interaction term ( $\mathrm{p}$ $=0.409)$ while Pride and Total UGS visitation remained significant $(\mathrm{p}=0.014$ and 0.024, respectively). I thus concluded that while pride does assist in explaining Total PEB, it does not moderate the relationship. While someone with more pride does perform more pro-environmental, this association does not change with urban green space visitation (or vice versa).

A logistic regression analysis was next conducted to determine whether there was a difference in how pride influenced pro-environmental behaviour (controlling for urban green space visitation) (equation 45).

\section{Equation 45}

More than seven PEBs ${ }_{i}=0.476+0.062$ Total UGS -0.416 disagree in having pride -

$$
\text { (0.149) (33.088) (0.097) }
$$

(0.573) neither agree nor disagree in having pride $+(0.096)$ agree in having pride +

(0.157)Strongly agree in having pride.

(0.016)

$\mathrm{R}^{2}=0.049 ; \mathrm{N}=916$

Pride was an insignificant contributor to the prediction of more than seven proenvironmental behaviours $(\mathrm{p}=0.149)$. A one way ANOVA, however, indicated there was a statistically significant difference in whether someone performs more than seven pro-environmental behaviours across the five categories of pride $(\mathrm{p}=0.048)$. When the dependent variable was changed to Total PEB, the result was even more significant ( $\mathrm{p}=$ 0.000). There was also a statistically significant difference in the mean amount of Total UGS visitation across the five levels of pride $(\mathrm{p}=0.001)$. The mean level of urban green space visitation and pro-environmental behaviour was not equal across the five levels of pride, suggesting there was perhaps a level of pride which correlated with a greater amount of pro-environmental behaviour and urban green space visitation. A two-way ANOVA was thus performed and the results are shown in table 49. There was no statistically significant interaction between pride and urban green space visitation once a month or more $(p=0.995)$. Therefore, the slopes of the regression lines do not differ significantly across the five levels of pride. However, it may be that some slopes are negative and some are positive, thereby cancelling each other out. Figure 11 illustrates the regression slopes across the five levels of pride. 
Table 49: Two way-ANOVA testing the presence of an interaction between Total UGS and pride on the prediction of Total PEB.

Dependent Variable: Total PEB

\begin{tabular}{|l|r|r|r|r|r|}
\hline Source & $\begin{array}{c}\text { Type III Sum of } \\
\text { Squares }\end{array}$ & df & Mean Square & F & Sig. \\
\hline Corrected Model & 1049.579 & 120 & 8.746 & 1.737 & .000 \\
Intercept & 5799.861 & 1 & 5799.861 & 1151.963 & .000 \\
Total UGS & 371.139 & 39 & 9.516 & 1.890 & .001 \\
Pride & 79.607 & 4 & 19.902 & 3.953 & .003 \\
Total UGS * Pride & 423.734 & 77 & 5.503 & 1.093 & .281 \\
Error & 4002.635 & 795 & 5.035 & & \\
Total & 85382.000 & 916 & & & \\
Corrected Total & 5052.214 & 915 & & & \\
\hline
\end{tabular}

a. R Squared $=.208$ (Adjusted R Squared $=.088$ )

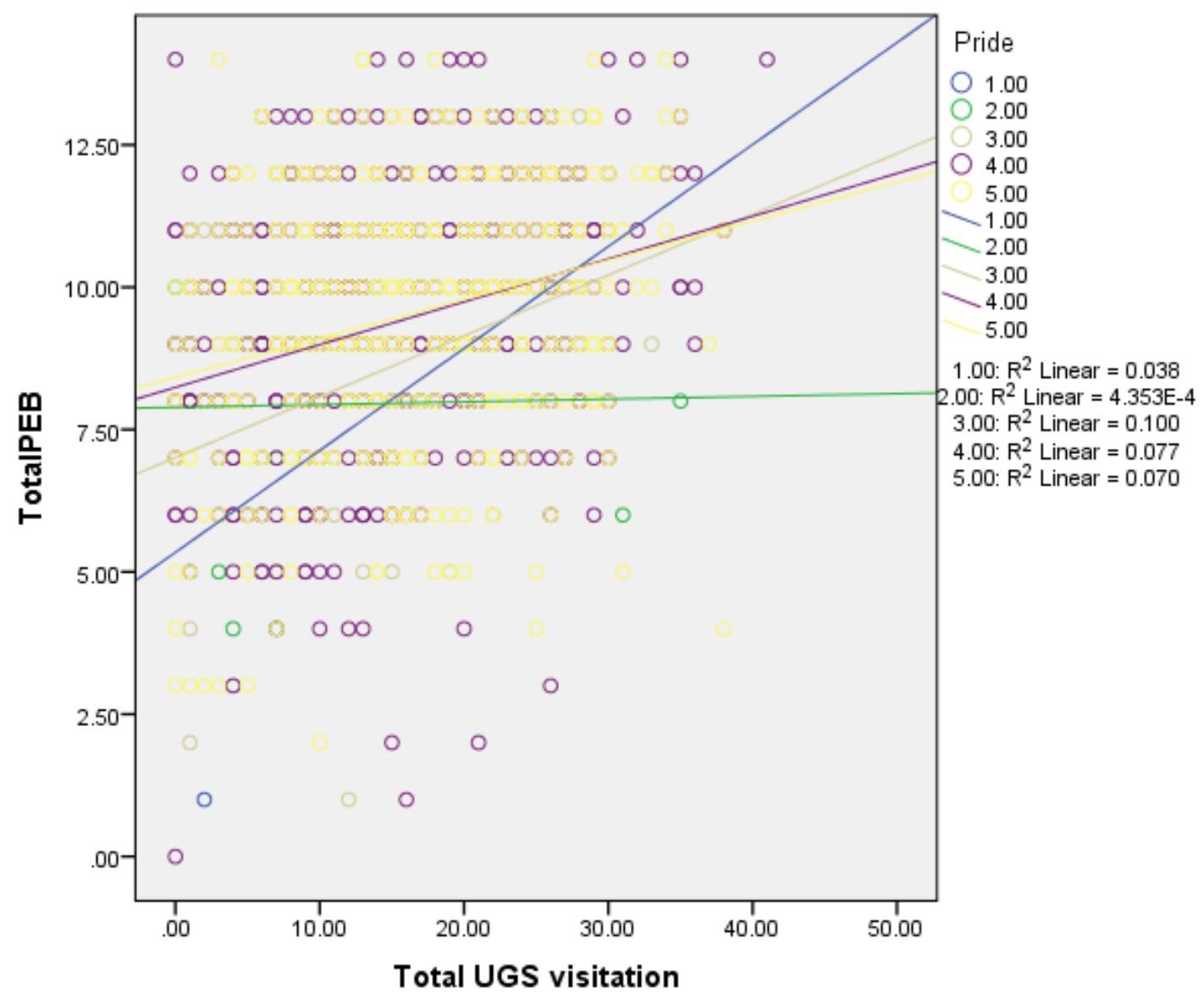

Figure 11: Linear relationship between pro-environmental behaviour (measured as a score out of 14) as a function of urban green space visitation (measured as a combined score for visitation to six urban green space types). Linear trend lines fitted for the subgroups of gender. Pride categories denoted by five values pertaining to how strongly they agree or disagree with the statement, 'I feel a sense of pride in the way the city looks and feels' $(1.00=$ strongly disagree, $2.00=$ dis agree, $3.00=$ neither agree nor disagree, $4.00=$ agree, $5.00=$ strongly agree $)$. 
The trend line for the points reflecting those neither agreeing nor disagreeing with holding pride in the city was very similar to the trend line for agreeing they hold pride in the city. Those who disagree with holding pride reported the poorest fit, indicated by the smallest $\mathrm{R}^{2}$ value. I hypothesised someone with more pride would be more susceptible to biophilia and be more likely to express nature connections through proenvironmental behaviour. However, I found there to be no interaction between pride and urban green space visitation on pro-environmental behaviour. Dummy variable analysis reported there to be no significant difference in the association between pride and proenvironmental behaviour across the five categories of pride. Therefore, my hypothesis was rejected in the case of the Wellington sample. There was one additional variable I chose to examine for a possible role in moderating the relationship between urban green space visitation and pro-environmental behaviour. This variable was quality of life and was analysed next.

\subsection{Quality of Life}

When I applied the affluence hypothesis of Givens and Jorgenson (2011) in the development of my hypothesis suggesting those living in higher income earning households would show a stronger relationship between urban green space visitation and pro-environmental behaviour I was assuming these households allow respondents to focus on issues beyond their immediate situation. What if someone lives in a high earning household but is still subjected to associated stresses and competing priorities reducing this ability? The affluence hypothesis suggests those on a lower income have priorities of simply making ends meet which override any feelings for environmental preservation, a primarily altruistic action. Income as an explanatory variable has its caveats. Just because someone lives in a high earning household does not automatically mean they follow a lifestyle conducive to biophilia and pro-environmental behaviour. The affluence hypothesis does not take into account the amount of hour's one works (restricting their ability to visit urban green space or perform pro-environmental behaviour) or that high earning households may be very career oriented, thus emotional connections to nature may not be so easily fostered. There is the possibility that quality of life could thus be a better measure of one's ability to respond to biophilia and act on the emotional connections that being in nature instils. While the Wellington City Council's Residents Satisfaction Survey did not provide a definition for quality of life, quality of life has been defined as referring to ones well-being or life satisfaction 
(Grinde and Patil, 2009). Quality of life has also been used to reflect well-being and the subsequent ability to focus on issues beyond one's self (Cervinka et al., 2012, Givens and Jorgenson, 2011).

I hypothesised that those with a high quality of life would show a stronger relationship between urban green space visitation and pro-environmental behaviour. I predicted an interaction would exist, with regression slopes being different depending on the level of quality of life. Individuals with a higher quality of life are less likely to be striving to improve their own living situation, thus making them more able to act on biophilic responses gained from urban green space visitation. Simply promoting urban green space visitation to aide pro-environmental behaviour change may be ineffective if the quality of life of individuals is not at a level high enough to allow a positive association to exist.

The following analysis used question 10 of the Wellington City Council Residents Satisfaction Survey which asked, 'Would you say that overall your quality of life is...', with five categories to choose from; extremely poor, poor, neither good nor poor, good, extremely good (see table 50). Each category was attributed a value from one to five, respectively, with those answering 'don't know' set as system missing. To test for moderation, an interaction term was computed by multiplying the quality of life variable with Total UGS visitation. Linear regression was first performed with the model including Total UGS and Quality of life as main effects, as well as the Total UGS*Quality of life interaction term displayed in equation 50.

Table 50: Frequency table for distribution of responses across the five categories of quality of life using the concatenated sample. Quality of life depicted by $1.00=$ extremely poor, $2.00=$ poor, $3.00=$ neither poor nor good, $4.00=$ good, $5.00=$ extremely good.

\begin{tabular}{|ll|r|r|r|r|}
\hline Quality of life & Frequency & Percent & Valid Percent & \multicolumn{2}{|c|}{$\begin{array}{c}\text { Cumulative } \\
\text { Percent }\end{array}$} \\
\hline & 1.00 & 3 & .3 & .3 & .3 \\
2.00 & 14 & 1.4 & 1.5 & 1.8 \\
Valid & 3.00 & 58 & 6.0 & 6.0 & 7.8 \\
& 4.00 & 544 & 56.1 & 56.6 & 64.4 \\
& 5.00 & 342 & 35.3 & 35.6 & 100.0 \\
& Total & 961 & 99.2 & 100.0 & \\
Missing & System & 8 & .8 & & \\
Total & & 969 & 100.0 & & \\
\hline
\end{tabular}


There was a statistically significant improvement in $\mathrm{R}^{2}$ between model one, which only included Total UGS, and model two which included both Total UGS and quality of life $(\mathrm{p}=0.001)$. However, there was no statistical change between model two and model three (which included the interaction term) $(\mathrm{p}=0.443)$ (see equation 46$)$. There was no statistically significant interaction between quality of life and urban green space visitation when it came to the prediction of Total PEB.

\section{Equation 46}

Model 3:

Total $\mathrm{PEB}_{\mathrm{i}}=5.945+0.117$ Total UGS +0.532 Quality of Life (6.442) (2.026) (2.453)

0.010 Total UGS*Quality of Life

$(-0.768)$

$\mathrm{R}^{2}=0.095 ; \mathrm{N}=911$

The scatterplot of Total PEB by Total UGS with trend lines fitted for the sub groups of quality of life is shown in figure 12, below. There appears to be little difference in the regression lines across the five quality of life categories. The lack of data points for those that report poor or extremely poor quality of life skews the results of the $\mathrm{R}^{2}$ values, however, their placement in the bottom left of the plot suggests that these groups visit urban green space rarely and perform only a small number of pro-environmental behaviours. 


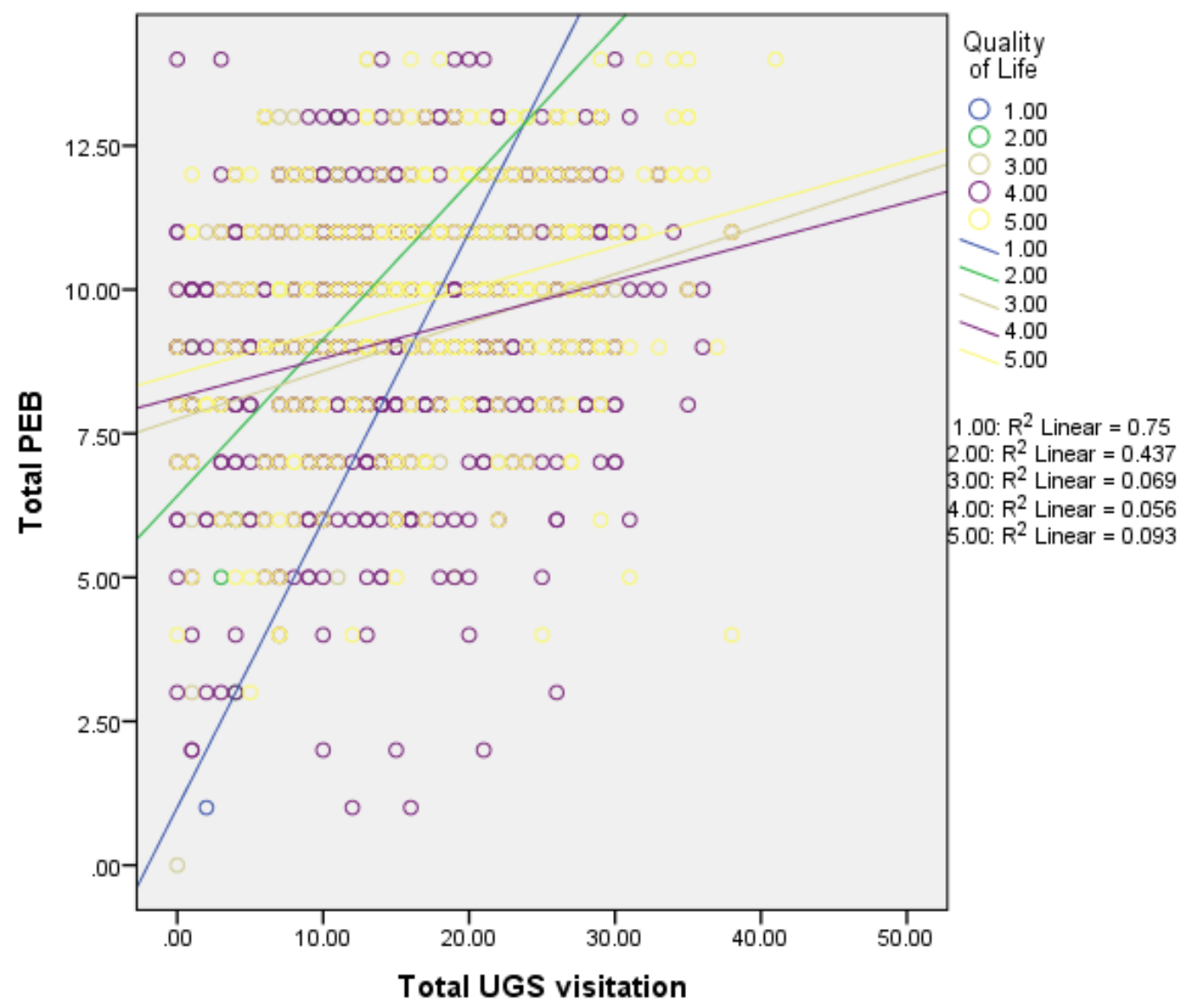

Figure 12: Linear relationship between Total PEB (number of pro-environmental behaviours performed) as a function of Total UGS visitation (combined score from all six urban green space types) for each of the five subgroups of Quality of Life. Quality of life depicted by five categories $(1.00=$ extremely poor, $2.00=$ poor, $3.00=$ neither poor nor good, $4.00=$ good, 5.00 $=$ extremely good).

To determine whether there were significant differences between the coefficients for each level of quality of life relative to the base value of having an extremely good quality of life, dummy variables were used. The categories for poor and extremely poor were collated together to increase the sample size. A scatterplot was produced to illustrate the regression lines for each of the four categories of quality of life (figure 13). 


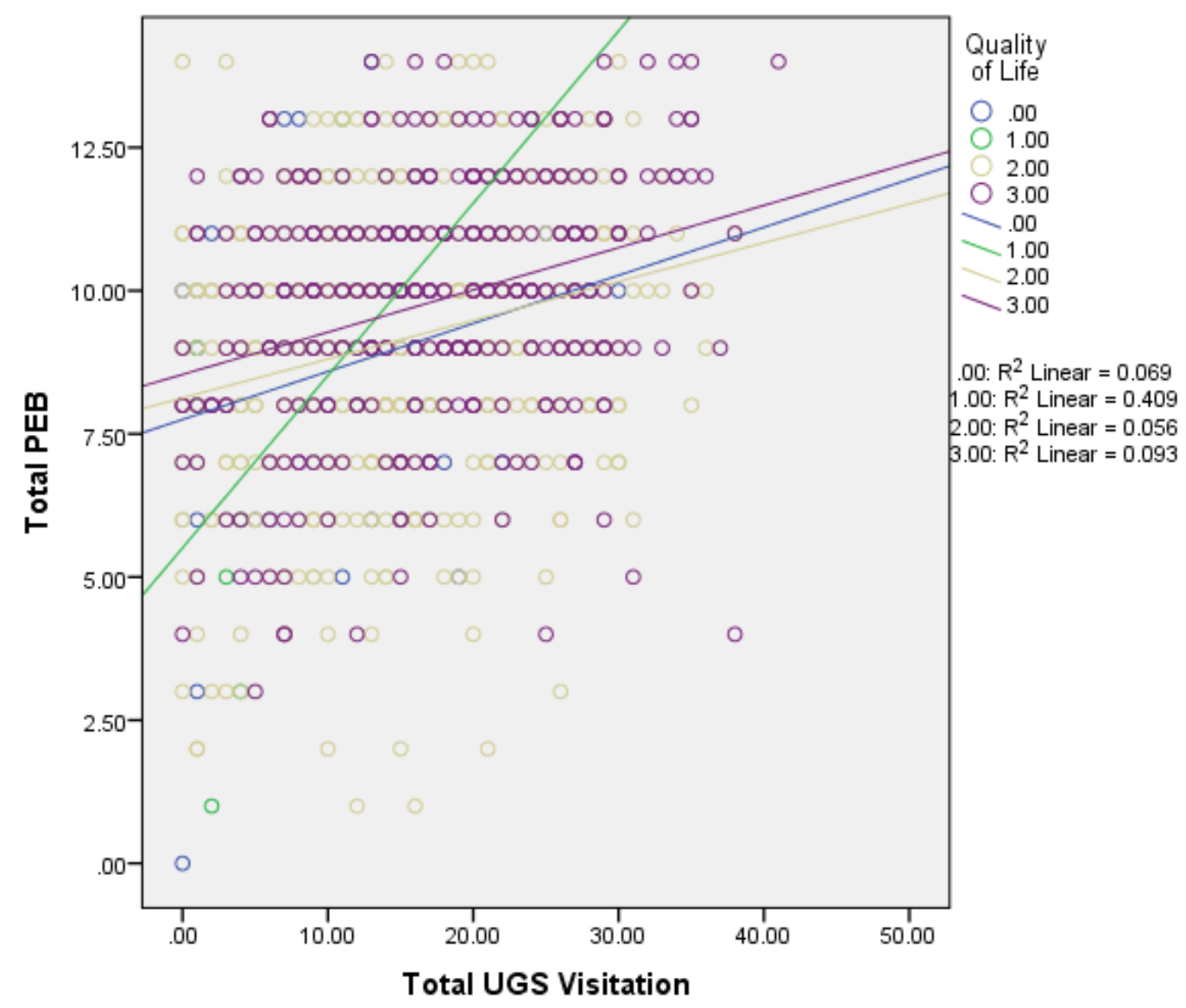

Figure 13 Linear relationship between Total PEB (number of pro-environmental behaviours performed) and Total UGS visitation (combined score from all six urban green space types). Trend lines fitted for four subgroups of Quality of Life. Quality of life depicted by four categories, $.00=$ neither good nor poor quality of life, $1.00=$ extremely poor or poor, $2.00=$ good, $3.00=$ extremely good.

It appears that there is an obvious difference between category one, poor/extremely poor quality of life with the remaining three categories, evidenced by the steeper trend line and stronger $\mathrm{R}^{2}$ value. The next test, statistically assesses whether there is a significant difference between the four categories using logistic regression (equation 47).

\section{Equation 47}

More than seven PEBs $s_{i}=0.433+0.063$ Total UGS -0.350 neither poor nor good $(1.595)(33.900)$ (0.917)

quality of life -0.330 poor/extremely poor quality of life -0.414 good quality of life (0.285)

$\mathrm{R}^{2}=0.049 ; \mathrm{N}=911$. 
Dummy coding allowed each of the four categories to be tested for their relative influence on Total PEB (controlling for urban green space visitation). Overall, quality of life was not a statistically significant contributor to the prediction of performing more than seven pro-environmental behaviours $(\mathrm{p}=0.201)$. When broken down by category, the only category that returned a significant result was that for 'good quality of life'. If someone reported having a good quality of life, the odds that they performed more than seven pro-environmental behaviours was 0.661 times the odds of those that reported an extremely good quality of life. It does seem that if you have an 'extremely' good quality of life relative to 'good' you will be more likely to perform pro-environmental behaviour. However, lack of statistical interaction meant I thus concluded that quality of life does not moderate the relationship between urban green space visitation and proenvironmental behaviour.

\subsection{Summary of Results}

Results from the preceding quantitative analysis can be summarised using the original research questions.

1.0 What is the relationship between urban green space visitations and proenvironmental behaviour in Wellington city?

There is a statistically significant positive relationship existing here. While both the linear and log-linear models were significant, the log-linear model returned a stronger $t$ statistic for the Total UGS $\beta$ coefficient when fitted on the data which was recoded for linearity.

1.1 Do urban green space visitors and non-visitors exhibit a difference in their amount of pro-environmental behaviour?

The odds of a monthly urban green space visitor performing more than seven pro-environmental behaviours is 1.95 times the odds of a less than monthly visitor.

The odds of an urban green space visitor performing more than seven proenvironmental behaviours is 2.538 times the odds of a non-visitor.

1.2 Does the strength and statistical significance of the relationship between urban green space visitation and pro-environmental behaviour change depending on the type of urban green space visited and the type of proenvironmental behaviour measured? 
All types of urban green space show a significant, positive association with pro-environmental behaviour.

Sports fields is the weakest predictor. The best model for explaining proenvironmental behaviour omits town belt and sports field variables

Putting litter in the bin was the only pro-environmental behaviour not statistically associated with urban green space visitation.

Water based pro-environmental behaviours were not better explained by visitation to coastal urban green spaces relative to terrestrial urban green spaces.

1.3 How do socio-demographic factors of gender, age, and household income moderate the relationship between urban green space visitation and proenvironmental behaviour?

The odds of females who visit urban green space performing more than seven pro-environmental behaviours is 3.484 times the odds of non-visitors. For males, the increase in odds was only 1.604.

Being female increases the likelihood of performing more than seven proenvironmental behaviours by 56 percent (controlling for urban green space visitation).

Gender was not a statistically significant moderator.

Middle aged respondents returned the best fitting linear model. The oldest age category returned the weakest fit.

Age was not a statistically significant predictor when controlling for the main effects of urban green space visitation and age.

The odds of those who lived in low income households performing more than seven pro-environmental behaviours and visiting urban green space monthly was 3.485 times the odds for six figure households.

Respondents living in households earning between $\$ 20,001$ and $\$ 30,000$ a year returned the best fitting linear model.

Income was not a statistically significant moderator. 
1.4 Does the relationship between urban green space visitation and proenvironmental behaviour vary across people with different levels of pride in the city?

Pride was not a statistically significant moderator.

1.5 Does the relationship between urban green space visitation and proenvironmental behaviour vary across people with different levels of quality of life?

Quality of life was not a statistically significant moderator. 


\section{CHAPTER 4}

\subsection{Conclusions and Discussion}

Urban green spaces are crucial to the well-being of societies. However, there has been limited recognition of such spaces for their ability to foster connections with nature and build a more environmentally conscious urban population. Urban expansion is seeing more and more people choose to live in cities. Direct contact with nature is thus diminishing to the point where the media is often the only form of nature experience for many and a lack of exposure to nature is posited as a reason behind a poor emotional engagement with environmental issues. Such a claim is supported by Wilson's (1984) biophilia hypothesis. Biophilia underpinned my research and provided the theoretical evidence with which I developed my hypotheses and interpreted the results. Despite its prominence in my study, biophilia does not receive great recognition in the literature. It is hoped my study can start the ball rolling and bring biophilia to the forefront of proenvironmental behaviour change.

Biophilia is an interesting theory which posits humans have not been around long enough for the evolution based tendency to favour living things to be erased from our biological make-up. Humans are programmed to gain pleasurable and positive physiological responses from being in and around nature, a response which is enhanced with direct nature exposure. Biophilia is a relatively new construct within the environment and behaviour literature but has been used more frequently within environmental psychology. Biophilia explains that humans evoke positive emotional and physiological reactions when experiencing nature because the body has evolved an innate inclination to favour living things (Lee, 2012). My study is not the first to investigate such a phenomenon, with Nelson and Shaw (2013) and Nicol (2013) having examined the use of natural areas to enhance pro-environmental attitudes and proenvironmental behaviour. Nelson and Shaw (2013), rather than using urban green space, used natural schoolyards ${ }^{8}$ with school students as the sample population. Nelson and Shaw (2013) predicted that natural schoolyards could provide children with the nature exposure necessary to develop pro-environmental attitudes and, consequently, proenvironmental behaviours. Interestingly, their results did not support their assumptions. While there are differences between ecological sanctuaries confined to the school grounds and the green spaces existing within and around the urban landscape, Freeman

\footnotetext{
${ }^{8}$ Native ecological communities on school grounds to provide a space for students to interact with their natural environment (Nelson and Shaw 2013).
} 
et al. (2012), who looked at the relationship between people and their household gardens, found gardens to also play a role building connections with nature. Interestingly, biophilia was not discussed by any of these authors despite the crux of their research being nature exposure and pro-environmental attitudes. Biophilia deserves greater recognition in the literature and my results give much needed exposure to an undervalued theory.

Policy makers striving to develop pro-environmental behaviour change policies have struggled with a lack of engagement in environmental issues and such a barrier has been attributed to a weak emotional connection with nature. Fostering an emotional connection with nature could aide in pro-environmental behaviour change efforts yet it has not been addressed for such a purpose in the current literature. If biophilia can be fostered through nature exposure therein lies a possible solution for poor engagement in pro-environmental behaviour change policies. There have been findings indicating that children who have grown up in rural relative to urban environments perform more proenvironmental behaviour in adulthood with nature exposure additionally positively linked to pro-environmental attitudes and nature connectedness (Kals et al., 1999, Lohr and Pearson-Mims, 2005, Louv, 2008, Wells and Lekies, 2006). However, urban green space has not specifically been used as a proxy for nature exposure, nor has urban green space visitation been assessed for possible links to pro-environmental behaviour. In order for policy makers to give nature connectedness the attention it deserves in behaviour change policy they require empirical evidence proving an association between nature exposure and pro-environmental behaviour. My study provides such evidence.

Using data collected by the Wellington City Council for their annual Residents Satisfaction Survey, data from the years 2010 through 2012 was collated together to provide a sample size large enough for robust quantitative analysis. Each respondent was asked to indicate their level of visitation across six types of urban green space. In an additional section, respondents were asked to indicate whether or not they performed a pro-environmental behaviour. Fourteen pro-environmental behaviours were included in the survey categorised into two sub groups; resource use and waste reduction, and water pollution minimisation. With two separate types of pro-environmental behaviour measured I was able to address whether visitation to water based nature spaces was more associated with water based pro-environmental behaviours. With literature suggesting that humans gain more positive experiences and develop stronger 
connections to water based spaces, I sought out to determine whether there was indeed potential for water based urban green space to be prioritised for its role in fostering biophilia. However, there was also considerable literature citing the benefits of vegetated spaces on the well-being of visitors and the presence of being around vegetation for nature connectedness. The Wellington City Council data set allowed me to look at the association between visitation to vegetated spaces and pro-environmental behaviour and compare with the association found for the non-vegetated spaces. It is important that the urban green spaces most associated with pro-environmental behaviour be determined if green space marketing is to be used for pro-environmental behaviour change purposes.

Regression techniques were used to provide the necessary $R^{2}$ values and $\beta$ coefficients and to provide the $\mathrm{p}$ values to determine level of significance. Cross tabulation analysis provided the conditional probabilities of performing pro-environmental behaviour across urban green space visitors and non-visitors. Odds ratio analysis was conducted using binary logistic regression as a useful way of communicating how visitation to urban green space could increase the odds of performing pro-environmental behaviour.

When looking at the current literature surrounding pro-environmental behaviour there is great attention placed on what types of people are more likely to be environmentally friendly. Females, the affluent, the well-educated, and the older, have been reported as the socio-demographic categories most likely to perform pro-environmental behaviours. With the Wellington City Council survey recording gender, age, and household income, I was able to use this data to test for moderation. There is obviously far more to the explanation of pro-environmental behaviour than nature exposure alone. However, my study was simply looking to support biophilia by providing statistical evidence of a significant positive association between urban green space visitation and proenvironmental behaviour. Along with this, I wished to determine whether the association differed in accordance with ones gender, age, and income. With females shown to gain more positive experiences from being in nature it was hypothesised that biophilia may be stronger in women. The older, due to having more time to visit nature and perform pro-environmental behaviour, were also assumed to show a stronger presence of biophilia. The affluence hypothesis suggests that those earning more have the ability to focus on issues beyond their immediate selves, suggesting a greater ability to act on biophilic feelings of protecting nature (Givens and Jorgenson, 2011, Cervinka et al., 2012). I was able to create an interaction term and test for moderation using 
regression. If moderation did exist then there is reason to believe that nature exposure as a behaviour change tool is better suited to certain demographics. Moderation means that the relationship is different across the categories included in the test. For example, if there was statistical interaction between gender and urban green space visitation on the prediction of pro-environmental behaviour then the slope of the relationship is significantly different between men and women. While I expect the slope to be steeper for women, the absence of significant interaction meant my hypothesis was rejected.

On top of the socio-demographics included in my analysis, the survey I used also allowed me to investigate pride and quality of life for any statistical moderation. With pride and quality of life both factors that have previously been proven to be associated with nature exposure and pro-environmental attitudes it was predicted that those who held more pride in Wellington city or who scored highly for quality of life, would show a steeper slope in the urban green space visitation - pro-environmental behaviour relationship. If people are living a high quality of life, similar to the affluence hypothesis, they likely have the ability to focus on issues beyond themselves, resulting in a greater chance these individuals can respond to biophilia (more pro-environmental behaviour). Those that have a high sense of pride were expected to be more likely to want to preserve their pride in the city and take action (pro-environmental behaviour) to preserve such a feeling. Despite the evidence suggesting otherwise, my results did not report any statistical moderation of such factors when it came to predicting proenvironmental behaviour through urban green space visitation.

As I conducted my analysis, I continually referenced back to the biophilia hypothesis, the theory of planned behaviour, and the principle of compatibility. All are theories which provide the underpinning evidence for the assumptions I make in the direction of causality (pro-environmental behaviour as the dependent, left hand term and urban green space visitation as the predictor on the right hand side of my regression equations). Throughout my study, I have used evidence from the literature to make the following assumptions; pro-environmental attitudes are positively linked to proenvironmental behaviour, pro-environmental attitudes are linked to emotional connections to nature, and exposure to nature reinforces emotional connections to nature via biophilia. Recall the diagram in figure one illustrating where my study sits in relation to previous research. Through my statistical analysis I have come to a series of conclusions regarding the association between urban green space visitation and proenvironmental behaviour. I next summarise these findings and discuss how such 
findings relate to my original hypotheses. I also outline how my findings contribute to the ultimate aim of my research which was to provide policy makers with evidence supporting nature exposure as a tool for pro-environmental behaviour change.

My overarching hypothesis posited that with more frequent urban green space visitation an individual would be more likely to perform pro-environmental behaviour. My results supported such an assumption with a statistically significant positive association detected. Additionally, the odds of performing more than seven types of proenvironmental behaviour almost doubles if the individual visited urban green space once a month or more. With literature showing nature exposure to be correlated with nature connectedness, it is likely that when an individual is exposed to urban green space they become more connected to nature and develop pro-environmental attitudes conducive to pro-environmental behaviour. Kovacs et al. (2014) concluded there to exist a positive relationship between pro-environmental attitudes and pro-environmental behaviour, which supports my results.

There is research which suggests that the more one is exposed to environmental issues via the media, the more likely they are to be involved in everyday pro-environmental behaviour (Östman, 2013). Biophilia explicitly revolves around physical exposure to nature while Östman's (2013) research focuses on media exposure, i.e., conversations about environmental issues with peers, use of news media, and how such actions promote pro-environmental behaviour by raising awareness of environmental issues. If I am making the conclusion that exposure to nature increases the likelihood that one will perform pro-environmental behaviour, what is the difference to saying that one can also experience nature through the media and feel a similar motivation to act? Policy makers could look to my research and compare it to the conclusions of researchers such as Östman (2013) and decide it is easier to simply advertise environmental issues rather than spend money on promoting and providing for nature participation in the city. However, biophilia works on an engrained biological makeup of human beings and acts to reinforce emotions and motivations for nature preservation that are said to be already coded into our DNA (Wilson, 1984). Experiencing nature through technological and indirect means does not impact on the human body in the same way as physical interaction. There has been research into the physiological reactions the human body evokes with nature exposure and biophilia has been claimed to be most effective when people are physically experiencing nature (as opposed to observing it) (Millar and Millar, 1996). There is no reason to doubt that being in nature has the ability to stir up 
personalised, emotional connections to nature, but whether these emotions are then manifested as pro-environmental behaviour has not been addressed. Until policy makers are provided with empirical evidence which supports the link between urban green space visitation and pro-environmental behaviour, it is unlikely that such a direction will be pursued as a tool for pro-environmental behaviour change. My results provide the starting point for further investigations into urban green space visitation as a proenvironmental behaviour change tool. However, issues surrounding the interpretation of terms such as 'emotional connections' and 'nature connectedness' remain problematic barriers to the successful understanding and acceptance of empirical studies such as my own.

Connections to nature is a broad term and is alternatively referred to as "nature relatedness' by Zelenski and Nisbet (2014). Many nature connectedness studies (as well as biophilia) focus on the emotional connections developed through nature exposure. Emotional connections are complex, developing from positive responses such as happiness, pride, and pleasure, and can manifest into feelings of responsibility, obligation to care, and altruism (Freeman et al., 2012). All such factors are cognitive and have been shown to positively correlate with intentions to perform proenvironmental behaviour. When Azeem et al. (2013) used an economic lens to investigate the determinants of pro-environmental behaviour they concluded that only hedonic motives, which related to those which are considered in terms of pleasant sensations, significantly explained pro-environmental behaviour. Therefore, Azeem et al. (2013) concluded that people will perform pro-environmental behaviour if they receive positive emotions from doing so. Chen et al. (2013) believe that biophilia as a leisure tool (working off humans' tendency to affiliate with nature and enjoy it) has the potential to benefit both human well-being and the natural environment. Biophilia encourages someone to want to preserve the environment as they receive pleasant experiences (biologically) from being in nature, add this to the pleasant experiences derived from recreation performed within the green space itself and urban green space visitation becomes a highly positive practise. Protecting nature is therefore preserving the source of this positive feeling. Azeem et al. (2013) did not come to this conclusion in their discussion highlighting the lack of acknowledgement for biophilia in the economic based sphere. If biophilia is to become mainstream it needs to be considered outside of the environmental psychology discipline. 
Perhaps the biggest caveat of my study is the inability to prove causality and the myriad of factors involved in one's decision to both visit urban green space and perform proenvironmental behaviour. I have concluded that there is an association and posited the direction of association to run from nature exposure to pro-environmental behaviour. Van der Werff et al. (2013) are unknowingly supporting biophilia when they state that some people act in pro-environmental ways because they are intrinsically motivated to do so. However, the authors here link this intrinsic (as opposed to external motivation) to an environmental self-identity. If someone views themselves as an environmentally conscious individual they may be visiting urban green space more often in order to reinforce this identity. Here I end up in full circle. Whether one's predisposed environmental identity means they are both performing pro-environmental behaviour and visiting urban green space in order to remain in line with such an identity, or whether biophilia is the catalyst creating the association between urban green space visitation and pro-environmental behaviour is unable to be proven. Van der Werff et al. (2013) also highlight that obligation-based intrinsic motivation mediates the relationship between environmental self-identity and environmentally friendly behaviour. Mediation means that there is only a relationship between environmental identity and proenvironmental behaviour if there is also present an internal desire to be environmentally friendly. Therefore, biophilia could potentially provide the internal desire necessary for environmental identity to be associated with pro-environmental behaviour.

When mentioning environmental identity, it is important to mention the role of place attachment and how this is related to my findings. Evidence from Folmer et al. (2013) shows place attachment to protected areas is associated with pro-environmental behaviour. What the authors noted, which is important for my study, is that visitors to the wildlife park in question were visiting such a place with the intention of seeing wildlife. Therefore, when results reported an interest in guided wildlife encounters to be significant in predicting emotional attachment to the area of visitation, it was posited that the wildlife experiences were reinforcing rather than creating emotional attachment. Biophilia does not advocate for the creation of emotional bonds but simply the fostering of innate emotions that have been supressed over time, described by Pyle (2002) as the 'extinction of experience'. Even if urban green space visitation is simply acting to reinforce behavioural intentions already present (rather than creating them), it still certifies urban green space visitation as a useful tool for fostering pro-environmental behaviour. 
When discussing why biophilia is so important in fostering pro-environmental behaviour intentions, it is useful to mention the work of Grinde and Patil (2009) who talk of 'discords'. Discords represent any mismatch between a present living condition and the type of environment that the human body was evolutionarily adapted for. For example, a discord has been described as a lack of nature exposure and, more specifically, the visual presence of plants (Grinde and Patil, 2009). Humans subconsciously prefer those environments which we have evolved in. Urban green space visitations as a form of nature exposure are able to provide the necessary stimulation for biophilia to function, which has been suggested by my results. My results showed that that visitation to vegetated urban green spaces better explained pro-environmental behaviour relative to sports fields. On top of this, forward selection regression which produced the most efficient model for predicting pro-environmental behaviour using the least amount of parameters omitted town belt and sports field visitation. It was likely that town belt was not included due to its high correlation with other urban green spaces such as tracks.

Hinds and Sparks (2011) found that people experienced different types of positive emotions in different nature settings (e.g., mountain, forest, beach, river, garden, parks, and farmland fields). Those visiting natural environments more often reported a greater level of positive emotional response in general (Hinds and Sparks, 2011). De Groot et al. (2003) explain how people prefer certain landscapes over other forms when categorised on their level of 'wildness' with Purcell and Lamb (1998) confirming that people prefer more natural landscapes. Robinson (2001) similarly outlined how nature spaces can be categorised according to their relative level of naturalness. I hypothesised that those who visited the more natural forms of urban green space (coasts, walking tracks, town belt) would show a stronger connection between their visitation levels and their level of pro-environmental behaviour due to biophilia working stronger in the more natural settings. While this hypothesis was only partially supported, with parks showing the strongest connection despite this category encompassing many man-made spaces such as playgrounds, there was a weaker connection between pro-environmental behaviour and sports fields (a non-vegetated space). While De Groot et al. (2003) found their sample population to prefer those landscapes that were more 'wild', Hinds and Sparks (2011) showed how more wild spaces also entail higher levels of negative emotions such as isolation and loneliness. My study did not include spaces as 'wild' as those employed by other authors, and by using urban green space, my choice of nature exposure runs the risk of being labelled too commercialised or more cultural rather than 
natural. For the purposes of biophilia, however, all living things are viewed in an equal hierarchy. Pyle (2003) even emphasises that even small spaces of nature in urban settings can be just as effective as big wildlife reserves in awakening biophilia.

Interestingly, as mentioned above, those spaces considered comparatively more natural (e.g., forests and mountains) elicited more negative feelings such as isolation and apprehension, with the most positive responses (fun, relaxation) coming from waterscapes and parks (Hinds and Sparks, 2011). It has been shown that humans prefer water based landscapes due to the evolutionary based need for water for survival (Hartmann and Apaolaza-Ibáñez, 2010). However, my model using coasts as the explanatory variable for pro-environmental behaviour showed an $\mathrm{R}^{2}$ lower than that for visitation to vegetated spaces. I found that visitation to vegetated spaces was more strongly associated with pro-environmental behaviour relative to coast visitation. It is likely that vegetative spaces showed a stronger association with pro-environmental behaviour as biophilia does put forward that human's gain positive reactions from the presence of 'living' things (Lee, 2012). Coasts and harbours are possibly not visibly 'living'. While water based scenes may have been shown to evoke positive emotions, it could be that the positive feelings necessary for pro-environmental orientations are better stimulated in 'living' spaces (e.g., vegetation). Future research should aim to distinguish the type of emotions water based versus terrestrial spaces. It could also be that sports fields attract a different type of individual. Perhaps those holding competitive values are more likely to participate in sport and be less altruistic (a precursor of proenvironmental behaviour) (Tapia-Fonllem et al., 2013). Also, with pleasurable experiences being linked to stronger connections to nature, vegetated spaces could represent those spaces where relaxation and enjoyment is most experienced (Hinds and Sparks, 2011). While it was predicted that there would exist differences between the urban green space types in relation to the strength of the association with proenvironmental behaviour, I found that using the combined variable, Total UGS visitation, returned the strongest $\mathrm{R}^{2}$. It seems that it does not matter which type of urban green space is being experienced, with any form of nature exposure positively associated with pro-environmental behaviour.

There is evidence which suggests that, in many instances, urban green spaces are primarily used as a means of access to a destination or as a thoroughfare (Tzoulas and James, 2010). In other cases, they are sources of recreation and relaxation (Tarrant and Green, 1999). Perelman et al. (2013) confirmed that all visitors to an urban nature 
reserve in Buenos Aires rated the value of nature for enhancing the quality of human life over the value of nature for biodiversity. It would be useful to determine whether the reason one visits urban green space moderates the relationship between visitation and pro-environmental behaviour. It may be that those who visit urban green space for the biodiversity aspect or to specifically experience plants and wildlife may already hold pro-environmental attitudes and a stronger inclination to perform pro-environmental behaviour. It may be that those who visit urban green space for recreational purposes or as thoroughfares are less likely to be responsive to the effects of biophilia. My data set does not allow for the reasoning behind visitation to be determined, with such intentions remaining as a possible explanatory factor in the association between urban green space and pro-environmental behaviour. If people are visiting urban green space more often because they already hold a predisposed appreciation for nature, then it cannot be concluded that nature visitation is increasing their positive environmental attitudes and pro-environmental behaviour intentions. Including questions relating to motivations for visiting UGS would be beneficial and should be noted for future studies.

The second major component of my study, following urban green space visitation, is pro-environmental behaviour. Pro-environmental behaviour is a heavily researched topic within the environmental planning and social psychology discipline and has been approached in different ways. In my case, the pro-environmental behaviours measured were restricted to those chosen by the Wellington City Council. There were 14 proenvironmental behaviours analysed in my study which were organised into two categories, resource use and waste reduction, and water pollution minimisation. Such categories were chosen because the survey was designed to measure the effectiveness of council services. Inconsistency in the measurement of pro-environmental behaviour has been regularly reported in the literature, and my study runs the risk of producing results that are unable to be compared to other studies due to the specific nature of the proenvironmental behaviours included in the survey as well as my method of reporting level of pro-environmental behaviour. There have been studies where different measures of pro-environmental behaviour have been tested for consistency (Stern et al., 1999, Stets and Biga, 2003). Consistency results ranged from low to high indicating that there is considerable difference in how authors are measuring this variable. Future research should aim to employ a widely used and acknowledged method for measuring pro-environmental behaviour to enable accurate comparison of results. 
Importantly, the environmental impact of the behaviours measured in my study were not outlined in detail. There were also some questionable pro-environmental behaviours included in the analysis, such as washing a car at a carwash or on the lawn. While washing a car on a lawn does prevent pollution entering the storm water system (a proenvironmental behaviour), owning a car and using water to wash it seem to be actions contradictory to environmental preservation. Markle (2013) also highlights that people differ in their degree of engagement in environmentally significant behaviour, meaning they may perform a behaviour often or rarely. In my study, pro-environmental behaviour was recorded through a series of 'yes' or 'no' questions. An individual that always recycles will therefore indicate 'yes' on the survey, as would an individual that only recycles occasionally. Without the ability to distinguish between the frequencies of pro-environmental behaviour, I was unable to determine whether there was a stronger correlation between urban green space visitation and frequent pro-environmental behaviour performance. In effect, the conclusions that are made in my analysis potentially hide the presence of stronger associations. Again, it is important that future studies into the relationship between urban green space visitation and proenvironmental behaviour use a pro-environmental behaviour measure that has been reviewed and tested by authors elsewhere.

While there appears to be great support for the hypotheses proposed for research question 1.1 and 1.2, support for hypotheses regarding question 1.3 was varied. Hartig et al. (2007a) have shown women, more so than men, perceive being in nature as a positive experience. Hinds and Sparks (2011) research, which supported the correlation between nature exposure and pro-environmental intentions, had a disproportionately female sample. Therefore, their conclusions were likely only reporting on the association between nature exposure and pro-environmental attitudes provided by the high proportion of females in their sample. Using an unbiased sample of men and women, my results did show that being a female increases the likelihood that someone would perform more pro-environmental behaviours. I cannot say that this difference is due to females being more emotionally responsive to nature exposure, as it may be the function of lifestyle factors associated with being female. I found no interaction between gender and urban green space visitation on the prediction of pro-environmental behaviour, suggesting that being female does not change the relationship. I simply found that females are more likely to perform pro-environmental behaviour, irrespective of urban green space visitation. 
Torgler and Garcia-Valiñas (2007) stated that age effects the way that people experience nature, with older individuals expecting a lower return from investment in proenvironmental behaviour. With that being said, due to a greater array of evidence supporting time spent in nature to be most effective at building nature connections, I predicted older people to be more responsive to the effects of biophilia as they have had more time to develop connections with nature (Åberg and Tapsell, 2013, Arnberger, 2012, Kals et al., 1999, Nisbet et al., 2009). My results did show a statistically significant interaction between age and urban green space visitation on the prediction of pro-environmental behaviour; however, not supporting the hypothesis. I had predicted as age increased, urban green space visitation would be associated with more proenvironmental behaviour. However, my results showed as age increased, the effect of urban green space visitation on pro-environmental behaviour decreased. For the same level of urban green space visitation, a younger person performs more proenvironmental behaviour. It is thus likely that older people are less responsive to biophilia because they see a lower return on investment from their pro-environmental behaviour or they are physically less able to perform the pro-environmental behaviours I examined.

As a person ages, they likely experience a great array of lifestyle changes surrounding their income, spare time for recreation, priorities, and issue awareness. It could be that it is one of these lifestyle differences between the older and younger that is restricting biophilia in older people. The difficulty lies in deciphering which factors are simply covariates, and which are the significant explanatory factors for pro-environmental behaviour. While my hypothesis centred on older individuals being more susceptible to biophilia, there are those who posit that such pre-programmed affiliation is most easily fostered in children. There have been studies showing children who grew up in rural locations hold a greater affiliation to nature when they are older (Wells and Lekie, 2006). A longitudinal study into urban green space visitation and pro-environmental behaviour would be more accurate at determining whether biophilia functions better across certain age groups (e.g., childhood years, teenage years, or middle age, retired).

Applying the affluence hypothesis of Givens and Jorgensen (2011), I expected those with a higher income would be more able to act on the emotional connections to nature fostered through urban green space visitation as they have fewer financial worries. As well as this, the ability to focus on issues beyond one's self has been attributed to income (Cervinka et al., 2012, Givens and Jorgenson, 2011). However, my results did 
not show this to be the case. While arguments regarding the cost of performing some pro-environmental behaviours led me to assume such behaviours are a luxury for the wealthy, my results showed that income does not play a statistically significant role in how pro-environmental behaviour is associated with nature exposure. It could be that those earning more have more demanding jobs and less time for urban green space visitation. While these individuals may be more susceptible to the calming and positive benefits of nature exposure, even if this is reflected in a higher amount of proenvironmental behaviour, their lower rates of urban green space visitation lowers the presence of a positive correlation between urban green space visitation and proenvironmental behaviour.

Venhoeven et al. (2013) reference the role of pro-environmental behaviour on one's well-being (with well-being synonymous with quality of life). I predicted that those with a higher score for quality of life would in turn show correlating scores for high amounts of pro-environmental behaviour. The World Happiness Report claimed that the quest for happiness is intimately linked to the quest for sustainable development, suggesting that those who are happier or have a higher quality of life, may also perform more PEB (Venhoeven et al., 2013). Some studies have shown pro-environmental behaviour to be positively correlated with well-being (Brown and Kasser, 2005), lifesatisfaction (Xiao and Li, 2011), and happiness (Kasser and Sheldon, 2002). Despite such studies, my results failed to return a statistically significant moderating effect of quality of life. The data I used showed limited variation across responses, with the majority reporting a 'good' quality of life. Had I had access to a sample that held a wide variation in perceived quality of life, I may have detected a significant result.

When considering how my results could benefit the behaviour change policy arena, I can look to the work of Fink (2011) who explores biophilia as one of five key elements for contributing to behaviour change towards lower energy consumption. Fink puts forward that biophilia, through instilling an environmental consciousness, is able to foster behaviour change towards a low carbon lifestyle. Emotional connections to environmental issues are necessary for engagement in behaviour change (Lorenzoni et al., 2007). When people feel emotionally connected to an issue they are more likely make more drastic changes to their lifestyles (Lorenzoni et al., 2007). Couple this with those who have concluded the link between nature connectedness and nature visitation (Kals et al., 1999, Nisbet et al., 2009), as well as the documented association between nature exposure and pro-environmental attitudes (Schultz et al., 2004), my research has 
added to the literature calling for an investigation into how visitation to urban green space could promote sustainable behaviour change in an urban population.

There is not going to be a one-size-fits-all solution to pro-environmental behaviour change. The more that can be understood about the possible relationships between environmental attitudes, urban green space visitation and pro-environmental behaviour, and how these are moderated by socio-demographics, is crucial to developing tailored, cost-effective environmental interventions. Simply establishing emotional connections to nature may not be enough to gain widespread change in environmental behaviours, however, I strongly believe it to be the first step. 


\section{APPENDICES}

Copies of the 2010, 2011, and 2012 Wellington City Council Residents Satisfaction Surveys are attached at end of document. 


\section{REFERENCES}

ÅBERG, E. U. \& TAPSELL, S. 2013. Revisiting the River Skerne: The long-term social benefits of river rehabilitation. Landscape and Urban Planning, 113, 94-103.

ABKAR, M., MUSTAFA KAMAL, M. S., MARIAPAN, M., MAULAN, S. \& SHEYBANI, M. 2010. The role of urban green spaces in mood change. Australian Journal of Basic and Applied Sciences, 4, 5352-5361.

AJZEN, I. 1991. The theory of planned behavior. Organizational Behavior and Human Decision Processes, 50, 179-211.

AJZEN, I. \& FISHBEIN, M. 1977. Attitude-behavior relations: A theoretical analysis and review of empirical research. Psychological Bulletin, 84, 888-918.

ARNBERGER, A. 2012. Urban densification and recreational quality of public Urban green spaces-A viennese case study. Sustainability, 4, 703-720.

ARNBERGER, A. \& EDER, R. 2012. The influence of green space on community attachment of urban and suburban residents. Urban Forestry and Urban Greening, 11, 41-49.

ASPINALl, P., MAVROS, P., COYNE, R. \& ROE, J. 2013. The urban brain: Analysing outdoor physical activity with mobile EEG. British Journal of Sports Medicine.

AZEEM, M., HASSAN, M. \& KOUSER, R. 2013. What Causes Pro-Environmental Action: Case of Business Graduates, Pakistan. World Applied Sciences Journal, 24, 1642-1650.

BALRAM, S. \& DRAGIĆEVIĆ, S. 2005. Attitudes toward urban green spaces: integrating questionnaire survey and collaborative GIS techniques to improve attitude measurements. Landscape and Urban Planning, 71, 147-162.

BAMBERG, S., AJZEN, I. \& SCHMIDT, P. 2003. Choice of travel mode in the theory of planned behavior: The roles of past behavior, habit, and reasoned action. Basic and applied social psychology, 25, 175-187.

BARBOSA, O., TRATALOS, J. A., ARMSWORTH, P. R., DAVIES, R. G., FULLER, R. A., JOHNSON, P. \& GASTON, K. J. 2007. Who benefits from access to green space? A case study from Sheffield, UK. Landscape and Urban Planning, 83, 187-195.

BARR, S. 2003. Strategies for sustainability: citizens and responsible environmental behaviour. Area, 35, 227-240.

BARR, S. 2007. Factors Influencing Environmental Attitudes and Behaviors A UK Case Study of Household Waste Management. Environment and behavior, 39, 435-473.

BARR, S., GILG, A. \& SHAW, G. 2011. 'Helping People Make Better Choices': Exploring the behaviour change agenda for environmental sustainability. Applied Geography, 31, 712720.

BEIL, K. \& HANES, D. 2013. The influence of urban natural and built environments on physiological and psychological measures of stress- A pilot study. International Journal of Environmental Research and Public Health, 10, 1250-1267.

BINGLEY, A. 2013. Woodland as working space: Where is the restorative green idyll? Social Science and Medicine.

BLAKE, D. E. 2001. Contextual Effects on Environmental Attitudes and Behavior. Environment and Behavior, 33, 708-725.

BLOCKER, T. J. \& ECKBERG, D. L. 1997. Gender and environmentalism: Results from the 1993 general social survey. SOCIAL SCIENCE QUARTERLY-AUSTIN-, 78, 841-858. 
BOLUND, P. \& HUNHAMMAR, S. 1999. Ecosystem services in urban areas. Ecological Economics, 29, 293-301.

BORD, R. J. \& O'CONNOR, R. E. 1997. The gender gap in environmental attitudes: The case of perceived vulnerability to risk. Social Science Quarterly, 78, 830-840.

BROWN, K. W. \& KASSER, T. 2005. Are psychological and ecological well-being compatible? The role of values, mindfulness, and lifestyle. Social Indicators Research, 74, 349-368.

BUDRUK, M., THOMAS, H. \& TYRRELL, T. 2009. Urban green spaces: A study of place attachment and environmental attitudes in India. Society and Natural Resources, 22, 824-839.

CARIÑANOS, P. \& CASARES-PORCEL, M. 2011. Urban green zones and related pollen allergy: A review. Some guidelines for designing spaces with low allergy impact. Landscape and Urban Planning, 101, 205-214.

CARPENTER, M. 2013. From 'healthful exercise' to 'nature on prescription': The politics of urban green spaces and walking for health. Landscape and Urban Planning.

CERVINKA, R., RÖDERER, K. \& HEFLER, E. 2012. Are nature lovers happy? On various indicators of well-being and connectedness with nature. Journal of health psychology, $17,379-388$.

CHEN, H. M., TU, H. M. \& HO, C. I. 2013. Understanding Biophilia Leisure as Facilitating Well-Being and the Environment: An Examination of Participants' Attitudes Toward Horticultural Activity. Leisure Sciences, 35, 301-319.

CHIESURA, A. 2004. The role of urban parks for the sustainable city. Landscape and Urban Planning, 68, 129-138.

CHOI, H. \& LEE, W. K. Effect of green spaces on urban heat distribution using satellite imagery. 2011. 2286-2289.

COTTRELL, S. P. 2003. Influence of sociodemographics and environmental attitudes on general responsible environmental behavior among recreational boaters. Environment and Behavior, 35, 347-375.

COTTRELL, S. P. \& GRAEFE, A. R. 1997. Testing a conceptual framework of responsible environmental behavior. The Journal of Environmental Education, 29, 17-27.

DAHLSTRAND, U. \& BIEL, A. 1997. Pro-environmental habits: Propensity levels in behavioral change. Journal of Applied Social Psychology, 27, 588-601.

DE GROOT, W. T. \& VAN DEN BORN, R. J. G. 2003. Visions of nature and landscape type preferences: An exploration in The Netherlands. Landscape and Urban Planning, 63, 127-138.

DIAMANTOPOULOS, A., SCHLEGELMILCH, B. B., SINKOVICS, R. R. \& BOHLEN, G. M. 2003. Can socio-demographics still play a role in profiling green consumers? A review of the evidence and an empirical investigation. Journal of Business Research, $56,465-480$.

DIEKMANN, A. \& PREISENDÖRFER, P. 2003. Green and Greenback The Behavioral Effects of Environmental Attitudes in Low-Cost and High-Cost Situations. Rationality and Society, 15, 441-472.

DUPONT, D. P. 2004. Do children matter? An examination of gender differences in environmental valuation. Ecological Economics, 49, 273-286.

ECONOMIST INTELLIGENCE UNIT. 2012. A summary of the Green City Index research series. The Green City Index. Wittelsbacherplatz.

ECONOMIST INTELLIGENCE UNIT. 2013. Australia and New Zealand Green City Index. The Green City Index. Wittelsbacherplatz. 
ERDOGAN, M., AKBUNAR, S., ASIK, U. O., KAPLAN, H. \& KAYIR, C. G. 2012. The Effects of Demographic Variables on Students' Responsible Environmental Behaviors. Procedia - Social and Behavioral Sciences, 46, 3244-3248.

FERGUSON, M. A. \& BRANSCOMBE, N. R. 2010. Collective guilt mediates the effect of beliefs about global warming on willingness to engage in mitigation behavior. Journal of Environmental Psychology, 30, 135-142.

FINGER, M. 1994. From knowledge to action? Exploring the relationships between environmental experiences, learning, and behavior. Journal of Social Issues, 50, 141160.

FINK, H. S. 2011. Promoting behavioral change towards lower energy consumption in the building sector. Innovation, 24, 7-26.

FOLMER, A., HAARTSEN, T. \& HUIGEN, P. P. P. 2013. The role of wildlife in emotional attachment to a nature-based tourism destination. Journal of Ecotourism.

FREEMAN, C., DICKINSON, K. J. M., PORTER, S. \& VAN HEEZIK, Y. 2012. " My garden is an expression of me" : Exploring householders' relationships with their gardens. Journal of Environmental Psychology, 32, 135-143.

GATERSLEBEN, B. 2008. Humans and nature; Ten useful findings from Environmental Psychology research. Counselling Psychology Review, 23, 24-34.

GATERSLEBEN, B., MURTAGH, N. \& ABRAHAMSE, W. 2012. Values, identity and proenvironmental behaviour. Contemporary Social Science, 1-19.

GIFFORD, R., KORMOS, C. \& MCINTYRE, A. 2011. Behavioral dimensions of climate change: drivers, responses, barriers, and interventions. Wiley Interdisciplinary Reviews: Climate Change, 2, 801-827.

GIVENS, J. E. \& JORGENSON, A. K. 2011. The effects of affluence, economic development, and environmental degradation on environmental concern: a multilevel analysis. Organization \& Environment, 24, 74-91.

GOOGLE. 2014. Map of Wellington city. [Online]. Google Maps. Available: https://maps.google.co.nz/maps?q=map+of+wellington+city\&ie=UTF8\&hq=\&hnear=0x6d38b1fc49e974cb:0xa00ef63a213b470, Wellington\&gl=nz\&ei=Rhw RU6WWFYaVkQXa1ICwAQ\&ved=0CCkQ8gEwAA [Accessed 3 March 2014].

GREATER WELLINGTON REGIONAL COUNCIL. 2009a. Wellington Region Open Space Strategy and Action Plan. In: COMMITTEE, W. R. S. (ed.). Greater Wellington Regional Council: Wellington

GREATER WELLINGTON REGIONAL COUNCIL, G. W. R. 2009b. Wellington Regional Open Space Strategy and Action Plan. In: COMMITTEE, W. R. S. (ed.). Wellington: Wellington Regional Strategy Office.

GREENWALD, A. G., POEHLMAN, T. A., UHLMANN, E. L. \& BANAJI, M. R. 2009. Understanding and Using the Implicit Association Test: III. Meta-Analysis of Predictive Validity. Journal of Personality and Social Psychology, 97, 17-41.

GRINDE, B. \& PATIL, G. G. 2009. Biophilia: Does visual contact with nature impact on health and well-being? International Journal of Environmental Research and Public Health, 6, 2332-2343.

GUAGNANO, G. A. \& MARKEE, N. 1995. Regional differences in the sociodemographic determinants of environmental concern. Population and Environment, 17, 135-149.

HAN, K.-T. 2007. Responses to six major terrestrial biomes in terms of scenic beauty, preference, and restorativeness. Environment and Behavior, 39, 529-556.

HARTH, N. S., LEACH, C. W. \& KESSLER, T. 2013a. Guilt, anger, and pride about in-group environmental behaviour: Different emotions predict distinct intentions. Journal of Environmental Psychology, 34, 18-26. 
HARTH, N. S., LEACH, C. W. \& KESSLER, T. 2013b. Guilt, anger, and pride about in-group environmental behaviour: Different emotions predict distinct intentions. Journal of Environmental Psychology, 34, 18-26.

HARTMANN, P. \& APAOLAZA-IBÁÑEZ, V. 2010. Beyond savanna: An evolutionary and environmental psychology approach to behavioral effects of nature scenery in green advertising. Journal of Environmental Psychology, 30, 119-128.

HINDS, J. \& SPARKS, P. 2008. Engaging with the natural environment: The role of affective connection and identity. Journal of Environmental Psychology, 28, 109-120.

HINDS, J. \& SPARKS, P. 2011. The affective quality of human-natural environment relationships. Evolutionary Psychology, 9, 451-469.

HINES, J. M., HUNGERFORD, H. R. \& TOMERA, A. N. 1987. Analysis and synthesis of research on responsible environmental behavior: A meta-analysis. The Journal of environmental education, 18, 1-8.

HOLT, A. R., MOUG, P. \& LERNER, D. N. 2012. The Network Governance of Urban River Corridors. Ecology and Society, 17, 25.

JACKSON, T. 2005. Motivating sustainable consumption. A review of evidence on consumer behaviour and behavioural change. A report to the Sustainable Development Research Network, Surrey: Centre for Environmental Strategies.

JIM, C. Y. \& CHEN, W. Y. 2006. Perception and attitude of residents toward urban green spaces in Guangzhou (China). Environmental Management, 38, 338-349.

JOYE, Y. \& VAN DEN BERG, A. 2011. Is love for green in our genes? A critical analysis of evolutionary assumptions in restorative environments research. Urban Forestry and Urban Greening, 10, 261-268.

KABISCH, N. \& HAASE, D. 2013. Green spaces of European cities revisited for 1990-2006. Landscape and Urban Planning, 110, 113-122.

KAHN JR, P. H. 1997. Developmental psychology and the biophilia hypothesis: Children's affiliation with nature. Developmental review, 17, 1-61.

KAISER, F. G., WÖLFING, S. \& FUHRER, U. 1999. Environmental attitude and ecological behaviour. Journal of Environmental Psychology, 19, 1-19.

KALS, E., SCHUMACHER, D. \& MONTADA, L. 1999. Emotional Affinity toward Nature as a Motivational Basis to Protect Nature. Environment and Behavior, 31, 178-202.

KAPLAN, R. \& KAPLAN, S. 1989. The experience of nature: A psychological perspective, CUP Archive.

KASSER, T. \& SHELDON, K. M. 2002. What makes for a merry Christmas? Journal of Happiness Studies, 3, 313-329.

KELLERT, S. R. 1993a. The biological basis for human values of nature. The biophilia hypothesis, 42-69.

KELLERT, S. R. 1993b. The biophilia hypothesis, Island Press.

KOLLMUSS, A. \& AGYEMAN, J. 2002. Mind the Gap: why do people act environmentally and what are the barriers to pro-environmental behavior? Environmental Education Research, 8, 239-260.

KOVÁCS, J., PÁNTYA, J., MEDVÉS, D., HIDEGKUTI, I., HEIM, O. \& BURSAVICH, J. B. 2014. Justifying environmentally significant behavior choices: An American-Hungarian cross-cultural comparison. Journal of Environmental Psychology, 37, 31-39.

LEE, A. C. K. \& MAHESWARAN, R. 2011. The health benefits of urban green spaces: A review of the evidence. Journal of Public Health, 33, 212-222. 
LEE, P. C. 2012. The Human Child's Nature Orientation. Child Development Perspectives, 6, 193-198.

LOHR, V. I. \& PEARSON-MIMS, C. H. 2005. Children's active and passive interactions with plants influence their attitudes and actions toward trees and gardening as adults. HortTechnology, 15, 472-476.

LORENZONI, I., NICHOLSON-COLE, S. \& WHITMARSH, L. 2007. Barriers perceived to engaging with climate change among the UK public and their policy implications. Global environmental change, 17, 445-459.

LOUV, R. 2008. Last child in the woods: Saving our children from nature-deficit disorder, Algonquin Books.

LUCAS, K., BROOKS, M., DARNTON, A. \& JONES, J. E. 2008. Promoting proenvironmental behaviour: existing evidence and policy implications. Environmental Science \&amp; Policy, 11, 456-466.

MAHMOUDI, P., HATTON MACDONALD, D., CROSSMAN, N. D., SUMMERS, D. M. \& VAN DER HOEK, J. 2013. Space matters: The importance of amenity in planning metropolitan growth. Australian Journal of Agricultural and Resource Economics, 57, 38-59.

MARKETING CHARTS. 2012. Telephone Survey Response Rates Dropping; Accuracy Remains High. [Online]. Watershed Publishing. Available: http://www.marketingcharts.com/wp/direct/telephone-survey-response-rates-droppingaccuracy-remains-high-22107/ [Accessed August 232013.

MARKLE, G. L. 2013. Pro-Environmental Behavior: Does It Matter How It's Measured? Development and Validation of the Pro-Environmental Behavior Scale (PEBS). Human Ecology, 41, 905-914.

MAYER, F. S. \& FRANTZ, C. M. 2004. The connectedness to nature scale: A measure of individuals' feeling in community with nature. Journal of Environmental Psychology, 24, 503-515.

MILLAR, M. G. \& MILLAR, K. U. 1996. The Effects of Direct and Indirect Experience on Affective and Cognitive Responses and the Attitude-Behavior Relation. Journal of Experimental Social Psychology, 32, 561-579.

MINISTRY FOR THE ENVIRONMENT. 2010. Statement of Intent 2010 - 2013. In: ENVIRONMENT, M. F. T. (ed.). Wellington: Ministry for the Environment.

NELSON, N. \& SHAW, B. R. 2013. Testing the use of natural schoolyards to develop stewardship attitudes in students. Journal of Extension, 51.

NICOL, R. 2013. Returning to the richness of experience: is autoethnography a useful approach for outdoor educators in promoting pro-environmental behaviour? Journal of Adventure Education and Outdoor Learning, 13, 3-17.

NISBET, E. K., ZELENSKI, J. M. \& MURPHY, S. A. 2009. The Nature Relatedness Scale Linking Individuals' Connection With Nature to Environmental Concern and Behavior. Environment and Behavior, 41, 715-740.

NISBET, M. C. 2009. Communicating Climate Change: Why Frames Matter for Public Engagement. Environment: Science and Policy for Sustainable Development, 51, 12-23.

NORD, M., LULOFF, A. E. \& BRIDGER, J. C. 1998. The Association of Forest Recreation with Environmentalism. Environment and Behavior, 30, 235-246.

ÖSTMAN, J. 2013. The Influence of Media Use on Environmental Engagement: A Political Socialization Approach. Environmental Communication.

ÖZGÜNER, H., ERASLAN, S. \& YILMAZ, S. 2012. Public perception of landscape restoration along a degraded urban streamside. Land Degradation and Development, 23, 24-33. 
PERELMAN, P., BREUSTE, J., MADANES, N., GROPPER, C., MELIGNANI, E. \& FAGGI, A. 2013. Use of visitors' perception in urban reserves in the Buenos Aires metropolis. Urban Ecosystems, 16, 841-851.

POOLEY, J. A. \& O'CONNOR, M. 2000. Environmental Education and Attitudes Emotions and Beliefs are what is needed. Environment and Behavior, 32, 711-723.

POORTINGA, W., SPENCE, A., WHITMARSH, L., CAPSTICK, S. \& PIDGEON, N. F. 2011. Uncertain climate: An investigation into public scepticism about anthropogenic climate change. Global environmental change, 21, 1015-1024.

PURCELL, A. T. \& LAMB, R. J. 1998. Preference and naturalness: An ecological approach. Landscape and Urban Planning, 42, 57-66.

PYLE, R. M. 2002. Eden in a vacant lot: Special places, species, and kids in the neighborhood of life. Children and nature: Psychological, sociocultural, and evolutionary investigations, 305-327.

PYLE, R. M. 2003. Nature matrix: Reconnecting people and nature. ORYX, 37, 206-214.

ROBINSON, J. M. 2001. The new biophilia: An exploration of visions of nature in western countries. Environmental Conservation, 28, 65-75.

SCANNELL, L. \& GIFFORD, R. 2010. The relations between natural and civic place attachment and pro-environmental behavior. Journal of environmental psychology, 30, 289-297.

SCHÄFFLER, A. \& SWILLING, M. 2013. Valuing green infrastructure in an urban environment under pressure - The Johannesburg case. Ecological Economics, 86, 246257.

SCHIPPERIJN, J., BENTSEN, P., TROELSEN, J., TOFTAGER, M. \& STIGSDOTTER, U. K. 2013. Associations between physical activity and characteristics of urban green space. Urban Forestry and Urban Greening, 12, 109-116.

SCHUlTZ, P., SHRIVER, C., TABANICO, J. J. \& KHAZIAN, A. M. 2004. Implicit connections with nature. Journal of environmental psychology, 24, 31-42.

SCHULTZ, P. W. 2000. New Environmental Theories: Empathizing With Nature: The Effects ofPerspective Taking on Concern for Environmental Issues. Journal of Social Issues, 56, 391-406.

SCHULTZ, P. W. 2002. Inclusion with nature: The psychology of human-nature relations. Psychology of sustainable development. Springer.

SCHULTZ, P. W. \& TABANICO, J. 2007. Self, Identity, and the Natural Environment: Exploring Implicit Connections With Nature1. Journal of Applied Social Psychology, 37, 1219-1247.

STERN, P. C. 2000. Toward a coherent theory of environmentally significant behavior. Journal of Social Issues, 56, 407-424.

STERN, P. C., DIETZ, T., ABEL, T., GUAGNANO, G. A. \& KALOF, L. 1999. A value-beliefnorm theory of support for social movements: The case of environmentalism. Human ecology review, 6, 81-98.

STERN, P. C., DIETZ, T. \& KALOF, L. 1993. Value orientations, gender, and environmental concern. Environment and Behavior, 25, 322-348.

STETS, J. E. \& BIGA, C. F. 2003. Bringing Identity Theory into Environmental Sociology. Sociological Theory, 21, 398-423.

SUSHINSKY, J. R., RHODES, J. R., POSSINGHAM, H. P., GILL, T. K. \& FULLER, R. A. 2013. How should we grow cities to minimize their biodiversity impacts? Global Change Biology, 19, 401-410. 
SWANWICK, C. 2009. Society's attitudes to and preferences for land and landscape. Land Use Policy, 26, S62-S75.

TAPIA-FONLLEM, C., CORRAL-VERDUGO, V., FRAIJO-SING, B. \& DURÓN-RAMOS, M. F. 2013. Assessing sustainable behavior and its correlates: A measure of proecological, frugal, altruistic and equitable actions. Sustainability (Switzerland), 5, 711723.

TARRANT, M. A. \& GREEN, G. T. 1999. Outdoor recreation and the predictive validity of environmental attitudes. Leisure Sciences, 21, 17-30.

TEISL, M. F. \& O'BRIEN, K. 2003. Who cares and who acts?: Outdoor recreationists exhibit different levels of environmental concern and behavior. Environment and Behavior, 35, 506-522.

THØGERSEN, J. \& ÖLANDER, F. 2006. The Dynamic Interaction of Personal Norms and Environment-Friendly Buying Behavior: A Panel Study1. Journal of Applied Social Psychology, 36, 1758-1780.

TORGLER, B. \& GARCIA-VALIÑAS, M. A. 2007. The determinants of individuals' attitudes towards preventing environmental damage. Ecological economics, 63, 536-552.

TRACY, J. L. \& ROBINS, R. W. 2007. Emerging insights into the nature and function of pride. Current Directions in Psychological Science, 16, 147-150.

TSUNETSUGU, Y., LEE, J., PARK, B. J., TYRVÄINEN, L., KAGAWA, T. \& MIYAZAKI, Y. 2013. Physiological and psychological effects of viewing urban forest landscapes assessed by multiple measurements. Landscape and Urban Planning, 113, 90-93.

TZOULAS, K. \& JAMES, P. 2010. Peoples' use of, and concerns about, green space networks: A case study of Birchwood, Warrington New Town, UK. Urban Forestry and Urban Greening, 9, 121-128.

VAN DER WERFF, E., STEG, L. \& KEIZER, K. 2013. It is a moral issue: The relationship between environmental self-identity, obligation-based intrinsic motivation and proenvironmental behaviour. Global Environmental Change, 23, 1258-1265.

VASKE, J. J. \& DONNELLY, M. P. 1999. A value-attitude-behavior model predicting wildland preservation voting intentions. Society and Natural Resources, 12, 523-537.

VENHOEVEN, L. A., BOLDERDIJK, J. W. \& STEG, L. 2013. Explaining the paradox: How pro-environmental behaviour can both thwart and foster well-being. Sustainability (Switzerland), 5, 1372-1386.

VÖLKER, S. \& KISTEMANN, T. 2013. "I'm always entirely happy when I'm here!" Urban blue enhancing human health and well-being in Cologne and Düsseldorf, Germany. Social Science and Medicine, 78, 113-124.

WALKER, A. J. \& RYAN, R. L. 2008. Place attachment and landscape preservation in rural New England: A Maine case study. Landscape and Urban Planning, 86, 141-152.

WATTS, G., MIAH, A. \& PHEASANT, R. 2013. Tranquillity and soundscapes in urban green spaces- predicted and actual assessments from a questionnaire survey. Environment and Planning B: Planning and Design, 40, 170-181.

WEIGEL, R. H. \& NEWMAN, L. S. 1976. Increasing attitude-behavior correspondence by broadening the scope of the behavioral measure. Journal of Personality and Social Psychology, 33, 793.

WELLS, N. M. \& LEKIES, K. S. 2006. Nature and the Life Course: Pathways from Childhood Nature Experiences to Adult Environmentalism. Children, Youth and Environments, 16, $1-24$.

WILSON, E. O. 1984. Biophilia, Harvard University Press. 
XIAO, J. J. \& LI, H. 2011. Sustainable consumption and life satisfaction. Social indicators research, 104, 323-329.

YIN, H. W. \& KONG, F. H. 2005. Spatio-temporal gradient analysis of urban green space in Ji'nan City. Acta Ecologica Sinica, 25, 3010-3018.

STATISTICS NEW ZEALAND. 2013. New Zealand Income Survey: June 2013 Quarter [Online]. Statistics New Zealand. Available: http://www.stats.govt.nz/browse_for_stats/income-andwork/Income/NZIncomeSurvey_HOTPJun13qtr.aspx [Accessed 1 March 2013].

ZELENSKI, J. M. \& NISBET, E. K. 2014. Happiness and Feeling Connected: The Distinct Role of Nature Relatedness. Environment and Behavior, 46, 3-23.

ZHOU, X. \& KIM, J. 2013. Social disparities in tree canopy and park accessibility: A case study of six cities in Illinois using GIS and remote sensing. Urban Forestry and Urban Greening, 12, 88-97. 


\section{WELLINGTON CITY COUNCIL RESIDENTS SATISFACTION SURVEY}

$\begin{array}{lll}\text { Study ID } & \text { FEB10-RSS } & \text { Resp. No. } \\ \text { Interviewer No. } & - & \text { Interview Length } \\ \text { No. Of Queries } & & \text { Reference No. }\end{array}$

\section{Wellington City Council}

Resident Satisfaction Survey

This Questionnaire is split into two parts at question 46. Ask Part A and Part B Demographic Questions.

Good morning/afternoon/evening.

My name is <name> calling from OCIS on behalf of Nielsen the market research company.

We are conducting a survey for Wellington City Council about the services they provide to the people of Wellington. To help me select the right person for this survey, I need to speak to:

- A person living in this household who is 15-24 years of age

- The person living in this household $\mathbf{1 5}$ years of age or over, who had the last birthday (or person to fill quotas).

${ }^{*}$ CHECK QUOTAS*

*IF NOT AVAILABLE ARRANGE CALLBACK*

*REINTRODUCE IF NECESSARY*

The interview will take about 20 minutes of your time. Everything you say will be confidential and the results of the survey will help the Council improve the services it provides to the people of Wellington.

Is it convenient for you now, or shall I make an appointment to call you back at a better time for you.

\section{*IF NECESSARY ARRANGE CALLBACK*}

\section{**** IF ASKED ABOUT WHAT IS THE SURVEY ABOUT ****}

The survey covers a range of topics about services the council currently provides.

Q95 For quality control and training purposes, this call will be recorded and may also be monitored however your answers are confidential and can not be traced back to you personally. Is this ok with you?

$$
\text { Yes....... }
$$

No

\begin{tabular}{|c|c|}
\hline Code & Route \\
& \\
1 & \\
2 & \\
\hline
\end{tabular}

Firstly, can I just check that you actually live in Wellington City, that is, the area extending as far north as Tawa but not including Porirua, Petone or the Hutt Valley?

\begin{tabular}{|l|l|}
\hline Code & Route \\
& \\
\end{tabular}




\begin{tabular}{|c|c|c|}
\hline 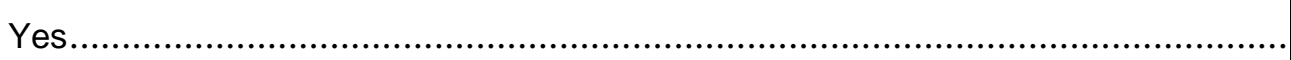 & 1 & Q2 \\
\hline No & 2 & CLOSE \\
\hline
\end{tabular}

I'm sorry but for this survey we need to speak to people that live in Wellington City,

Thank you for your time.

Should you have any queries about this interview my name is <> calling on behalf of Nielsen

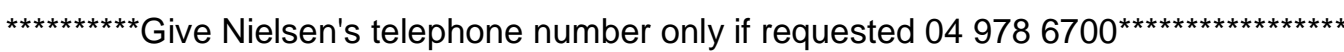

Q2 If yes, close with thanks

Are you by any chance an employee of, or contractor to the Wellington City

Council, or are you an elected representative or a member of a community board?

Yes.

\begin{tabular}{|c|c|}
\hline Code & Route \\
& \\
1 & CLOSE \\
2 & Q3 \\
\hline
\end{tabular}

I'm sorry but we cannot speak to employees or contractors for the Wellington City Council, or elected members of community boards.

Thank you for your time.

Should you have any queries about this interview, my name is <> calling on behalf of Nielsen.

${ }^{\star \star \star \star \star \star \star * *}$ Give Nielsen phone number if requested $049786700^{\star *}$

Q3

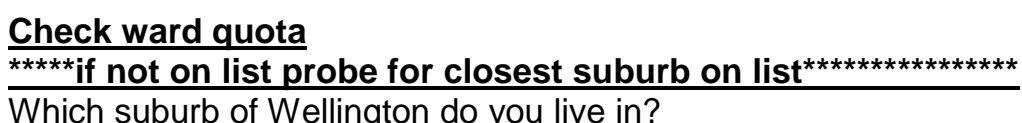

Aro Valley

Berhampore

Breaker Bay

Broadmeadows

Brooklyn

Chartwell

Central City

Churton Park

Crofton Downs

Glenside

Grenada North 


\begin{tabular}{|c|c|}
\hline Happy Valley................................. & 14 \\
\hline Highbury .......... & 15 \\
\hline Horokiwi...... & 16 \\
\hline Houghton Bay ............ & 17 \\
\hline Island Bay.......................................... & 18 \\
\hline Johnsonville ................................... & 19 \\
\hline Kaiwharawhara .......................... & 20 \\
\hline 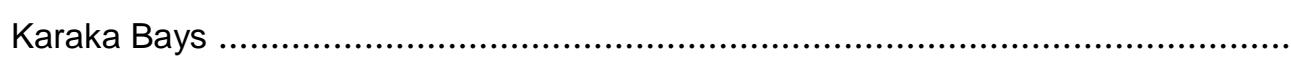 & 21 \\
\hline 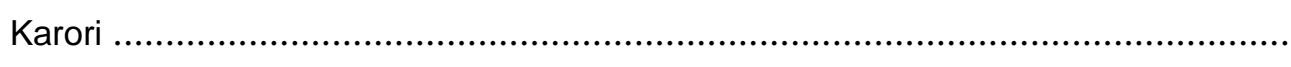 & 22 \\
\hline Kelburn .................................. & 23 \\
\hline Khandallah.......................... & 24 \\
\hline Kilbirnie & 25 \\
\hline Kingston ................................ & 26 \\
\hline Kowhai Park..................................... & 27 \\
\hline Linden ............... & 28 \\
\hline 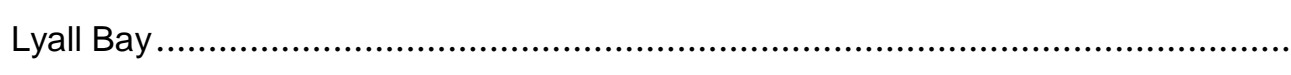 & 29 \\
\hline 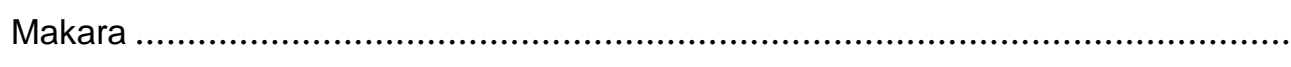 & 30 \\
\hline Makara Beach ....................................... & 31 \\
\hline Maupuia...................................... & 32 \\
\hline Melrose (west - city side) & 33 \\
\hline 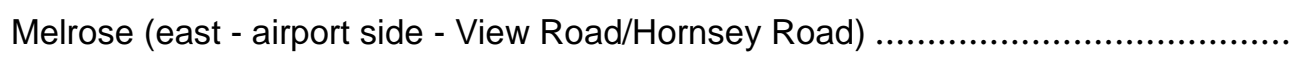 & 34 \\
\hline Miramar & 35 \\
\hline Mitchelltown ........... & 36 \\
\hline Moa Point ......................................... & 37 \\
\hline 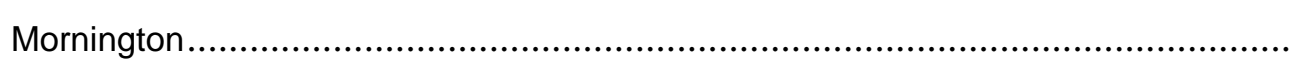 & 38 \\
\hline Mount Cook ............. & 39 \\
\hline Mount Victoria ................................. & 40 \\
\hline Newlands............. & 41 \\
\hline Newtown & 42 \\
\hline 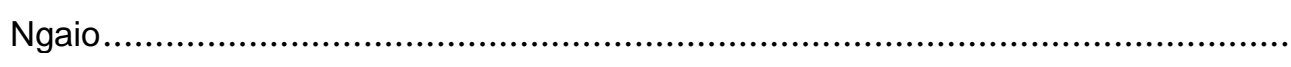 & 43 \\
\hline Ngauranga ............... & 44 \\
\hline Northland ............... & 45 \\
\hline 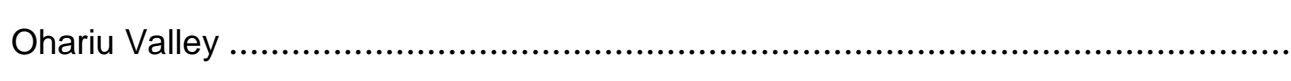 & 46 \\
\hline Oriental Bay ......................... & 47 \\
\hline Owhiro Bay & 48 \\
\hline
\end{tabular}




\begin{tabular}{|c|c|c|}
\hline Paparangi & 49 & \\
\hline Pipitea ......... & 50 & \\
\hline Raroa & 51 & \\
\hline Rongotai ................... & 52 & \\
\hline Roseneath .......................... & 53 & \\
\hline 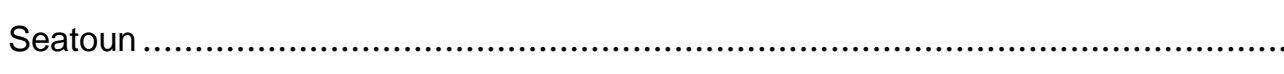 & 54 & \\
\hline Seatoun Bays/Karaka Bays.................................. & 55 & \\
\hline Southgate ........................................... & 56 & \\
\hline Strathmore Park & 57 & \\
\hline Takapu Valley .................. & 58 & \\
\hline Tawa .................................... & 59 & \\
\hline 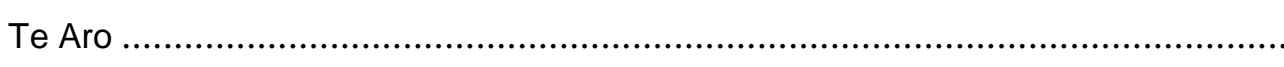 & 60 & \\
\hline Thorndon ............................................ & 61 & \\
\hline Vogeltown................................. & 62 & \\
\hline Wadestown ...................... & 63 & \\
\hline Wilton & 64 & \\
\hline 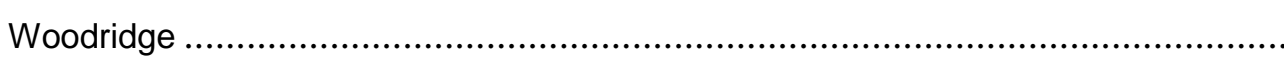 & 65 & \\
\hline (Do not read) Refused ......................................... & 97 & CLOSE \\
\hline 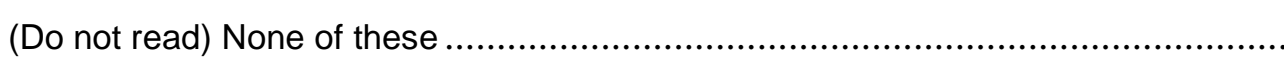 & 98 & CLOSE \\
\hline (Do not read) Don't Know & 99 & CLOSE \\
\hline
\end{tabular}

\section{CLOSE FOR Q3 SUBURB}

I'm sorry but for this survey we need to know which suburb you live in.

Thank you for your time.

Should you have any queries about this interview, my name is <> calling on behalf of Nielsen.

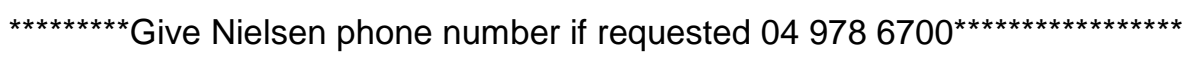

Q4 This question is set from Q3

\section{Don't need to ask, record only from Q3}

Ward

Northern

Q5 $\quad$ Code Gender

\begin{tabular}{|c|c|}
\hline Code & Route \\
& \\
1 & \\
2 & \\
3 & \\
4 & \\
5 & \\
\hline
\end{tabular}

Code $\mid$ Route 
Gender

Male

Female

Q6 If answered 1 terminate

Read out - code one only

Which age group do you fit into?

Under 15 years

CLOSE

15-24 years

1

2

25-39 years

Code

Route

40-59 years

60-64 years

65 years and over.....

(Do not read out) Refused

\section{CLOSE FOR Q6 age}

IF $Q 6=1$

I'm sorry but for this survey we need to speak to people aged 15 or over.

Thank you for your time.

Should you have any queries about this interview, my name is <> calling on behalf of Nielsen.

${ }^{* * \star * \star * * * *}$ Give Nielsen phone number if requested $049786700^{*}$

\section{ELSE}

I'm sorry but for this survey we need your age.

Thank you for your time.

Should you have any queries about this interview, my name is <> calling on behalf of Nielsen.

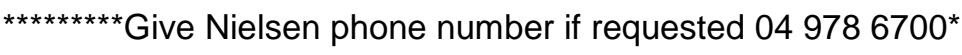

Q7 Read out - code one only

Which of the following best describes your household?

Young couple without children

Household with youngest child under 5

Household with youngest child 5 to 13

Household with youngest child 14 or over 
Older couple - no children or none living at home

Single/one person household

Flat - not a family home

Other - specify

(Do not read) Refused

Q8 Display codes in reverse order 5-4-3-2-1

Code

Read out - code one only

First of all, i'd like you to think about all the dealings you've had with Wellington City Council; all the things it has done over the last 12 months; and all the services and facilities that Wellington City Council provides. Overall, how would you rate the performance of Wellington City Council over the last 12 months? Would you say it was....

Very poor

Poor

Neither good nor poor

Good

Very good

(Do not read) Don't know

Q112 If Q8 code 5 then ask Q112

Why do you say the council's performance is very good?

PROBE Fully
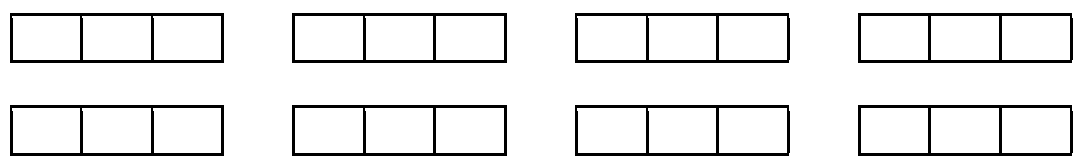

Q113 If Q8 code 4, 3, 2, or 1 ask Q113

What could the council do for you to give them a higher rating?

PROBE Fully
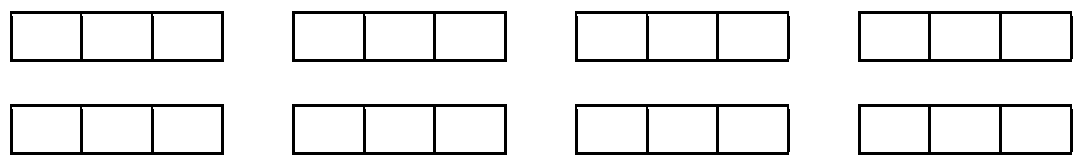

Q88 Read out in reverse order 5-4-3-2-1

Read out, code one only 
Thinking about all the dealings you've had with Wellington City Council; all the things it has done over the last 12 months; and all the services and facilities that Wellington City Council provides, overall, how would you rate the value for money from all the services the Council provides?

Very Poor.

Poor

Neither good nor poor

Good

Very Good

(Do not read out) Don't know

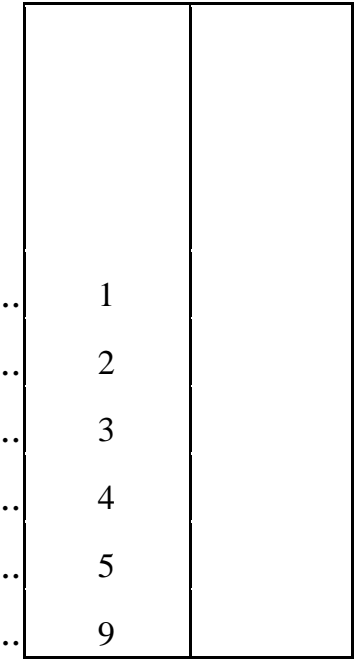

Q10 Read out in reverse order 5-4-3-2-1

Code

Route

Read out, code one only

The next question concerns your overall quality of life.

Would you say that overall your quality of life is ...

Extremely poor

Poor

Neither good nor poor

Good

Extremely good

(Do not read) Don't know

\section{Urban Development}

Q11 Read out in reverse order 5-4-3-2-1 ${ }^{\star \star \star}$ Probe: Is that strongly agree/disagree or just agree/disagree ${ }^{\star \star \star \star \star \star \star \star \star \star ~}$ The next questions cover such things as the design and layout of Wellington. Generally speaking, do you agree or disagree that Wellington is a great place to live?

PROBE Probe: Is that strongly agree/disagree or just agree/disagree

Strongly disagree

Disagree

Neither agree nor disagree

Agree

Strongly agree

(Do not read out) Don't know 
Q12 Read out in reverse order 5-4-3-2-1

***Probe: Is that strongly agree/disagree or just agree/disagree ${ }^{\star \star \star \star \star \star \star \star \star \star \star ~}$

And do you agree or disagree that the different suburbs and communities in

Wellington provide a good variety of places to live in?

PROBE Probe: Is that strongly agree/disagree or just agree/disagree

Strongly disagree

Disagree

Neither agree nor disagree

Agree

Strongly agree

(Do not read out) Don't know

\begin{tabular}{|c|c|}
\hline Code & Route \\
& \\
1 & \\
2 & \\
3 & \\
4 & \\
5 & \\
9 & \\
\hline
\end{tabular}

Q13 Read out in reverse order 5-4-3-2-1

${ }^{\star \star *}$ Probe: Is that strongly agree/disagree or just agree/disagree ${ }^{\star \star \star \star \star \star \star \star \star \star ~}$

And do you agree or disagree that there is a variety of opportunities and places to work in Wellington in your occupation, or for someone with your experience and/or qualifications?

PROBE Probe: Is that strongly agree/disagree or just agree/disagree

Strongly disagree

Disagree

Neither agree nor disagree

Code

Route

Agree

Strongly agree

(Do not read out) Don't know Route

Read out in reverse order 5-4-3-2-1

${ }^{\star \star *}$ Probe: Is that strongly agree/disagree or just agree/disagree ${ }^{\star \star \star \star \star \star \star \star \star \star \star ~}$

And do you agree or disagree that there is a good variety of leisure activities and opportunities to socialise in Wellington?

PROBE Probe: Is that strongly agree/disagree or just agree/disagree

Strongly disagree

Disagree

Neither agree nor disagree

Agree

Strongly agree

(Do not read out) Don't know

Rotate statements

Read out scale 5-4-3-2-1, strongly agree (5) to strongly disagree (1) Read out - code one only 


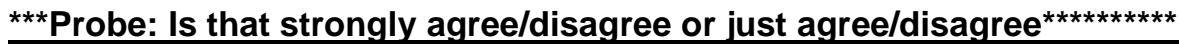

I am going to read you some statements about Wellington and would like you to tell me if you agree or disagree with each statement.

In general, do you agree or disagree with the statement....

PROBE Probe: Is that strongly agree/disagree or just agree/disagree

(R1) Heritage buildings, areas, trees and objects contribute to the city's unique character

(R2) Heritage buildings, areas, trees and objects contribute to your community's unique character

(R3) The city centre is lively and attractive.

(R4) My local suburban centre is lively and attractive

(R5) The city is developing in a way that takes into account its unique urban character and natural environment

\begin{tabular}{|c|c|c|c|c|c|}
\hline $\begin{array}{c}\text { Strongly } \\
\text { disagree }\end{array}$ & Disagree & $\begin{array}{c}\text { Neither } \\
\text { agree nor } \\
\text { disagree }\end{array}$ & Agree & $\begin{array}{c}\text { Strongly } \\
\text { agree }\end{array}$ & $\begin{array}{c}\text { (Do not } \\
\text { read out) } \\
\text { Don't know }\end{array}$ \\
\hline 1 & 2 & 3 & 4 & 5 & 9 \\
1 & 2 & 3 & 4 & 5 & 9 \\
1 & 2 & 3 & 4 & 5 & 9 \\
1 & 2 & 3 & 4 & 5 & 9 \\
1 & 2 & 3 & 4 & 5 & 9 \\
\hline
\end{tabular}

Q114 Rotate statements

Read out in reverse 5,4,3,2,1

In general, how strongly do you agree or disagree that...

PROBE Is that strongly agree/disagree or just agree/disagree

(R1) Heritage buildings, areas, trees and objects are appropriately valued and protected in the central city

(R2) Heritage buildings, areas trees and objects are appropriately valued and protected in your local/suburban area

\begin{tabular}{|c|c|c|c|c|c|}
\hline $\begin{array}{c}\text { Strongly } \\
\text { disagree }\end{array}$ & Disagree & $\begin{array}{c}\text { Neither } \\
\text { agree nor } \\
\text { disagree }\end{array}$ & Agree & $\begin{array}{c}\text { Strongly } \\
\text { agree }\end{array}$ & $\begin{array}{c}\text { (Do not } \\
\text { read out) } \\
\text { Don't know }\end{array}$ \\
\hline 1 & 2 & 3 & 4 & 5 & 9 \\
1 & 2 & 3 & 4 & 5 & 9 \\
\hline
\end{tabular}

Q16 Read out in reverse order 5-4-3-2-1

Read out - code one only

How strongly do you agree or disagree with the statement, 'I feel a sense of pride in the way Wellington looks and feels'?

PROBE Probe: Is that strongly agree/disagree or just agree/disagree

Strongly disagree

Disagree

Neither agree nor disagree

Agree

Strongly agree

(Do not read) Don't know

Code $\quad$ Route 


\section{Social and Recreation / Environmental}

Q17 Read out scale in order: very safe to very unsafe

Read out - code one only

The next few questions are about safety.

Thinking of your overall sense of freedom from crime, how safe or unsafe do you feel in the following situations. Would you say that you were very safe, reasonably safe, somewhat unsafe or very unsafe...?

....and would you say that you were very safe, reasonably safe, somewhat unsafe or very unsafe...?

(R1) In your neighbourhood during the (R2) day

${ }^{(R 3)}$ In your city centre during the day

(R4) In your city centre after dark

\begin{tabular}{|c|c|c|c|c|c|}
\hline $\begin{array}{c}\text { Very } \\
\text { unsafe }\end{array}$ & $\begin{array}{c}\text { Somewhat } \\
\text { unsafe }\end{array}$ & $\begin{array}{c}\text { Reasonabl } \\
\text { y safe }\end{array}$ & Very safe & $\begin{array}{c}\text { (Do not } \\
\text { read out) } \\
\text { Not } \\
\text { applicable: } \\
\text { Don't } \\
\text { come into } \\
\text { city centre }\end{array}$ & $\begin{array}{c}\text { (Do not } \\
\text { read) Don't } \\
\text { know }\end{array}$ \\
\hline 1 & 2 & 3 & 4 & 7 & 9 \\
1 & 2 & 3 & 4 & 7 & 9 \\
1 & 2 & 3 & 4 & 7 & 9 \\
1 & 2 & 3 & 4 & 7 & 9 \\
\hline
\end{tabular}

Q18 Note for post-coding and analysis: Listing of new codes to be approved by WCC before back coding. All new codes to be grouped into broad themes in parenthesis below and nets of themes to be included in data tabulations.

Ask Question 19 if more than one coded

Read in rotated order - code each mention ${ }^{* \star P r o b e: ~ W h a t ~ e l s e ~}{ }^{\star \star \star \star \star \star *}$

The following list I am about to read identifies things that might make people feel unsafe in their neighbourhoods or city. Which of the following, if any, are particularly concerning in Wellington at present?

\section{PROBE What else?}

Poorly lit or dark public areas such as streets, paths and parks

Vandalism such as broken windows in shops and public buildings

Graffiti

Code

Route

Poorly maintained or dangerous public areas such as streets, paths and parks

Traffic, including busy roads and lack of pedestrian facilities 
Dangerous driving including speeding, drunk drivers and so on

Alcohol and drug problems

Car theft or vandalism, and theft from cars

Threatening people and/or people behaving dangerously

(Do not read out) None of these

Other (specify)

(Do not read out) Don't know

Note for post-coding and analysis: Listing of new codes to be approved by WCC before back coding. All new codes to be grouped into broad themes in parenthesis below and nets of themes to be included in data tabulations.

$<$ Ask If more than one coded in question 18> Read in rotated order - code only one

And which of these is of most concern to you at present in Wellington?

Poorly lit or dark public areas such as streets, paths and parks

Vandalism such as broken windows in shops and public buildings

Graffiti

Poorly maintained or dangerous public areas such as streets, paths and parks

Traffic, including busy roads and lack of pedestrian facilities

Dangerous driving including speeding, drunk drivers and so on

Alcohol and drug problems

Car theft or vandalism, and theft from cars

Threatening people and/or people behaving dangerously

(Do not read out) None of these

Other (specify)

(Do not read out) Don't know

Q20 Read out in reverse order 5-4-3-2-1 Read out - code one only

Wellington City is becoming home for an increasing number of people with different lifestyles and cultures and from different countries. Overall do you think this makes the city...? 
A much worse place to live

A worse place to live

Makes no difference

A better place to live

A much better place to live

(Do not read out) Don't know

Q21 Read out in reverse order 5-4-3-2-1

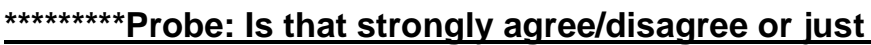

agree/disagree ${ }^{\star \star \star \star \star \star \star \star \star \star \star \star \star \star \star \star \star ~}$

We want to find out about the sense of community strength and spirit in Wellington. In general, do you agree or disagree with the statement......The community works together and people support each other?

PROBE Probe: Is that strongly agree/disagree or just agree/disagree

Strongly disagree

Disagree

Neither agree nor disagree

Agree

Strongly agree

(Do not read out) Don't know

Code $\quad$ Route

51. Community advocacy

Read out in reverse order 5-4-3-2-1

Read out - code one only

Wellington City Council works to help ensure Wellington is made up of strong and thriving communities. How satisfied or dissatisfied are you that the Council provides appropriate services and resources to ensure strong and thriving communities?

Would you say you are...

Very dissatisfied

Quite dissatisfied

Neither satisfied nor dissatisfied

Quite satisfied

Very satisfied

(Do not read out) Don't know 
As far as you are aware, which of the following community support services are provided by the Wellington City Council?

${ }^{\text {(R1) }}$ Grants (e.g. social and recreation, and education)

(R2) Provide support networks for various groups (e.g. Pacific people, young people, senior citizens etc.)

(R3) Organising community events

(R4) Provide advocacy services for various groups (if necessary: that is the Council would act as a go between for services such as public health and various community groups)

(R5) Support for homeless.

\begin{tabular}{|c|c|c|}
\hline Yes & No & Don't know \\
\hline 1 & 2 & 9 \\
1 & 2 & 9 \\
1 & 2 & 9 \\
& & 9 \\
1 & 2 & 9 \\
\hline
\end{tabular}

Do not read - code only one

Have you used a Wellington City Council public toilet in the last 12 months?

Yes.

No

Don't Know

\begin{tabular}{|c|c|}
\hline Code & Route \\
1 & \\
2 & Q26 \\
9 & Q26 \\
\hline
\end{tabular}

Q25 Read out in reverse order 5-4-3-2-1

Read out - code one only

And how satisfied or dissatisfied are you with the cleanliness of Wellington City

Council public toilets?

Would you say you are...?

Very dissatisfied

Quite dissatisfied

Neither satisfied nor dissatisfied

Code $\quad$ Route

Quite satisfied

Very satisfied

(Do not read out) Don't know

Q26 Do not read out - code one only

Do you have essential emergency items in your home? By emergency items I mean a supply of everyday use items that you can easily find and use when an emergency occurs.

Yes.

No

Don't know

Q27 Code None of these as 97

Code Don't know as 99

Read out - code all that apply

As I read out this list please tell me which, if any, of these you would easily be able 
to find in the event of an emergency

Ten litres of bottled water per person in your household

Canned food

Can opener

Other non-perishable food.

First aid kit

A battery operated radio

Spare batteries.

A plastic bucket

Plastic bags

Toilet paper.

Soap.

Disinfectant

A primus or gas barbeque to cook on

Waterproof torches

Other essential medication

Pet supplies

Blankets, towels, sleeping bags

Sturdy footwear

Baby/infant supplies.

Essential documents (birth/marriage certificates, insurance policies)

Family photos.

None of these.

(Do not read out) Don't know

Q28 Ask all respondents

Do not read out - code one only

Do you have an emergency plan for your family or your household about what they will do if a significant emergency occurs?

Yes.

No

\begin{tabular}{|c|c|}
\hline Code & Route \\
1 & \\
2 & \\
9 & \\
\hline
\end{tabular}

Don't know in Q29 , otherwise omit statement 3 and ask all other statements Ask all respondents

Read out - code all that apply

Which of the following have you done. Have you...? 
Discussed ways to get in touch with other family members when an emergency occurs

Made plans for re-uniting with family members when an emergency occurs

Arranged for authorised people to collect children from school, and provided the school with a list of these people for when an emergency occurs

Established a meeting place in the event your house becomes unusable or if family members are separated when an emergency occurs

Allocated tasks for those at home when an emergency occurs eg. turning off power or checking with neighbours

Completed a first aid course

Found out where your nearest Civil Defence Centre is

\begin{tabular}{|l|l|}
01 & \\
02 & \\
03 & \\
04 & \\
05 & \\
06 & \\
07 & \\
98 & \\
99 & \\
\hline
\end{tabular}

(Do not read out) Don't know

\begin{tabular}{|c|c|}
\hline Code & Route \\
& \\
1 & \\
9 & \\
\hline
\end{tabular}

(Do not read) Don't know

Allow entry up to 2 decimal places

Type 000 for zero/none

Type 999 for Don't know

IE 2 HOURS $=002.0,10.5$ HOURS $=010.5$

Thinking now about recreational opportunities in Wellington....

How many hours would you spend in some form of regular physical activity in an average week?

Type in number (use decimal places)

Q31 Check Q7 - if children aged 13 and under in household (code 2/3) ask Q31 , otherwise skip to Q34

Do not read out

Have any of the children aged 13 or under in your household used a Council playground or skate park in the last 12 months?

Yes

No

Code

Route

(Do not read out) Don't know

Q32 Read out in reverse order 5-4-3-2-1

Code

Route

Read out - code one only

How satisfied or dissatisfied were you with the playground or skate park you visited most recently?

Very dissatisfied 
Quite dissatisfied

Neither satisfied nor dissatisfied

Quite satisfied

Very satisfied

(Do not read out) Don't know

Q33 ASK of those with school aged children (Q7=code 2 or 3)

\section{Read out - code only one}

On average, How often do the children aged 13 or under in your household walk to and from school?

Everyday

3-4 days a week

1-2 days a week

Less often

Never

No school aged children

(Do not read out) Don't know

\section{Read out - code all that apply}

Have you used any of the following Wellington City Council recreation facilities in the last 12 months?

A Council Recreation Centre

A Council Swimming Pool

A Council skate park

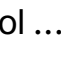

The Mountain Bike Park in Karori

A Council Playground

(Do not read out) None of these

(Do not read out) Don't know

Ask Q35 if Q34 code = 1

Read out in reverse order 5-4-3-2-1

\section{Read out - code one only}

How satisfied or dissatisfied were you with the Wellington City Council's recreation centre you visited most recently? 
Very dissatisfied

Quite dissatisfied

Neither satisfied nor dissatisfied

Quite satisfied

Very satisfied

(Do not read out) Don't know

Q36 Ask Q36 if Q34 code $=2$

Read out in reverse order 5-4-3-2-1

Read out - code one only

And how satisfied or dissatisfied were you with the Wellington City Council's swimming pool you visited most recently?

Very dissatisfied

Quite dissatisfied

Neither satisfied nor dissatisfied

Quite satisfied

Very satisfied

(Do not read out) Don't know

Code

Read out scale 5-4-3-2-1, strongly agree (5) to strongly disagree (1)

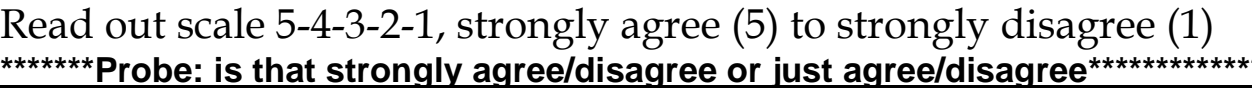
In general do you agree or disagree that Wellington city offers a wide range of recreational activities?

PROBE Is that strongly agree/disagree or just agree/disagree

Strongly disagree

Disagree

Neither agree nor disagree

Agree

Strongly agree

(Do not read out) Don't know

\begin{tabular}{|c|c|}
\hline Code & Route \\
& \\
& \\
1 & \\
2 & \\
3 & \\
4 & \\
5 & \\
9 & \\
\hline
\end{tabular}

\begin{tabular}{|c|c|}
\hline Code & Route \\
& \\
& \\
1 & \\
2 & \\
3 & \\
4 & \\
5 & \\
9 & \\
\hline
\end{tabular}

Q45 Please code others as 99 and don't know as 99

Code

Route

Do not read out - code all that apply

What, if anything, makes it difficult for you to take part in these recreational activities?

Too busy

Poor health

Activity costs too much 
Activity too far away.

No facilities for child care

Weather

Not at a convenient time

Shift work

Lack of motivation

No facilities exist.

Tiredness

Lack of knowledge about how to do it

Environmental factors (eg road conditions, pollution)

Lack of parking/public transport/transport.

None/nothing/not interested

Other (specify).

Don't know .....

\section{Ask all}

Read out scale 5,4,3,2,1

Read out

In general, how easy is it to access Wellington City Council's recreation facilities and programmes?

Very difficult

Quite difficult

Neither easy nor difficult.

Code

Route

Quite easy

Very easy.....

(Do not read out) Don't know

Q104 Scale to be read in reverse 5,4,3,2,1

To provide recreation services and facilities it costs, on average, $\$ 135.12$ per resident per year (or $\$ 0.37$ per day). How strongly do you agree or disagree this is good value for money?

Strongly disagree

Disagree

Neither agree nor disagree

Agree

Strongly agree

(Do not read out) Don't know

\begin{tabular}{|c|c|}
\hline Code & Route \\
& \\
1 & \\
2 & \\
3 & \\
4 & \\
5 & \\
9 & \\
\hline
\end{tabular}

Q37 Read out - code all that apply 
Have you used any of the following Wellington City Council community facilities in the last 12 months?

A public library

A Community Centre

A Community Hall

(Do not read out) None of these

(Do not read out) Don't know

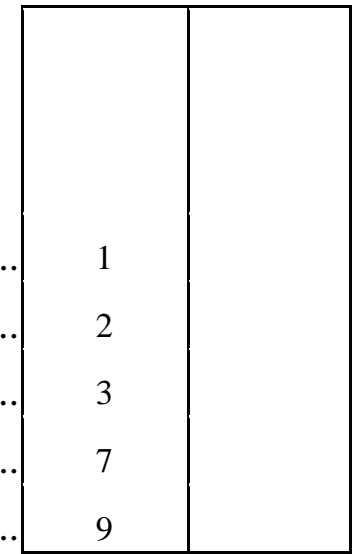

Q97 if Q37 code $=1$ then ask Q97

Read out

How often on average would you use, or visit a Wellington City Council library?

More than once a week

Once a week

Once every 2-3 weeks

Once a month

Once every 2-3 months

Once every 4-6 months

Less often than once every 6 months

(Do Not Read Out) Don't Know.

Q98 if Q37 code $=1$ then ask Q98

Read out

Thinking about the library items that you use, how satisfied or dissatisfied are you with the range and variety of the items available?

Very dissatisfied

Quite dissatisfied

Neither satisfied nor dissatisfied

Quite satisfied

Very satisfied

(Do not read out) Don't know

Q38 If $\mathbf{Q 3 7}$ code $=1$, then ask Q38

Code

Route

Read out in reverse order 5-4-3-2-1

Read out - code one only

Thinking about all the libraries and library services you've used over the last 12 months, how satisfied or dissatisfied are you with the library services overall?

Very dissatisfied

Quite dissatisfied 
Neither satisfied nor dissatisfied

Quite satisfied

Very satisfied

(Do not read out) Don't know

Q99 Scale to be read out in reverse

To provide library services it costs, on average, $\$ 115.61$ per resident per year (or $\$ 0.32$ per day). How strongly do you agree or disagree this is good value for money?

Strongly disagree

Disagree

Neither agree nor disagree

Agree

Strongly agree

(Do not read out) Don't know

\section{Ask of all}

29, 31 \& 33. New \& existing (how often used...)

DO NOT ROTATE

Read out - code one only

In the last twelve months, how often on average have you used...?

....And in the last 12 months how often have you used....?

(R1) Wellington City's coastal areas or beaches

(R2) Botanic gardens, including Otari/Wiltons Bush Native Botanic Reserve

(R3) Wellington City Council parks

(R4) Town Belt or Outer Green Belt

(R5) The city's walking tracks .

(R6) Wellington City Council outdoor sports fields

\begin{tabular}{|c|c|c|c|c|c|c|c|c|}
\hline $\begin{array}{c}\text { Most } \\
\text { days }\end{array}$ & $\begin{array}{c}\text { Once or } \\
\text { twice a } \\
\text { week }\end{array}$ & $\begin{array}{c}\text { Once } \\
\text { every 2- } \\
3 \text { weeks }\end{array}$ & $\begin{array}{c}\text { Once a } \\
\text { month }\end{array}$ & $\begin{array}{c}\text { Once } \\
\text { every 2- } \\
3 \\
\text { months }\end{array}$ & $\begin{array}{c}\text { Once } \\
\text { every 4- } \\
5 \\
\text { months }\end{array}$ & $\begin{array}{c}\text { Once } \\
\text { every 6 6 } \\
\text { months } \\
\text { or less } \\
\text { often }\end{array}$ & $\begin{array}{c}\text { Never } \\
\text { in the } \\
\text { last 12 } \\
\text { months }\end{array}$ & $\begin{array}{c}\text { (Do not } \\
\text { read) } \\
\text { Don't } \\
\text { know }\end{array}$ \\
\hline 01 & 02 & 03 & 04 & 05 & 06 & 07 & 08 & 99 \\
01 & 02 & 03 & 04 & 05 & 06 & 07 & 08 & 99 \\
01 & 02 & 03 & 04 & 05 & 06 & 07 & 08 & 99 \\
01 & 02 & 03 & 04 & 05 & 06 & 07 & 08 & 99 \\
01 & 02 & 03 & 04 & 05 & 06 & 07 & 08 & 99 \\
01 & 02 & 03 & 04 & 05 & 06 & 07 & 08 & 99 \\
\hline
\end{tabular}

Q40 $\quad 30$ \& 33. New (rate quality and maintenance)

Rotate

Ask this question, Q40R1 if Q39 R3 = code 1,2,3,4,5,6 or 7 (have used WCC park in the last 12 months) Ask this question, Q40 R2 if Q39 R5 =code 1,2,3,4,5,6 or 7 (have used walkways and tracks in the last 12 months) 
Ask this question, Q40 R3 if Q39 R6 = code 1,2,3,4,5,6 or 7 (have used WCC outdoor sports field in the last 12 months)

Read out in reverse order 5-4-3-2-1

Read out - code one only

Overall, how satisfied or dissatisfied are you with the quality and maintenance of...

(R1) Wellington City Council parks, (R2) excluding the Botanic Gardens

(R3) Wellington City Council outdoor sports fields

\begin{tabular}{|c|c|c|c|c|c|}
\hline $\begin{array}{c}\text { Very } \\
\text { dissatisfie } \\
d\end{array}$ & $\begin{array}{c}\text { dissatisfie } \\
\text { d }\end{array}$ & $\begin{array}{c}\text { Neither } \\
\text { satisfied } \\
\text { nor } \\
\text { dissatisfie } \\
\mathrm{d}\end{array}$ & satisfied & $\begin{array}{c}\text { Very } \\
\text { satisfied }\end{array}$ & $\begin{array}{c}\text { (Do not } \\
\text { read) Don't } \\
\text { know }\end{array}$ \\
\hline 1 & 2 & 3 & 4 & 5 & 9 \\
1 & 2 & 3 & 4 & 5 & 9 \\
1 & 2 & 3 & 4 & 5 & 9 \\
\hline
\end{tabular}

Q41 31 \& 32. New (cleanliness \& maintenance)

Ask this question, Q41 R1 if Q39 R4 = code 1,2,3,4,5,6 or 7 (have used Town Belt or Outer Green Belt in the last 12 months)

Ask this question, Q41 R2 if Q39 R1 = code 1,2,3,4,5,6 or 7 (have used coastline or beaches in the last 12 months)

Ask this question, Q41 R3 if Q39 R2 = code 1,2,3,4,5,6 or 7 (have used botanic gardens in the last 12 months)

Read out in reverse order 5-4-3-2-1

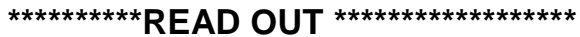

And, overall, how satisfied or dissatisfied are you with the quality and maintenance of...

(R1) The Town Belt or Outer Green Belt.

\begin{tabular}{|c|c|c|c|c|c|}
\hline $\begin{array}{c}\text { Very } \\
\text { dissatisfie } \\
\mathrm{d}\end{array}$ & $\begin{array}{c}\text { dissatisfie } \\
\mathrm{d}\end{array}$ & $\begin{array}{c}\text { Neither } \\
\text { satisfied } \\
\text { nor } \\
\text { dissatisfie } \\
\mathrm{d}\end{array}$ & satisfied & $\begin{array}{c}\text { Very } \\
\text { satisfied }\end{array}$ & $\begin{array}{c}\text { (Do not } \\
\text { read) Don't } \\
\text { know }\end{array}$ \\
\hline 1 & 2 & 3 & 4 & 5 & 9 \\
1 & 2 & 3 & 4 & 5 & 9 \\
1 & 2 & 3 & 4 & 5 & 9 \\
\hline
\end{tabular}

Q100 Ask all

\section{Do not rotate order}

Read out

In general, how easy or difficult is it to access...

Your local park

(R2) Wellington City's coastal areas or beaches.

\begin{tabular}{|c|c|c|c|c|c|}
\hline $\begin{array}{c}\text { Very } \\
\text { difficult }\end{array}$ & $\begin{array}{c}\text { quite } \\
\text { difficult }\end{array}$ & $\begin{array}{c}\text { Neither } \\
\text { easy nor } \\
\text { difficult }\end{array}$ & Quite easy & Very easy & $\begin{array}{c}\text { (Do not } \\
\text { read) Don't } \\
\text { know }\end{array}$ \\
\hline 1 & 2 & 3 & 4 & 5 & 9 \\
1 & 2 & 3 & 4 & 5 & 9 \\
\hline
\end{tabular}


(R3) Green open spaces (such as sports fields, town belts, gardens and parks etc.)

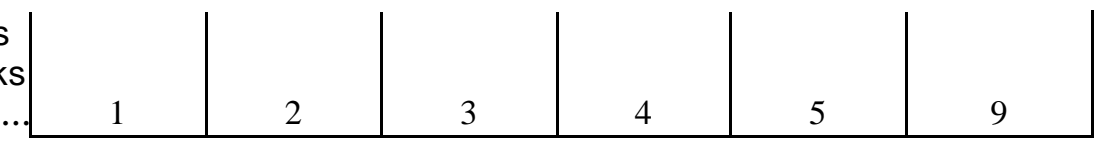

Q101 To provide garden (botanic gardens and parks) and beach and coastal services it costs, on average, $\$ 62.37$ per resident per year (or $\$ 0.17$ per day). How strongly do you agree or disagree this is good value for money?

Strongly disagree

Disagree

Neither agree nor disagree

Code

Route

Agree

Strongly agree.

(Do not read out) Don't know

\begin{tabular}{|c|c|}
\hline Code & Route \\
& \\
1 & \\
2 & \\
3 & \\
4 & \\
5 & \\
9 & \\
\hline
\end{tabular}

Q102 Read out scale in reverse

To provide green open spaces (e.g. sports fields, town belts, parks and gardens) it costs, on average, $\$ 67.49$ per resident per year (or $\$ 0.18$ per day). How strongly do you agree or disagree this is good value for money?

Strongly disagree

Disagree

Neither agree nor disagree

\begin{tabular}{|c|c|}
\hline Code & Route \\
& \\
1 & \\
2 & \\
3 & \\
4 & \\
5 & \\
9 &
\end{tabular}

Q43 Read out scale 5-4-3-2-1, strongly agree (5) to strongly disagree (1) Read out - code one only

${ }^{* * * * \star * *}$ Probe: is that strongly agree/disagree or just agree/disagree ${ }^{*}$

Thinking about Wellington's natural environment overall, do you agree or disagree that it is appropriately managed and protected?

PROBE Probe: Is that strongly agree/disagree or just agree/disagree

Strongly disagree

Disagree

Neither agree nor disagree

Agree

Strongly agree

(Do not read out) Don't know

\begin{tabular}{|l|l|}
\hline Code & Route \\
& \\
& \\
1 & \\
2 & \\
3 & \\
4 & \\
5 & \\
9 & \\
\hline
\end{tabular}

${ }^{\star \star \star \star \star \star \star}$ This is the text used to ask respondents if they want to continue on to part $2^{\star \star \star \star \star \star \star \star \star \star ~}$

Only included so interviewers know what this text is when reading the questionnaire. It should come after 


\section{Part 1 demos as in surveycraft script}

There is more text before this in surveycraft informing respondents what the second part of the survey is about etc.

Is it convenient for you to continue now, or shall I make an appointment to call you back at a more convenient time.

Continue .1

Make appointment......2

Split Questionnaire at this point.

\section{Cultural Wellbeing}

Q46 Rotate statements

Read out scale 5-4-3-2-1, strongly agree (5) to strongly disagree (1)

Read out - code one only

${ }^{\star \star \star}$ Probe: Is that strongly agree/disagree or just agree/disagree ${ }^{\star \star \star \star \star \star \star \star ~}$

Thinking about the community involvement in arts and culture in Wellington, I am going to read you some statements and l'd like you to tell me if you agree or disagree with each statement.

In general, do you agree or disagree with the statement...

...And do you agree or disagree with the statement. ...

PROBE Probe: Is that strongly agree/disagree or just agree/disagree

(R1) Wellington has a culturally rich and diverse arts scene

(R2) Wellington is the events capital of New Zealand.

(R3) Wellington is the arts capital of New Zealand

\begin{tabular}{|c|c|c|c|c|c|}
\hline $\begin{array}{c}\text { Strongly } \\
\text { disagree }\end{array}$ & Disagree & $\begin{array}{c}\text { Neither } \\
\text { agree nor } \\
\text { disagree }\end{array}$ & Agree & $\begin{array}{c}\text { Strongly } \\
\text { agree }\end{array}$ & $\begin{array}{c}\text { (Do not } \\
\text { read out) } \\
\text { Don't know }\end{array}$ \\
\hline 1 & 2 & 3 & 4 & 5 & 9 \\
1 & 2 & 3 & 4 & 5 & 9 \\
1 & 2 & 3 & 4 & 5 & 9 \\
\hline
\end{tabular}

Q96 Read out - code only one

How frequently do you attend, or participate in cultural and arts activities in

Wellington?

At least once a week

At least once a month

Code

Route

Once every six months

At least once a year

Less often

(DO NOT READ) Never

(DO NOT READ) Don't know.

\begin{tabular}{|c|c|}
\hline Code & Route \\
& \\
1 & \\
2 & \\
3 & \\
4 & \\
5 & \\
7 & \\
9 & \\
\hline
\end{tabular}


Wellington City Council is associated with events and festivals such as community festivals, sports events and arts and cultural events. Have you attended any of these types of events and festivals in the last 12 months?

Yes.

No

Don't Know

\begin{tabular}{|c|c|}
\hline Code & Route \\
& \\
1 & \\
2 & Q50 \\
9 & Q50 \\
\hline
\end{tabular}

Q49 28. New (Events \& Festivals)

Read out in reverse order 5-4-3-2-1

Read out - code one only

Overall, how satisfied or dissatisfied are you with these types of events and festivals?

Would you say you are....

Very dissatisfied

Quite dissatisfied

Neither satisfied nor dissatisfied

Quite satisfied

Very satisfied

(Do not read out) Don't know

\begin{tabular}{|c|c|}
\hline Code & Route \\
& \\
& \\
& \\
1 & \\
2 & \\
3 & \\
4 & \\
5 & \\
9 & \\
\hline
\end{tabular}

Q50 36. New

Read out in reverse order $5,4,3,2,1$

Read out - code one only

****Probe: is that strongly agree/disagree or just agree/disagree

Do you agree or disagree that Wellington's distinct local identity, its sense of place, is appropriately valued and protected?

PROBE Is that strongly agree/disagree or just agree/disagree

Strongly disagree

Disagree

Neither agree nor disagree

Agree

Strongly agree

(Do not read out) Don't know

\begin{tabular}{l||} 
\\
\\
\\
1 \\
2 \\
3 \\
4 \\
5 \\
9 \\
\hline
\end{tabular}

\section{Resources and Waste}

Q51 Read out - code all that apply

If asked question relates to households behaviour not individual

The next couple of questions are about waste reduction and rubbish collection. 
Which, if any, of the following things are you doing to try and reduce the amount of waste from your home?

Home composting

Using the Council's kerbside recycling service

Taking things to the recycling stations

Donating things to 2 nd hand shops or charities

Buying refills

Avoiding using plastic bottles or bags

Reusing plastic containers such as food containers

Anything else (specify)

(Do not read out) None of these

Q52 Check Q51, if 2 coded ask $\mathbf{Q 5 2}$ otherwise skip to Q90

Read out - code one only

On average, how often do you put out recycling for WCC kerbside collection?"

Every week

Once every two weeks

Once every three weeks

Once a month

Less often than once a month

(Do not read out) Don't know

Q53 Ask Q53 if $\mathbf{Q 5 2}=$ code 1,2,3,4 or 5 (ie. know how often on average they put out recycling - doesn't have to be in the last month)

Read out $5,4,3,2,1$

Read out - code one only

How satisfied or dissatisfied are you with the Wellington City Council's kerbside recycling?

Very dissatisfied

Quite dissatisfied

Neither satisfied nor dissatisfied

Code

Route

Quite satisfied

Very satisfied

(Do not read out) Don't know 
yellow coloured bags that can be brought at the supermarket, some dairies or from the Council?

Yes.

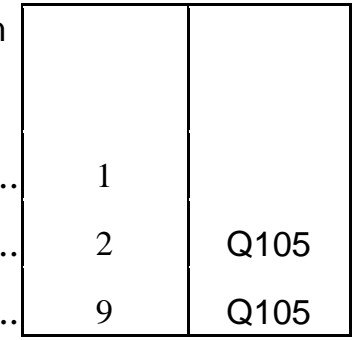

Q91 Check Q90, if 1 coded ask otherwise skip to Q54

Read out - code one only

On average, how often do you put out yellow plastic Council rubbish bags for WCC kerbside collection?

Every week

Once every two weeks

Once every three weeks

Once a month

Less often than once a month

(Do not read out) Don't know

Q92 Ask Q92 if Q91 = code 1,2,3,4 or 5 (ie. know how often on average they put out rubbish bags - doesn't have to be in the last month)

Read out $5,4,3,2,1$

Read out - code one only

How satisfied or dissatisfied are you with the Wellington City Council's kerbside rubbish collection?

Very dissatisfied

Code

Route

Quite dissatisfied

Neither satisfied nor dissatisfied

Quite satisfied

Very satisfied

(Do not read out) Don't know

\section{Ask all}

\section{Scale to be read out in reverse}

To provide waste management services it costs, on average, $\$ 49.40$ per resident per year (or $\$ 0.14$ per day). How strongly do you agree or disagree this is good value for money?

Strongly disagree

Disagree

Neither agree nor disagree 
Strongly agree

(Do not read out) Don't know

Q54 Rotate statements

Read out - code all that apply

If asked question relates to households behaviour not individual

The storm water system collects rainwater from your roof and yard and transfers it to local streams or to the seashore.

Thinking now about the storm water system, which, if any, of the following things are you doing to try and reduce the amount of pollution entering the storm water system?

Dispose of oil, paint or chemicals by putting them out with your household rubbish or taking them for recycling

Washing paint brushes in an inside sink

Pouring all household liquid wastes down an inside sink, toilet or gully trap

Put your litter in a rubbish bin rather than drop it in the street or in the gutter

Pick up droppings left by dogs

Collect sweepings from your driveway, paths, or yard for composting or for disposal with your household rubbish.

Wash the car at a carwash or on the lawn

Anything else (specify)

None of these.

To provide wastewater and storm water services it costs, on average, $\$ 248.71$ per resident per year (or $\$ 0.68$ per day). How strongly do you agree or disagree this is good value for money?

Strongly disagree

Disagree

Neither agree nor disagree

Agree

Strongly agree

(Do not read out) Don't know

\section{Scale to be read in reverse}

To provide water services it costs, on average, $\$ 171.09$ per resident per year (or $\$ 0.47$ per day). How strongly do you agree or disagree this is good value for money?

Strongly disagree

Disagree

Neither agree nor disagree. 
Agree

Strongly agree

(Do not read out) Don't know

\section{Transport}

Q55 Read out in reverse order 5-4-3-2-1

Read out - code one only

I'd now like to ask you about city traffic and the public transport system.

Thinking about moving around the city, how easy is it to drive about in the city?

Would you say it is.....

Very difficult

Quite difficult

Neither easy nor difficult

Quite easy

Very easy

(Do not read out) Never drive/drive in a car.....

(Do not read out) Don't know

\begin{tabular}{|c|c|}
\hline Code & Route \\
& \\
& \\
1 & \\
2 & \\
3 & \\
4 & \\
5 & \\
7 & \\
9 & \\
\hline
\end{tabular}

Q56 Read out in reverse order 5-4-3-2-1

Code

Route

Read out - code one only

And how would you rate how easy it is to walk around the city?

Would you say it is.....

Very difficult

Quite difficult

Neither easy nor difficult.

Quite easy

Very easy.

(Do not read out) Don't know

Q60 Rotate statements

Read out scale 5-4-3-2-1, strongly agree (5) to strongly disagree (1)

Read out - code one only

Do you agree or disagree that public transport in Wellington is...

And do you agree or disagree that public transport in Wellington is....

PROBE Probe: Is that strongly agree/disagree or just agree/disagree

\begin{tabular}{|l|l|l|l|l|l|} 
Strongly & Disagree & Neither & Agree & Strongly & (Do not \\
\hline
\end{tabular}


(R1) Convenient

\begin{tabular}{|c|c|c|c|c|c|}
\hline disagree & & $\begin{array}{c}\text { agree nor } \\
\text { disagree }\end{array}$ & & agree & $\begin{array}{c}\text { read out) } \\
\text { Don't know }\end{array}$ \\
\hline 1 & 2 & 3 & 4 & 5 & 9 \\
1 & 2 & 3 & 4 & 5 & 9 \\
\hline
\end{tabular}

Q108 If code 7 in Q55 do not ask this question

Read scale 5,4,3,2,1

Read out

How satisfied or dissatisfied are you with the availability of on-street parking during the

(R1)

(R2)

\begin{tabular}{|c|c|c|c|c|c|c|}
\hline $\begin{array}{c}\text { Very } \\
\text { dissatisfie } \\
d\end{array}$ & $\begin{array}{c}\text { dissatisfie } \\
d\end{array}$ & $\begin{array}{c}\text { Neither } \\
\text { satisfied } \\
\text { nor } \\
\text { dissatisfie } \\
d\end{array}$ & satisfied & $\begin{array}{c}\text { Very } \\
\text { satisfied }\end{array}$ & $\begin{array}{c}\text { (Do not } \\
\text { read) Don't } \\
\text { know }\end{array}$ \\
\cline { 2 - 7 } & 1 & 2 & 3 & 4 & 5 & 9 \\
\hline
\end{tabular}

Q62 Read out in reverse order 5-4-3-2-1

Read out - code one only

**Probe: is that strongly agree/disagree, or just agree/disagree ${ }^{\star \star \star \star \star \star \star \star}$

Do you agree or disagree that the city's transport system, that is the roads and the public transport, allows easy access from the suburbs to the city?

PROBE Probe: Is that strongly agree/disagree or just agree/disagree

Strongly disagree

Disagree

Neither agree nor disagree

Agree

Strongly agree

(Do not read out) Don't know

\begin{tabular}{|c|c|}
\hline Code & Route \\
& \\
& \\
1 & \\
2 & \\
3 & \\
4 & \\
5 & \\
9 & \\
\hline
\end{tabular}

Q109 Scale read out in reverse

To provide transport network services it costs, on average, $\$ 186.35$ per resident per year (or $\$ 0.51$ per day). How strongly do you agree or disagree this is good value for money?

Strongly disagree

Disagree

Neither agree nor disagree

Code

Route

Agree

Strongly agree

(Do not read out) Don't know

\begin{tabular}{|c|c|}
\hline Code & Route \\
\hline 1 & \\
\hline 2 & \\
\hline 3 & \\
\hline 4 & \\
\hline 5 & \\
\hline 9 & \\
\hline Code & Route \\
\hline
\end{tabular}

Q63 Do not read - code one only

Do you travel into central Wellington most weekdays? 
Yes

\begin{tabular}{|l|l|}
\hline 1 & \\
2 & Q68 \\
9 & Q68 \\
\hline
\end{tabular}

Q64 Code other 98

Code don't know 99

Do not read out - Code one only

What is your main method of travelling to Wellington on these occasions?

Motorbike

\begin{tabular}{|l|l|}
\hline Code & Route \\
& \\
& \\
01 & \\
02 & \\
03 & \\
05 & \\
07 & \\
08 & \\
09 & \\
98 & \\
99 & \\
\hline
\end{tabular}

Q65 Do not read out - Code one only

Is there anything that prevents you from using your preferred method of transport?

Yes.

No

Don't know.....

\begin{tabular}{|c|c|}
\hline Code & Route \\
1 & \\
2 & Q68 \\
9 & Q68 \\
\hline
\end{tabular}

Q66 Code other 98

Code don't know 99

Do not read out - Code one only

How would you prefer to travel into Central Wellington most weekdays?

PROBE If say public transport, ask: What type of public transport?

Car.

Code

Route

Motorbike

Bus.

Taxi

Train

Cable Car 
Bicycle

Walk

Scooter

Skateboard

Public transport non-specific

Other (specify).

Don't know.....

Q67 Code Other as 98

Code Don't know as 99

Do not read out - code all that apply Probe fully

What stops you travelling by <insert response from Q66> into Central Wellington most weekdays?

PROBE Probe fully

Very heavy/heavy traffic

Buses infrequent/overcrowded

Code

Route

Roadworks.

Parking

Train problems/line signal problems/running late

Bus drivers/bus breakdowns/trolley lines down

Roads too narrow/lane markings/no room for bikes/bike lanes.

Other (specify).....

Don't know.....

\section{Do not read out - Code one only}

Do you travel into or through central Wellington during weekday peak traffic times, that is between 7 and 9 in the morning or 4 and 6 in the evening?

Yes.

No

Don't know.....

\begin{tabular}{|c|c|}
\hline Code & Route \\
1 & \\
2 & Q70 \\
9 & Q70 \\
\hline
\end{tabular}

Q69 Do not read out - Code one only

Do you believe peak traffic volumes are acceptable?

Yes.

No

Don't know.....

\begin{tabular}{|c|c|}
\hline Code & Route \\
1 & \\
2 & \\
9 & \\
\hline
\end{tabular}

Q70 Read out - code one only

Now l'd like you to think about the on road cycleways. Have you used any of Wellington city's on road cycleways in the last 12 months? 


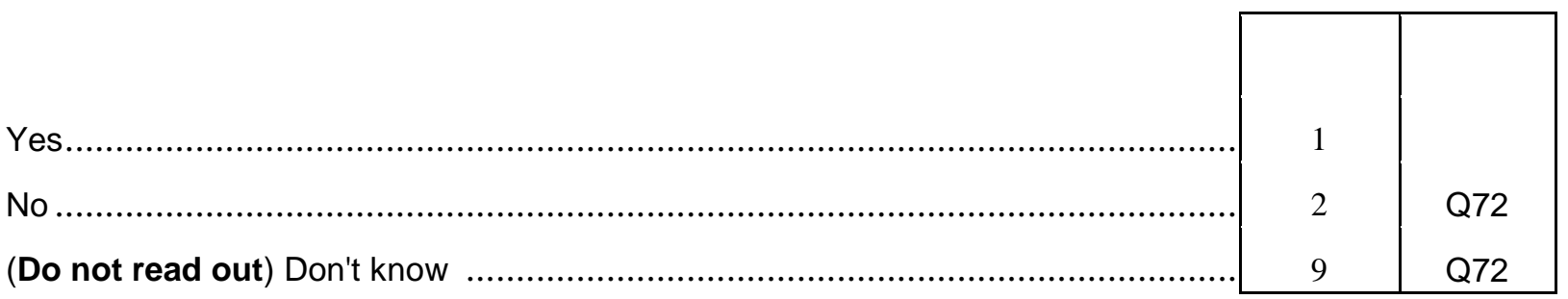

Q71 Read out scale in order: very satisfied to very dissatisfied Read out - code one only

How satisfied or dissatisfied are you with Wellington City's cycleways for....

And how satisfied or dissatisfied are you with Wellington City's cycleways for....

\begin{tabular}{|c|c|c|c|c|c|c|c|}
\hline & \begin{tabular}{|c|} 
Very \\
dissatisfie \\
d
\end{tabular} & \begin{tabular}{|c|} 
Quite \\
dissatisfie \\
d
\end{tabular} & \begin{tabular}{|c|} 
Neither \\
satisfied \\
nor \\
dissatisfie \\
d
\end{tabular} & $\begin{array}{c}\text { Quite } \\
\text { satisfied }\end{array}$ & $\begin{array}{c}\text { Very } \\
\text { satisfied }\end{array}$ & \begin{tabular}{|c|} 
(Do not \\
read out) \\
Not \\
applicable \\
:Don't use \\
cycleway \\
s or \\
public \\
transport \\
\end{tabular} & $\begin{array}{l}\text { (Do not } \\
\text { read) } \\
\text { Don't } \\
\text { know }\end{array}$ \\
\hline${ }^{(\mathrm{R} 1)}$ Safety & 1 & 2 & 3 & 4 & 5 & 7 & 9 \\
\hline${ }^{(R 2)}$ How well they are maintained.. & 1 & 2 & 3 & 4 & 5 & 7 & 9 \\
\hline
\end{tabular}

Q72 Read out in reverse order 5-4-3-2-1

Read out - code one only

How would you rate the condition of the city's roads?

Very poor

Poor

Neither good nor poor

Code $\quad$ Route

Good

Very Good

(Do not read out) Don't know

\begin{tabular}{|c|c|}
\hline Code & Route \\
& \\
1 & \\
2 & \\
3 & \\
4 & \\
5 & \\
9 & \\
\hline
\end{tabular}

Q110 Read out in reverse order 5,4,3,2,1

\section{Read out}

And how would you rate the condition of the city's footpaths?

Very poor

Code

Route

Poor

Neither good nor poor

Good

Very Good 
(Do not read out) Don't know

Q73 Read out in reverse order 5-4-3-2-1

\begin{tabular}{|c|c|}
\hline Code & Route \\
& \\
1 & \\
2 & \\
3 & \\
4 & \\
5 & \\
9 & \\
\hline
\end{tabular}

Read out - code one only

How satisfied or dissatisfied are you with the quality of the street cleaning in central

Wellington?

Very dissatisfied

Quite dissatisfied

Neither satisfied nor dissatisfied

(Do not read out) Don't know

Read out - code one only

How satisfied or dissatisfied are you with the quality and maintenance of road side vegetation? By maintenance I mean kept free of weeds and trimmed back to be clear of the edges of the road. Are you...

Very dissatisfied

Quite dissatisfied

Neither satisfied nor dissatisfied

Quite satisfied

Very satisfied

(Do not read out) Don't know

Q75 Read out in reverse order 5-4-3-2-1

Read out - code one only

Now thinking about street lighting, how satisfied or dissatisfied are you with...?

Would you say you are...?

....and how satisfied or dissatisfied are you with.......

would you say you are....?

(R1) Street lighting in the central city

\begin{tabular}{|c|c|c|c|c|c|}
\hline $\begin{array}{c}\text { Very } \\
\text { dissatisfie } \\
d\end{array}$ & $\begin{array}{c}\text { Quite } \\
\text { dissatisfie } \\
\text { d }\end{array}$ & $\begin{array}{c}\text { Neither } \\
\text { satisfied } \\
\text { nor } \\
\text { dissatisfie } \\
\mathrm{d}\end{array}$ & $\begin{array}{c}\text { Quite } \\
\text { satisfied }\end{array}$ & $\begin{array}{c}\text { Very } \\
\text { satisfied }\end{array}$ & $\begin{array}{c}\text { (Do not } \\
\text { read out) } \\
\text { Don't know }\end{array}$ \\
\hline 1 & 2 & 3 & 4 & 5 & 9
\end{tabular}


${ }^{(\mathrm{R} 2)}$ Street lighting in your suburban area



\begin{tabular}{l|l}
1 & 2 \\
\hline
\end{tabular}

\begin{tabular}{l|l|l|l}
3 & 4 & 5 \\
\hline
\end{tabular}

\section{Governance and citizen information}

Q76 Rotate codes 1 and 3, do not rotate 2

Read out - code one only

We just have a few more questions to go. I'd like you to think about the contact you have with Wellington City Council and the involvement of the community in Council decision-making.

In your view, does the Council consult you....?

Not enough

The right amount

Too much

(Do not read out) Don't know

\begin{tabular}{|c|c|}
\hline Code & Route \\
& \\
& \\
1 & \\
2 & \\
3 & \\
9 & \\
\hline
\end{tabular}

Q77 Read out in reverse order 5-4-3-2-1

Read out - code one only

And how satisfied or dissatisfied are you with the way the Council involves people in decision-making?

Would you say you are...?

Very dissatisfied

Quite dissatisfied

Neither satisfied nor dissatisfied

Code

Route

Quite satisfied

Very satisfied

(Do not read out) Don't know

Q78 63/64/65 New

Rotate statements

Read out scale 5-4-3-2-1, strongly agree (5) to strongly disagree (1)

\section{Read out - code one only}

\section{${ }^{\star *}$ Probe: is that strongly agree/disagree or just agree/disagree ${ }^{\star \star \star \star}$}

In general, do you agree or disagree with the statement....

and do you agree or disagree with the statement....

PROBE Probe: Is that strongly agree/disagree or just agree/disagree

(R1) I understand how Wellington City

\begin{tabular}{|c|c|c|c|c|c|}
\hline $\begin{array}{c}\text { Strongly } \\
\text { disagree }\end{array}$ & Disagree & $\begin{array}{c}\text { Neither } \\
\text { agree nor } \\
\text { disagree }\end{array}$ & Agree & $\begin{array}{c}\text { Strongly } \\
\text { agree }\end{array}$ & $\begin{array}{c}\text { (Do not } \\
\text { read out) } \\
\text { Don't know }\end{array}$ \\
\hline 1 & 2 & 3 & 4 & 5 & 9
\end{tabular}


Council makes decisions

(R2) Wellington City Council makes decisions that are in the best interests of the city

(R3) Information from Wellington City Council is easy to access

\begin{tabular}{|l|l|l|l|l|l|}
\hline & & & & & \\
1 & 2 & 3 & 4 & 5 & 9 \\
1 & 2 & 3 & 4 & 5 & 9 \\
\hline
\end{tabular}

Q79 Read out - code one only

Overall, how much influence do you feel the public has on the decisions the Wellington City Council makes? Would you say the public has...

No influence

Small influence

Some influence

3

Large influence.

(Do not read out) Don't know

\begin{tabular}{|c|c|}
\hline Code & Route \\
1 & \\
2 & \\
3 & \\
4 & \\
9 & \\
\hline
\end{tabular}

\section{Ask Part A and Part B Demographics \\ Demographics}

Q80 Code other 98

Code don't know 99

Read out - code all that apply

Finally just a few questions about yourself and your household, to make sure we have talked to a good cross-section of Wellingtonians.

Which ethnic group or groups do you belong to?

NZ European

\begin{tabular}{|l|l|}
\hline Code & Route \\
& \\
01 & \\
02 & \\
03 & \\
04 & \\
05 & \\
06 & \\
07 & \\
08 & \\
98 & \\
99 & \\
\hline
\end{tabular}

Q89 Read out code only one

What type of home internet connection do you have?

Dial-up modem or regular connection.

Broadband 
(Do not read out) Don't have a home internet connection

Own your home

Rent

Live with parents/other relatives/caregivers

Other (specify)

(Do not read out) Don't know

\begin{tabular}{l|l|} 
& \\
1 \\
2 \\
3 \\
4 & \\
9 & \\
\hline
\end{tabular}

Q82 Read out - code one only

Approximately, what is your total household income (that is, from all income earners in your household as well as income from other sources, before tax)?

$\$ 20,000$ or less a year

1

$\$ 20,001-\$ 30,000$

$\$ 30,001-\$ 50,000$

$\$ 50,001-\$ 70,000$

$\$ 70,000-\$ 100,000$

More than $\$ 100,000$.

(Do not read out) Refused or don't know

\section{Q83 Do not read out - Code one only}

From time to time, Wellington City Council undertakes specific research about topics of current interest. Would you be willing for us to call you again in the future to see if you are interested in taking part in such research for the Wellington City Council?

Yes.

No

Don't know

If respondent agrees

Can you let me have your contact details please, so that if we call you back we can ask for you by name?

\section{Record contact details}

Name:

\section{Phone Number:}


Thanks, that's all the questions I have for you. Should you have any queries about this interview my name is...... calling on behalf of Nielsen

As this is market research, it is carried out in compliance with the Privacy act and the information you provided will be used only for research purposes. Under the Privacy Act, you have the right to request access to the information you have provided.

Interviewer name: Date:

Interviewer pay number:

Interview Time

Start Time:

Finish Time:

Duration of Interview: 


\section{WELLINGTON CITY COUNCIL RESIDENTS SATISFACTION SURVEY}

\begin{tabular}{lll} 
Study ID & FEB11-RSS & Resp. No. \\
Interviewer No. & - & $\begin{array}{l}\text { Interview Length } \\
\text { No. Of Queries }\end{array}$ \\
\hline
\end{tabular}

\section{Wellington City Council}

Resident Satisfaction Survey

\section{This Questionnaire is split into two parts at question 46. Ask Part A and Part B Demographic Questions.}

Good morning/afternoon/evening.

My name is <name > calling from OCIS on behalf of Nielsen the market research company.

We are conducting a survey for Wellington City Council about the services they provide to the people of Wellington. To help me select the right person for this survey, I need to speak to:

- A person living in this household who is 15-24 years of age

- The person living in this household 15 years of age or over, who had the last birthday (or person to fill quotas).

\section{${ }^{*}$ CHECK QUOTAS*}

\section{*IF NOT AVAILABLE ARRANGE CALLBACK*}

\section{${ }^{*}$ REINTRODUCE IF NECESSARY*}

The interview will take about 20 minutes of your time. Everything you say will be confidential and the results of the survey will help the Council improve the services it provides to the people of Wellington.

Is it convenient for you now, or shall I make an appointment to call you back at a better time for you.

\section{*IF NECESSARY ARRANGE CALLBACK*}

\section{**** IF ASKED ABOUT WHAT IS THE SURVEY ABOUT ****}

The survey covers a range of topics about services the council currently provides.

Q95 For quality control and training purposes, this call will be recorded and may also be monitored however your answers are confidential and can not be traced back to you personally. Is this ok with you?

$$
\begin{aligned}
& \text { Yes. } \\
& \text { No... }
\end{aligned}
$$

\begin{tabular}{|c|c|}
\hline Code & Route \\
& \\
1 & \\
2 & \\
\hline
\end{tabular}

Q1 Do not read out

\section{If no, close with thanks}

Firstly, can I just check that you actually live in Wellington City, that is, the area extending as far north as Tawa but not including Porirua, Petone or the Hutt Valley?

$$
\text { Yes. }
$$

\begin{tabular}{|c|c|}
\hline Code & Route \\
& \\
1 & Q2 \\
2 & CLOSE \\
\hline
\end{tabular}


I'm sorry but for this survey we need to speak to people that live in Wellington City,

Thank you for your time.

Should you have any queries about this interview my name is <> calling on behalf of Nielsen

*Give Nielsen's telephone number only if requested $049786700^{*}$

Q2 If yes, close with thanks

Are you by any chance an employee of, or contractor to the Wellington City

Council, or are you an elected representative or a member of a community board?

Yes.

No

\begin{tabular}{|c|c|}
\hline Code & Route \\
& \\
1 & CLOSE \\
2 & Q3 \\
\hline
\end{tabular}

I'm sorry but we cannot speak to employees or contractors for the Wellington City Council, or elected members of community boards.

Thank you for your time.

Should you have any queries about this interview, my name is <> calling on behalf of Nielsen.

${ }^{\star * \star \star \star * \star *}$ Give Nielsen phone number if requested 049786700

Q3

Check ward quota

Whif not on list probe for closest suburb on list ${ }^{\star \star \star \star \star \star \star \star \star \star \star \star \star \star \star \star \star \star \star ~}$

Which suburb of Wellington do you live in?

Aro Valley

Berhampore

Breaker Bay

Broadmeadows

Brooklyn.

Chartwell.

Central City

Churton Park

Crofton Downs.

Glenside

Grenada North.

Grenada Village.

Hataitai

Happy Valley.

Highbury

Horokiwi. 


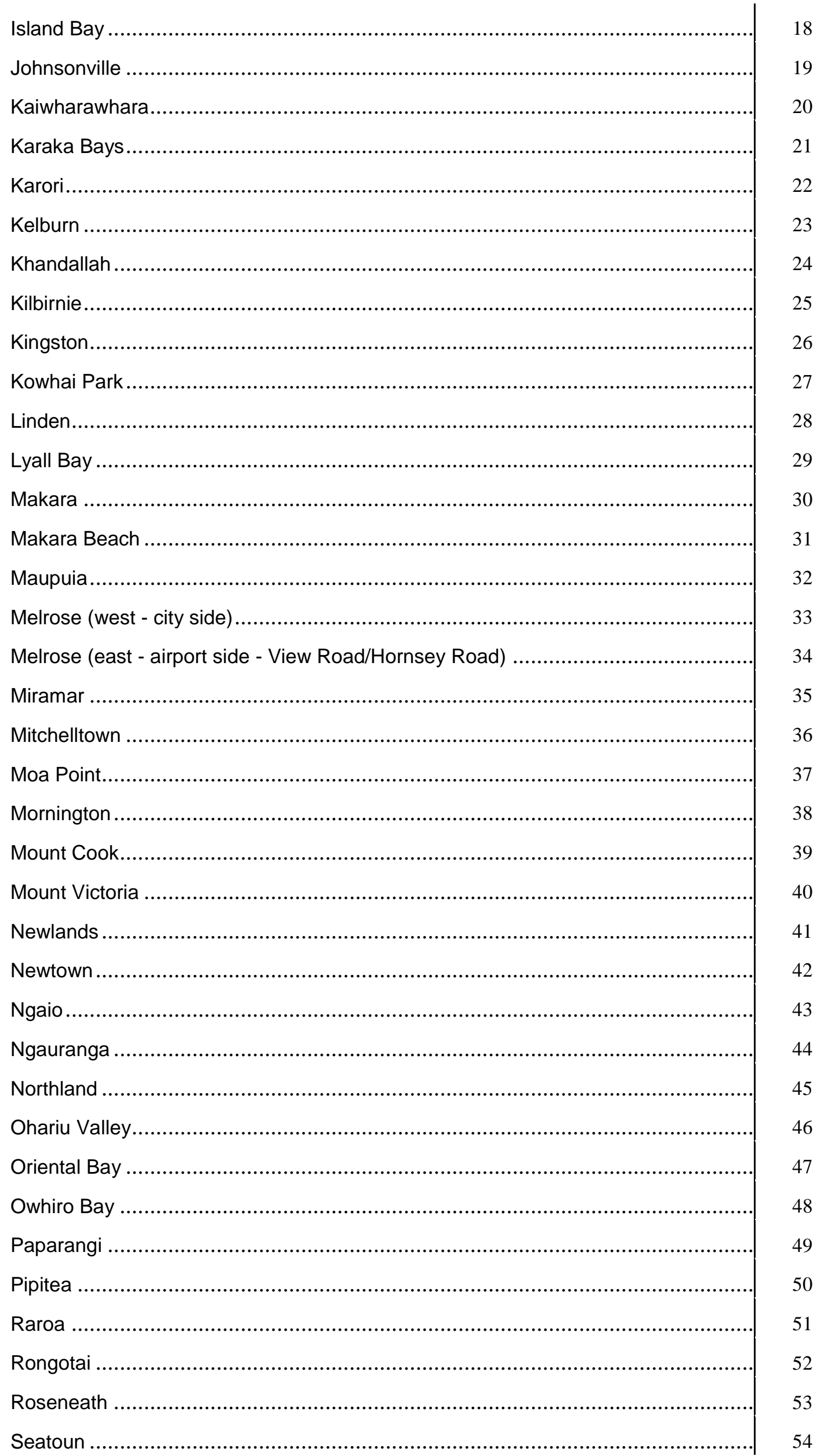




\begin{tabular}{|c|c|c|}
\hline 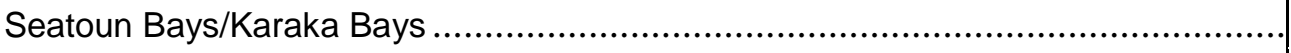 & 55 & \\
\hline Southgate .................................................. & 56 & \\
\hline Strathmore Park ................. & 57 & \\
\hline Takapu Valley ............................. & 58 & \\
\hline Tawa & 59 & \\
\hline Te Aro............... & 60 & \\
\hline Thorndon & 61 & \\
\hline Vogeltown & 62 & \\
\hline Wadestown & 63 & \\
\hline Wilton ............................... & 64 & \\
\hline Woodridge ............................... & 65 & \\
\hline (Do not read) Refused.... & 97 & CLOSE \\
\hline (Do not read) None of these & 98 & CLOSE \\
\hline 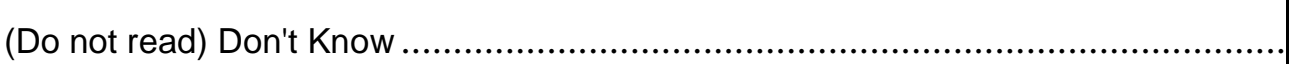 & 99 & CLOSE \\
\hline
\end{tabular}

\section{CLOSE FOR Q3 SUBURB}

I'm sorry but for this survey we need to know which suburb you live in.

Thank you for your time.

Should you have any queries about this interview, my name is <> calling on behalf of Nielsen.

${ }^{*}$ Give Nielsen phone number if requested $049786700^{*}$

Q4 This question is set from Q3

Don't need to ask, record only from Q3

Ward

Northern.

Onslow-Western

Lambton.

Southern

Eastern

\begin{tabular}{|c|c|}
\hline Code & Route \\
& \\
1 & \\
2 & \\
3 & \\
4 & \\
5 & \\
\hline
\end{tabular}

Q5 Code Gender

Gender

Male

Female

\begin{tabular}{|c|c|}
\hline Code & Route \\
1 & \\
2 & \\
\hline
\end{tabular}

Q6 If answered 1 terminate

Read out - code one only

Which age group do you fit into?

Under 15 years

\begin{tabular}{c|c|} 
Code & Route \\
1 & CLOSE
\end{tabular}




\begin{tabular}{|c|c|c|}
\hline 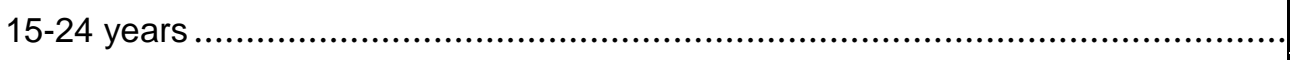 & 2 & \\
\hline $25-39$ years ........... & 3 & \\
\hline $40-59$ years & 4 & \\
\hline 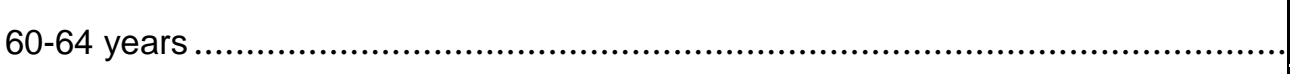 & 5 & \\
\hline 65 years and over ................... & 6 & \\
\hline (Do not read out) Refused & 9 & CLOSE \\
\hline
\end{tabular}

\section{CLOSE FOR Q6 age \\ IF Q6=1}

I'm sorry but for this survey we need to speak to people aged 15 or over.

Thank you for your time.

Should you have any queries about this interview, my name is <> calling on behalf of Nielsen.

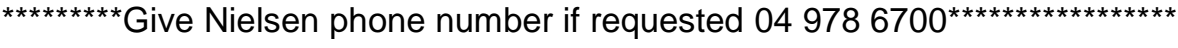

\section{ELSE}

I'm sorry but for this survey we need your age.

Thank you for your time.

Should you have any queries about this interview, my name is <> calling on behalf of Nielsen.

Give Nielsen phone number if requested $049786700^{* *}$

Q7 Read out - code one only

Which of the following best describes your household?

Young couple without children

Code

Route

Household with youngest child under 5

01

Household with youngest child 5 to 13

02

Household with youngest child 14 or over.

Older couple - no children or none living at home.....

04

Single/one person household

Flat - not a family home.

Other - specify.

(Do not read) Refused

Q8 Display codes in reverse order 5-4-3-2-1

\section{Read out - code one only}

First of all, i'd like you to think about all the dealings you've had with Wellington City Council; all the things it has done over the last 12 months; and all the services and facilities that Wellington City Council provides. Overall, how would you rate the performance of Wellington City Council over the last 12 months? Would you say it was.... 


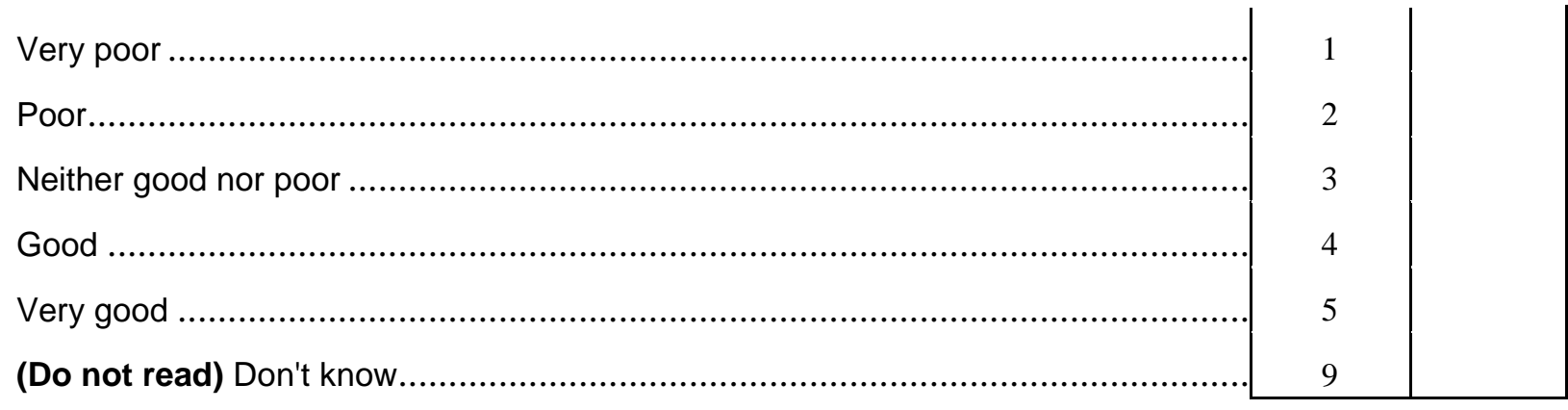

\section{Q112 If Q8 code 5 then ask Q112}

Why do you say the council's performance is very good?

PROBE Fully

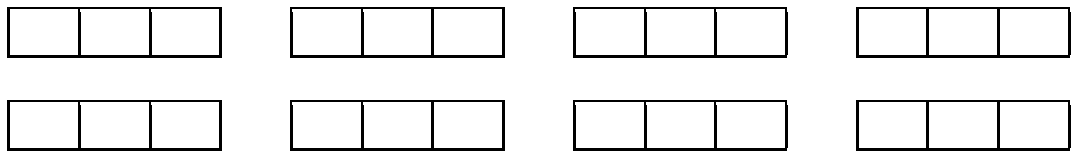

Q113 If Q8 code 4, 3, 2, or 1 ask Q113

What could the council do for you to give them a higher rating?

PROBE Fully
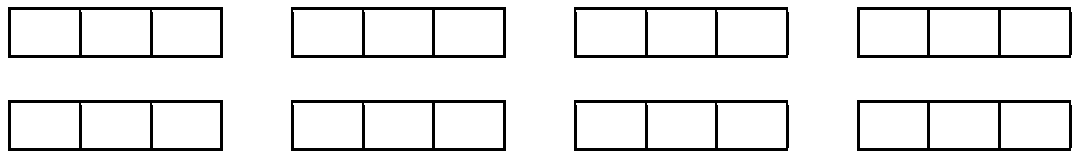

Q88 Read out in reverse order 5-4-3-2-1

Read out, code one only

Thinking about all the dealings you've had with Wellington City Council; all the things it has done over the last 12 months; and all the services and facilities that Wellington City Council provides, overall, how would you rate the value for money from all the services the Council provides?

Very Poor.

Poor.

Neither good nor poor

Good

Very Good

(Do not read out) Don't know

\begin{tabular}{|c|c|}
\hline Code & Route \\
& \\
& \\
1 & \\
2 & \\
3 & \\
4 & \\
5 & \\
9 & \\
\hline
\end{tabular}

Q10 Read out in reverse order 5-4-3-2-1

Code

Route

Read out, code one only

The next question concerns your overall quality of life. 
Would you say that overall your quality of life is ...

Extremely poor

Poor

Neither good nor poor

Good

Extremely good

(Do not read) Don't know.

\begin{tabular}{|l|l|}
\hline 1 & \\
2 & \\
3 & \\
4 & \\
5 & \\
9 & \\
\hline
\end{tabular}

\section{Urban Development}

Q11 Read out in reverse order 5-4-3-2-1

${ }^{\star * *}$ Probe: Is that strongly agree/disagree or just agree/disagree ${ }^{\star \star \star \star \star \star \star \star \star * *}$

The next questions cover such things as the design and layout of Wellington. Generally speaking, do you agree or disagree that Wellington is a great place to live?

PROBE Probe: Is that strongly agree/disagree or just agree/disagree

Strongly disagree.

Disagree

Neither agree nor disagree

Agree

Strongly agree

(Do not read out) Don't know

\begin{tabular}{|c|c|}
\hline Code & Route \\
& \\
& \\
1 & \\
2 & \\
3 & \\
4 & \\
5 & \\
9 & \\
\hline
\end{tabular}

Q12 Read out in reverse order 5-4-3-2-1

${ }^{\star \star \star}$ Probe: Is that strongly agree/disagree or just agree/disagree ${ }^{\star \star \star \star \star \star \star \star \star \star ~}$

And do you agree or disagree that the different suburbs and communities in

Wellington provide a good variety of places to live in?

PROBE Probe: Is that strongly agree/disagree or just agree/disagree

Strongly disagree.

Disagree

Neither agree nor disagree

Agree

Strongly agree.

(Do not read out) Don't know

\begin{tabular}{|c|c|}
\hline Code & Route \\
& \\
1 & \\
2 & \\
3 & \\
4 & \\
5 & \\
9 & \\
\hline
\end{tabular}

Q13 Read out in reverse order 5-4-3-2-1

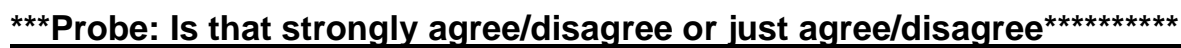

And do you agree or disagree that there is a variety of opportunities and places to work in Wellington in your occupation, or for someone with your experience and/or qualifications?

PROBE Probe: Is that strongly agree/disagree or just agree/disagree

\begin{tabular}{|l|l|}
\hline Code & Route \\
&
\end{tabular}


Strongly disagree.

\begin{tabular}{|l|l|}
\hline & \\
1 & \\
2 & \\
3 & \\
4 & \\
5 & \\
9 & \\
\hline
\end{tabular}

Q14 Read out in reverse order 5-4-3-2-1

***Probe: Is that strongly agree/disagree or just agree/disagree ${ }^{\star \star \star \star \star \star \star \star \star \star * ~}$

\begin{tabular}{|l|l|} 
Code & Route \\
& \\
1 & \\
2 & \\
3 & \\
4 & \\
5 & \\
9 &
\end{tabular}

And do you agree or disagree that there is a good variety of leisure activities and opportunities to socialise in Wellington?

PROBE Probe: Is that strongly agree/disagree or just agree/disagree

Strongly disagree.

Disagree

Neither agree nor disagree

Agree

Strongly agree.....

(Do not read out) Don't know

Q15

Rotate statements

Read out scale 5-4-3-2-1, strongly agree (5) to strongly disagree (1)

Read out - code one only

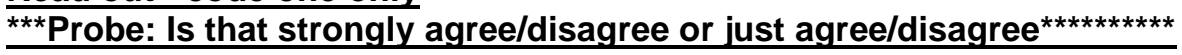

I am going to read you some statements about Wellington and would like you to tell me if you agree or disagree with each statement.

In general, do you agree or disagree with the statement....

PROBE Probe: Is that strongly agree/disagree or just agree/disagree

(R1) Heritage buildings, areas, trees and objects contribute to the city's unique character

(R2) Heritage buildings, areas, trees and objects contribute to your community's unique character

(R3) The city centre is lively and attractive

(R4) My local suburban centre is lively and attractive

(R5) The city is developing in a way that takes into account its unique urban character and natural environment.

\begin{tabular}{|c|c|c|c|c|c|}
\hline $\begin{array}{c}\text { Strongly } \\
\text { disagree }\end{array}$ & Disagree & $\begin{array}{c}\text { Neither } \\
\text { agree nor } \\
\text { disagree }\end{array}$ & Agree & $\begin{array}{c}\text { Strongly } \\
\text { agree }\end{array}$ & $\begin{array}{c}\text { (Do not } \\
\text { read out) } \\
\text { Don't know }\end{array}$ \\
\hline 1 & 2 & 3 & 4 & 5 & 9 \\
1 & 2 & 3 & 4 & 5 & 9 \\
1 & 2 & 3 & 4 & 5 & 9 \\
1 & 2 & 3 & 4 & 5 & 9 \\
1 & 2 & 3 & 4 & 5 & 9 \\
\hline
\end{tabular}

\section{Q114 Rotate statements}

Read out in reverse 5,4,3,2,1

In general, how strongly do you agree or disagree that... 
PROBE Is that strongly agree/disagree or just agree/disagree

(R1) Heritage buildings, areas, trees and objects are appropriately valued and protected in the central city

(R2) Heritage buildings, areas trees and objects are appropriately valued and protected in your local/suburban area.

\begin{tabular}{|c|c|c|c|c|c|}
\hline $\begin{array}{c}\text { Strongly } \\
\text { disagree }\end{array}$ & Disagree & $\begin{array}{c}\text { Neither } \\
\text { agree nor } \\
\text { disagree }\end{array}$ & Agree & $\begin{array}{c}\text { Strongly } \\
\text { agree }\end{array}$ & $\begin{array}{c}\text { (Do not } \\
\text { read out) } \\
\text { Don't know }\end{array}$ \\
\hline 1 & 2 & 3 & 4 & 5 & 9 \\
1 & 2 & 3 & 4 & 5 & 9 \\
\hline
\end{tabular}

Q16 Read out in reverse order 5-4-3-2-1

\section{Read out - code one only}

How strongly do you agree or disagree with the statement, 'I feel a sense of pride in the way Wellington looks and feels'?

PROBE Probe: Is that strongly agree/disagree or just agree/disagree

Strongly disagree

Disagree

Neither agree nor disagree

Agree

Strongly agree

(Do not read) Don't know

\begin{tabular}{|c|c|}
\hline Code & Route \\
& \\
1 & \\
2 & \\
3 & \\
4 & \\
5 & \\
9 & \\
\hline
\end{tabular}

\section{Social and Recreation / Environmental}

Q17 Read out scale in order: very safe to very unsafe

Read out - code one only

The next few questions are about safety.

Thinking of your overall sense of freedom from crime, how safe or unsafe do you feel in the following situations. Would you say that you were very safe, reasonably safe, somewhat unsafe or very unsafe...?

.....and would you say that you were very safe, reasonably safe, somewhat unsafe or very unsafe...?

(R1) In your neighbourhood during the

(R2) In your neighbourhood after dark

(R3) In your city centre during the day

(R4) In your city centre after dark

\begin{tabular}{|c|c|c|c|c|c|}
\hline $\begin{array}{c}\text { Very } \\
\text { unsafe }\end{array}$ & $\begin{array}{c}\text { Somewhat } \\
\text { unsafe }\end{array}$ & $\begin{array}{c}\text { Reasonabl } \\
\text { y safe }\end{array}$ & Very safe & $\begin{array}{c}\text { (Do not } \\
\text { read out) } \\
\text { Not } \\
\text { applicable: } \\
\text { Don't } \\
\text { come into } \\
\text { city centre }\end{array}$ & $\begin{array}{c}\text { (Do not } \\
\text { read) Don't } \\
\text { know }\end{array}$ \\
\hline 1 & 2 & 3 & 4 & 7 & 9 \\
1 & 2 & 3 & 4 & 7 & 9 \\
1 & 2 & 3 & 4 & 7 & 9 \\
1 & 2 & 3 & 4 & 7 & 9 \\
\hline
\end{tabular}

Q18 Note for post-coding and analysis: Listing of new codes to be approved by WCC

\begin{tabular}{l|l|} 
Code & Route
\end{tabular} 
before back coding. All new codes to be grouped into broad themes in parenthesis below and nets of themes to be included in data tabulations.

Ask Question 19 if more than one coded

Read in rotated order - code each mention ${ }^{\star \star}$ Probe: What else ${ }^{\star \star \star \star \star \star \star}$

The following list I am about to read identifies things that might make people feel unsafe in their neighbourhoods or city. Which of the following, if any, are particularly concerning in Wellington at present?

PROBE What else?

Poorly lit or dark public areas such as streets, paths and parks

Vandalism such as broken windows in shops and public buildings

Graffiti

Poorly maintained or dangerous public areas such as streets, paths and parks

Traffic, including busy roads and lack of pedestrian facilities

Dangerous driving including speeding, drunk drivers and so on

Alcohol and drug problems

Car theft or vandalism, and theft from cars

Threatening people and/or people behaving dangerously

(Do not read out) None of these

Other (specify)

(Do not read out) Don't know

Note for post-coding and analysis: Listing of new codes to be approved by WCC before back coding. All new codes to be grouped into broad themes in parenthesis below and nets of themes to be included in data tabulations.

<Ask If more than one coded in question 18>

Read in rotated order - code only one

And which of these is of most concern to you at present in Wellington?

Poorly lit or dark public areas such as streets, paths and parks

Vandalism such as broken windows in shops and public buildings

Graffiti

Poorly maintained or dangerous public areas such as streets, paths and parks 
Traffic, including busy roads and lack of pedestrian facilities

Dangerous driving including speeding, drunk drivers and so on

Dangerous driving including speeding, drunk drivers and so on

Alcohol and drug problems

Car theft or vandalism, and theft from cars

Threatening people and/or people behaving dangerously

(Do not read out) None of these

Other (specify)

(Do not read out) Don't know

Q20 Read out in reverse order 5-4-3-2-1

Read out - code one only

Wellington City is becoming home for an increasing number of people with different lifestyles and cultures and from different countries. Overall do you think this makes the city...?

A much worse place to live

A worse place to live

Makes no difference.

A better place to live

A much better place to live

Q21 Read out in reverse order 5-4-3-2-1

$\star \star \star \star \star \star \star \star \star \star$ Probe: Is that strongly agree/disagree or just

agree/disagree ${ }^{\star \star \star \star \star \star \star \star \star \star \star \star \star \star \star \star ~}$

We want to find out about the sense of community strength and spirit in Wellington. In general, do you agree or disagree with the statement......The community works together and people support each other?

PROBE Probe: Is that strongly agree/disagree or just agree/disagree

Strongly disagree.

Code

Route

Disagree

Neither agree nor disagree

Agree

Strongly agree.....

(Do not read out) Don't know

\begin{tabular}{|c|c|}
\hline Code & Route \\
& \\
& \\
1 & \\
2 & \\
3 & \\
4 & \\
5 & \\
9 & \\
\hline
\end{tabular}

Q22 51. Community advocacy

\begin{tabular}{|l|l|} 
Code & Route \\
&
\end{tabular}

\section{Read out in reverse order 5-4-3-2-1}

\section{Read out - code one only}

Wellington City Council works to help ensure Wellington is made up of strong and thriving communities. How satisfied or dissatisfied are you that the Council provides appropriate services and resources to ensure strong and thriving 
communities?

Would you say you are...

Very dissatisfied

Quite dissatisfied

Neither satisfied nor dissatisfied

Quite satisfied

Very satisfied

(Do not read out) Don't know

\begin{tabular}{|l|l|}
\hline & \\
& \\
& \\
1 & \\
2 & \\
3 & \\
4 & \\
5 & \\
9 & \\
\hline
\end{tabular}

\section{Q115 Ask all}

Rotate

\section{Do Not Read Out}

As far as you are aware, which of the following community support services are provided by the Wellington City Council?

(R1)

Grants (e.g. social and recreation, and education)

(R2) Provide support networks for various groups (e.g. Pacific people, young people, senior citizens etc.)

(R3)

Organising community events

(R4) Provide advocacy services for various groups (if necessary: that is the Council would act as a go between for services such as public health and various community groups)

Support for homeless

\begin{tabular}{|c|c|c|}
\hline Yes & No & Don't know \\
\hline 1 & 2 & 9 \\
1 & 2 & 9 \\
1 & 2 & 9 \\
1 & 2 & 9 \\
1 & 2 & 9 \\
\hline
\end{tabular}

Q24 Do not read - code only one

Have you used a Wellington City Council public toilet in the last 12 months?

Yes

No

Don't Know.

\begin{tabular}{|c|c|}
\hline Code & Route \\
1 & \\
2 & Q26 \\
9 & Q26 \\
\hline
\end{tabular}

Q25 Read out in reverse order 5-4-3-2-1

Read out - code one only

And how satisfied or dissatisfied are you with the cleanliness of Wellington City

Council public toilets?

Would you say you are...?

Very dissatisfied

Quite dissatisfied

Neither satisfied nor dissatisfied

\begin{tabular}{|c|c|} 
Code & Route \\
& \\
1 & \\
2 & \\
3 & \\
4 & \\
5 &
\end{tabular}

Very satisfied 
Do you have essential emergency items in your home? By emergency items I mean a supply of everyday use items that you can easily find and use when an emergency occurs.

Yes

\begin{tabular}{|c|c|}
\hline Code & Route \\
1 & \\
2 & Q28 \\
9 & Q28 \\
\hline
\end{tabular}

Q27 Code None of these as 97

Code Don't know as 99

\section{Read out - code all that apply}

As I read out this list please tell me which, if any, of these you would easily be able to find in the event of an emergency

Ten litres of bottled water per person in your household

Code

Canned food

Can opener

Other non-perishable food.

First aid kit

A battery operated radio

Spare batteries

A plastic bucket

Plastic bags.

Toilet paper

Soap

Disinfectant

A primus or gas barbeque to cook on

Waterproof torches

Other essential medication

Pet supplies

Blankets, towels, sleeping bags

Sturdy footwear

Baby/infant supplies

Essential documents (birth/marriage certificates, insurance policies)

Family photos

None of these 
Do you have an emergency plan for your family or your household about what they will do if a significant emergency occurs?

Yes

No

Don't know

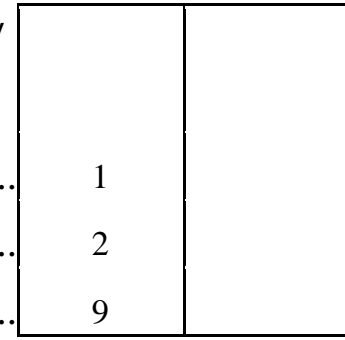

Q29 Check Q7 - if school age children (code 2,3 or 4) in household ask all statements in Q29, otherwise omit statement 3 and ask all other statements

Ask all respondents

Read out - code all that apply

Which of the following have you done. Have you...?

Discussed ways to get in touch with other family members when an emergency occurs

Made plans for re-uniting with family members when an emergency occurs

Arranged for authorised people to collect children from school, and provided the school with a list of these people for when an emergency occurs

Code

Route

Established a meeting place in the event your house becomes unusable or if family members are separated when an emergency occurs

Allocated tasks for those at home when an emergency occurs eg. turning off power or checking with neighbours

Completed a first aid course

Found out where your nearest Civil Defence Centre is

(Do not read out) None of these

(Do not read out) Don't know

Q30 Allow entry up to 2 decimal places

Type 000 for zero/none

Type 999 for Don't know

IE 2 HOURS $=002.0,10.5$ HOURS $=010.5$

Thinking now about recreational opportunities in Wellington....

How many hours would you spend in some form of regular physical activity in an average week?

Type in number (use decimal places)

(Do not read) Don't know.

\begin{tabular}{|l|l|}
\hline Code & Route \\
& \\
1 & \\
9 & \\
\hline
\end{tabular}

Q31 Check Q7 - if children aged 13 and under in household (code 2/3) ask Q31 , otherwise skip to Q34

\section{Do not read out}

Have any of the children aged 13 or under in your household used a Council playground or skate park in the last 12 months?

Yes.

No

\begin{tabular}{|c|c|}
\hline Code & Route \\
& \\
1 & \\
2 & Q33 \\
9 & Q33 \\
\hline
\end{tabular}

(Do not read out) Don't know 
Q32 Read out in reverse order 5-4-3-2-1

\begin{tabular}{|c|c|}
\hline Code & Route \\
& \\
& \\
1 & \\
2 & \\
3 & \\
4 & \\
5 & \\
9 & \\
\hline
\end{tabular}

Q33 ASK of those with school aged children (Q7=code 2 or 3)

Read out - code only one

On average, How often do the children aged 13 or under in your household walk to and from school?

Everyday

\begin{tabular}{|l|l|}
\hline Code & Route \\
& \\
1 & \\
2 & \\
3 & \\
4 & \\
5 & \\
6 & \\
9 & \\
\hline
\end{tabular}

Q34 Read out - code all that apply

Have you used any of the following Wellington City Council recreation facilities in the last 12 months?

A Council Recreation Centre

\begin{tabular}{|c|c|}
\hline Code & Route \\
& \\
1 & \\
2 & \\
3 & \\
4 & \\
5 & \\
8 & \\
9 & \\
\hline
\end{tabular}

Q35 Ask Q35 if Q34 code $=1$

Read out in reverse order 5-4-3-2-1

\begin{tabular}{|l|l|}
\hline Code & Route \\
\end{tabular}




\section{Read out - code one only}

How satisfied or dissatisfied were you with the Wellington City Council's recreation centre you visited most recently?

Very dissatisfied

Quite dissatisfied

Neither satisfied nor dissatisfied

Quite satisfied

Very satisfied

(Do not read out) Don't know

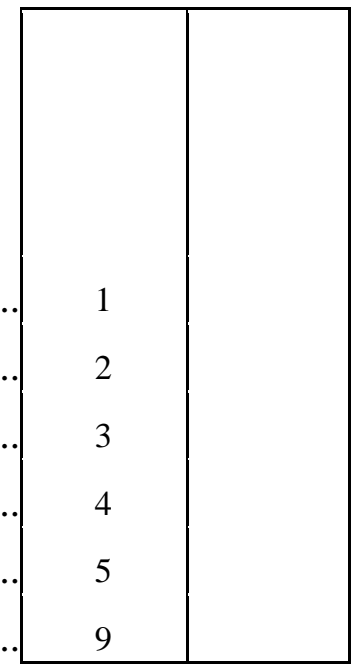

Q36 Ask Q36 if $\mathbf{Q 3 4}$ code $=2$

Read out in reverse order 5-4-3-2-1

Read out - code one only

And how satisfied or dissatisfied were you with the Wellington City Council's swimming pool you visited most recently?

Very dissatisfied

Quite dissatisfied

Neither satisfied nor dissatisfied

Quite satisfied

Very satisfied.

(Do not read out) Don't know

\begin{tabular}{|c|c|}
\hline Code & Route \\
& \\
& \\
2 & \\
3 & \\
4 & \\
5 & \\
9 & \\
\hline
\end{tabular}

Q42 Read out scale 5-4-3-2-1, strongly agree (5) to strongly disagree (1)

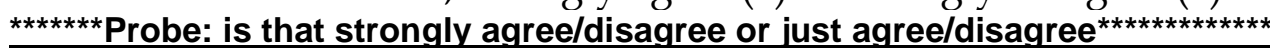
In general do you agree or disagree that Wellington city offers a wide range of recreational activities?

PROBE Is that strongly agree/disagree or just agree/disagree

Strongly disagree.

Code

Route

Disagree

Neither agree nor disagree

Agree.

Strongly agree

(Do not read out) Don't know

\begin{tabular}{|c|c|}
\hline Code & Route \\
& \\
& \\
1 & \\
2 & \\
3 & \\
4 & \\
5 & \\
9 & \\
\hline
\end{tabular}

Q45 Please code others as 99 and don't know as 99

\begin{tabular}{|l|l|}
\hline Code & Route \\
01 & \\
02 &
\end{tabular}


Activity costs too much

Activity too far away

No facilities for child care.

Weather.

Not at a convenient time

Shift work

Lack of motivation

No facilities exist

Tiredness

Lack of knowledge about how to do it

Environmental factors (eg road conditions, pollution)

Lack of parking/public transport/transport

None/nothing/not interested

Other (specify)

Don't know

\section{Ask all \\ Read out scale 5,4,3,2,1 \\ Read out}

In general, how easy is it to access Wellington City Council's recreation facilities and programmes?

Very difficult

Quite difficult

Neither easy nor difficult

Quite easy

Very easy.

(Do not read out) Don't know

\begin{tabular}{l||} 
\\
1 \\
1 \\
2 \\
3 \\
4 \\
5 \\
9
\end{tabular}

\section{Scale to be read in reverse $5,4,3,2,1$}

To provide recreation services and facilities it costs, on average, $\$ 147.58$ per resident per year (or $\$ 0.40$ per day). How strongly do you agree or disagree this is good value for money?

Strongly disagree.

\begin{tabular}{|c|c|}
\hline Code & Route \\
& \\
1 & \\
2 & \\
3 & \\
4 & \\
5 & \\
9 & \\
\hline
\end{tabular}

(Do not read out) Don't know

Have you used any of the following Wellington City Council community facilities in the last 12 months? 
A public library

A Community Centre

A Community Hall

(Do not read out) None of these

(Do not read out) Don't know

\begin{tabular}{|l|l|}
\hline & \\
1 & \\
2 & \\
3 & \\
7 & \\
9 & \\
\hline
\end{tabular}

Q97 if Q37 code $=1$ then ask Q97

Read out

How often on average would you use, or visit a Wellington City Council library?

More than once a week

Once a week

Once every 2-3 weeks

Once a month

Once every 2-3 months

Once every 4-6 months

Less often than once every 6 months

\begin{tabular}{|c|c|}
\hline Code & Route \\
1 & \\
2 & \\
3 & \\
4 & \\
5 & \\
6 & \\
7 & \\
9 & \\
\hline
\end{tabular}

(Do Not Read Out) Don't Know

\begin{tabular}{|c|c|}
\hline Code & Route \\
& \\
1 & \\
2 & \\
3 & \\
4 & \\
5 & \\
9 & \\
\hline
\end{tabular}

(Do not read out) Don't know

\begin{tabular}{|l|l|}
\hline Code & Route \\
& \\
& \\
1 & \\
2 & \\
3 & \\
4 & \\
5 &
\end{tabular}


Q99 Scale to be read out in reverse

To provide library services it costs, on average, $\$ 109.01$ per resident per year (or $\$ 0.30$ per day). How strongly do you agree or disagree this is good value for money?

Strongly disagree.

Disagree

Neither agree nor disagree

Agree.

Strongly agree

(Do not read out) Don't know

\begin{tabular}{|c|c|}
\hline Code & Route \\
& \\
1 & \\
2 & \\
3 & \\
4 & \\
5 & \\
9 & \\
\hline
\end{tabular}

\section{Q39 Ask of all}

29, 31 \& 33. New \& existing (how often used...)

\section{DO NOT ROTATE}

\section{Read out - code one only}

In the last twelve months, how often on average have you used...?

......And in the last 12 months how often have you used....?

(R1) Wellington City's coastal areas or beaches.

(R2) Botanic gardens, including Otari/Wiltons Bush Native Botanic Reserve.....

(R3) Wellington City Council parks

(R4) Town Belt or Outer Green Belt.

(R5) The city's walking tracks...

(R6) Wellington City Council outdoor sports fields

\begin{tabular}{|c|c|c|c|c|c|c|c|c|}
\hline $\begin{array}{c}\text { Most } \\
\text { days }\end{array}$ & $\begin{array}{c}\text { Once or } \\
\text { twice a } \\
\text { week }\end{array}$ & $\begin{array}{c}\text { Once } \\
\text { every 2- } \\
3 \text { weeks }\end{array}$ & $\begin{array}{c}\text { Once a } \\
\text { month }\end{array}$ & $\begin{array}{c}\text { Once } \\
\text { every 2- } \\
3 \\
\text { months }\end{array}$ & $\begin{array}{c}\text { Once } \\
\text { every 4- } \\
5 \\
\text { months }\end{array}$ & $\begin{array}{c}\text { Once } \\
\text { every 6 } \\
\text { months } \\
\text { or less } \\
\text { often }\end{array}$ & $\begin{array}{c}\text { Never } \\
\text { in the } \\
\text { last 12 } \\
\text { months }\end{array}$ & $\begin{array}{c}\text { (Do not } \\
\text { read) } \\
\text { Don't } \\
\text { know }\end{array}$ \\
\hline 01 & 02 & 03 & 04 & 05 & 06 & 07 & 08 & 99 \\
01 & 02 & 03 & 04 & 05 & 06 & 07 & 08 & 99 \\
01 & 02 & 03 & 04 & 05 & 06 & 07 & 08 & 99 \\
01 & 02 & 03 & 04 & 05 & 06 & 07 & 08 & 99 \\
01 & 02 & 03 & 04 & 05 & 06 & 07 & 08 & 99 \\
01 & 02 & 03 & 04 & 05 & 06 & 07 & 08 & 99 \\
\hline
\end{tabular}

Q40 30 \& 33. New (rate quality and maintenance)

Rotate

Ask this question, Q40R1 if Q39 R3 = code 1,2,3,4,5,6 or 7 (have used WCC park in the last 12 months) Ask this question, Q40 R2 if Q39 R5 =code 1,2,3,4,5,6 or 7 (have used walkways and tracks in the last 12 months)

Ask this question, Q40 R3 if Q39 R6 = code 1,2,3,4,5,6 or 7 (have used WCC outdoor sports field in the last 12 months)

\section{Read out in reverse order 5-4-3-2-1 \\ Read out - code one only}

Overall, how satisfied or dissatisfied are you with the quality and maintenance of... 
(R1) Wellington City Council parks, excluding the Botanic Gardens

(R2) The city's walking tracks

(R3) Wellington City Council outdoor sports fields

\begin{tabular}{|c|c|c|c|c|c|}
\hline $\begin{array}{c}\text { Very } \\
\text { dissatisfie } \\
d\end{array}$ & $\begin{array}{c}\text { dissatisfie } \\
\mathrm{d}\end{array}$ & $\begin{array}{c}\text { Neither } \\
\text { satisfied } \\
\text { nor } \\
\text { dissatisfie } \\
\mathrm{d}\end{array}$ & satisfied & $\begin{array}{c}\text { Very } \\
\text { satisfied }\end{array}$ & $\begin{array}{c}\text { (Do not } \\
\text { read) Don't } \\
\text { know }\end{array}$ \\
\hline 1 & 2 & 3 & 4 & 5 & 9 \\
1 & 2 & 3 & 4 & 5 & 9 \\
1 & 2 & 3 & 4 & 5 & 9 \\
\hline
\end{tabular}

Q41 31 \& 32. New (cleanliness \& maintenance)

Ask this question, Q41 R1 if Q39 R4 = code 1,2,3,4,5,6 or 7 (have used Town Belt or Outer Green Belt in the last 12 months)

Ask this question, Q41 R2 if Q39 R1 = code 1,2,3,4,5,6 or 7 (have used coastline or beaches in the last 12 months)

Ask this question, Q41 R3 if Q39 R2 = code 1,2,3,4,5,6 or 7 (have used botanic gardens in the last 12 months)

\section{Read out in reverse order 5-4-3-2-1}

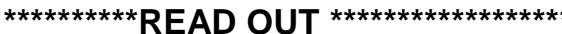

And, overall, how satisfied or dissatisfied are you with the quality and maintenance of...

\begin{tabular}{|c|c|c|c|c|c|c|}
\hline & \begin{tabular}{|c|} 
Very \\
dissatisfie \\
d
\end{tabular} & $\begin{array}{c}\text { dissatisfie } \\
\mathrm{d}\end{array}$ & $\begin{array}{c}\text { Neither } \\
\text { satisfied } \\
\text { nor } \\
\text { dissatisfie } \\
d \\
\end{array}$ & satisfied & $\begin{array}{c}\text { Very } \\
\text { satisfied }\end{array}$ & $\begin{array}{c}\text { (Do not } \\
\text { read) Don't } \\
\text { know }\end{array}$ \\
\hline 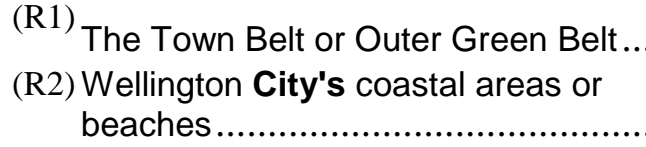 & 1 & 2 & 3 & 4 & 5 & 9 \\
\hline 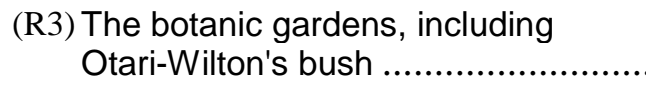 & 1 & 2 & 3 & 4 & & 9 \\
\hline
\end{tabular}

Q100 Ask all

Do not rotate order

Read out

In general, how easy or difficult is it to access...

\begin{tabular}{|c|c|c|c|c|c|c|}
\hline \multirow{4}{*}{ 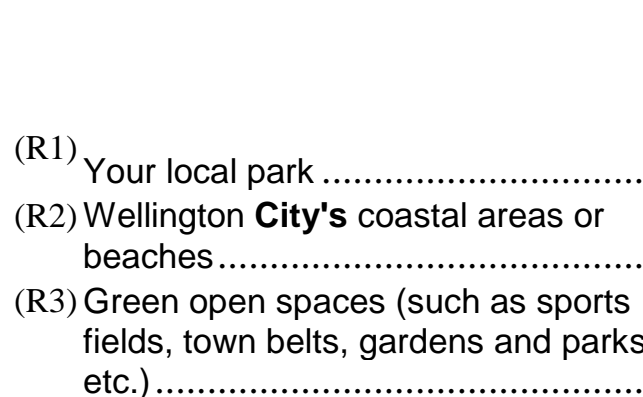 } & $\begin{array}{c}\text { Very } \\
\text { difficult }\end{array}$ & $\begin{array}{l}\text { quite } \\
\text { difficult }\end{array}$ & $\begin{array}{c}\text { Neither } \\
\text { easy nor } \\
\text { difficult }\end{array}$ & Quite easy & Very easy & $\begin{array}{c}\text { (Do not } \\
\text { read) Don't } \\
\text { know }\end{array}$ \\
\hline & 1 & 2 & 3 & 4 & 5 & 9 \\
\hline & 1 & 2 & 3 & 4 & 5 & 9 \\
\hline & 1 & 2 & 3 & 4 & 5 & 9 \\
\hline
\end{tabular}

Q101 To provide garden (botanic gardens and parks) and beach and coastal services it costs, on average, $\$ 65.71$ per resident per year (or $\$ 0.18$ per day). How strongly do you agree or disagree this is good value for money?

Strongly disagree.

\begin{tabular}{|c|c|}
\hline Code & Route \\
1 & \\
2 &
\end{tabular}

Disagree 
Neither agree nor disagree

Agree

Strongly agree.

(Do not read out) Don't know

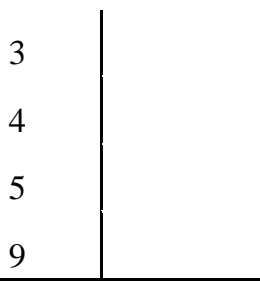

Q102

Read out scale in reverse

To provide green open spaces (e.g. sports fields, town belts, parks and gardens) it costs, on average, $\$ 78.26$ per resident per year (or $\$ 0.21$ per day). How strongly do you agree or disagree this is good value for money?

Strongly disagree.

Disagree

Neither agree nor disagree

Agree

Strongly agree

(Do not read out) Don't know

\begin{tabular}{|c|c|}
\hline Code & Route \\
& \\
1 & \\
2 & \\
3 & \\
4 & \\
5 & \\
9 & \\
\hline
\end{tabular}

Q43 Read out scale 5-4-3-2-1, strongly agree (5) to strongly disagree (1) Read out - code one only

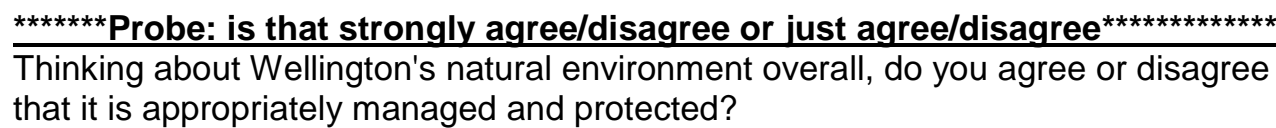

PROBE Probe: Is that strongly agree/disagree or just agree/disagree

Strongly disagree

Code

Route

Disagree

Neither agree nor disagree

Agree

Strongly agree.

(Do not read out) Don't know

${ }^{\star \star \star \star \star \star \star} T h i s$ is the text used to ask respondents if they want to continue on to part $2^{\star \star \star \star \star \star \star \star \star \star}$

Only included so interviewers know what this text is when reading the questionnaire. It should come after Part 1 demos as in surveycraft script

There is more text before this in surveycraft informing respondents what the second part of the survey is about etc.

Is it convenient for you to continue now, or shall I make an appointment to call you back at a more convenient time.

Continue .1

Make appointment......2

Split Questionnaire at this point.

Cultural Wellbeing 
Rotate statements

Read out scale 5-4-3-2-1, strongly agree (5) to strongly disagree (1)

Read out - code one only

***Probe: Is that strongly agree/disagree or just agree/disagree ${ }^{\star \star \star \star \star \star \star \star *}$

Thinking about the community involvement in arts and culture in Wellington, I am going to read you some statements and l'd like you to tell me if you agree or disagree with each statement.

In general, do you agree or disagree with the statement...

...And do you agree or disagree with the statement.

PROBE Probe: Is that strongly agree/disagree or just agree/disagree

(R1) Wellington has a culturally rich and diverse arts scene

(R2) Wellington is the events capital of New Zealand

(R3) Wellington is the arts capital of New Zealand

\begin{tabular}{|c|c|c|c|c|c|}
\hline $\begin{array}{c}\text { Strongly } \\
\text { disagree }\end{array}$ & Disagree & $\begin{array}{c}\text { Neither } \\
\text { agree nor } \\
\text { disagree }\end{array}$ & Agree & $\begin{array}{c}\text { Strongly } \\
\text { agree }\end{array}$ & $\begin{array}{c}\text { (Do not } \\
\text { read out) } \\
\text { Don't know }\end{array}$ \\
\hline 1 & 2 & 3 & 4 & 5 & 9 \\
1 & 2 & 3 & 4 & 5 & 9 \\
1 & 2 & 3 & 4 & 5 & 9 \\
\hline
\end{tabular}

\section{Read out - code only one}

How frequently do you attend, or participate in cultural and arts activities in Wellington?

At least once a week

At least once a month

Once every six months

At least once a year

Less often

(DO NOT READ) Never

(DO NOT READ) Don't know

\begin{tabular}{|c|c|}
\hline Code & Route \\
1 & \\
2 & \\
3 & \\
4 & \\
5 & \\
7 & \\
9 & \\
\hline
\end{tabular}

Q48

Do not read out

Wellington City Council is associated with events and festivals such as community festivals, sports events and arts and cultural events. Have you attended any of these types of events and festivals in the last 12 months?

Yes

No

\begin{tabular}{|c|c|}
\hline Code & Route \\
1 & \\
2 & Q50 \\
9 & Q50 \\
\hline
\end{tabular}

Don't Know.

\begin{tabular}{|l|l|}
\hline Code & Route \\
&
\end{tabular}


Very dissatisfied

Quite dissatisfied

Neither satisfied nor dissatisfied

Quite satisfied

Very satisfied

(Do not read out) Don't know

\begin{tabular}{|l|l|}
\hline 1 & \\
2 & \\
3 & \\
4 & \\
5 & \\
9 & \\
\hline
\end{tabular}

Q50 36. New

Read out in reverse order $5,4,3,2,1$

Read out - code one only

****Probe: is that strongly agree/disagree or just agree/disagree ${ }^{\star \star \star \star \star \star * \star}$

Do you agree or disagree that Wellington's distinct local identity, its sense of place, is appropriately valued and protected?

PROBE Is that strongly agree/disagree or just agree/disagree

Strongly disagree.

Code

Route

Disagree

Neither agree nor disagree

Agree

Strongly agree.

(Do not read out) Don't know

\begin{tabular}{|c|c|}
\hline Code & Route \\
& \\
& \\
1 & \\
2 & \\
3 & \\
4 & \\
5 & \\
9 & \\
\hline
\end{tabular}

\section{Resources and Waste}

\section{Read out - code all that apply}

If asked question relates to households behaviour not individual

The next couple of questions are about waste reduction and rubbish collection.

Which, if any, of the following things are you doing to try and reduce the amount of waste from your home?

Home composting

Using the Council's kerbside recycling service

Taking things to the recycling stations

Donating things to 2 nd hand shops or charities

Buying refills

Avoiding using plastic bottles or bags

Reusing plastic containers such as food containers

Anything else (specify) 
Every week

Once every two weeks

Once every three weeks

Once a month

Less often than once a month

(Do not read out) Don't know

Q53 Ask Q53 if Q52 = code 1,2,3,4 or 5 (ie. know how often on average they put out recycling - doesn't have to be in the last month)

Read out $5,4,3,2,1$

Read out - code one only

How satisfied or dissatisfied are you with the Wellington City Council's kerbside recycling?

Very dissatisfied

Quite dissatisfied

Neither satisfied nor dissatisfied

Quite satisfied

Very satisfied.

(Do not read out) Don't know

\begin{tabular}{|l|l|}
\hline Code & Route \\
& \\
& \\
& \\
1 & \\
2 & \\
3 & \\
4 & \\
5 & \\
9 & \\
\hline
\end{tabular}

Q90 Does your household ever use the official Wellington City Council rubbish bags, the yellow coloured bags that can be brought at the supermarket, some dairies or from the Council?

Yes

No

Code

Route

Don't know

Q91 Check Q90, if 1 coded ask otherwise skip to Q54

Read out - code one only

On average, how often do you put out yellow plastic Council rubbish bags for WCC kerbside collection?

Every week

Once every two weeks

Once every three weeks.

Once a month

Less often than once a month

\begin{tabular}{|c|c|} 
Code & Route \\
& \\
1 & \\
2 & \\
3 & \\
4 & \\
5 & \\
9 & Q105 \\
\hline
\end{tabular}

(Do not read out) Don't know 

rubbish bags - doesn't have to be in the last month)

Read out $5,4,3,2,1$

Read out - code one only

How satisfied or dissatisfied are you with the Wellington City Council's kerbside rubbish collection?

Very dissatisfied

Quite dissatisfied

Neither satisfied nor dissatisfied

Quite satisfied

Very satisfied.

(Do not read out) Don't know

\begin{tabular}{|c|c|}
\hline Code & Route \\
& \\
& \\
1 & \\
2 & \\
3 & \\
4 & \\
5 & \\
9 & \\
\hline
\end{tabular}

Q105

\section{Ask all}

Scale to be read out in reverse

To provide waste management services it costs, on average, $\$ 42.91$ per resident per year (or $\$ 0.12$ per day). How strongly do you agree or disagree this is good value for money?

Strongly disagree.

Disagree

Neither agree nor disagree

Agree

Strongly agree

(Do not read out) Don't know

Q54 Rotate statements

Read out - code all that apply

If asked question relates to households behaviour not individual

The storm water system collects rainwater from your roof and yard and transfers it to local streams or to the seashore.

Thinking now about the storm water system, which, if any, of the following things are you doing to try and reduce the amount of pollution entering the storm water system?

Dispose of oil, paint or chemicals by putting them out with your household rubbish or taking them for recycling.....

Washing paint brushes in an inside sink

Pouring all household liquid wastes down an inside sink, toilet or gully trap

Put your litter in a rubbish bin rather than drop it in the street or in the gutter

Pick up droppings left by dogs

Collect sweepings from your driveway, paths, or yard for composting or for disposal with your household rubbish

Wash the car at a carwash or on the lawn 
None of these

Scale to be read out in reverse

To provide wastewater and storm water services it costs, on average, $\$ 244.55$ per resident per year (or $\$ 0.67$ per day). How strongly do you agree or disagree this is good value for money?

Strongly disagree.

\begin{tabular}{|c|c|}
\hline Code & Route \\
& \\
1 & \\
2 & \\
3 & \\
4 & \\
5 & \\
9 & \\
\hline
\end{tabular}

Q107 Scale to be read in reverse

To provide water services it costs, on average, $\$ 170.57$ per resident per year (or $\$ 0.47$ per day). How strongly do you agree or disagree this is good value for money?

Strongly disagree.

Disagree

Neither agree nor disagree

Agree.

Strongly agree.

(Do not read out) Don't know

\begin{tabular}{|l|l|}
\hline Code & Route \\
& \\
1 & \\
2 & \\
3 & \\
4 & \\
5 & \\
9 & \\
\hline
\end{tabular}

\section{Transport}

Q55 Read out in reverse order 5-4-3-2-1

Read out - code one only

I'd now like to ask you about city traffic and the public transport system.

Thinking about moving around the city, how easy is it to drive about in the city?

Would you say it is.....

Very difficult

Quite difficult

Neither easy nor difficult

Quite easy

Very easy.

(Do not read out) Never drive/drive in a car

(Do not read out) Don't know

\begin{tabular}{|l|l|} 
Code & Route \\
& \\
& \\
& \\
1 & \\
2 & \\
3 & \\
4 & \\
5 & \\
7 & \\
9 &
\end{tabular}

Q56 Read out in reverse order 5-4-3-2-1 
Would you say it is.....

Very difficult

Quite difficult

Neither easy nor difficult

Quite easy

Very easy.

(Do not read out) Don't know

Q60 Rotate statements

Read out scale 5-4-3-2-1, strongly agree (5) to strongly disagree (1)

Read out - code one only

Do you agree or disagree that public transport in Wellington is...

And do you agree or disagree that public transport in Wellington is....

PROBE Probe: Is that strongly agree/disagree or just agree/disagree

\begin{tabular}{|c|c|c|c|c|c|c|}
\hline & $\begin{array}{l}\text { Strongly } \\
\text { disagree }\end{array}$ & Disagree & $\begin{array}{l}\text { Neither } \\
\text { agree nor } \\
\text { disagree }\end{array}$ & Agree & $\begin{array}{c}\text { Strongly } \\
\text { agree }\end{array}$ & \begin{tabular}{|c|} 
(Do not \\
read out) \\
Don't know
\end{tabular} \\
\hline${ }^{(\mathrm{R} 1)}$ Convenient .................. & 1 & 2 & 3 & 4 & 5 & 9 \\
\hline 22) Affordable & 1 & 2 & 3 & 4 & 5 & 9 \\
\hline
\end{tabular}

Q108 If code 7 in Q55 do not ask this question

Read scale 5,4,3,2,1

Read out

How satisfied or dissatisfied are you with the availability of on-street parking during the

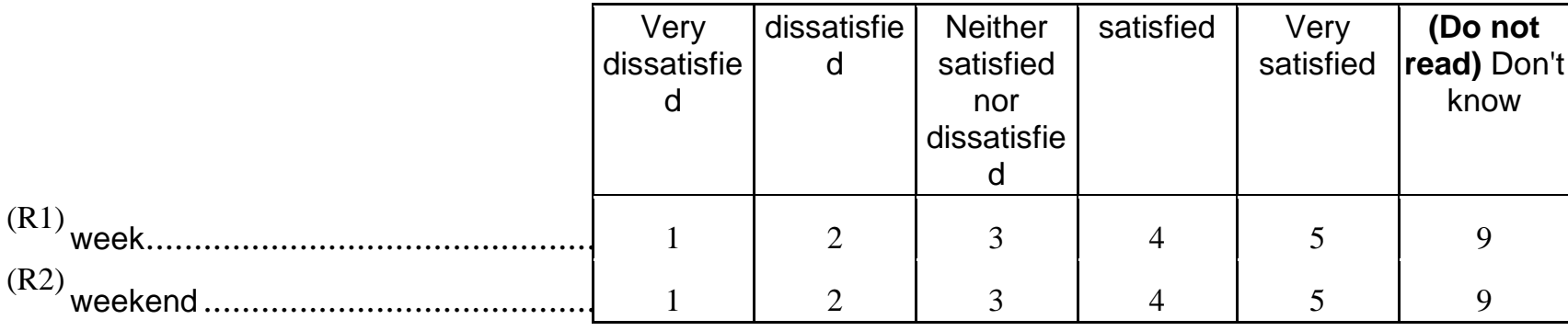

Q62 Read out in reverse order 5-4-3-2-1

Read out - code one only

**Probe: is that strongly agree/disagree, or just agree/disagree ${ }^{\star \star \star \star \star \star \star \star *}$

Do you agree or disagree that the city's transport system, that is the roads and the public transport, allows easy access from the suburbs to the city?

PROBE Probe: Is that strongly agree/disagree or just agree/disagree

Strongly disagree.

Disagree

Neither agree nor disagree

\begin{tabular}{|c|c|}
\hline Code & Route \\
& \\
1 & \\
2 & \\
3 & \\
4 & \\
5 &
\end{tabular}


(Do not read out) Don't know

Q109 Scale read out in reverse

To provide transport network services it costs, on average, $\$ 191.20$ per resident per year (or $\$ 0.52$ per day). How strongly do you agree or disagree this is good value for money?

Strongly disagree.

\begin{tabular}{|c|c|}
\hline Code & Route \\
& \\
1 & \\
2 & \\
3 & \\
4 & \\
5 & \\
9 & \\
\hline
\end{tabular}

Q63 Do not read - code one only

Do you travel into central Wellington most weekdays?

Yes

\begin{tabular}{|c|c|}
\hline Code & Route \\
1 & \\
2 & Q68 \\
9 & Q68 \\
\hline
\end{tabular}

Don't know

\section{Code $\quad$ Route}

Code don't know 99

Do not read out - Code one only

What is your main method of travelling to Wellington on these occasions?

Car

01

Motorbike

02

Bus

Train

Bicycle.

Walk

Scooter

Other (specify)

Don't know

Q65 Do not read out - Code one only

Is there anything that prevents you from using your preferred method of transport?

Yes

No

\begin{tabular}{c|c|} 
Code & Route \\
1 & \\
2 & Q68 \\
9 & Q68 \\
\hline
\end{tabular}

Don't know 
Code don't know 99

Do not read out - Code one only

How would you prefer to travel into Central Wellington most weekdays?

PROBE If say public transport, ask: What type of public transport?

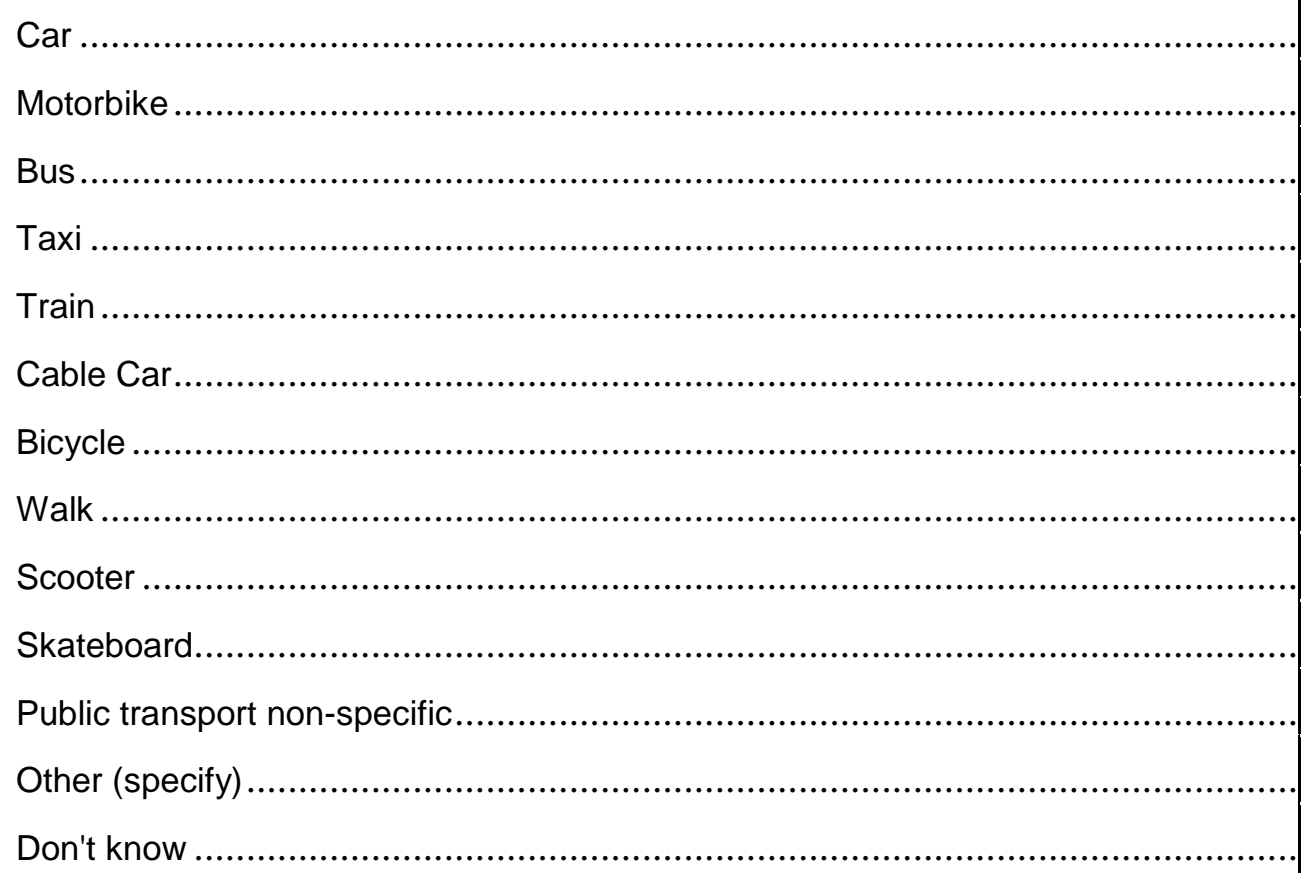

Q67 Code Other as 98

Code Don't know as 99

Do not read out - code all that apply Probe fully

What stops you travelling by <insert response from Q66> into Central Wellington most weekdays?

\section{PROBE Probe fully}

Very heavy/heavy traffic

Buses infrequent/overcrowded

Roadworks

Parking

Train problems/line signal problems/running late

Bus drivers/bus breakdowns/trolley lines down

Roads too narrow/lane markings/no room for bikes/bike lanes

Other (specify)

Don't know 
Don't know

9 Q70

Q69

\section{Do not read out - Code one only}

Do you believe peak traffic volumes are acceptable?

Yes

No

Don't know

\begin{tabular}{|c|c|}
\hline Code & Route \\
1 & \\
2 & \\
9 & \\
\hline
\end{tabular}

Q70 Read out - code one only

Now l'd like you to think about the on road cycleways. Have you used any of

Wellington city's on road cycleways in the last 12 months?

Yes

No

(Do not read out) Don't know

\begin{tabular}{|c|c|}
\hline Code & Route \\
1 & \\
2 & Q72 \\
9 & Q72 \\
\hline
\end{tabular}

Q71 Read out scale in order: very satisfied to very dissatisfied

\section{Read out - code one only}

How satisfied or dissatisfied are you with Wellington City's cycleways for...

And how satisfied or dissatisfied are you with Wellington City's cycleways for....

(R1) Safety

${ }^{(\mathrm{R} 2)}$ How well they are maintained

\begin{tabular}{|c|c|c|c|c|c|c|}
\hline $\begin{array}{c}\text { Very } \\
\text { dissatisfie } \\
\text { d }\end{array}$ & $\begin{array}{c}\text { Quite } \\
\text { dissatisfie } \\
\text { d }\end{array}$ & $\begin{array}{c}\text { Neither } \\
\text { satisfied } \\
\text { nor } \\
\text { dissatisfie } \\
\text { d }\end{array}$ & $\begin{array}{c}\text { Quite } \\
\text { satisfied }\end{array}$ & $\begin{array}{c}\text { Very } \\
\text { satisfied }\end{array}$ & $\begin{array}{c}\text { (Do not } \\
\text { read out }) \\
\text { Not } \\
\text { applicable } \\
\text { Don't use } \\
\text { cycleway } \\
\text { s or } \\
\text { public } \\
\text { transport }\end{array}$ & $\begin{array}{c}\text { (Do not } \\
\text { read) } \\
\text { Don't } \\
\text { know }\end{array}$ \\
\hline 1 & 2 & 3 & 4 & 5 & 7 & 9 \\
1 & 2 & 3 & 4 & 5 & 7 & 9 \\
\hline
\end{tabular}

Q72 Read out in reverse order 5-4-3-2-1

Read out - code one only

How would you rate the condition of the city's roads?

Very poor

Code

Route

Poor

Neither good nor poor

Good

Very Good

(Do not read out) Don't know

\begin{tabular}{|c|c|}
\hline Code & Route \\
& \\
& \\
1 & \\
2 & \\
3 & \\
4 & \\
5 & \\
9 & \\
\hline
\end{tabular}


And how would you rate the condition of the city's footpaths?

Very poor

\begin{tabular}{|l|l|}
\hline & \\
1 & \\
2 & \\
3 & \\
4 & \\
5 & \\
9 & \\
\hline
\end{tabular}

(Do not read out) Don't know

\begin{tabular}{|c|c|}
\hline Code & Route \\
& \\
1 & \\
2 & \\
3 & \\
4 & \\
5 & \\
9 & \\
\hline
\end{tabular}

Q74 Read out in reverse order 5-4-3-2-1

\section{Read out - code one only}

How satisfied or dissatisfied are you with the quality and maintenance of road side vegetation? By maintenance I mean kept free of weeds and trimmed back to be clear of the edges of the road. Are you...

Very dissatisfied

Quite dissatisfied

Neither satisfied nor dissatisfied

Quite satisfied

Very satisfied.

(Do not read out) Don't know

Q75 Read out in reverse order 5-4-3-2-1

Read out - code one only

Now thinking about street lighting, how satisfied or dissatisfied are you with...?

Would you say you are...?

...and how satisfied or dissatisfied are you with.

would you say you are....? 


\begin{tabular}{|c|c|c|c|c|c|c|}
\hline & $\begin{array}{c}\text { Very } \\
\text { dissatisfie } \\
\text { d }\end{array}$ & $\begin{array}{c}\text { Quite } \\
\text { dissatisfie } \\
\text { d }\end{array}$ & $\begin{array}{c}\text { Neither } \\
\text { satisfied } \\
\text { nor } \\
\text { dissatisfie } \\
\text { d }\end{array}$ & $\begin{array}{c}\text { Quite } \\
\text { satisfied }\end{array}$ & $\begin{array}{c}\text { Very } \\
\text { satisfied }\end{array}$ & \begin{tabular}{|c|} 
(Do not \\
read out) \\
Don't know
\end{tabular} \\
\hline (R1) Street lighting in the central city ........ & 1 & 2 & 3 & 4 & 5 & 9 \\
\hline$(\mathrm{R} 2)$ Street lighting in your suburban area & 1 & 2 & 3 & 4 & 5 & 9 \\
\hline
\end{tabular}

\section{Governance and citizen information}

Q76 Rotate codes 1 and 3, do not rotate 2

Read out - code one only

We just have a few more questions to go. I'd like you to think about the contact you have with Wellington City Council and the involvement of the community in Council decision-making.

In your view, does the Council consult you....?

Not enough

The right amount

Too much.

(Do not read out) Don't know

\begin{tabular}{|c|c|}
\hline Code & Route \\
& \\
& \\
1 & \\
2 & \\
3 & \\
9 & \\
\hline
\end{tabular}

Q77 Read out in reverse order 5-4-3-2-1

Read out - code one only

And how satisfied or dissatisfied are you with the way the Council involves people in decision-making?

Would you say you are...?

Very dissatisfied

Quite dissatisfied

Neither satisfied nor dissatisfied

Code

Route

Quite satisfied

Very satisfied

(Do not read out) Don't know

Q78 63/64/65 New

Rotate statements

Read out scale 5-4-3-2-1, strongly agree (5) to strongly disagree (1)

Read out - code one only

${ }^{\star \star}$ Probe: is that strongly agree/disagree or just agree/disagree ${ }^{\star \star \star \star}$

In general, do you agree or disagree with the statement....

and do you agree or disagree with the statement...

PROBE Probe: Is that strongly agree/disagree or just agree/disagree

\begin{tabular}{|l|l|l|l|l|l|} 
Strongly & Disagree & Neither & Agree & Strongly & (Do not \\
\hline
\end{tabular}


(R1) I understand how Wellington City Council makes decisions.

\begin{tabular}{|c|c|c|c|c|c|}
\hline disagree & & $\begin{array}{c}\text { agree nor } \\
\text { disagree }\end{array}$ & & agree & $\begin{array}{c}\text { read out) } \\
\text { Don't know }\end{array}$ \\
\hline 1 & 2 & 3 & 4 & 5 & 9 \\
1 & 2 & 3 & 4 & 5 & 9 \\
1 & 2 & 3 & 4 & 5 & 9 \\
\hline
\end{tabular}

Q79 Read out - code one only

Overall, how much influence do you feel the public has on the decisions the Wellington City Council makes? Would you say the public has...

No influence

Small influence

Some influence

Large influence

(Do not read out) Don't know

\begin{tabular}{|c|c|}
\hline Code & Route \\
1 & \\
2 & \\
3 & \\
4 & \\
9 & \\
\hline
\end{tabular}

\section{Ask Part A and Part B Demographics}

\section{Demographics}

Q80

Code other 98

Code don't know 99

\section{Read out - code all that apply}

Finally just a few questions about yourself and your household, to make sure we have talked to a good cross-section of Wellingtonians.

Which ethnic group or groups do you belong to?

NZ European

Maori

Samoan

Cook Island Maori

Tongan

Niuean ....

Chinese

Indian

Other (specify)

(Do not read out) Refused

\section{Read out code only one}

What type of home internet connection do you have?

Dial-up modem or regular connection

Broadband 
Q111 Read out

Do you...

\begin{tabular}{|c|c|}
\hline Code & Route \\
1 & \\
2 & \\
3 & \\
4 & \\
9 & \\
\hline
\end{tabular}

Q82 Read out - code one only

Approximately, what is your total household income (that is, from all income earners in your household as well as income from other sources, before tax)?

$\$ 20,000$ or less a year

\begin{tabular}{|l|l|}
\hline Code & Route \\
& \\
1 & \\
2 & \\
3 & \\
4 & \\
5 & \\
6 & \\
9 & \\
\hline
\end{tabular}

Q83

$\$ 20,001-\$ 30,000$

$\$ 30,001-\$ 50,000$

$\$ 50,001-\$ 70,000$

$\$ 70,000-\$ 100,000$

More than $\$ 100,000$

(Do not read out) Refused or don't know.

\begin{tabular}{|c|c|}
\hline Code & Route \\
& \\
1 & \\
2 & \\
9 & \\
\hline
\end{tabular}

If respondent agrees

Can you let me have your contact details please, so that if we call you back we can ask for you by name?

\section{Record contact details}

\section{Name:}

Phone Number:

Thanks, that's all the questions I have for you. Should you have any queries about this interview my name is...... calling on behalf of Nielsen

As this is market research, it is carried out in compliance with the Privacy act and the information you provided will be used only for research purposes. Under the Privacy Act, you have the right to request access to the information you have provided. 
Interviewer name: Date:

Interviewer pay number:

Interview Time

\section{Start Time:}

Finish Time:

Duration of Interview: 


\section{WELLINGTON CITY COUNCIL RESIDENTS SATISFACTION SURVEY}

\begin{tabular}{lll} 
Study ID & FEB12-RSS & Resp. No. \\
Interviewer No. & - & $\begin{array}{l}\text { Interview Length } \\
\text { No. Of Queries }\end{array}$ \\
\hline
\end{tabular}

\section{Wellington City Council}

Resident Satisfaction Survey

This Questionnaire is split into two parts at question 46. Ask Part A and Part B Demographic Questions.

Good morning/afternoon/evening.

My name is <name> calling from OCIS on behalf of Nielsen the market research company.

We are conducting a survey on behalf of Wellington City Council about the services they provide to the people of Wellington. To help me select the right person for this survey, I need to speak to:

- A person living in this household who is 15-24 years of age

- The person living in this household 15 years of age or over, who had the last birthday (or person to fill quotas).

\section{${ }^{*}$ CHECK QUOTAS*}

\section{*IF NOT AVAILABLE ARRANGE CALLBACK*}

\section{${ }^{*}$ REINTRODUCE IF NECESSARY*}

The interview will take about 20 minutes of your time. Everything you say will be confidential and the results of the survey will help the Council improve the services it provides to the people of Wellington.

Is it convenient for you now, or shall I make an appointment to call you back at a better time for you.

\section{*IF NECESSARY ARRANGE CALLBACK*}

**** IF ASKED ABOUT WHAT IS THE SURVEY ABOUT ****

The survey covers a range of topics about services the council currently provides.

Q95 For quality control and training purposes, this call will be recorded and may also be monitored however your answers are confidential and can not be traced back to you personally. Is this ok with you?

[SA]

Yes

No

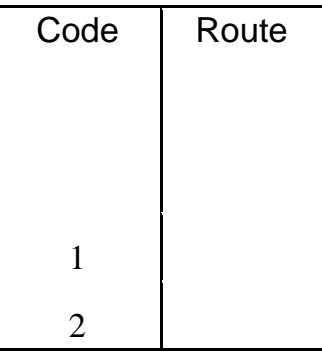

Q1 Do not read out

If no, close with thanks

Firstly, can I just check that you actually live in Wellington City, that is, the area extending as far north as Tawa but not including Porirua, Petone or the Hutt Valley? [SA]

\begin{tabular}{c|c|} 
Code & Route \\
1 & Q2
\end{tabular}


No

I'm sorry but for this survey we need to speak to people that live in Wellington City,

Thank you for your time.

Should you have any queries about this interview my name is <> calling on behalf of Nielsen

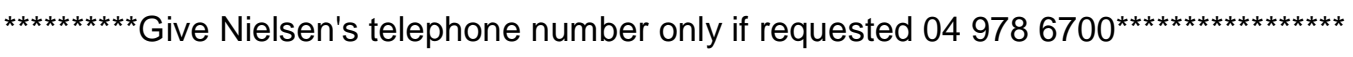

Q2 If yes, close with thanks

Are you by any chance an employee of, or contractor to the Wellington City

Council, or are you an elected representative or a member of a community board?[SA]

Yes.

\begin{tabular}{|c|c|}
\hline Code & Route \\
& \\
& \\
1 & CLOSE \\
2 & Q3 \\
\hline
\end{tabular}

No

I'm sorry but we cannot speak to employees or contractors for the Wellington City Council, or elected members of community boards.

Thank you for your time.

Should you have any queries about this interview, my name is <> calling on behalf of Nielsen.

Give Nielsen phone number if requested 049786700

Q3

Check ward quota



Which suburb of Wellington do you live in?

[SA]

Aro Valley

Berhampore

Breaker Bay

Broadmeadows

Brooklyn.

Chartwell.

Central City

Churton Park.

Crofton Downs.

Glenside

Grenada North.

Grenada Village.

Hataitai

Happy Valley

Highbury 


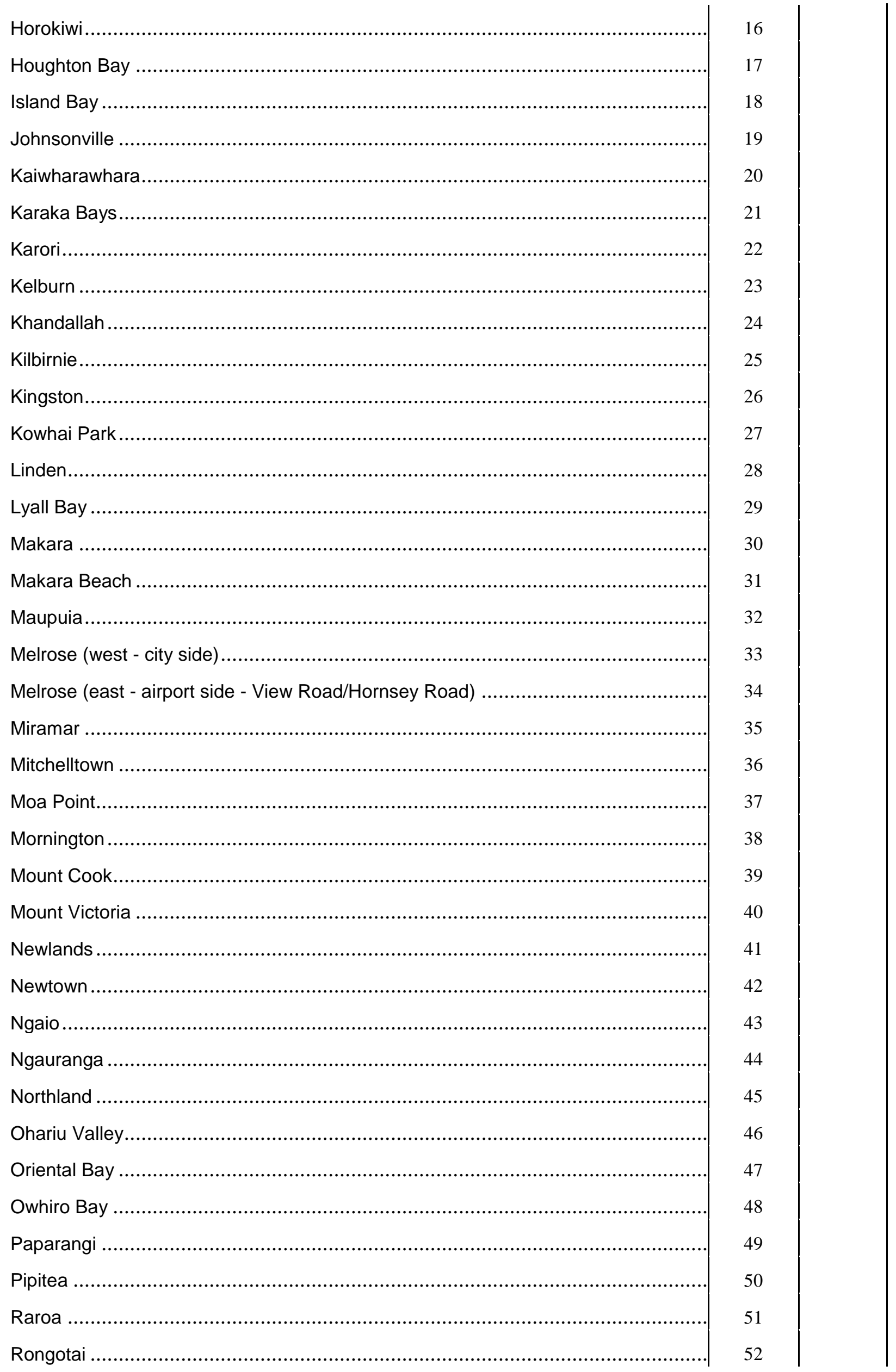




\begin{tabular}{|c|c|c|}
\hline 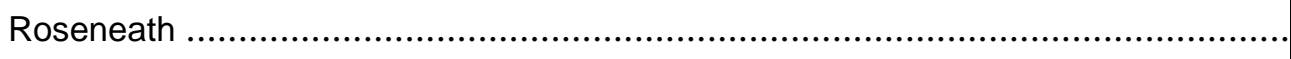 & 53 & \\
\hline Seatoun & 54 & \\
\hline Seatoun Bays/Karaka Bays .............. & 55 & \\
\hline 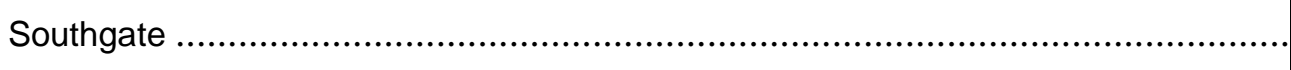 & 56 & \\
\hline Strathmore Park & 57 & \\
\hline Takapu Valley ................ & 58 & \\
\hline Tawa & 59 & \\
\hline Te Aro.................................................. & 60 & \\
\hline Thorndon & 61 & \\
\hline Vogeltown & 62 & \\
\hline Wadestown & 63 & \\
\hline Wilton ..................... & 64 & \\
\hline 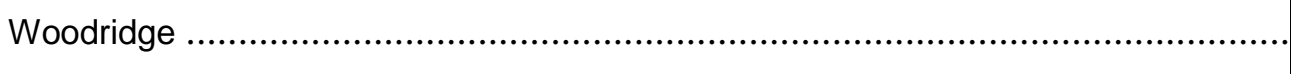 & 65 & \\
\hline (Do not read) Refused..................... & 97 & CLOSE \\
\hline 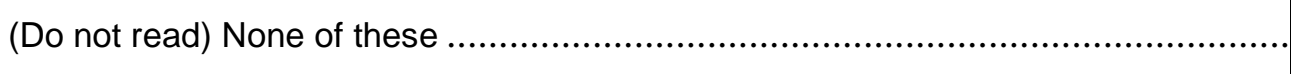 & 98 & CLOSE \\
\hline 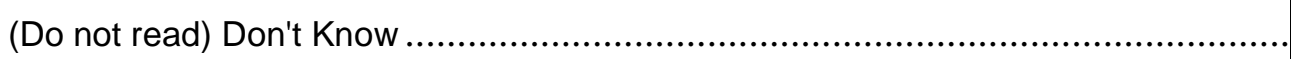 & 99 & CLOSE \\
\hline
\end{tabular}

\section{CLOSE FOR Q3 SUBURB}

I'm sorry but for this survey we need to know which suburb you live in.

Thank you for your time.

Should you have any queries about this interview, my name is <> calling on behalf of Nielsen.

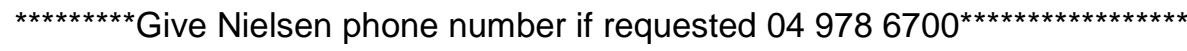

Q4 This question is set from Q3

Don't need to ask, record only from Q3

\section{CHECK WARD DEFINITIONS WITH WCC \\ Ward[SA]}

Northern.

Onslow-Western

Lambton.

Southern

Eastern

\begin{tabular}{|c|c|}
\hline Code & Route \\
& \\
1 & \\
2 & \\
3 & \\
4 & \\
5 & \\
\hline
\end{tabular}

Q5

\section{Code Gender}

Gender[SA]

Male

Female

\begin{tabular}{|c|c|}
\hline Code & Route \\
1 & \\
2 & \\
\hline
\end{tabular}

Q6 If answered 1 terminate 
Read out - code one only

Which age group do you fit into?

[SA]

Under 15 years

15-24 years

25-39 years

40-59 years

60-64 years

65 years and over

(Do not read out) Refused

\section{CLOSE FOR Q6 age \\ IF Q6=1}

I'm sorry but for this survey we need to speak to people aged 15 or over.

Thank you for your time.

Should you have any queries about this interview, my name is <> calling on behalf of Nielsen.

${ }^{* \star \star * \star * \star *}$ Give Nielsen phone number if requested $049786700^{* \star \star}$

\section{ELSE}

I'm sorry but for this survey we need your age.

Thank you for your time.

Should you have any queries about this interview, my name is <> calling on behalf of Nielsen.

*Give Nielsen phone number if requested $049786700^{*}$

Q7 Read out - code one only

Which of the following best describes your household?

[SA]

Young couple without children

Household with youngest child under 5

Household with youngest child 5 to 13

Household with youngest child 14 or over.

Older couple - no children or none living at home.....

Single/one person household

Flat - not a family home.

Other - specify.....

(Do not read) Refused

\begin{tabular}{|c|c|}
\hline Code & Route \\
& \\
01 & \\
02 & \\
03 & \\
04 & \\
05 & \\
06 & \\
07 & \\
98 & \\
99 & \\
\hline
\end{tabular}

Q8 Display codes in reverse order 5-4-3-2-1

Read out - code one only 
First of all, i'd like you to think about all the dealings you've had with Wellington City Council; all the things it has done over the last 12 months; and all the services and facilities that Wellington City Council provides. Overall, how would you rate the performance of Wellington City Council over the last 12 months? Would you say it was.... [SA]

Very poor .

Poor.

Neither good nor poor

Good

Very good

(Do not read) Don't know.

\section{Q112 If Q8 code 5 then ask Q112}

Why do you say the council's performance is very good?

PROBE Fully

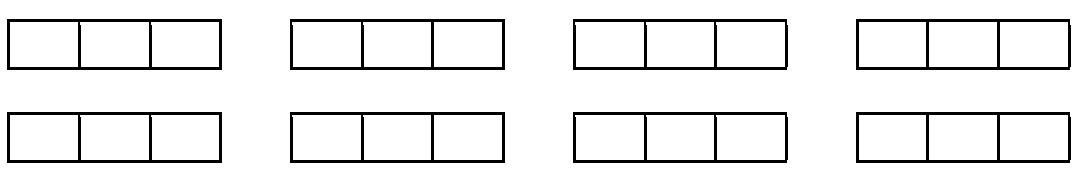

Q113 If Q8 code 4, 3, 2, or 1 ask Q113

What could the council do for you to give them a higher rating?

PROBE Fully

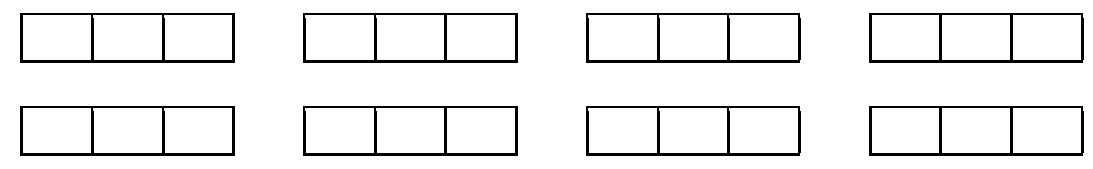

Q88 Read out in reverse order 5-4-3-2-1

Read out, code one only

Thinking about all the dealings you've had with Wellington City Council; all the things it has done over the last 12 months; and all the services and facilities that Wellington City Council provides, overall, how would you rate the value for money from all the services the Council provides?

$[\mathrm{SA}]$

Very Poor.

Poor.

Neither good nor poor

Good

Very Good.....

\begin{tabular}{|l|l|}
\hline Code & Route \\
& \\
1 & \\
2 & \\
3 & \\
4 & \\
5 &
\end{tabular}


Q10 Read out in reverse order 5-4-3-2-1

Read out, code one only

The next question concerns your overall quality of life.

Would you say that overall your quality of life is ...[SA]

Extremely poor

\begin{tabular}{|l|l|}
\hline Code & Route \\
& \\
& \\
1 & \\
2 & \\
3 & \\
4 & \\
5 & \\
9 & \\
\hline
\end{tabular}

\section{Urban Development}

Q11 Read out in reverse order 5-4-3-2-1

***Probe: Is that strongly agree/disagree or just agree/disagree ${ }^{\star \star \star \star \star \star \star \star \star \star * ~}$

The next questions cover such things as the design and layout of Wellington.

Generally speaking, do you agree or disagree that Wellington is a great place to live?

[SA]

PROBE Probe: Is that strongly agree/disagree or just agree/disagree

Strongly disagree.

Disagree

Neither agree nor disagree

Agree

Strongly agree.....

(Do not read out) Don't know

\begin{tabular}{|c|c|}
\hline Code & Route \\
& \\
& \\
1 & \\
2 & \\
3 & \\
4 & \\
5 & \\
9 & \\
\hline
\end{tabular}

Q12 Read out in reverse order 5-4-3-2-1

${ }^{\star \star *}$ Probe: Is that strongly agree/disagree or just agree/disagree ${ }^{\star \star \star \star \star \star \star \star \star \star \star \star}$

And do you agree or disagree that the different suburbs and communities in

Wellington provide a good variety of places to live in? [SA]

PROBE Probe: Is that strongly agree/disagree or just agree/disagree

Strongly disagree.

Code

Route

Disagree

Neither agree nor disagree

Agree

Strongly agree.

(Do not read out) Don't know

\begin{tabular}{|l|l|} 
Code & Route \\
& \\
1 & \\
2 & \\
3 & \\
4 & \\
5 & \\
9 & \\
\hline
\end{tabular}



work in Wellington in your occupation, or for someone with your experience and/or qualifications? [SA]

PROBE Probe: Is that strongly agree/disagree or just agree/disagree

Strongly disagree.

Disagree

Neither agree nor disagree

Agree.

Strongly agree

(Do not read out) Don't know

\begin{tabular}{|c|c|}
\hline Code & Route \\
& \\
1 & \\
2 & \\
3 & \\
4 & \\
5 & \\
9 & \\
\hline
\end{tabular}

Q14 Read out in reverse order 5-4-3-2-1

${ }^{\star * *}$ Probe: Is that strongly agree/disagree or just agree/disagree ${ }^{\star \star \star \star * \star \star * \star \star *}$

And do you agree or disagree that there is a good variety of leisure activities and opportunities to socialise in Wellington? [SA]

PROBE Probe: Is that strongly agree/disagree or just agree/disagree

Strongly disagree.

Disagree

Neither agree nor disagree

Agree

Strongly agree.

(Do not read out) Don't know

Rotate statements

Read out scale 5-4-3-2-1, strongly agree (5) to strongly disagree (1)

\section{Read out - code one only}

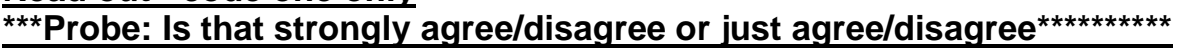

I am going to read you some statements about Wellington and would like you to tell me if you agree or disagree with each statement.

In general, do you agree or disagree with the statement....

[SA]

PROBE Probe: Is that strongly agree/disagree or just agree/disagree

(R1) Heritage buildings, areas, trees and objects contribute to the city's unique character.

(R2) Heritage buildings, areas, trees and objects contribute to your community's unique character

(R3) The city centre is lively and attractive....

(R4) My local suburban centre is lively and attractive

\begin{tabular}{|c|c|c|c|c|c|}
\hline $\begin{array}{c}\text { Strongly } \\
\text { disagree }\end{array}$ & Disagree & $\begin{array}{c}\text { Neither } \\
\text { agree nor } \\
\text { disagree }\end{array}$ & Agree & $\begin{array}{c}\text { Strongly } \\
\text { agree }\end{array}$ & $\begin{array}{c}\text { (Do not } \\
\text { read out) } \\
\text { Don't know }\end{array}$ \\
\hline 1 & 2 & 3 & 4 & 5 & 9 \\
1 & 2 & 3 & 4 & 5 & 9 \\
1 & 2 & 3 & 4 & 5 & 9 \\
1 & 2 & 3 & 4 & 5 & 9 \\
\hline
\end{tabular}


(R5) The city is developing in a way that takes into account its unique urban character and natural environment.

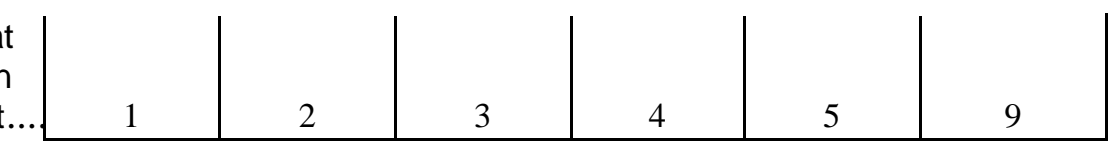

\section{Q114 Rotate statements}

\section{Read out in reverse 5,4,3,2,1}

In general, how strongly do you agree or disagree that...[SA]

PROBE Is that strongly agree/disagree or just agree/disagree

(R1) Heritage buildings, areas, trees and objects are appropriately valued and protected in the central city

(R2) Heritage buildings, areas trees and objects are appropriately valued and protected in your local/suburban

area.

\begin{tabular}{|c|c|c|c|c|c|}
\hline $\begin{array}{c}\text { Strongly } \\
\text { disagree }\end{array}$ & Disagree & $\begin{array}{c}\text { Neither } \\
\text { agree nor } \\
\text { disagree }\end{array}$ & Agree & $\begin{array}{c}\text { Strongly } \\
\text { agree }\end{array}$ & $\begin{array}{c}\text { (Do not } \\
\text { read out) } \\
\text { Don't know }\end{array}$ \\
\hline 1 & 2 & 3 & 4 & 5 & 9 \\
1 & 2 & 3 & 4 & 5 & 9 \\
\hline
\end{tabular}

Q16 Read out in reverse order 5-4-3-2-1

Read out - code one only

How strongly do you agree or disagree with the statement, 'I feel a sense of pride in the way Wellington looks and feels'? [SA]

PROBE Probe: Is that strongly agree/disagree or just agree/disagree

Strongly disagree

Disagree

Neither agree nor disagree

Agree

Strongly agree

(Do not read) Don't know.

\begin{tabular}{|c|c|}
\hline Code & Route \\
& \\
& \\
1 & \\
2 & \\
3 & \\
4 & \\
5 & \\
9 & \\
\hline
\end{tabular}

\section{Social and Recreation / Environmental}

Q17 Read out scale in order: very safe to very unsafe

Read out - code one only

The next few questions are about safety.

Thinking of your overall sense of freedom from crime, how safe or unsafe do you feel in the following situations. Would you say that you were very safe, reasonably safe, somewhat unsafe or very unsafe...?

.....and would you say that you were very safe, reasonably safe, somewhat unsafe or very unsafe...? [SA]

(R1) In your neighbourhood during the day

\begin{tabular}{|c|c|c|c|c|c|}
\hline $\begin{array}{c}\text { Very } \\
\text { unsafe }\end{array}$ & $\begin{array}{c}\text { Somewhat } \\
\text { unsafe }\end{array}$ & $\begin{array}{c}\text { Reasonabl } \\
\text { y safe }\end{array}$ & Very safe & $\begin{array}{c}\text { (Do not } \\
\text { read out }) \\
\text { Not } \\
\text { applicable: } \\
\text { Don't } \\
\text { come into } \\
\text { city centre }\end{array}$ & $\begin{array}{c}\text { (Do not } \\
\text { read) Don't } \\
\text { know }\end{array}$ \\
\hline 1 & 2 & 3 & 4 & 7 & 9
\end{tabular}




\begin{tabular}{c|c|c|c|c|c|c|} 
(R2) In your neighbourhood after dark .... & 1 & 2 & 3 & 4 & 7 & 9 \\
(R3) In your city centre during the day ..... & 1 & 2 & 3 & 4 & 7 & 9 \\
(R4) In your city centre after dark ........... & 1 & 2 & 3 & 4 & 7 & 9 \\
\hline
\end{tabular}

Q18 Note for post-coding and analysis: Listing of new codes to be approved by WCC before back coding. All new codes to be grouped into broad themes in parenthesis below and nets of themes to be included in data tabulations.

Ask Question 19 if more than one coded

Read in rotated order - code each mention ${ }^{\star \star}$ Probe: What else ${ }^{\star \star \star \star \star \star \star}$

The following list I am about to read identifies things that might make people feel unsafe in their neighbourhoods or city. Which of the following, if any, are particularly concerning in Wellington at present?

[MA]

PROBE What else?

Poorly lit or dark public areas such as streets, paths and parks

Vandalism such as broken windows in shops and public buildings

Graffiti

Poorly maintained or dangerous public areas such as streets, paths and parks

Traffic, including busy roads and lack of pedestrian facilities

Dangerous driving including speeding, drunk drivers and so on

Alcohol and drug problems

Car theft or vandalism, and theft from cars

Threatening people and/or people behaving dangerously

(Do not read out) None of these

Other (specify)

Q19 Note for post-coding and analysis: Listing of new codes to be approved by WCC before back coding. All new codes to be grouped into broad themes in parenthesis below and nets of themes to be included in data tabulations.

<Ask If more than one coded in question 18>

Read in rotated order - code only one

And which of these is of most concern to you at present in Wellington? $[\mathrm{MA}]$ 
Poorly lit or dark public areas such as streets, paths and parks

Vandalism such as broken windows in shops and public buildings

Graffiti

Poorly maintained or dangerous public areas such as streets, paths and parks

Traffic, including busy roads and lack of pedestrian facilities

Dangerous driving including speeding, drunk drivers and so on

Alcohol and drug problems

Car theft or vandalism, and theft from cars

Threatening people and/or people behaving dangerously

(Do not read out) None of these

Other (specify)

(Do not read out) Don't know

Q20 Read out in reverse order 5-4-3-2-1

Read out - code one only

Wellington City is becoming home for an increasing number of people with different lifestyles and cultures and from different countries. Overall do you think this makes the city...? [SA]

A much worse place to live

A worse place to live

Makes no difference.

A better place to live

A much better place to live

(Do not read out) Don't know

\begin{tabular}{|l|l|} 
Code & Route \\
& \\
1 & \\
2 & \\
3 & \\
4 & \\
5 & \\
9 & \\
\hline
\end{tabular}

Q21 Read out in reverse order 5-4-3-2-1

$\star \star \star \star \star \star * \star \star *$ Probe: Is that strongly agree/disagree or just

agree/disagree ${ }^{\star \star \star \star \star \star \star \star \star \star \star \star \star \star \star \star \star \star}$

We want to find out about the sense of community strength and spirit in Wellington. In general, do you agree or disagree with the statement......The community works together and people support each other? [SA]

PROBE Probe: Is that strongly agree/disagree or just agree/disagree

Strongly disagree.

Disagree

Neither agree nor disagree

Agree

Strongly agree.

(Do not read out) Don't know 


\section{Read out in reverse order 5-4-3-2-1}

\section{Read out - code one only}

Wellington City Council works to help ensure Wellington is made up of strong and thriving communities. How satisfied or dissatisfied are you that the Council provides appropriate services and resources to ensure strong and thriving communities?

Would you say you are...

\section{$[\mathrm{SA}]$}

Very dissatisfied

Quite dissatisfied

Neither satisfied nor dissatisfied

Quite satisfied

Very satisfied

\begin{tabular}{|c|c|}
\hline Code & Route \\
& \\
& \\
& \\
1 & \\
2 & \\
3 & \\
4 & \\
5 & \\
9 &
\end{tabular}

(Do not read out) Don't know

\section{Q115 Ask all}

\section{Rotate}

\section{Do Not Read Out}

As far as you are aware, which of the following community support services are provided by the Wellington City Council?[SA]

(R1) Grants (e.g. social and recreation, and education)

(R2) Provide support networks for various groups (e.g. Pacific people, young people, senior citizens etc.)

(R3)

Organising community events

(R4) Provide advocacy services for various groups (if necessary: that is the Council would act as a go between for services such (R5) as public health and various community groups)

Support for homeless

\begin{tabular}{|c|c|c|}
\hline Yes & No & Don't know \\
\hline 1 & 2 & 9 \\
1 & 2 & 9 \\
1 & 2 & 9 \\
1 & 2 & 9 \\
1 & 2 & 9 \\
\hline
\end{tabular}

Q24 Do not read - code only one

Have you used a Wellington City Council public toilet in the last 12 months?[SA]

Yes

No

Don't Know.

\begin{tabular}{|c|c|}
\hline Code & Route \\
1 & \\
2 & Q26 \\
9 & Q26 \\
\hline
\end{tabular}

Q25 Read out in reverse order 5-4-3-2-1

Read out - code one only

And how satisfied or dissatisfied are you with the cleanliness of Wellington City Council public toilets?

Would you say you are...? [SA]

Very dissatisfied

\begin{tabular}{|c|c|}
\hline Code & Route \\
& \\
1 &
\end{tabular}


Quite dissatisfied

Neither satisfied nor dissatisfied

Quite satisfied

Very satisfied

(Do not read out) Don't know

\section{Do not read out - code one only}

Do you have essential emergency items in your home? By emergency items I mean a supply of everyday use items that you can easily find and use when an emergency occurs. [SA]

Yes

\begin{tabular}{|c|c|}
\hline Code & Route \\
1 & \\
2 & Q28 \\
9 & Q28 \\
\hline
\end{tabular}

Don't know

\section{Code Don't know as 99}

\section{Read out - code all that apply}

As I read out this list please tell me which, if any, of these you would easily be able to find in the event of an emergency [MA]

Ten litres of bottled water per person in your household

Canned food

Can opener

Other non-perishable food

First aid kit

A battery operated radio

Spare batteries

A plastic bucket

Plastic bags

Toilet paper

Soap

Disinfectant

A primus or gas barbeque to cook on

Waterproof torches

Other essential medication

Pet supplies

Blankets, towels, sleeping bags

Sturdy footwear

Baby/infant supplies

Essential documents (birth/marriage certificates, insurance policies) 
None of these

Q28 Ask all respondents

\section{Do not read out - code one only}

Do you have an emergency plan for your family or your household about what they will do if a significant emergency occurs?[SA]

Yes

No

Don't know

\begin{tabular}{|c|c|}
\hline Code & Route \\
& \\
1 & \\
2 & \\
9 & \\
\hline
\end{tabular}

Check Q7 - if school age children (code 2,3 or 4) in household ask all statements in Q29 , otherwise omit statement 3 and ask all other statements

Ask all respondents

Read out - code all that apply

Which of the following have you done. Have you...?

[MA]

Discussed ways to get in touch with other family members when an emergency occurs

Made plans for re-uniting with family members when an emergency occurs

Arranged for authorised people to collect children from school, and provided the school with a list of these people for when an emergency occurs

Established a meeting place in the event your house becomes unusable or if family members are separated when an emergency occurs

Allocated tasks for those at home when an emergency occurs eg. turning off power or checking with neighbours

Completed a first aid course

Found out where your nearest Civil Defence Centre is

(Do not read out) None of these

(Do not read out) Don't know

\begin{tabular}{l|l} 
& \\
01 & \\
02 & \\
03 & \\
04 & \\
05 & \\
06 & \\
07 & \\
98 & \\
99 &
\end{tabular}

Q30

Allow entry up to 2 decimal places

Type 000 for zero/none

Type 999 for Don't know

IE 2 HOURS $=002.0,10.5$ HOURS $=010.5$

Thinking now about recreational opportunities in Wellington....

How many hours would you spend in some form of regular physical activity in an average week? [MA]

Type in number (use decimal places)

\begin{tabular}{|c|c|}
\hline Code & Route \\
& \\
1 & \\
9 & \\
\hline
\end{tabular}

(Do not read) Don't know.

\begin{tabular}{|l|l|}
\hline Code & Route \\
&
\end{tabular}

Q31 Check Q7 - if children aged 13 and under in household (code 2/3) ask Q31 , otherwise skip to Q34

Do not read out

Have any of the children aged 13 or under in your household used a Council playground or skate park in the last 12 months? [SA] 


\begin{tabular}{|c|c|c|}
\hline Yes. & 1 & \\
\hline 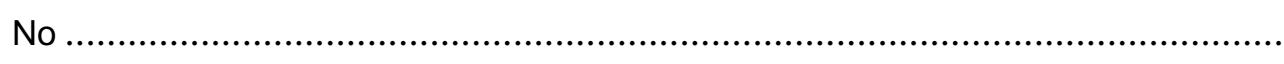 & 2 & Q33 \\
\hline (Do not read out) Don't know ......................... & 9 & Q33 \\
\hline
\end{tabular}

Q32 Read out in reverse order 5-4-3-2-1

\begin{tabular}{|c|c|}
\hline Code & Route \\
& \\
& \\
1 & \\
2 & \\
3 & \\
4 & \\
5 & \\
9 & \\
\hline
\end{tabular}

Q33 ASK of those with school aged children (Q7=code 2 or 3)

Read out - code only one

On average, How often do the children aged 13 or under in your household walk to and from school?

$[\mathrm{MA}]$

Everyday

3-4 days a week

1-2 days a week

Less often

Never

No school aged children

(Do not read out) Don't know

(

Route

Read out - code all that apply

Have you used any of the following Wellington City Council recreation facilities in the last 12 months?

$[\mathrm{MA}]$

A Council Recreation Centre

A Council Swimming Pool

A Council skate park

The Mountain Bike Park in Karori

A Council Playground

(Do not read out) None of these 
(Do not read out) Don't know

Q35 Ask Q35 if Q34 code $=1$

Read out in reverse order 5-4-3-2-1

\begin{tabular}{|c|c|}
\hline Code & Route \\
& \\
& \\
1 & \\
2 & \\
3 & \\
4 & \\
5 & \\
9 & \\
\hline
\end{tabular}

Q36

Ask Q36 if $\mathbf{Q 3 4}$ code $=2$

Read out in reverse order 5-4-3-2-1

Read out - code one only

And how satisfied or dissatisfied were you with the Wellington City Council's

swimming pool you visited most recently? [SA]

Very dissatisfied

Code

Route

Quite dissatisfied

Neither satisfied nor dissatisfied

Quite satisfied

Very satisfied

(Do not read out) Don't know

Q42 Read out scale 5-4-3-2-1, strongly agree (5) to strongly disagree (1)

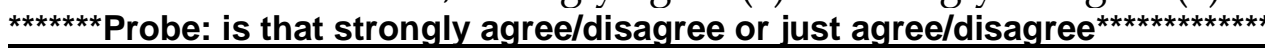
In general do you agree or disagree that Wellington city offers a wide range of recreational activities? [SA]

PROBE Is that strongly agree/disagree or just agree/disagree

Strongly disagree.

Disagree

Neither agree nor disagree

Agree

Strongly agree.

(Do not read out) Don't know

\begin{tabular}{|l|l|} 
Code & Route \\
& \\
1 & \\
2 & \\
3 & \\
4 & \\
5 & \\
9 & \\
\hline
\end{tabular}

Q45 Please code others as 99 and don't know as 99

Code $\mid$ Route


Do not read out - code all that apply

What, if anything, makes it difficult for you to take part in these recreational activities? [MA]

Too busy

Poor health.

Activity costs too much

Activity too far away

No facilities for child care.

Weather.

Not at a convenient time

Shift work.

Lack of motivation

No facilities exist.

Tiredness.

Lack of knowledge about how to do it.

Environmental factors (eg road conditions, pollution)

Lack of parking/public transport/transport

None/nothing/not interested.

Other (specify)

Don't know

Read out scale 5,4,3,2,1

\section{Read out}

In general, how easy is it to access Wellington City Council's recreation facilities and programmes?[SA]

Very difficult

Quite difficult

Neither easy nor difficult

Quite easy

Very easy.

(Do not read out) Don't know

\begin{tabular}{|c|c|}
\hline Code & Route \\
& \\
& \\
1 & \\
2 & \\
3 & \\
4 & \\
5 & \\
9 & \\
\hline
\end{tabular}

\section{Q104 Scale to be read in reverse 5,4,3,2,1}

To provide recreation services and facilities it costs, on average, $\$ 168.70$ per

\begin{tabular}{|c|c|} 
Code & Route \\
& \\
1 & \\
2 & \\
3 & \\
4 &
\end{tabular}


Strongly agree

(Do not read out) Don't know

Q37 Read out - code all that apply

Have you used any of the following Wellington City Council community facilities in the last 12 months?

$[\mathrm{MA}]$

A public library

A Community Centre

A Community Hall

(Do not read out) None of these

(Do not read out) Don't know

\begin{tabular}{|c|c|}
\hline Code & Route \\
& \\
1 & \\
2 & \\
3 & \\
7 & \\
9 & \\
\hline
\end{tabular}

Q97 if Q37 code $=1$ then ask Q97

Read out

How often on average would you use, or visit a Wellington City Council library?[SA]

More than once a week

Once a week

Once every 2-3 weeks

Once a month

Once every 2-3 months

Once every 4-6 months

Less often than once every 6 months

Code

Route

(Do Not Read Out) Don't Know

Q98 if $\mathbf{Q} 37$ code $=1$ then ask Q98

Read out

Thinking about the library items that you use, how satisfied or dissatisfied are you with the range and variety of the items available?[SA]

Very dissatisfied

Quite dissatisfied

Neither satisfied nor dissatisfied

Code

Route

Quite satisfied

Very satisfied.

(Do not read out) Don't know

9

Q38 If $\mathbf{Q 3 7}$ code $=1$, then ask Q38

Code

Route

Read out in reverse order 5-4-3-2-1

Read out - code one only

Thinking about all the libraries and library services you've used over the last 12 months, how satisfied or dissatisfied are you with the library services overall? [SA] 


\begin{tabular}{|c|c|c|}
\hline Very dissatisfied & 1 & \\
\hline Quite dissatisfied ....... & 2 & \\
\hline Neither satisfied nor dissatisfied ......... & 3 & \\
\hline Quite satisfied ................................ & 4 & \\
\hline Very satisfied................................... & 5 & \\
\hline (Do not read out) Don't know ............................. & 9 & \\
\hline $\begin{array}{l}\text { Scale to be read out in reverse } \\
\text { To provide library services it costs, on average, } \$ 106.65 \text { per resident per year (or } \\
\$ 0.29 \text { per day). How strongly do you agree or disagree this is good value for } \\
\text { money? [SA] }\end{array}$ & Code & Route \\
\hline Strongly disagree......................... & 1 & \\
\hline Disagree ................................... & 2 & \\
\hline 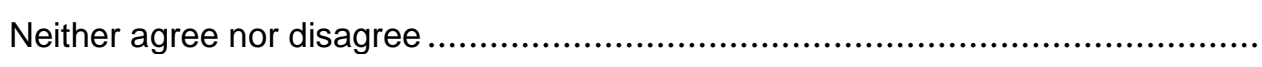 & 3 & \\
\hline 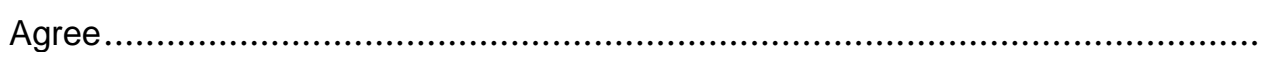 & 4 & \\
\hline Strongly agree.. & 5 & \\
\hline (Do not read out) Don't know ...... & 9 & \\
\hline
\end{tabular}

\section{Q39 Ask of all}

29, 31 \& 33. New \& existing (how often used...) DO NOT ROTATE

\section{Read out - code one only}

In the last twelve months, how often on average have you used...?

......And in the last 12 months how often have you used....? [SA]

(R1) Wellington City's coastal areas or beaches.

(R2) Botanic gardens, including Otari/Wiltons Bush Native Botanic Reserve.

(R3) Wellington City Council parks

(R4) Town Belt or Outer Green Belt.

(R5) The city's walking tracks...

(R6) Wellington City Council outdoor grass sports fields

(R7) A Wellington City Council sports field which has artificial turf

\begin{tabular}{|c|c|c|c|c|c|c|c|c|}
\hline $\begin{array}{l}\text { Most } \\
\text { days }\end{array}$ & $\begin{array}{c}\text { Once or } \\
\text { twice a } \\
\text { week }\end{array}$ & $\begin{array}{c}\text { Once } \\
\text { every 2- } \\
3 \text { weeks }\end{array}$ & $\begin{array}{l}\text { Once a } \\
\text { month }\end{array}$ & \begin{tabular}{|c|} 
Once \\
every 2- \\
3 \\
months
\end{tabular} & \begin{tabular}{|c|} 
Once \\
every 4- \\
5 \\
months
\end{tabular} & $\begin{array}{c}\text { Once } \\
\text { every } 6 \\
\text { months } \\
\text { or less } \\
\text { often }\end{array}$ & $\begin{array}{l}\text { Never } \\
\text { in the } \\
\text { last } 12 \\
\text { months }\end{array}$ & $\begin{array}{l}\text { (Do not } \\
\text { read) } \\
\text { Don't } \\
\text { know }\end{array}$ \\
\hline 01 & 02 & 03 & 04 & 05 & 06 & 07 & 08 & 99 \\
\hline 01 & 02 & 03 & 04 & 05 & 06 & 07 & 08 & 99 \\
\hline 01 & 02 & 03 & 04 & 05 & 06 & 07 & 08 & 99 \\
\hline 01 & 02 & 03 & 04 & 05 & 06 & 07 & 08 & 99 \\
\hline 01 & 02 & 03 & 04 & 05 & 06 & 07 & 08 & 99 \\
\hline 01 & 02 & 03 & 04 & 05 & 06 & 07 & 08 & 99 \\
\hline 01 & 02 & 03 & 04 & 05 & 06 & 07 & 08 & 99 \\
\hline
\end{tabular}

Q40 30 \& 33. New (rate quality and maintenance) 
Rotate

Ask this question, Q40R1 if Q39 R3 = code 1,2,3,4,5,6 or 7 (have used WCC park in the last 12 months)

Ask this question, Q40 R2 if Q39 R5 =code 1,2,3,4,5,6 or 7 (have used walkways and tracks in the last 12 months)

Ask this question, Q40 R3 if Q39 R6 = code 1,2,3,4,5,6 or 7 (have used WCC outdoor grass sports field in the last 12 months)

Ask this question, Q40 R4 if Q39 R7 = code 1,2,3,4,5,6 or 7 (have used WCC sports field which have artificial turf in the last 12 months)

\section{Read out in reverse order 5-4-3-2-1 \\ Read out - code one only}

Overall, how satisfied or dissatisfied are you with the quality and maintenance of...

(R1) Wellington City Council parks, excluding the Botanic Gardens

(R2) The city's walking tracks

(R3) Wellington City Council outdoor grass sports fields

(R4) Wellington City Council sports fields which have artificial turf

\begin{tabular}{|c|c|c|c|c|c|}
\hline $\begin{array}{c}\text { Very } \\
\text { dissatisfie } \\
\mathrm{d}\end{array}$ & $\begin{array}{c}\text { dissatisfie } \\
\mathrm{d}\end{array}$ & $\begin{array}{c}\text { Neither } \\
\text { satisfied } \\
\text { nor } \\
\text { dissatisfie } \\
\mathrm{d}\end{array}$ & satisfied & $\begin{array}{c}\text { Very } \\
\text { satisfied }\end{array}$ & $\begin{array}{c}\text { (Do not } \\
\text { read) Don't } \\
\text { know }\end{array}$ \\
\hline 1 & 2 & 3 & 4 & 5 & 9 \\
1 & 2 & 3 & 4 & 5 & 9 \\
1 & 2 & 3 & 4 & 5 & 9 \\
1 & 2 & 3 & 4 & 5 & 9 \\
\hline
\end{tabular}

Q41 31 \& 32. New (cleanliness \& maintenance)

Ask this question, Q41 R1 if Q39 R4 = code 1,2,3,4,5,6 or 7 (have used Town Belt or Outer Green Belt in the last 12 months)

Ask this question, Q41 R2 if Q39 R1 = code 1,2,3,4,5,6 or 7 (have used coastline or beaches in the last 12 months)

Ask this question, Q41 R3 if Q39 R2 = code 1,2,3,4,5,6 or 7 (have used botanic gardens in the last 12 months)

\section{Read out in reverse order 5-4-3-2-1}

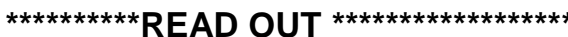

And, overall, how satisfied or dissatisfied are you with the quality and maintenance of...[SA]

\begin{tabular}{|c|c|c|c|c|c|c|}
\hline & $\begin{array}{c}\text { Very } \\
\text { dissatisfie } \\
\mathrm{d}\end{array}$ & $\begin{array}{c}\text { dissatisfie } \\
\text { d }\end{array}$ & $\begin{array}{c}\text { Neither } \\
\text { satisfied } \\
\text { nor } \\
\text { dissatisfie } \\
\text { d }\end{array}$ & satisfied & $\begin{array}{c}\text { Very } \\
\text { satisfied }\end{array}$ & \begin{tabular}{|} 
(Do not \\
read) Don't \\
know
\end{tabular} \\
\hline $\begin{array}{l}\text { The Town Belt or Outer Green Belt... } \\
\text { Wellington City's coastal areas or } \\
\text { beaches }\end{array}$ & 1 & 2 & 3 & 4 & 5 & 9 \\
\hline $\begin{array}{l}\text { The botanic gardens, including } \\
\text { Otari-Wilton's bush ................... }\end{array}$ & 1 & 2 & 3 & 4 & 5 & 9 \\
\hline
\end{tabular}

Q100 Ask all

Do not rotate order

Read out

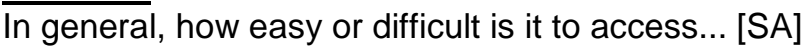

\begin{tabular}{|c|c|c|c|c|c|}
\hline $\begin{array}{c}\text { Very } \\
\text { difficult }\end{array}$ & $\begin{array}{c}\text { quite } \\
\text { difficult }\end{array}$ & $\begin{array}{c}\text { Neither } \\
\text { easy nor }\end{array}$ & Quite easy & Very easy & $\begin{array}{c}\text { (Do not } \\
\text { read) Don't }\end{array}$ \\
\hline
\end{tabular}


(R1) Your local park

(R2) Wellington City's coastal areas or beaches.

(R3) Green open spaces (such as sports fields, town belts, gardens and parks etc.)

\begin{tabular}{|c|c|c|c|c|c|}
\hline & & difficult & & & know \\
\hline 1 & 2 & 3 & 4 & 5 & 9 \\
1 & 2 & 3 & 4 & 5 & 9 \\
1 & 2 & 3 & 4 & 5 & 9 \\
\hline
\end{tabular}

Q101 To provide garden (botanic gardens and parks) and beach and coastal services it costs, on average, $\$ 66.19$ per resident per year (or $\$ 0.18$ per day). How strongly do you agree or disagree this is good value for money? [SA]

Strongly disagree.

Disagree

Neither agree nor disagree

Agree

Strongly agree

(Do not read out) Don't know

\begin{tabular}{|c|c|}
\hline Code & Route \\
& \\
1 & \\
2 & \\
3 & \\
4 & \\
5 & \\
9 & \\
\hline
\end{tabular}

\section{Q102 Read out scale in reverse}

To provide green open spaces (e.g. sports fields, town belts, parks and gardens) it costs, on average, $\$ 80.58$ per resident per year (or $\$ 0.22$ per day). How strongly do you agree or disagree this is good value for money? [SA]

Strongly disagree.

Disagree

Code

Route

Neither agree nor disagree

Agree

Strongly agree

(Do not read out) Don't know

\begin{tabular}{|c|c|}
\hline Code & Route \\
& \\
1 & \\
2 & \\
3 & \\
4 & \\
5 & \\
9 & \\
\hline
\end{tabular}

Q43 Read out scale 5-4-3-2-1, strongly agree (5) to strongly disagree (1) Read out - code one only

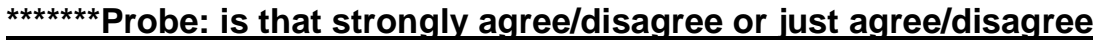

Thinking about Wellington's natural environment overall, do you agree or disagree that it is appropriately managed and protected?

[SA]

PROBE Probe: Is that strongly agree/disagree or just agree/disagree

Strongly disagree.

Disagree

Neither agree nor disagree

Agree

Strongly agree.

(Do not read out) Don't know 
Only included so interviewers know what this text is when reading the questionnaire. It should come after Part 1 demos as in surveycraft script

There is more text before this in surveycraft informing respondents what the second part of the survey is about etc.

Is it convenient for you to continue now, or shall I make an appointment to call you back at a more convenient time.

Continue .1

Make appointment......2

\section{Split Questionnaire at this point.}

\section{Cultural Wellbeing}

Q46 Rotate statements

Read out scale 5-4-3-2-1, strongly agree (5) to strongly disagree (1)

Read out - code one only

***Probe: Is that strongly agree/disagree or just agree/disagree ${ }^{\star \star \star \star \star \star \star \star ~}$

Thinking about the community involvement in arts and culture in Wellington, I am going to read you some statements and l'd like you to tell me if you agree or disagree with each statement.

In general, do you agree or disagree with the statement...

...And do you agree or disagree with the statement.....

[SA]

PROBE Probe: Is that strongly agree/disagree or just agree/disagree

(R1) Wellington has a culturally rich and diverse arts scene

\begin{tabular}{|c|c|c|c|c|c|}
\hline $\begin{array}{l}\text { Strongly } \\
\text { disagree }\end{array}$ & Disagree & $\begin{array}{c}\text { Neither } \\
\text { agree nor } \\
\text { disagree }\end{array}$ & Agree & $\begin{array}{c}\text { Strongly } \\
\text { agree }\end{array}$ & \begin{tabular}{|c|} 
(Do not \\
read out) \\
Don't know \\
\end{tabular} \\
\hline 1 & 2 & 3 & 4 & 5 & 9 \\
\hline 1 & 2 & 3 & 4 & 5 & 9 \\
\hline 1 & 2 & 3 & 4 & 5 & 9 \\
\hline
\end{tabular}

Q96 Read out - code only one

(R2) Wellington is the events capital of New Zealand

(R3) Wellington is the arts capital of New Zealand

How frequently do you attend, or participate in cultural and arts activities in Wellington?[SA]

At least once a week

At least once a month

Once every six months

At least once a year

\begin{tabular}{|c|c|}
\hline Code & Route \\
& \\
1 & \\
2 & \\
3 & \\
4 & \\
5 & \\
7 & \\
9 & \\
\hline
\end{tabular}

Less often

(DO NOT READ) Never

(DO NOT READ) Don't know 
festivals, sports events and arts and cultural events. Have you attended any of these types of events and festivals in the last 12 months?[SA]

Yes

No

Don't Know.....

Q49 28. New (Events \& Festivals)

Read out in reverse order 5-4-3-2-1

Read out - code one only

Overall, how satisfied or dissatisfied are you with these types of events and festivals?

Would you say you are....

[SA]

Very dissatisfied

Quite dissatisfied

Neither satisfied nor dissatisfied

Quite satisfied

Very satisfied

(Do not read out) Don't know

\begin{tabular}{|l|l|}
\hline Code & Route \\
& \\
& \\
& \\
1 & \\
2 & \\
3 & \\
4 & \\
5 & \\
9 & \\
\hline
\end{tabular}

Q50

36. New

Read out in reverse order $5,4,3,2,1$

Read out - code one only

${ }^{\star \star \star \star}$ Probe: is that strongly agree/disagree or just agree/disagree ${ }^{\star \star \star \star \star \star \star \star}$

Do you agree or disagree that Wellington's distinct local identity, its sense of place, is appropriately valued and protected? [SA]

PROBE Is that strongly agree/disagree or just agree/disagree

Strongly disagree.

Disagree

Neither agree nor disagree

Agree

Strongly agree.....

(Do not read out) Don't know

\section{Resources and Waste}

Q51 Read out - code all that apply

\section{If asked question relates to households behaviour not individual}

The next couple of questions are about waste reduction and rubbish collection.

Which, if any, of the following things are you doing to try and reduce the amount of waste from your home? 
Home composting

Using the Council's kerbside recycling service

Taking things to the recycling stations

Donating things to 2 nd hand shops or charities

Buying refills

Avoiding using plastic bottles or bags

Reusing plastic containers such as food containers

Anything else (specify)

(Do not read out) None of these

Q52 Check Q51, if 2 coded ask Q52 otherwise skip to Q90

\section{Read out - code one only}

On average, how often do you put out recycling for WCC kerbside collection?" [SA]

Every week

Once every two weeks

\section{Code}

Route

Once every three weeks

Once a month

Less often than once a month

(Do not read out) Don't know

Q53 Ask Q53 if Q52 = code 1,2,3,4 or 5 (ie. know how often on average they put out recycling - doesn't have to be in the last month)

Read out $5,4,3,2,1$

Read out - code one only

How satisfied or dissatisfied are you with the Wellington City Council's kerbside recycling?[SA]

Very dissatisfied

Quite dissatisfied

Neither satisfied nor dissatisfied

Quite satisfied

Very satisfied.

(Do not read out) Don't know

\begin{tabular}{|c|c|}
\hline Code & Route \\
& \\
& \\
1 & \\
2 & \\
3 & \\
4 & \\
5 & \\
9 & \\
\hline
\end{tabular}

Does your household ever use the official Wellington City Council rubbish bags, the yellow coloured bags that can be brought at the supermarket, some dairies or from the Council? [SA]

Yes

No 
Q91 Check Q90, if 1 coded ask otherwise skip to Q54

Read out - code one only

On average, how often do you put out yellow plastic Council rubbish bags for WCC kerbside collection? [SA]

Every week

Once every two weeks

Once every three weeks

Once a month

Less often than once a month

(Do not read out) Don't know

Q92 Ask Q92 if Q91 = code 1,2,3,4 or 5 (ie. know how often on average they put out rubbish bags - doesn't have to be in the last month)

Read out $5,4,3,2,1$

Read out - code one only

How satisfied or dissatisfied are you with the Wellington City Council's kerbside rubbish collection?[SA]

Very dissatisfied

Quite dissatisfied

Neither satisfied nor dissatisfied

Quite satisfied

Very satisfied.

(Do not read out) Don't know

\begin{tabular}{|l|l|}
\hline Code & Route \\
& \\
& \\
& \\
1 & \\
2 & \\
3 & \\
4 & \\
5 & \\
9 & \\
\hline
\end{tabular}

Q105

Ask all

Scale to be read out in reverse

To provide waste management services it costs, on average, $\$ 50.31$ per resident per year (or $\$ 0.14$ per day). How strongly do you agree or disagree this is good value for money? [SA]

Strongly disagree.

Disagree

Neither agree nor disagree

Agree

Strongly agree

(Do not read out) Don't know

Q54 Rotate statements

Read out - code all that apply

If asked question relates to households behaviour not individual

The storm water system collects rainwater from your roof and yard and transfers it to local streams or to the seashore.

Thinking now about the storm water system, which, if any, of the following things 
are you doing to try and reduce the amount of pollution entering the storm water system? [MA]

Dispose of oil, paint or chemicals by putting them out with your household rubbish or taking them for recycling....

Washing paint brushes in an inside sink

Pouring all household liquid wastes down an inside sink, toilet or gully trap

Put your litter in a rubbish bin rather than drop it in the street or in the gutter

Pick up droppings left by dogs

Collect sweepings from your driveway, paths, or yard for composting or for disposal with your household rubbish...

Wash the car at a carwash or on the lawn

Anything else (specify)

None of these

To provide wastewater and storm water services it costs, on average, $\$ 262.16$ per resident per year (or $\$ 0.72$ per day). How strongly do you agree or disagree this is good value for money? [SA]

Strongly disagree.

Disagree

Neither agree nor disagree

Agree

Strongly agree.....

(Do not read out) Don't know

\begin{tabular}{|l|l|} 
Code & Route \\
1 & \\
2 & \\
3 & \\
4 & \\
5 & \\
9 & \\
\hline
\end{tabular}

\section{Q107 Scale to be read in reverse}

To provide water services it costs, on average, $\$ 180.00$ per resident per year (or $\$ 0.49$ per day). How strongly do you agree or disagree this is good value for money? [SA]

Strongly disagree.

Disagree

Neither agree nor disagree

Agree

Strongly agree.

(Do not read out) Don't know

\section{Transport}

Q55 Read out in reverse order 5-4-3-2-1

Read out - code one only

I'd now like to ask you about city traffic and the public transport system.

Thinking about moving around the city, how easy is it to drive about in the city? 
Would you say it is..... [SA]

Very difficult

Quite difficult

Neither easy nor difficult

Quite easy

Very easy.

(Do not read out) Never drive/drive in a car

(Do not read out) Don't know

\begin{tabular}{|l|l|}
\hline 1 & \\
2 & \\
3 & \\
4 & \\
5 & \\
7 & \\
9 & \\
\hline
\end{tabular}

Q56 Read out in reverse order 5-4-3-2-1

Read out - code one only

And how would you rate how easy it is to walk around the city?

Would you say it is..... [SA]

Very difficult

Quite difficult

Neither easy nor difficult

Quite easy

Very easy.

(Do not read out) Don't know

\begin{tabular}{|c|c|}
\hline Code & Route \\
& \\
1 & \\
2 & \\
3 & \\
4 & \\
5 & \\
9 & \\
\hline
\end{tabular}

Q60 Rotate statements

Read out scale 5-4-3-2-1, strongly agree (5) to strongly disagree (1)

Read out - code one only

Do you agree or disagree that public transport in Wellington is...

And do you agree or disagree that public transport in Wellington is....

[SA]

PROBE Probe: Is that strongly agree/disagree or just agree/disagree

\begin{tabular}{|c|c|c|c|c|c|c|}
\hline & $\begin{array}{l}\text { Strongly } \\
\text { disagree }\end{array}$ & Disagree & $\begin{array}{c}\text { Neither } \\
\text { agree nor } \\
\text { disagree }\end{array}$ & Agree & $\begin{array}{c}\text { Strongly } \\
\text { agree }\end{array}$ & \begin{tabular}{|c|} 
(Do not \\
read out) \\
Don't know \\
\end{tabular} \\
\hline 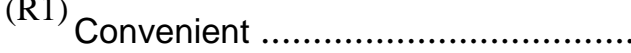 & 1 & 2 & 3 & 4 & 5 & 9 \\
\hline Ic & 1 & 2 & 3 & 4 & 5 & 9 \\
\hline
\end{tabular}

Q108 If code 7 in Q55 do not ask this question

Read scale 5,4,3,2,1

Read out

How satisfied or dissatisfied are you with the availability of on-street parking during the $[\mathrm{SA}]$

(R1)

week.

\begin{tabular}{|c|c|c|c|c|c|}
\hline $\begin{array}{c}\text { Very } \\
\text { dissatisfie } \\
\mathrm{d}\end{array}$ & $\begin{array}{c}\text { dissatisfie } \\
\mathrm{d}\end{array}$ & $\begin{array}{c}\text { Neither } \\
\text { satisfied } \\
\text { nor } \\
\text { dissatisfie } \\
\mathrm{d}\end{array}$ & satisfied & $\begin{array}{c}\text { Very } \\
\text { satisfied }\end{array}$ & $\begin{array}{c}\text { (Do not } \\
\text { read) Don't } \\
\text { know }\end{array}$ \\
\hline 1 & 2 & 3 & 4 & 5 & 9 \\
\hline
\end{tabular}


(R2)

weekend

Q62 Read out in reverse order 5-4-3-2-1

Read out - code one only

**Probe: is that strongly agree/disagree, or just agree/disagree ${ }^{\star \star \star \star \star \star \star \star}$

Do you agree or disagree that the city's transport system, that is the roads and the public transport, allows easy access from the suburbs to the city?[SA]

PROBE Probe: Is that strongly agree/disagree or just agree/disagree

Strongly disagree.

Disagree

Neither agree nor disagree

\begin{tabular}{|c|c|}
\hline Code & Route \\
& \\
& \\
1 & \\
2 & \\
3 & \\
4 & \\
5 & \\
9 & \\
\hline
\end{tabular}

Agree

Strongly agree

(Do not read out) Don't know

\begin{tabular}{|c|c|}
\hline Code & Route \\
& \\
1 & \\
2 & \\
3 & \\
4 & \\
5 & \\
9 & \\
\hline
\end{tabular}

Q63 Do not read - code one only

Do you travel into central Wellington most weekdays?[SA]

Yes

Tcale read out in reverse

To provide transport network services it costs, on average, $\$ 204.65$ per resident per year (or $\$ 0.56$ per day). How strongly do you agree or disagree this is good value for money? [SA]

Strongly disagree.

Disagree

Neither agree nor disagree

Agree.

Strongly agree.

(Do not read out) Don't know

\begin{tabular}{|c|c|}
\hline Code & Route \\
1 & \\
2 & Q68 \\
9 & Q68 \\
\hline
\end{tabular}

Q64 Code other 98

Code don't know 99

Do not read out - Code one only

What is your main method of travelling to Wellington on these occasions?

$[\mathrm{SA}]$

Car

Motorbike.

Code

Route

Bus

Train

Bicycle 


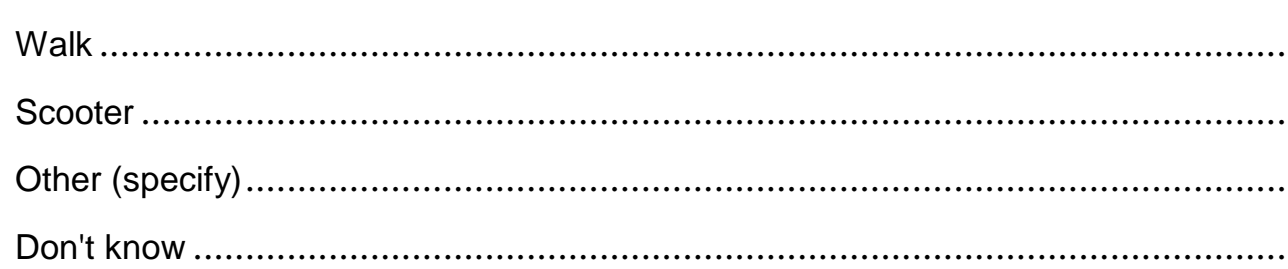

\section{Do not read out - Code one only}

Is there anything that prevents you from using your preferred method of transport? [SA]

Yes

No

Don't know

Q66 Code other 98

Code don't know 99

Do not read out - Code one only

How would you prefer to travel into Central Wellington most weekdays?

[SA]

PROBE If say public transport, ask: What type of public transport?

Car

Motorbike

Bus

Taxi

Train

Cable Car.

Bicycle.

Walk

Scooter

Skateboard.

Public transport non-specific

Other (specify) .....

Don't know

Q67 Code Other as 98

Code Don't know as 99

Do not read out - code all that apply Probe fully

What stops you travelling by <insert response from Q66> into Central Wellington most weekdays? [MA]

\section{PROBE Probe fully}

Very heavy/heavy traffic 
Parking

Train problems/line signal problems/running late

04

Bus drivers/bus breakdowns/trolley lines down

Roads too narrow/lane markings/no room for bikes/bike lanes

Other (specify)

Don't know

\section{Do not read out - Code one only}

Do you travel into or through central Wellington during weekday peak traffic times, that is between 7 and 9 in the morning or 4 and 6 in the evening?[SA]

Yes

No

\begin{tabular}{c|c} 
Code & Route \\
1 & \\
2 & Q70 \\
9 & Q70 \\
\hline
\end{tabular}

Don't know

\begin{tabular}{|c|c|}
\hline Code & Route \\
1 & \\
2 & \\
9 & \\
\hline
\end{tabular}

Don't know

\begin{tabular}{|c|c|}
\hline Code & Route \\
& \\
1 & \\
2 & Q72 \\
9 & Q72 \\
\hline
\end{tabular}

Q71 Read out scale in order: very satisfied to very dissatisfied

\section{Read out - code one only}

How satisfied or dissatisfied are you with Wellington City's cycleways for....

And how satisfied or dissatisfied are you with Wellington City's cycleways for.... [SA]

\begin{tabular}{|c|c|c|c|c|c|c|c|}
\hline & \begin{tabular}{|c|} 
Very \\
dissatisfie \\
d
\end{tabular} & \begin{tabular}{|c|} 
Quite \\
dissatisfie \\
d
\end{tabular} & \begin{tabular}{|c|} 
Neither \\
satisfied \\
nor \\
dissatisfie \\
d
\end{tabular} & $\begin{array}{c}\text { Quite } \\
\text { satisfied }\end{array}$ & $\begin{array}{c}\text { Very } \\
\text { satisfied }\end{array}$ & \begin{tabular}{|c|} 
(Do not \\
read out) \\
Not \\
applicable \\
:Don't use \\
cycleway \\
s or \\
public \\
transport \\
\end{tabular} & $\begin{array}{l}\text { (Do not } \\
\text { read) } \\
\text { Don't } \\
\text { know }\end{array}$ \\
\hline $\mathrm{R} 1)$ Safety & 1 & 2 & 3 & 4 & 5 & 7 & 9 \\
\hline${ }^{R 2)}$ How well they are maintained & 1 & 2 & & & & & \\
\hline
\end{tabular}


Q72 Read out in reverse order 5-4-3-2-1

Read out - code one only

How would you rate the condition of the city's roads?

[SA]

Very poor

Poor.

Neither good nor poor

Good

Very Good.

(Do not read out) Don't know

\begin{tabular}{|c|c|}
\hline Code & Route \\
& \\
1 & \\
2 & \\
3 & \\
4 & \\
5 & \\
9 & \\
\hline
\end{tabular}

Q110

\section{Read out in reverse order 5,4,3,2,1}

Read out

And how would you rate the condition of the city's footpaths?[SA]

Very poor

Poor.

Neither good nor poor

Good

Very Good.

(Do not read out) Don't know

\begin{tabular}{|c|c|}
\hline Code & Route \\
1 & \\
2 & \\
3 & \\
4 & \\
5 & \\
9 & \\
\hline
\end{tabular}

Q73 Read out in reverse order 5-4-3-2-1

Read out - code one only

How satisfied or dissatisfied are you with the quality of the street cleaning in centra Wellington?

$[\mathrm{SA}]$

Very dissatisfied

Quite dissatisfied

Neither satisfied nor dissatisfied

Quite satisfied

Very satisfied

\begin{tabular}{|l|l|}
\hline Code & Route \\
& \\
& \\
2 & \\
3 & \\
4 & \\
5 & \\
9 & \\
\hline
\end{tabular}

(Do not read out) Don't know

\begin{tabular}{|c|c|}
\hline Code & Route \\
1 & \\
2 &
\end{tabular}

\section{Read out - code one only}

How satisfied or dissatisfied are you with the quality and maintenance of road side vegetation? By maintenance I mean kept free of weeds and trimmed back to be clear of the edges of the road. Are you...

[SA]

Very dissatisfied

Quite dissatisfied 


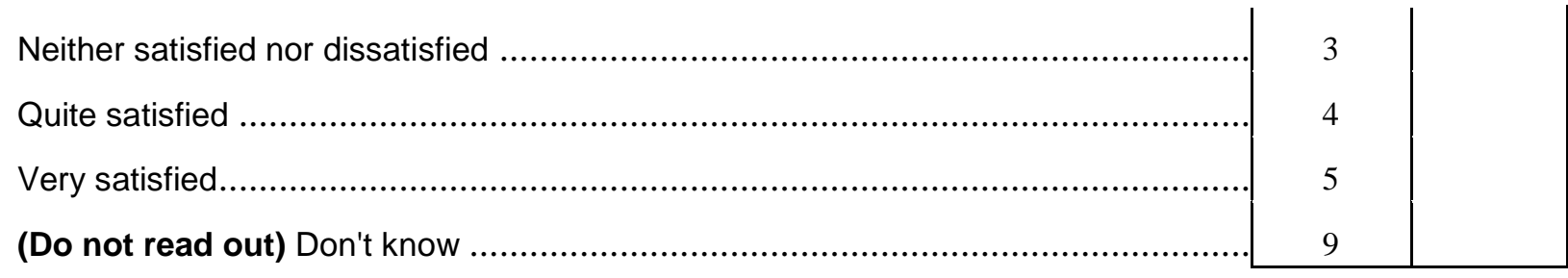

Q75 Read out in reverse order 5-4-3-2-1

Read out - code one only

Now thinking about street lighting, how satisfied or dissatisfied are you with...?

Would you say you are...?

....and how satisfied or dissatisfied are you with.......

would you say you are....?

[SA]

(R1) Street lighting in the central city

\begin{tabular}{|c|c|c|c|c|c|}
\hline $\begin{array}{c}\text { Very } \\
\text { dissatisfie } \\
\mathrm{d}\end{array}$ & $\begin{array}{c}\text { Quite } \\
\text { dissatisfie } \\
\mathrm{d}\end{array}$ & $\begin{array}{c}\text { Neither } \\
\text { satisfied } \\
\text { nor } \\
\text { dissatisfie } \\
\mathrm{d}\end{array}$ & $\begin{array}{c}\text { Quite } \\
\text { satisfied }\end{array}$ & $\begin{array}{c}\text { Very } \\
\text { satisfied }\end{array}$ & $\begin{array}{c}\text { (Do not } \\
\text { read out) } \\
\text { Don't know }\end{array}$ \\
\hline 1 & 2 & 3 & 4 & 5 & 9 \\
1 & 2 & 3 & 4 & 5 & 9 \\
\hline
\end{tabular}

Q116 Ask all

If respondent is unsure mention the website address www.wellington.govt.nz

Now we have some questions about the Council's website

(www.wellington.govt.nz).

Have you visited the Council's website in the last 12 months?[SA]

Yes

No

\begin{tabular}{|c|c|}
\hline Code & Route \\
& \\
1 & \\
2 & Q119 \\
\hline
\end{tabular}

Q117 Asked if visited website in last 12 months Q116 = code 1

During any of your visits to the Council's website in the last 12 months, was there anything you looked for but could not find?[SA]

Yes

No

\begin{tabular}{|c|c|}
\hline Code & Route \\
1 & \\
2 & \\
\hline
\end{tabular}

Q118 Only ask if they looked for something on website but could not find it (Q117= code 1)

What was it that you were trying to find?
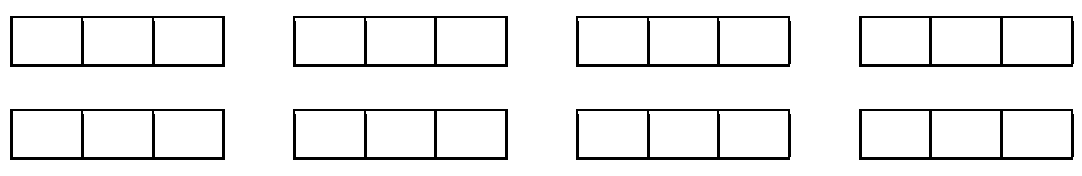
Which of the following online services would you use if they were on the Council's website[MA]

PROBE Would you use this service?

Online payments (e.g. paying for dog registration)

Online bookings (e.g. booking a Council venue).

Online applications (e.g. applying for a Land Information Memorandum)

Requesting repairs to Council property (e.g. a broken drain)

Tracking a service request (e.g. seeing the status of the response from the

Council)

None of these

\section{Q120 Ask all}

Is there anything else you would like to see offered on the Council's website?

PROBE Clarify response
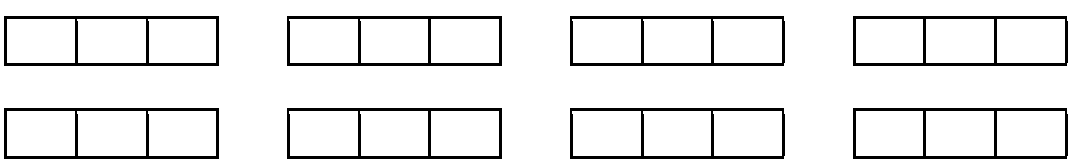

\section{Governance and citizen information}

Q76 Rotate codes 1 and 3, do not rotate 2

Read out - code one only

We just have a few more questions to go. I'd like you to think about the contact you have with Wellington City Council and the involvement of the community in Council decision-making.

In your view, does the Council consult you....? [SA]

Not enough

The right amount

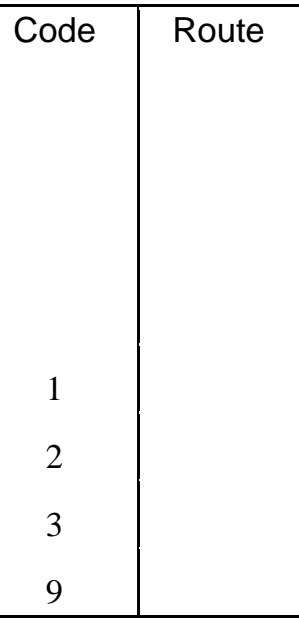

(Do not read out) Don't know

\begin{tabular}{|c|c|}
\hline Code & Route \\
& \\
1 & \\
2 &
\end{tabular}




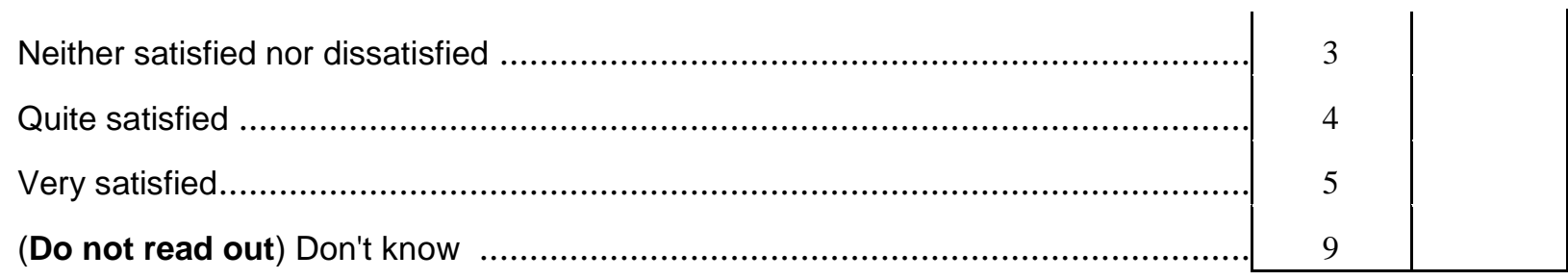

Q78 63/64/65 New

Rotate statements

Read out scale 5-4-3-2-1, strongly agree (5) to strongly disagree (1)

Read out - code one only

\section{${ }^{* *}$ Probe: is that strongly agree/disagree or just agree/disagree ${ }^{\star \star \star *}$}

In general, do you agree or disagree with the statement....

and do you agree or disagree with the statement....[SA]

PROBE Probe: Is that strongly agree/disagree or just agree/disagree

(R1) I understand how Wellington City

Council makes decisions.

\begin{tabular}{|c|c|c|c|c|c|}
\hline $\begin{array}{c}\text { Strongly } \\
\text { disagree }\end{array}$ & Disagree & $\begin{array}{c}\text { Neither } \\
\text { agree nor } \\
\text { disagree }\end{array}$ & Agree & $\begin{array}{c}\text { Strongly } \\
\text { agree }\end{array}$ & $\begin{array}{c}\text { (Do not } \\
\text { read out) } \\
\text { Don't know }\end{array}$ \\
\hline 1 & 2 & 3 & 4 & 5 & 9 \\
1 & 2 & 3 & 4 & 5 & 9 \\
1 & 2 & 3 & 4 & 5 & 9 \\
\hline
\end{tabular}

Q79 Read out - code one only

Overall, how much influence do you feel the public has on the decisions the

Wellington City Council makes? Would you say the public has...[SA]

No influence

Small influence

Some influence

Large influence

(Do not read out) Don't know

\begin{tabular}{|c|c|}
\hline Code & Route \\
1 & \\
2 & \\
3 & \\
4 & \\
9 & \\
\hline
\end{tabular}

\section{Ask Part A and Part B Demographics}

\section{Demographics}

Q80 Code other 98

Code don't know 99

Read out - code all that apply

Finally just a few questions about yourself and your household, to make sure we have talked to a good cross-section of Wellingtonians.

Which ethnic group or groups do you belong to? [MA]

NZ European

\begin{tabular}{|l|l|}
\hline Code & Route \\
01 & \\
02 &
\end{tabular}




Samoan $\ldots$

\section{Q82 Read out - code one only}

Approximately, what is your total household income (that is, from all income earners in your household as well as income from other sources, before tax)? $[\mathrm{SA}]$

$\$ 20,000$ or less a year

\begin{tabular}{|l|l|}
\hline Code & Route \\
& \\
1 & \\
2 & \\
3 & \\
4 & \\
5 & \\
6 & \\
9 & \\
\hline
\end{tabular}

$\$ 20,001-\$ 30,000$

From time to time, Wellington City Council undertakes specific research about topics of current interest. Would you be willing for us to call you again in the future to see if you are interested in taking part in such research for the Wellington City Council? [SA] 


\begin{tabular}{|c|c|}
\hline Yes & 1 \\
\hline No ..................... & 2 \\
\hline Don't know ...................................................... & 9 \\
\hline
\end{tabular}

\section{If respondent agrees}

Can you let me have your contact details please, so that if we call you back we can ask for you by name?

\section{Record contact details}

\section{Name:}

\section{Phone Number:}

\section{Email:}

Thanks, that's all the questions I have for you. Should you have any queries about this interview my name is...... calling on behalf of Nielsen

As this is market research, it is carried out in compliance with the Privacy act and the information you provided will be used only for research purposes. Under the Privacy Act, you have the right to request access to the information you have provided.

Interviewer name: Date:

Interviewer pay number:

Interview Time

\section{Start Time:}

Finish Time:

Duration of Interview: 